\title{
Cooperative Oligonucleotide-Directed Triple Helix Formation at Adjacent DNA Sites
}

\author{
Thesis by \\ Natalia Colocci \\ In Partial Fulfillment of the Requirements \\ for the Degree of \\ Doctor of Philosophy
}

California Institute of Technology

Pasadena, California

1996

(Submitted August 11, 1995) 
(C) 1996

Natalia Colocci

All Rights Reserved 
To my family 


\section{ACKNOWLEDGMENTS}

I would like to express my gratitude to all the people who have helped make my time enjoyable during the past four years at Caltech. First, I would like to thank my advisor, Professor Peter B. Dervan. His constructive guidance, ever-present enthusiasm, scientific vision, and tremendous support have made it a pleasure for me to work with him. I have learned a lot at Caltech, about science and about being a researcher, and this I owe greatly to Peter. I am also grateful to present and past members of the Dervan group, who provided me with a stimulating environment in which to work. In particular, Michelle Parks and Jim Kelly have been fantastic people, both as friends and colleagues. Going through graduate school with them has been an experience I cherish and will never forget. Jim and Michelle have been an integral part of my graduate career, and I hope that there will be plenty of occasions in the future to have as much fun together as we have in the past. George Best has been an incredible friend, and I could not have asked for a better buddy. Conversing with him about politics, history, music (alas, country music too), and medicine, among many other things, was simply delightful. Milan Mrksich, Jason Szewczyk, David Liberles and Jürg Hunziker

were great people to have around, and talking to them never ceased to be entertaining. Skiing with Scott Carter and Helmut Brunar was lots of fun. In addition, I would like to thank Eldon Baird for his tremendous help with technical ordeals.

Mark Distefano was a great person to start working with as a neophyte. $\mathrm{He}$ is an excellent teacher, in technical as well as intellectual matters, and a lot of 
what I learned in the lab I owe to him. Patrick Kearney from the Dougherty group helped me use the program Spartan for some of my studies.

I would also like to thank all my friends from orchestra, USC, and UCLA. Life at Caltech without them would have been very different, and very much less appreciated. Weekend parties and skiing trips were always a welcomed break from lab work. In particular, I am grateful to Rita and Cecco for their friendship (and pasta), and to Jennifer and Greg.

Finally, I would like to thank Ken. I had a great time with him during my last months at Caltech, and with him I shared many pleasant moments. I am also grateful to my family for their support in all my decisions. 


\section{ABSTRACT}

Cooperative interactions between DNA-binding ligands are essential for their sequence specificity, binding affinity, and biological activity. Oligonucleotides can bind cooperatively to adjacent sites on double-helical DNA by triple helix formation. The study of the cooperative binding of oligonucleotides to DNA by triple helix formation is important as it provides useful information for the development of new methods leading to the sequence-specific recognition of DNA. As a first step towards this goal, the thermodynamics of the cooperative binding of oligodeoxyribonucleotides to adjacent DNA sites by triple helix formation have been determined by quantitative affinity cleavage titrations (Chapter Two). A 20-fold enhancement in equilibrium association constant is realized for an 11 mer pyrimidine oligonucleotide binding in the presence of a neighboring bound site at $24{ }^{\circ} \mathrm{C}$ and $\mathrm{pH} 7.0$ (25 mM TrisOAc, $10 \mathrm{mM} \mathrm{NaCl}, 1 \mathrm{mM}$ spermine). This corresponds to an increase in binding free energy of $1.8 \mathrm{kcal} \bullet \mathrm{mol}^{-1}$. This cooperativity is not observed when the two binding sites are separated by one base pair. The observed cooperative energy likely arises from favorable polarization and charge-charge interactions between the terminal bases at the triple-helical junction.

In addition, the energetics of cooperative binding by oligodeoxyribonucleotides to adjacent sites by triple helix formation have been determined as a function of sequence composition at the junction (Chapter Three). The binding affinity of an 11 mer in the presence of a neighboring bound oligonucleotide is enhanced by a factor of $12,17,61$, and 127 when a 5'-TT-3', 
5'-m ${ }^{m} \mathrm{C}-3$ ', 5'-TmC-3', and 5'-mCT-3' stack, respectively, is formed at the junction (10 mM Bis-Tris $\bullet \mathrm{HCl}$ at $\mathrm{pH} 7.0,10 \mathrm{mM} \mathrm{NaCl}, 250 \mu \mathrm{M}$ spermine, 24 $\left.{ }^{\circ} \mathrm{C}\right)\left(\mathrm{m}^{\mathrm{C}} \mathrm{C}\right.$ designates 5-methyl-2'-deoxycytidine). These binding enhancements correspond to an interaction energy between the two oligonucleotides of 1.5, $1.7,2.5$, and $2.9 \mathrm{kcal} \cdot \mathrm{mol}^{-1}$, respectively. The energetic penalties for a singlebase mismatch differ depending on sequence and the location of the mismatch with respect to the $5^{\prime}$ - or $3^{\prime}$-side of the junction. In the case of a $5^{\prime}-\mathrm{TT}-3^{\prime}$ stack, a T•GC mismatch on the 5'- side of the junction decreases the interaction energy from $1.5 \mathrm{kcal} \bullet \mathrm{mol}^{-1}$ to $0.6 \mathrm{kcal} \bullet \mathrm{mol}^{-1}$, whereas a $\mathrm{T} \bullet \mathrm{GC}$ mismatch on the 3'- side destroys cooperativity. For a 5'-mCT-3' stack, a mC•AT mismatch on the $5^{\prime}$-side of the junction decreases the cooperative interaction energy from $2.9 \mathrm{kcal} \bullet \mathrm{mol}^{-1}$ to $1.7 \mathrm{kcal} \bullet \mathrm{mol}^{-1}$, whereas a $\mathrm{T} \bullet \mathrm{GC}$ mismatch on the 3 '-side of the junction destroys cooperativity. Most importantly, two 11 mer oligonucleotides interacting through a 5'-TT-3' stack binding to adjacent sites on DNA are significantly more sensitive to single-base mismatches than the corresponding 22 mer binding to the same two abutting sites.

The use of modified bases, such as 5-(1-propynyl)-2'-deoxyuridine, increases cooperativity between oligonucleotides bound to adjacent sites on DNA, presumably due to an increased stacking energy between the modified bases at the triplex junction (Chapter Four). Oligodeoxyribonucleotides containing 5-(1-propynyl)-2'-deoxyuridine and 5-methyl-2'-deoxycytidine as short as 8 nucleotides in length bind at micromolar concentrations to adjacent 8-bp sites on double-helical DNA at $24^{\circ} \mathrm{C}$ and pH $7.0(10 \mathrm{mM}$ Bis-Tris $\bullet \mathrm{HCl}, 10$ $\mathrm{mM} \mathrm{NaCl}, 1 \mathrm{mM}$ spermine). Quantitative affinity cleavage titrations reveal that the binding affinity of an $8 \mathrm{mer}$ in the presence of a neighboring bound 8 mer is enhanced by a factor of at least 40 . This corresponds to a remarkable 
cooperative interaction energy of $>4.5 \mathrm{kcal} \bullet \mathrm{mol}^{-1}$. In addition, these cooperative interactions allow oligonucleotides as short as 6 mers to bind to three adjacent sites on double-helical DNA at near micromolar concentrations (10 $\mathrm{mM}$ Bis-Tris $\bullet \mathrm{HCl}$ at $\mathrm{pH} 7.0,10 \mathrm{mM} \mathrm{NaCl}, 1 \mathrm{mM}$ spermine, $24^{\circ} \mathrm{C}$ ).

Cooperativity is also observed between purine-rich oligonucleotides (Chapter Five). Quantitative DNase footprinting titration experiments show that the binding affinity of an 11mer purine-rich oligonucleotide in the presence of a neighboring bound oligonucleotide is enhanced by a factor of 81 when a 5'-GG-3' stack is formed at the junction (50 mM TrisOAc at pH 7.0, 10 $\mathrm{mM} \mathrm{NaCl}, 10 \mathrm{mM} \mathrm{MgCl} 2,24^{\circ} \mathrm{C}$ ). This binding enhancement corresponds to an interaction energy between the two oligonucleotides of $2.7 \mathrm{kcal} \cdot \mathrm{mol}^{-1}$, and is abolished when the two binding sites are separated by one base pair.

The synthesis of pyrimidine oligonucleotide analogs containing 5-(1propynyl)- and 2'-O-allyl-modified nucleosides (Chapter Six), and the progress towards the synthesis of a novel base, $\mathrm{N}^{7}-2$-deoxyisoinosine, designed for the recognition of AT base pairs within a parallel isomorphous purine motif (Chapter Seven), are described. 


\section{TABLE OF CONTENTS}

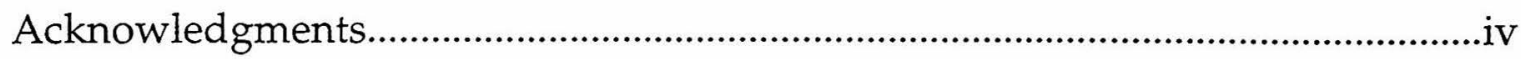

Abstract..............................................................................................................vi

Table of Contents...........................................................................................................ix

List of Figures and Tables.....................................................................................ii

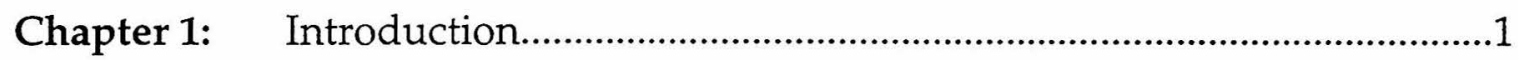

Chapter 2: Cooperative Oligonucleotide-Directed Triple Helix

Formation at Adjacent DNA Sites.................................................... 34

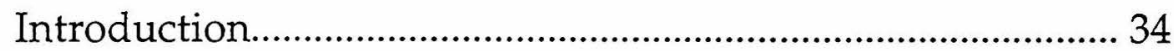

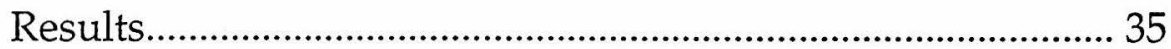

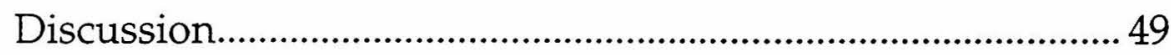

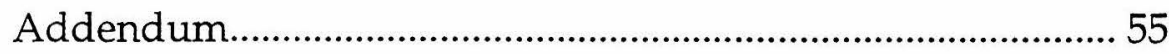

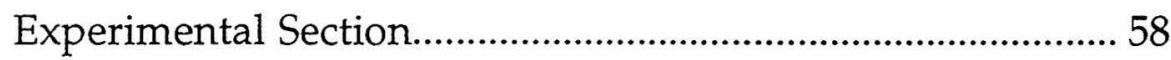

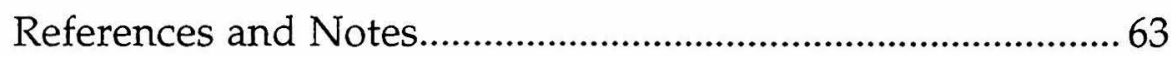

Chapter 3: Cooperative Triple Helix Formation at Adjacent DNA Sites: Sequence Composition Dependence at the Junction....... 67

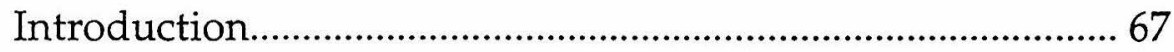

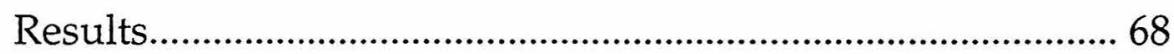

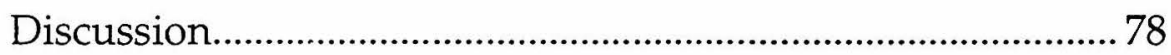

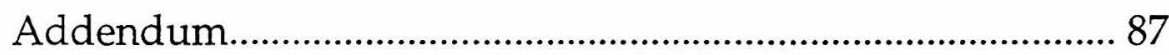

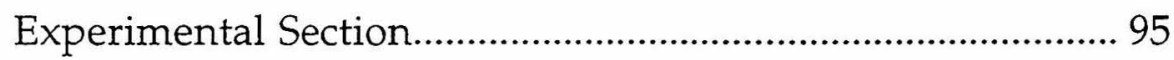

References and Note............................................................... 100 
Chapter 4: Cooperative Binding of Short Oligonucleotides

Containing 5-(1-Propynyl)-2'-deoxyuridine to Adjacent

DNA Sites by Triple Helix Formation..................................................103

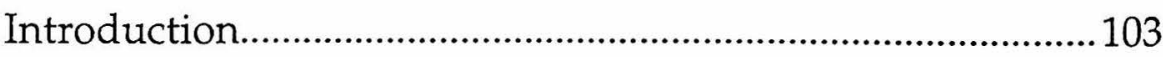

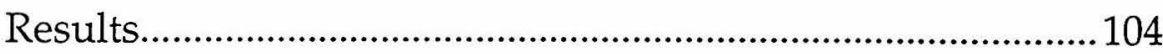

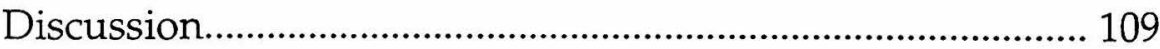

Experimental Section...............................................................116

References and Notes................................................................. 125

Chapter 5: Cooperative Binding of Purine-Rich Oligonucleotides

to Adjacent DNA Sites by Triple Helix Formation........................ 128

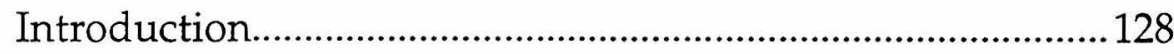

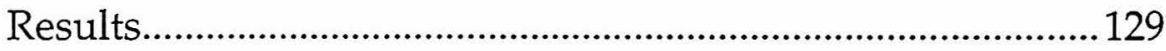

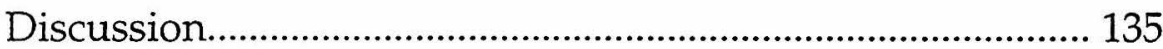

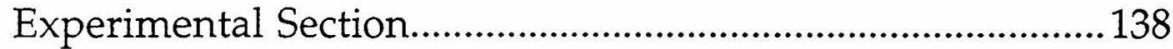

References and Notes............................................................... 143

Chapter 6: Synthesis of Oligonucleotide Analogs Containing

5-(1-Propynyl) and 2'-O-Allyl Substituents..................................... 145

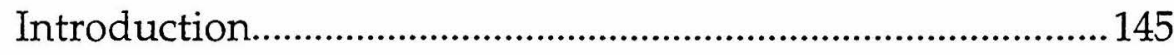

Research Design...................................................................... 148

Synthesis of Nucleosides.......................................................... 151

Experimental Section.................................................................156

References and Notes............................................................... 170

Chapter 7: Progress Towards the Synthesis of $N^{7}-2^{\prime}$-Deoxyisoinosine.......... 172

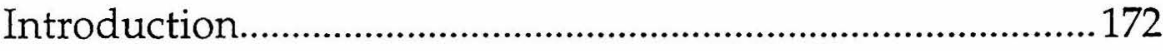

Research Design.......................................................................... 176

Synthesis of $\mathrm{N}^{7}$-2'-Deoxyisoinosine........................................ 180

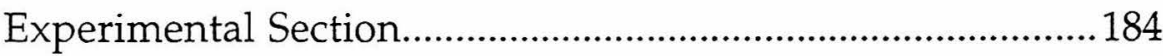


References and Notes....................................................... 188 


\section{LIST OF FIGURES AND TABLES}

\section{CHAPTER 1:}

\section{Figures.}

Figure 1.1. Structure of the four Watson-Crick base pairs.......................... 3

Figure 1.2. Structure of two base triplets...................................................5

Figure 1.3. Ribbon diagram of a triple-helical complex...........................7

Figure 1.4. Molecular model of a triple helix........................................... 8

Figure 1.5. Structure of purine-purine-pyrimidine base triplets.............. 12

Figure 1.6. Structure of noncanonical base triplets.................................. 13

Figure 1.7. Schematic diagram of DNA footprinting and affinity

cleaving techniques.............................................................. 15

Figure 1.8. Structure of the thymidine-EDTA derivative $\mathrm{T}^{*} \ldots \ldots \ldots \ldots \ldots \ldots . . . . . . .15$

Figure 1.9. Representation of cleavage patterns obtained by an EDTA-modified molecule bound to DNA........................17

Figure 1.10. Structure of protonated cytidine mimics................................ 19

Figure 1.11. Schematic diagram of phage $\lambda$ dimer repressors and RNA polymerase bound cooperatively to DNA...................22

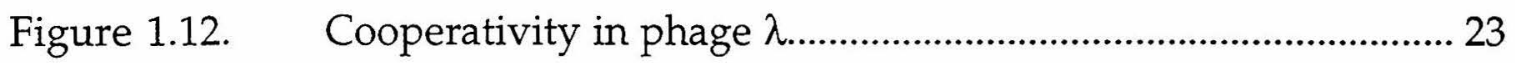

Figure 1.13. Diagram of a cooperatively formed Y-shaped triple-helical complex......................................................25

Tables.

Table 1.1. Relationship between duplex binding sites and number of unique sequences. 


\section{CHAPTER 2:}

\section{Figures.}

Figure 2.1. Representation of two oligonucleotides binding cooperatively to adjacent DNA sites................................................. 36

Figure 2.2. Autoradiogram of an affinity cleavage titration gel of oligonucleotides bound cooperatively to DNA.................... 38

Figure 2.3. Autoradiogram of an affinity cleavage titration gel of one oligonucleotide binding to DNA.

Figure 2.4. Binding isotherms of two oligonucleotides binding cooperatively to adjacent DNA sites.

Figure 2.5. Representation of two oligonucleotides binding to DNA sites that are separated by one base pair. 45

Figure 2.6. Binding isotherms of two oligonucleotides binding to DNA sites that are separated by one base pair. 46

Figure 2.7. Representation of two 11mer oligonucleotides binding cooperatively to adjacent DNA sites...

Figure 2.8. Binding isotherms of two 11mer oligonucleotides binding cooperatively to adjacent DNA sites

Figure 2.9. Ribbon model of two 11mer oligonucleotides binding cooperatively to adjacent DNA sites. 54

Figure 2.10. Representation of 5'- and 3'-phosphate-substituted oligonucleotides binding cooperatively to adjacent DNA sites. 56

\section{Tables.}

Table 2.1. Association constants of two oligonucleotides binding cooperatively to adjacent DNA sites. 
Table 2.2. Association constants of two oligonucleotides binding to DNA target sites that are separated by one base pair..

Table 2.3. Association constants of 5'- and 3'-phosphate-substituted oligonucleotides binding cooperatively to adjacent DNA sites 57

\section{CHAPTER 3:}

\section{Figures.}

Figure 3.1. Representation of two oligonucleotides binding cooperatively to adjacent DNA sites wherein four different stacks are formed at the triplex junction .69

Figure 3.2. Representation of two oligonucleotides binding to adjacent DNA sites in the presence of mismatches

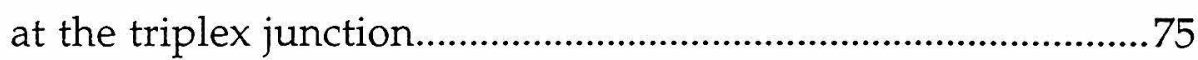

Figure 3.3. AM1 potential surfaces of model compounds of thymidine and protonated cytidine................................................. 80

Figure 3.4. Base stacking configurations of four triples................................. 83

Figure 3.5. Representation of two oligonucleotides containing terminal propynyl-modified bases binding

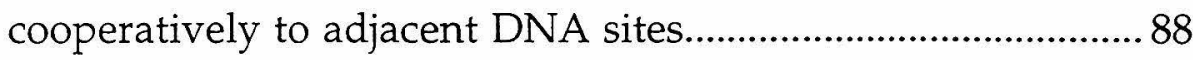

Figure 3.6. Base stacking configurations of modified triples...................... 91

Figure 3.7. Representation of two oligonucleotides binding to adjacent DNA sites in the presence of a series of 5-substituted bases at the triplex junction 
Tables.

Table 3.1. Association constants of two oligonucleotides binding cooperatively to adjacent DNA sites as a function

of four different base stacks................................................ 72

Table 3.2. Effect of mismatches on a 5'-TT-3' stack................................ 77

Table 3.3. Effect of mismatches on a $5^{\prime}-{ }^{m} \mathrm{CT}-3$ ' stack.............................. 78

Table 3.4. Effect of a single propynyl-modified base at the junction on cooperativity.

Table 3.5. Effect of a series of 5-substituted bases at the triplex junction on cooperativity.

\section{CHAPTER 4:}

\section{Figures.}

Figure 4.1. Representation of 5-(1-propynyl)-modified oligonucleotides binding cooperatively to adjacent DNA sites.

Figure 4.2. Representation of 6mer 5-(1-propynyl)-modified oligonucleotides binding cooperatively to adjacent DNA Sites... 106

Figure 4.3. Binding isotherms of 8 mer modified oligonucleotides binding cooperatively to adjacent DNA sites. 108

Figure 4.4. Autoradiogram of an affinity cleavage titration gel of 6mer 5-(1-propynyl)-modified oligonucleotides binding cooperatively to adjacent DNA sites.

Figure 4.5. Base stacking configurations of 5-(1-propynyl)modified triples

Figure 4.6. Ribbon model of three 6 mer modified oligonucleotides binding cooperatively to DNA 
Figure 4.7. Synthesis of the 5'-O-DMT-protected phosphoramidite of 5-(1-propynyl)-2'-deoxyuridine.

Figure 4.8. Synthesis of CPG support derivatized with

5-(1-propynyl)-2'-deoxyuridine.

Tables.

Table 4.1. Association constants of 5-(1-propynyl)-modified

oligonucleotides binding cooperatively

to adjacent DNA sites.

Table 4.2. Association constants of 6mer 5-(1-propynyl)-

modified oligonucleotides binding to DNA.

\section{CHAPTER 5:}

\section{Figures.}

Figure 5.1. Representation of two purine-rich oligonucleotides

$$
\text { binding cooperatively to adjacent DNA sites. }
$$

Figure 5.2. Binding isotherms of two purine-rich oligonucleotides

binding cooperatively to adjacent DNA sites.

Figure 5.3. Representation of two purine-rich oligonucleotides binding to DNA sites that are separated by one base pair..... 133

Figure 5.4. Binding isotherms of two purine-rich oligonucleotides binding to DNA sites that are separated by one base pair..... 134

Figure 5.5. Ribbon model of two purine-rich oligonucleotides binding cooperatively to adjacent DNA sites.

\section{Tables.}

Table 5.1. Association constants of two purine-rich oligonucleotides binding cooperatively to adjacent DNA sites. 
Table 5.2. Association constants of two purine-rich oligonucleotides binding to DNA sites that are separated by one base pair.

\section{CHAPTER 6:}

\section{Figures.}

Figure 6.1. Nucleoside analogs containing 5-(1-propynyl) and 2'-O-allyl substituents.

Figure 6.2. Representation of 5-(1-propynyl)- and 2'-O-allylmodified oligonucleotides binding to DNA by triple helix formation

Figure 6.3. Synthesis of the 5'-O-DMT-protected phosphoramidite of 5-(1-propynyl)-2'-O-allyluridine.

Figure 6.4. Synthesis of the 5'-O-DMT-protected phosphoramidite of 5-methyl-2'-O-allyluridine.

Figure 6.5. Synthesis of the 5'-O-DMT-protected phosphoramidite of 5-methyl-2'-O-allylcytidine.

\section{CHAPTER 7:}

\section{Figures.}

Figure 7.1. Schematic representation of a triplet in the parallel versus antiparallel purine motif. 174

Figure 7.2. Schematic representation of $\mathrm{N}^{7}-2^{1}$-deoxyguanosinecontaining oligonucleotides and their DNA target sites...... 175

Figure 7.3. Schematic representation of the $\mathrm{N}^{7}-2$-deoxyadenosine AT triplet 
Figure 7.4. Schematic representation of wholly N7-purine

oligonucleotides and their DNA target sites............................ 177

Figure 7.5. Diagram of nonisomorphous ${ }^{7} \mathrm{~A} \bullet \mathrm{AT}$ and ${ }^{7} \mathrm{G} \bullet \mathrm{GC}$

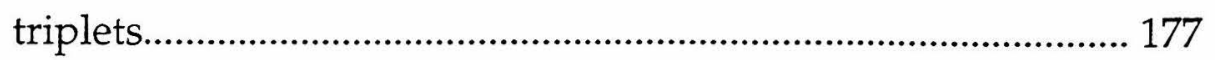

Figure 7.6. Structure of $\mathrm{N}^{7}-2^{1}$-deoxyisoinosine and of the

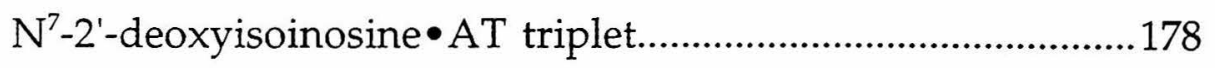

Figure 7.7. Interaction of the four canonical base pairs with

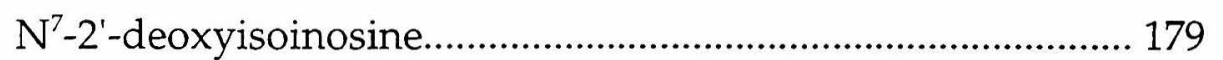

Figure 7.8. Schematic representation of oligonucleotides

containing $\mathrm{N}^{7}-2^{\prime}$-deoxyisoinosine and their DNA

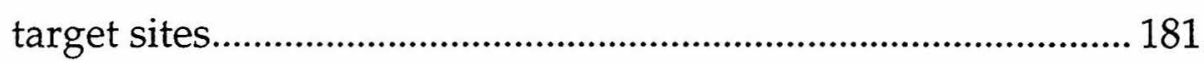

Figure 7.9. Synthesis of the 5'-O-DMT-protected phosphoramidite

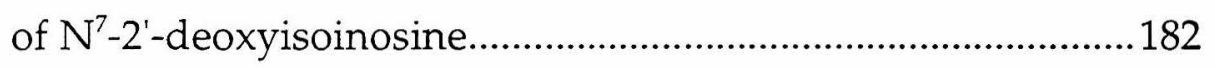




\section{CHAPTER ONE:}

\section{Introduction}

Deoxyribonucleic acid (DNA) is a molecule of unsurpassed importance as it provides the genetic information necessary for the functioning and regulation of cellular processes. Complex and diverse processes such as the biosynthesis of proteins, the immune response, and the hormonal action are only some of the fundamental ones responsible for the proper functioning of a living organism, and all depend on the specific interactions between native proteins and DNA. DNA plays a crucial role not only in biology, but also in medicine. The discovery that many diseases have a genetic component, and that nongenetic diseases are caused by improper gene expression, is revolutionizing the field of medicine. The regulation of such gene expression, essential to both biological and physiological processes, relies on the ability of structurally different molecules such as proteins, carbohydrates, and low molecular weight natural products, to recognize and bind to a specific sequence on double-helical DNA through the formation of individually weak, noncovalent interactions. An understanding of these interactions is of fundamental importance as it would allow us on a microscopic level to control gene expression and, as a result, on a macroscopic level to direct the functioning of a living organism.

DNA Structure. An analysis of the structure of DNA reveals the type of interactions involved in DNA-ligand complexes. The right-handed, double-

stranded helix comprises two antiparallel polymeric deoxyribonucleotide units held together by Watson-Crick hydrogen bonds between the bases on 
opposite strands, and stabilized by vertical $\pi-\pi$ stacking interactions between bases on the same strand. ${ }^{1}$ The major and minor groove present in DNA display different functionalities depending on the nature of the base pair (Figure 1.1). For example, the two hydrogen bond acceptors in the major groove of a GC base pair are the guanine-N7 and O6, and the hydrogen bond donor is the cytosine- $\mathrm{NH}_{2}$ group. In the major groove of an AT base pair, the two hydrogen bond acceptors are the adenine-N7 and thymine-O4, while the hydrogen bond donor is the adenine- $\mathrm{NH}_{2}$ group. It is through the differential hydrogen bonding interactions between these functional groups displayed in the grooves of DNA and a DNA-binding ligand, as well as through electrostatic and van der Waal forces, that molecules bind to DNA, often with remarkably high specificity.

Classes of DNA-Binding Molecules. DNA binding molecules can be classified depending on the type of interactions involved with the double helix of DNA. One category includes intercalators such as the dyes ethidium and acridine orange and the drug daunomycin, which contain an extended, flat, often positively charged aromatic chromophore capable of inserting itself between DNA base pairs via the formation of $\pi$-stacking interactions (London dispersion and hydrophobic forces) with concomitant helix unwinding, lengthening, and stiffening. ${ }^{1}$ A second category comprises minor groove binders such as netropsin, distamycin, and Hoeschst 33258, which bind A,Trich sequences, and echinomycin and actinomycin D, which bind G,C-rich sequences of DNA. ${ }^{1,2}$ These molecules recognize DNA through the formation of specific hydrogen bonds with the functional groups present in the minor groove, and/or a combination of electrostatic interactions with the negatively charged phosphodiester backbone, favorable stacking interactions with the bases, and favorable hydrophobic contacts with the deoxyribose rings 


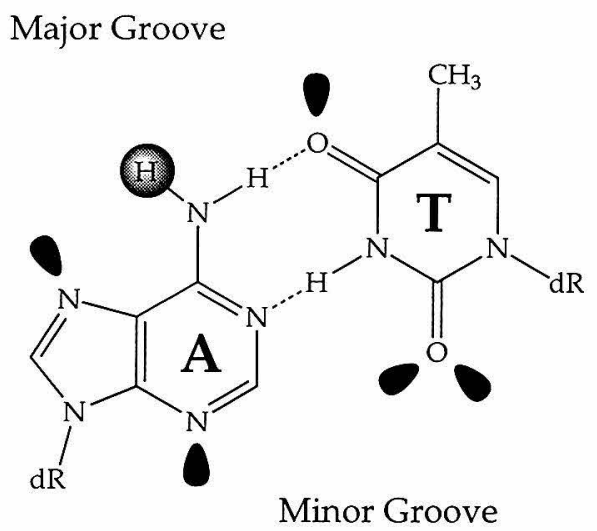

Major Groove

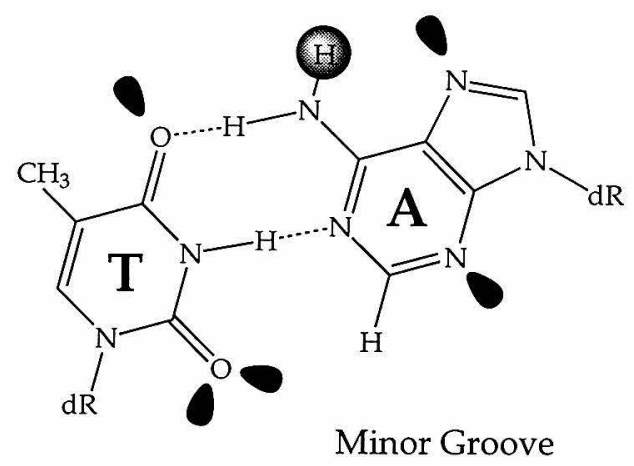

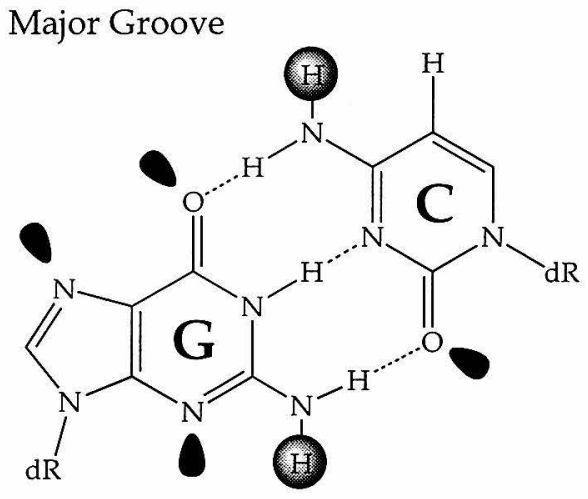

Minor Groove
Major Groove

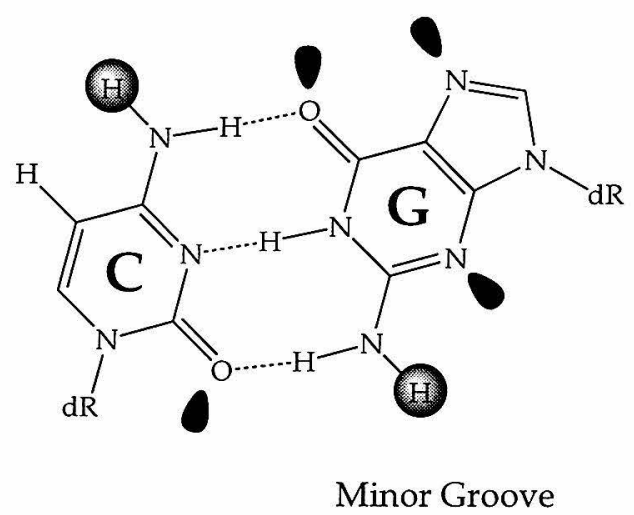

Figure 1.1. Structure of the four Watson-Crick base pairs. Lone pairs are represented by the black shaded areas. The hydrogens available for hydrogen bonding to DNA-ligands are shaded. 
present on the sides of the minor groove. Recently, a great deal of research has focused on the design and synthesis of distamycin and netropsin derivatives with the aim of learning more about the factors responsible for the sequence-specific recognition of DNA, and ultimately being able to modulate the specificity of these derivatives. ${ }^{2 k-r}$ Knowledge acquired from experiments of this nature has allowed Mrksich and Dervan to create oligomeric distamycin derivatives capable of GC (as opposed to AT) recognition. ${ }^{2 j-0,2 q, 2 r}$ A third category of DNA-binding ligands includes natural proteins characterized by different structural motifs, such as leucine zippers, zinc fingers, helix-turn-helix, and helix-loop-helix, which are responsible for the different specificities observed. ${ }^{3}$ Specificity is derived from hydrogen bonds to the DNA bases in the major, or both major and minor groove, as well as from shape complementarity between the proteins and the DNA grooves. Salt bridges to the negatively charged DNA backbone may also be involved. Due to the present difficulty in predicting the tertiary and quaternary structure of proteins and the lack of simple rules governing the specificity of amino acids, it is currently very difficult to design proteins with a predetermined DNA specificity. A fourth class of DNA-binding molecules comprises oligonucleotides capable of sequence-specific recognition of DNA via the formation of a local triple helix stabilized by specific hydrogen bonds between the bases of the Watson-Crick duplex and those of the third strand. Of the classes of DNA-binding molecules mentioned above, oligonucleotides are the most specific ones.

Triple-Helical Complexes. The first triple-helical complex was reported in 1957 by Felsenfeld, Davies, and Rich, when they observed that in the presence of $\mathrm{MgCl}_{2}$ three RNA strands form a polyribonucleotide complex in the stoichiometry of 2 poly $(\mathrm{rU})$ to 1 poly $(\mathrm{rA})$ strand. ${ }^{4}$ Rich et al. postulated the 
formation of specific Hoogsteen hydrogen bonds between the adenine of an $\mathrm{AU}$ base pair and uridine in the third strand, which was subsequently confirmed by physical methods (Figure 1.2). Later experiments showed that poly $(\mathrm{rC})$ was capable of forming a 2:1 complex with poly $(\mathrm{rG})$ at low $\mathrm{pH}^{5}$ presumably due to the required protonation of $C$, and that poly $(\mathrm{dT}-\mathrm{dC})$ or poly $(\mathrm{rU}-\mathrm{rC})$ was capable of associating with poly $(\mathrm{dG}-\mathrm{dA}) \bullet$ poly $(\mathrm{dC}-\mathrm{dT})$ also at acidic $\mathrm{pH}$ to form triple-helical complexes in which $\mathrm{T}(\mathrm{U}) \bullet \mathrm{AT}(\mathrm{U})$ and $\mathrm{C}+\mathrm{GC}$ triplets are likely isomorphous. ${ }^{6}$

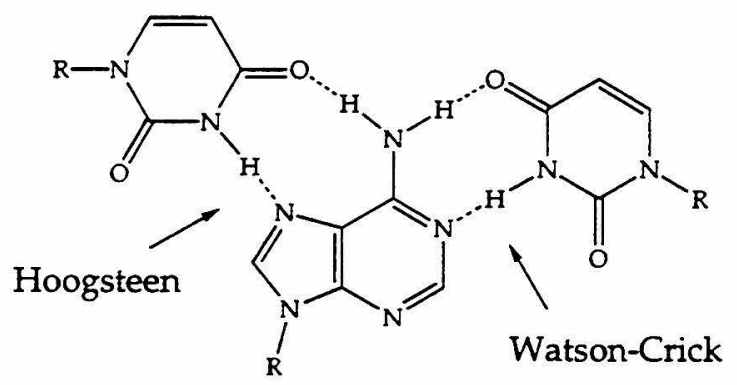

$\mathrm{U} \bullet A \mathrm{U}$ Base Triplet

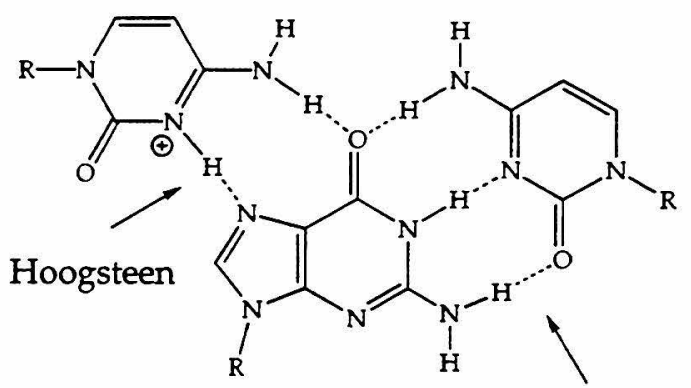

Watson-Crick

Figure 1.2. Structure of the two base triplets present in a poly $(\mathrm{rU}-\mathrm{rC})_{2} \bullet$ poly(rA-rG) triple-helical complex.

Fiber diffraction studies of $\operatorname{poly}(\mathrm{rU})_{2} \bullet \operatorname{poly}(\mathrm{rA})$ and $\operatorname{poly}(\mathrm{dT})_{2} \bullet \operatorname{poly}(\mathrm{dA})$ suggested that triple-helical complexes have an $\mathrm{A}^{\prime}$-conformation in which the third strand is parallel to the purine strand of the duplex, and the sugars are in a C-3' endo conformation with anti-glycosidic bonds. ${ }^{7}$ Subsequent NMR, electron microscopy, circular dichroism and Raman spectroscopy experiments suggested that triple-helical complexes contain structural features of both $\mathrm{A}$ and $\mathrm{B}$ conformation depending on solution conditions and 
sequence composition. ${ }^{8}$ Unfortunately, no high-resolution $x$-ray crystals of triplex DNA have been reported to date.

Oligonucleotide-Directed Recognition of Double-Helical DNA. The observation that long polypyrimidine and polypurine strands can associate to form triple-helical complexes prompted the question whether short $(<18$ base triplets) triple-helical complexes would be sufficiently stable to form in solution. Studies by Moser and Dervan demonstrated for the first time that a homopyrimidine oligodeoxyribonucleotide 15 nucleotides in length is capable of forming a stable local triple helix at a single site within a $4.06-\mathrm{kbp}$ linearized plasmid (Figures 1.3 and 1.4). ${ }^{9}$ Affinity cleaving experiments (see below) indicated that the homopyrimidine strand binds in the major groove of DNA parallel to the homopurine strand by the formation of specific $\mathrm{T} \bullet \mathrm{AT}$ and $C+G C$ triplets. In addition, it was observed that the stability of the triple helix is significantly decreased by the presence of a single base triplet mismatch. These findings are of pivotal importance as they suggested a new tool for the sequence-specific recognition of DNA. Because a 15-18-bp site on double-helical DNA is sufficient statistically to define a single site in $3 \times 10^{9}$-bp human genomic DNA (Table 1.1), ${ }^{10}$ 15-18mer oligonucleotides are in principle much more specific than restriction enzymes, which typically bind to 6-8-bp sites. The high specificity of oligonucleotides was demonstrated in experiments in which EDTA•Fe-modified pyrimidine oligodeoxyribonucleotides were able to cleave total genomic bacteriophage, yeast, and mammalian DNA at a single site. ${ }^{12}$ These considerations alone suggest the power of oligonucleotide-directed triple helix formation as a method for the sequence-specific recognition of DNA. 

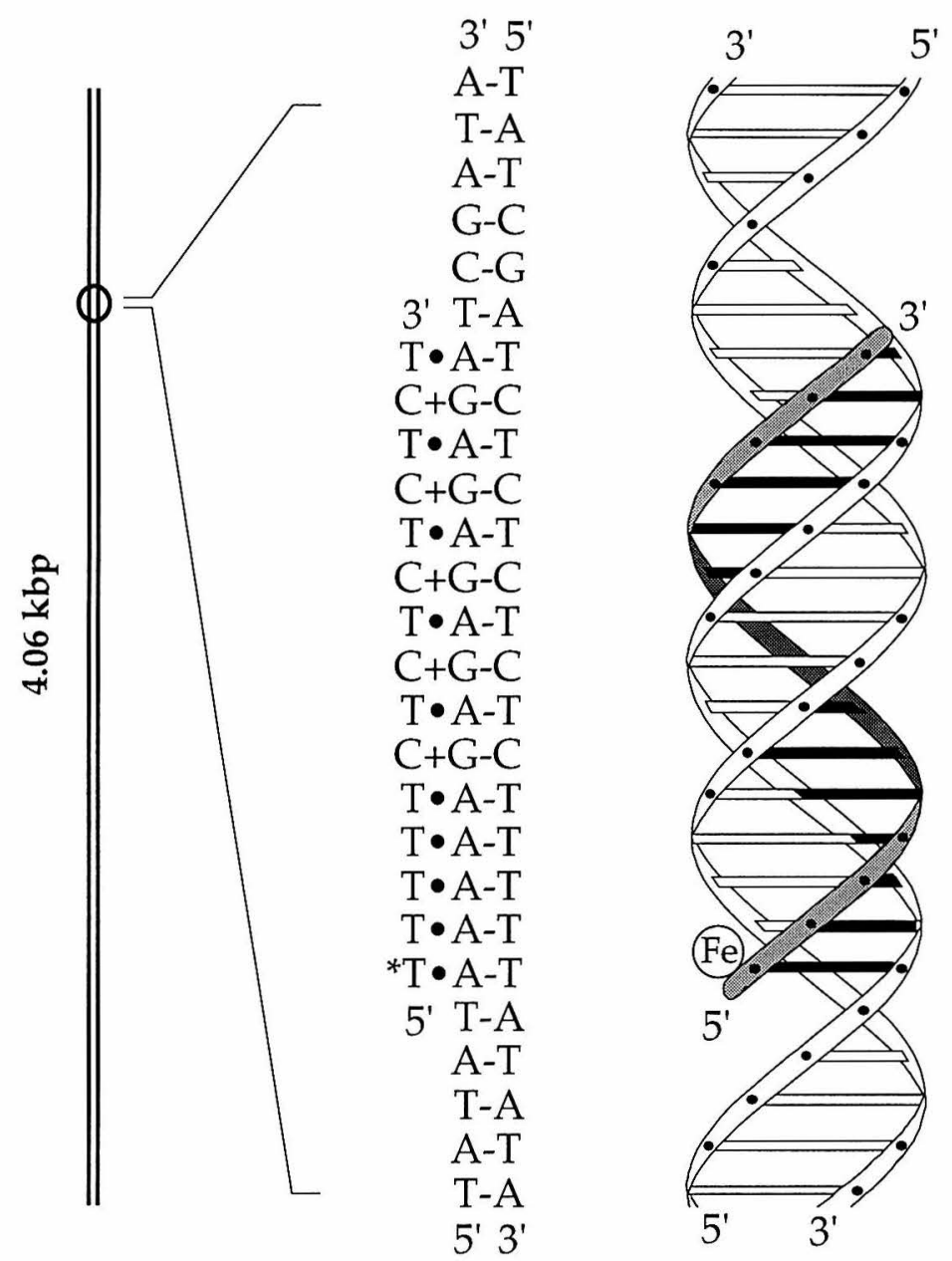

Figure 1.3. Ribbon diagram of a triple-helical complex between a 4.06kbp DNA fragment and a Hoogsteen-bound EDTA $\bullet$ Fe-modified 15mer oligodeoxyribonucleotide. 
Figure 1.4. Molecular model of a triple-helical complex. The third strand is depicted in gray. 


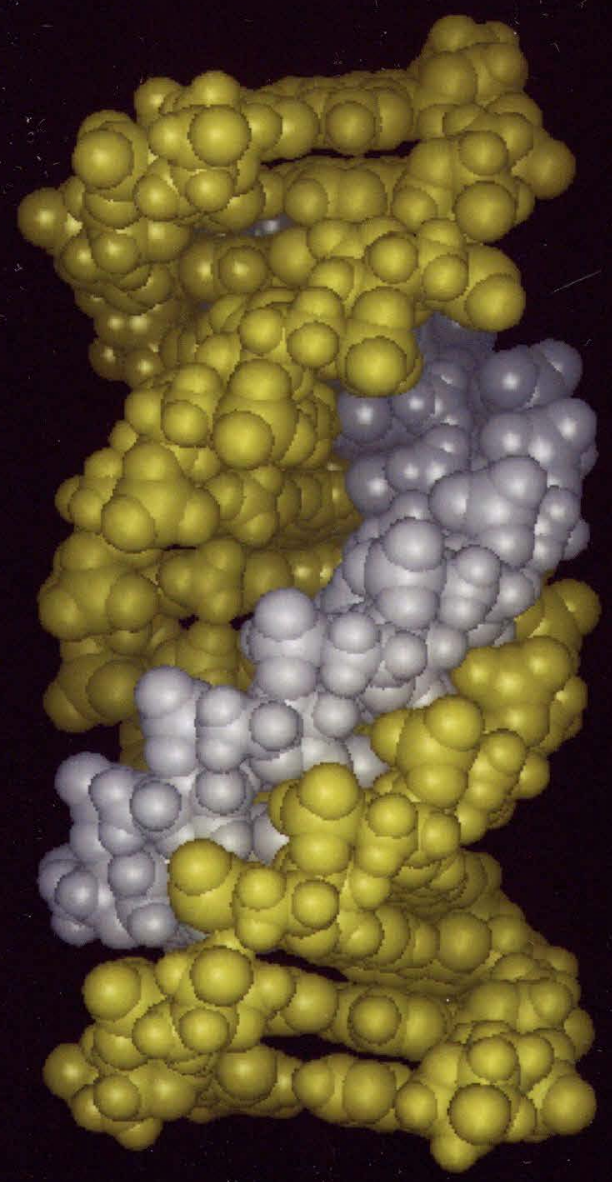


Table 1.1. Relationship between duplex binding site and number of unique sequences.

\begin{tabular}{cccc}
\hline $\begin{array}{c}\text { Binding Site } \\
\text { Size }^{a}\end{array}$ & $\begin{array}{c}\text { Unique } \\
\text { Sequences }^{b}\end{array}$ & $\begin{array}{c}\text { Binding Site } \\
\text { Size }^{a}\end{array}$ & $\begin{array}{c}\text { Unique } \\
\text { Sequences }^{b}\end{array}$ \\
\hline 4 & 136 & 12 & $8,390,656$ \\
6 & 2080 & 15 & $536,870,912$ \\
8 & 32,896 & 18 & $68,719,607,808$ \\
10 & 524,800 & 21 & $2,199,023,300,000$ \\
\hline
\end{tabular}

${ }^{a}$ The binding site size is given in number of base pairs. ${ }^{b}$ The number of unique sequences is determined from $4^{n} / 2$ when $n$ (the binding site size) is odd, and $\left(4^{n}+4^{n / 2}\right) / 2$ when $n$ is even. ${ }^{11}$

Since Moser and Dervan's experiment, the phenomenon of triple helix formation has been the subject of extensive research. ${ }^{13}$ Kinetic studies have shown that triple helix formation is a slower process by as much as three orders of magnitude than double helix formation, although the rate of formation can be affected by $\mathrm{pH}$ and salt. ${ }^{14}$ Additional kinetic studies indicate that triple helices form by a "nucleation-zipping" process in which three to five base triplets constitute the nucleus. ${ }^{14 \mathrm{~b}} \mathrm{UV}$ melting curves, ${ }^{8 \mathrm{~b}, 15 \mathrm{a}-\mathrm{d}}$ melting temperature studies, ${ }^{15 d}$ and differential scanning calorimetry studies ${ }^{8 b, 15 c, e}$ have been used to determine the thermodynamic parameters for pyrimidinepurine-pyrimidine complex formation. Recently, studies on the effect of $\mathrm{pH}^{16 \mathrm{a}}$ salt ${ }^{16 \mathrm{~b}}$ and temperature ${ }^{16 c}$ have been carried out by quantitative affinity cleavage titrations, and have shown that triplex stability is increased by low $\mathrm{pH}$ (favoring protonation of the third strand cytidine) and temperature (as 
might be expected for an associative process). The effects of salt concentration have been shown to vary depending on the cations present in solution. More recently, the thermodynamics of triple helix formation as a function of base triplet mismatches and oligonucleotide sequence composition were studied. ${ }^{17}$ According to these experiments, a mismatch in the third strand is capable of destabilizing a local triple helix by at least $0.5 \mathrm{kcal} \bullet \mathrm{mol}^{-1}(10 \mathrm{mM}$ Bis-Tris $\bullet \mathrm{HCl}$, $100 \mathrm{mM} \mathrm{NaCl}, 250 \mu \mathrm{M}$ spermine, $\left.\mathrm{pH} 7.0,22{ }^{\circ} \mathrm{C}\right) .{ }^{17 \mathrm{a}}$ In addition, measurement of the relative energetic contributions of the various dinucleotide units indicated that the stability of a triple helix is increased by a 5'-TT-3' and decreased by a $5^{\prime}-{ }^{m} C^{m} C-3$ dinucleotide $\left({ }^{m} \mathrm{C}=5\right.$-methyl-2'-deoxycytidine $) .{ }^{17 b}$

In a second class of triple-helical complexes, purine-rich oligonucleotides bind in the major groove of DNA antiparallel to the homopurine strand by formation of specific $\mathrm{G} \bullet \mathrm{GC}$ and $\mathrm{T} \bullet \mathrm{AT}$ or $\mathrm{A} \bullet \mathrm{AT}$ base triplets (Figure 1.5). ${ }^{18}$ These complexes are less sensitive to $\mathrm{pH}$ than pyrimidine-purine-pyrimidine ones, as protonation is not required for $\mathrm{G} \bullet \mathrm{GC}$ and $\mathrm{T} \bullet \mathrm{AT}$ or $\mathrm{A} \bullet \mathrm{AT}$ formation. Recently, a thermodynamic study of the stability of purine-purine-pyrimidine complexes as a function of sequence composition was reported. ${ }^{19}$

While the pyrimidine and purine motifs provide a powerful method for the recognition of homopurine sites, the recognition of mixed purinepyrimidine sequences presents great difficulties. Towards this goal, several approaches have been undertaken. One approach involves the search for other base triplets such as G・TA (Figure 1.6). ${ }^{20}$ An ongoing approach involves the design and synthesis of novel nucleotides that can recognize CG or TA base pairs through the formation of new hydrogen bonding patterns and/or favorable steric interactions within the contours of the major groove. Progress in this area has been slow. For CG and TA recognition within the 

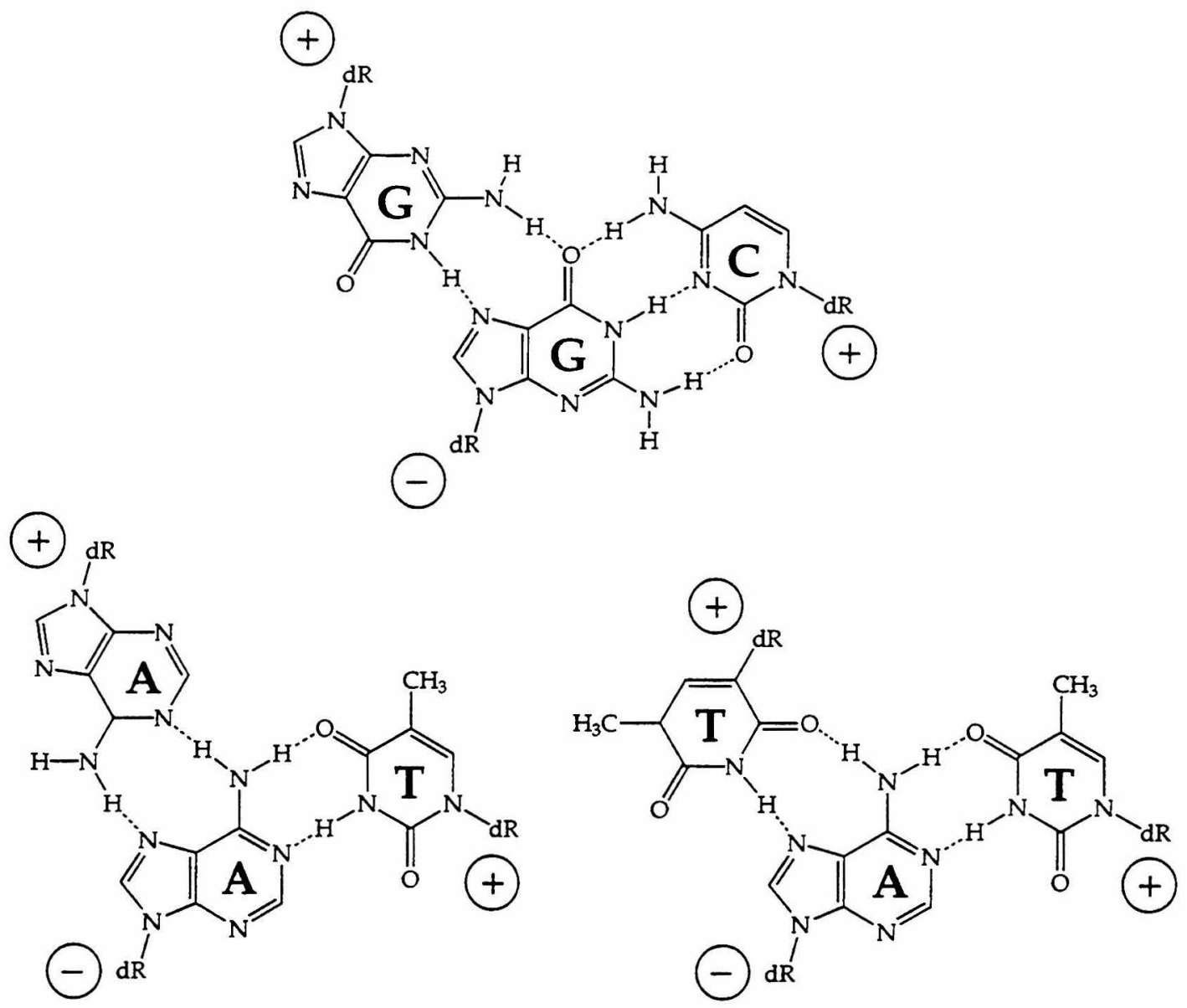

Figure 1.5. Structure of $G \bullet G C, A \bullet A T$ and $T \bullet A T$ base triplets found in the purine motif. The relative orientations of the strands are represented by the positive and negative signs.

pyrimidine motif, the nonnatural intercalating base $D_{3}$ (1-(2-deoxy- $\beta$ - $D$ ribofuranosyl)-4-(3-benzamido)phenylimidazole) seems to be the best solution presented to date (Figure 1.6). ${ }^{20 b, 21}$ For CG recognition within the purine motif, 2'-deoxynebularine seemed to be the most specific at first, although its specificity was later shown to be dependent on solution conditions and sequence composition. ${ }^{22}$ A recently synthesized series of imidazole derivatives, designed to fit snugly into the major groove of DNA, 


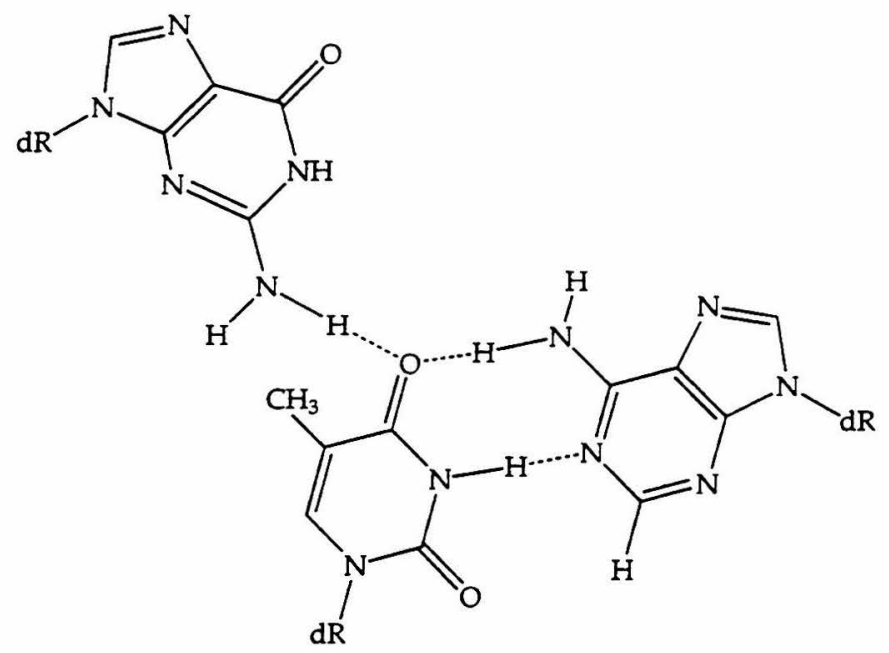

\section{$G \cdot T A$}<smiles>[R]C(=O)Nc1cccc(-c2cn([R])cn2)c1</smiles><smiles>[R]C(=O)Nc1cccc(-c2cn([R])cn2)c1</smiles>

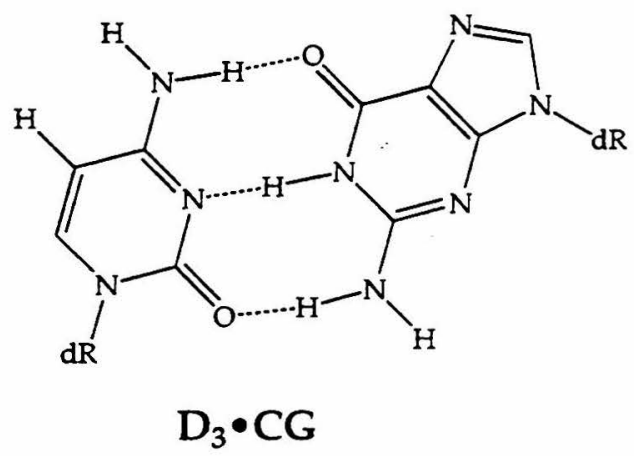

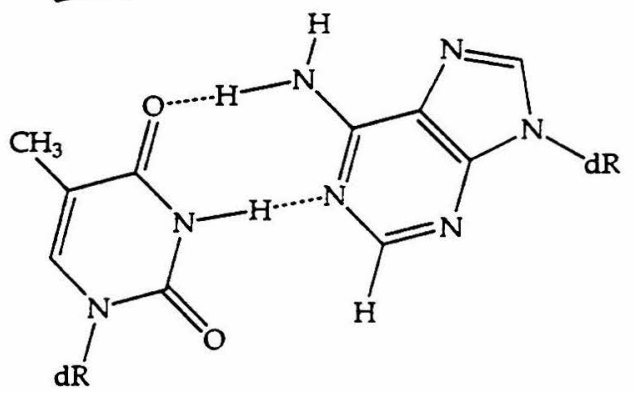

$\mathrm{D}_{3} \bullet \mathrm{TA}$

Figure 1.6. Structure of the natural base triplet G・TA (top) and of the specific $\mathrm{D}_{3} \bullet \mathrm{CG}$ and $\mathrm{D}_{3} \bullet$ TA base triplets (bottom). $\mathrm{D}_{3}$ is believed to intercalate between two DNA base pairs. 
displayed only weak CG and TA recognition. ${ }^{23}$ Lately, a nonnatural parallel N7-purine motif, in which the third strand orientation is reversed by moving the third strand deoxyribose from the N9 to the N7 position, was developed and may ultimately provide new leads for the recognition of CG and TA base pairs. ${ }^{24}$ A description of this motif is presented in Chapter Seven.

Although in principle the novel base design approach is very promising, the challenge of synthesizing novel heterocyclic compounds constitutes a limitation. In another, more synthetically feasible approach, oligonucleotides have been designed to cross-over the major groove, thus allowing the binding to mixed purine-pyrimidine sequences. ${ }^{25}$ Another strategy involves protein-mediated triple helix formation, as in the system described by Rao et al. in which a RecA nucleoprotein filament containing single-stranded DNA promotes strand exchange with duplex DNA via a three-stranded DNA intermediate. ${ }^{26}$

DNA Binding Assays. Two experimental techniques, DNA affinity cleaving and footprinting, are routinely used for analyzing the binding of oligonucleotides to DNA by triple helix formation (Figure 1.7). ${ }^{10}$ In affinity cleaving, a nonspecific DNA cleaving agent is covalently attached to a sequence-specific DNA binding oligonucleotide to afford a DNA sequencespecific cleaving molecule. A commonly used nonspecific DNA cleaving molecule is EDTA $\bullet$ Fe which, in the presence of a reducing agent such as dithiothreitol, generates a diffusible oxidant capable of hydrogen atom abstraction from the DNA backbone at locations near the bound site, leading to double strand cleavage. Functionalization of oligonucleotides with EDTA $\bullet \mathrm{Fe}$ is achieved by the incorporation of a 5'-O-DMT-protected thymidine-EDTA phosphoramidite $\left(T^{*}\right)$ using automated DNA synthesis (Figure 1.8). ${ }^{27}$ Analysis of the cleavage products from a ${ }^{32} \mathrm{P}$-end-labeled DNA 
A

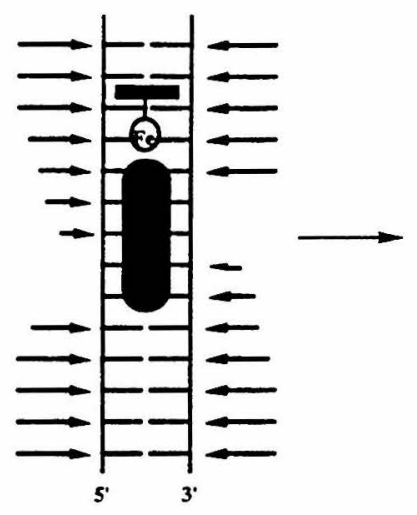

B
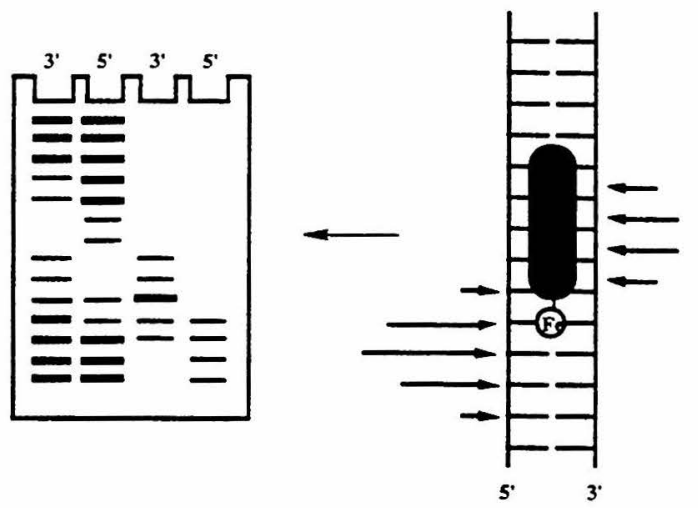

Figure 1.7. Schematic diagram of the DNA footprinting (A) and affinity cleaving (B) techniques used to determine the binding properties of a DNAbinding ligand. Autoradiography (middle) of a high-resolution gel of 5'- and $3^{\prime}-{ }^{32} \mathrm{P}$-end-labeled DNA fragments shows the location and size of the binding site (left two lanes for footprinting; right two lanes for affinity cleaving). A 5'shift in the cleavage pattern indicates that a ligand is bound in the major groove.<smiles>CCOC(=O)CN(CCN(CC(=O)OCC)CC(=O)OCC)CC(=O)NCCNC(=O)CCc1cn(C2CC(OP(OCCCN)C(C)C)C(COC(=O)OCc3ccccc3)O2)c(=O)[nH]c1=O</smiles>

Figure 1.8. Structure of 5'-O-DMT-protected thymidine-EDTA phosphoramidite derivative $\left(\mathrm{T}^{*}\right)$ used in affinity cleaving experiments and incorporated into oligonucleotides by automated DNA synthesis. 
restriction fragment on an autoradiogram of a high-resolution, nondenaturing gel gives information about the location and size of the binding site, and the orientation of the EDTA $• F e$-modified molecule on double-helical DNA. Analysis of the asymmetric pattern of the cleavage bands provides direct information on the groove location (Figure 1.9). The fact that the intensity of the observed cleavage bands is proportional to the fractional occupancy allows a qualitative comparison of the differences in binding affinities of molecules equipped with EDTA $\bullet$ Fe. In addition, the recently developed quantitative affinity cleavage titrations technique allows the determination of the equilibrium association constants for oligonucleotides to duplex DNA by triple helix formation. ${ }^{28}$

In DNA footprinting, ${ }_{1}^{10}$ a ${ }^{32} \mathrm{P}$-end-labeled DNA fragment and the ligand of interest are incubated in solution, after which they are treated with a nonspecific DNA cleaving agent, such as DNase I or the synthetic reagent methidiumpropyl-EDTA (MPE), which cleaves DNA at every base position that is not protected by a bound ligand (Figure 1.7). Analysis of the cleavage products on an autoradiogram of a high-resolution, nondenaturing gel containing a sequencing lane shows the location and size of the binding site. Quantitation of the intensity of the footprint allows determination of the binding free energy for triple helix formation (quantitative DNase I footprinting)..$^{29}$

Triple Helix-Mediated Control of Gene Expression. Despite its limitations, oligonucleotide-directed triple helix formation has already proven to be a powerful method for controlling gene expression in vitro. Oligonucleotides have been shown to inhibit the binding of proteins such as methylases, transcription factors, restriction enzymes, and polymerases, at sites overlapping with triplex binding sites. ${ }^{30}$ This ability was used to inhibit 


\section{MAJOR GROOVE}
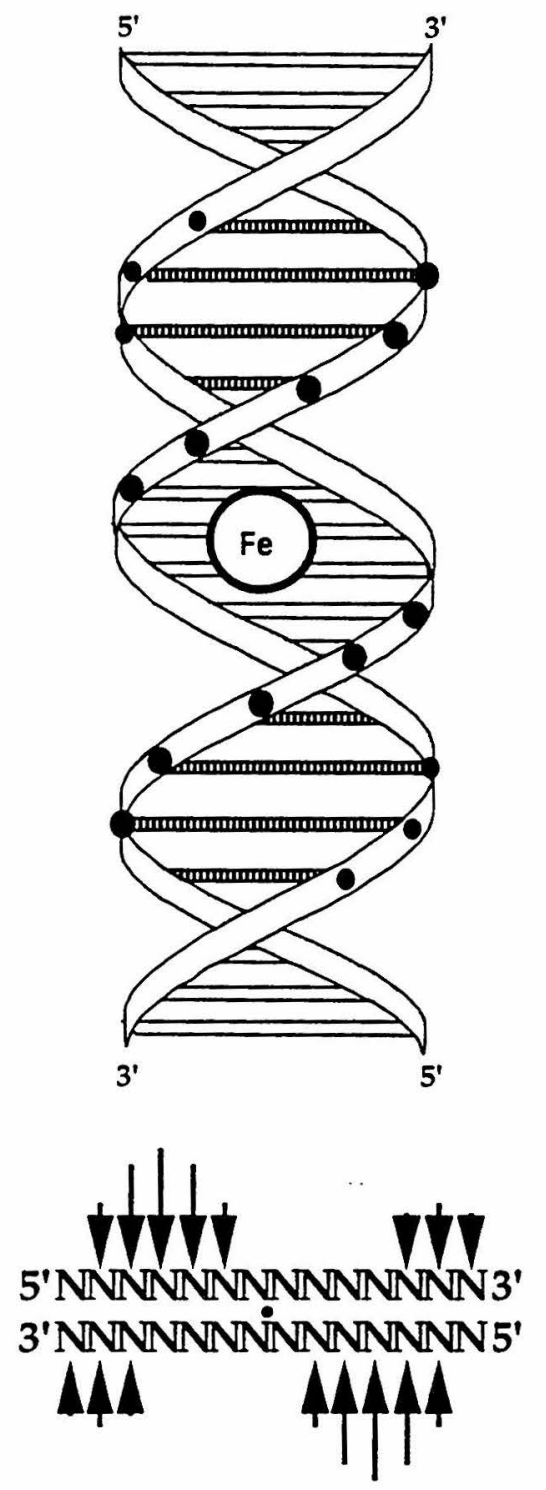

\section{MINOR GROOVE}
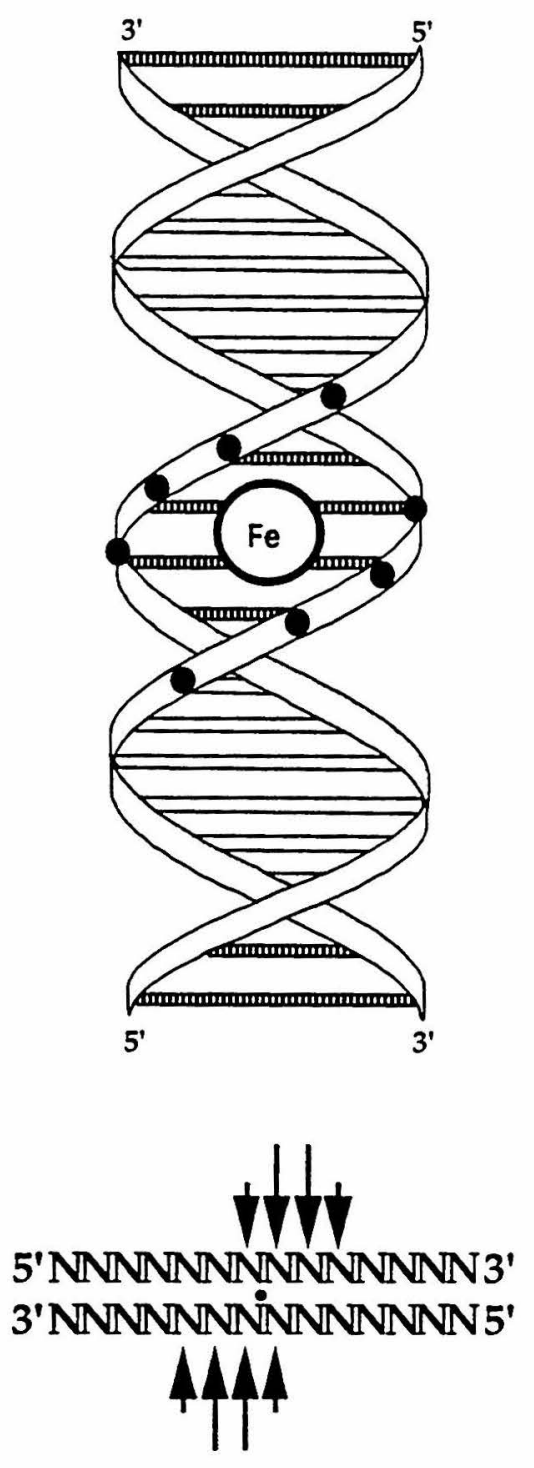

Figure 1.9. Ribbon diagram showing the two types of cleavage patterns obtained by an EDTA-modified molecule bound in the major or minor groove of double-helical DNA. 
transcription initiation and elongation in vitro. ${ }^{30 b, 31}$ These results suggest the possibility of using oligonucleotides for therapeutic purposes to control gene expression in diseases caused by improper gene expression. For this to occur, the great challenge, among many others, of designing and synthesizing oligonucleotides that are stable to nucleases and are capable of crossing membranes of specific cells must be solved.

Other Work in the Area of Triple Helix Formation. To overcome the $\mathrm{pH}$ dependence of triple helix formation by cytidine- or 5-methyl-2'-deoxycytidine-containing oligonucleotides, nonnatural bases such as 2'-O-methylpseudoisocytidine, ${ }^{32 \mathrm{a}}$ 6-methyl-8-oxo-deoxyadenosine, ${ }^{32 \mathrm{~b}}$ 8-oxoadenosine, ${ }^{32 \mathrm{c}}$ and 8-oxodeoxyadenosine, ${ }^{32 c} 1$-(2-deoxy- $\beta$-D-ribofuranosyl)-3-methyl-5-amino$1 H$-pyrazolo[4,3,-d]pyrimidone (P1), ${ }^{32 d-f}$ and a recently reported pyrazine $\operatorname{analog}^{32 g}$ were shown to recognize GC base pairs in a $\mathrm{pH}$-independent manner (Figure 1.10). The synthesis of bases capable of $\mathrm{K}+$-independent GC recognition is also an ongoing effort. ${ }^{33}$

To increase the stability of triple helices, their resistance to nucleases, and/or improve their cellular uptake, oligonucleotides containing modified phosphate backbones have been constructed. While many oligonucleotide analogs of this type have been shown to hybridize with single-stranded DNA, few of those synthesized to date are capable of binding to double-helical DNA. These include oligonucleotides containing phosphorothioate- ${ }^{34 a}$ phosphorodithioate-, methyl phosphonate- ${ }^{34 b}$ alkylphosphotriester- ${ }^{34 c}$ formacetal-,${ }^{34 d}$ and 3'-thioformacetal- modified backbones. ${ }^{34 d}$ Oligonucleotides with modifications in the ribose have also been synthesized (see Chapter Six). In addition, triplex formation by $\alpha$-oligonucleotides, ${ }^{13}$ as well as by oligonucleotides covalently linked to intercalating agents, DNA cross-linking 
<smiles></smiles><smiles></smiles><smiles>[Y]n1c(=O)n(CC)c2c(N(C)C)ncnc21</smiles>

D<smiles>[R]n1nc(C)c2nc(NCC)n([TlH]C)c(=O)c21</smiles><smiles>[R]c1ncc(NPC)n([TlH]CC)c1=O</smiles>

Figure 1.10. Structure of protonated cytidine mimics designed for the $\mathrm{pH}$ independent GC recognition within the pyrimidine motif. (A) protonated cytidine. (B) 2'-O-methylpseudoisocytidine. (C) 6-methyl-8-oxo-2'-deoxyadenosine. (D) 1-(2-deoxy- $\beta$-D-ribofuranosyl)-3-methyl-5-amino- $1 H$-pyrazolo$[4,3, d]$ pyrimidone (P1). (E) pyrazine analog.

reagents, and DNA-cleaving reagents other than EDTA $\bullet F e$ have also been reported..$^{13,35}$

Cooperative Oligonucleotide-Directed Triple Helix Formation. One of the challenges of oligonucleotide-directed triple helix formation is the development of systems in which oligonucleotides bind to duplex DNA not only with high affinity, but also with high specificity. The easiest solution to increasing a pyrimidine oligonucleotide's affinity to DNA is to increase its length, or change the solution conditions to low $\mathrm{pH}$ and/or temperature. Nonetheless, increasing affinity without lowering the specificity is a difficult intellectual task as oligonucleotides with higher affinities to DNA target sites are inherently less sensitive to base mismatches than lower affinity ones. In addition, the ability to solve this task may be important from a therapeutic 
stand point as well, as the side effects of nonspecific binding of oligonucleotides used in a therapeutic context would totally preclude their use.

Nature's solution to increasing the sequence specificity and affinity of a DNA-binding ligand is cooperativity. Cooperative interactions between macromolecules, especially proteins, are ubiquitous in biological systems, and critically influence the regulation of gene expression. ${ }^{36}$ The two main mechanisms by which cooperative interactions occur are ligand-induced allosteric conformational change of a receptor, and dimerization between ligands. ${ }^{36 \mathrm{~b}}$ These two mechanisms are conceptually different. In the first one, the binding of a ligand to a receptor causes a conformational change at a location distant from the binding site. In the second mechanism, generally leading to higher specificities, physical proximity between two ligands is required.

Cooperative interactions occur most commonly between enzymes and their substrates, but also between hormones and hormone receptors, small molecules and proteins transporting these small molecules, and between ions and proteins. ${ }^{37}$ The binding of oxygen to hemoglobin, of carbamoyl phosphate to aspartate in the pyrimidine biosynthesis, the self-assembly of lipid bilayers, and the stabilization of the triple-helical structure of collagen, are only few of the well studied cooperative processes naturally occurring in biological systems. Other more recently described cooperative systems involve the dimerization of transcription factors such as hepatocyte nuclear factor- $1 \alpha$, the heterodimerization of low molecular weight molecules such as cyclosporin $\mathrm{A}$ and $\mathrm{FK} 506^{38}$ and the cooperative binding of polyamides containing pyrroles and/or imidazoles to DNA. ${ }^{2 m}$ 
Cooperative interactions have also been observed in nucleic acid systems. According to the well studied nucleation-zipping model for double helix formation, after the generation of the first, isolated and rather unstable base pair, additional base pairs form and stack onto one another, creating a nucleus leading to the spontaneous construction of the rest of the helix. ${ }^{1}$ The binding of oligoinosines to a polycytidine template is believed to be cooperative. ${ }^{39 a}$ Cooperative interactions between short oligonucleotides bound to adjacent sites on DNA have been invoked in the nonenzymatic template-directed selfreplication of short RNA and DNA molecules ${ }^{39 b-d}$ as well as in a recently described DNA sequencing methodology based on primer walking of strings of continuous hexamers. ${ }^{40}$

The importance of cooperative ligand interactions in physiological processes has spurred an ongoing effort to explore these interactions in depth. Complex mathematical frameworks allowing for the analysis of ligand interactions in associative processes have been developed for representative cases in which either one type of ligand binds to a single class of identical sites, or two or more structurally different ligands bind to two or more sites. ${ }^{36 \mathrm{~b}}$

One of the best studied biological systems exemplifying the power of cooperativity is the phage $\lambda$ repressor system. ${ }^{36 a}$ During lysogeny, most genes of phage $\lambda$ are repressed, but can be efficiently switched on by external agents. The switch consists of a tripartite operator to which two different proteins bind (Figure 1.11). The binding of the first dimer repressor to one site on the operator enhances the binding of a second dimer repressor to a second site through protein-protein contacts, which in turn facilitates the binding of RNA polymerase to the third site. This system is remarkable in its dramatic sensitivity to changes in repressor concentration, allowing gene expression to be controlled very efficiently. Ptashne has illustrated the advantages of this 


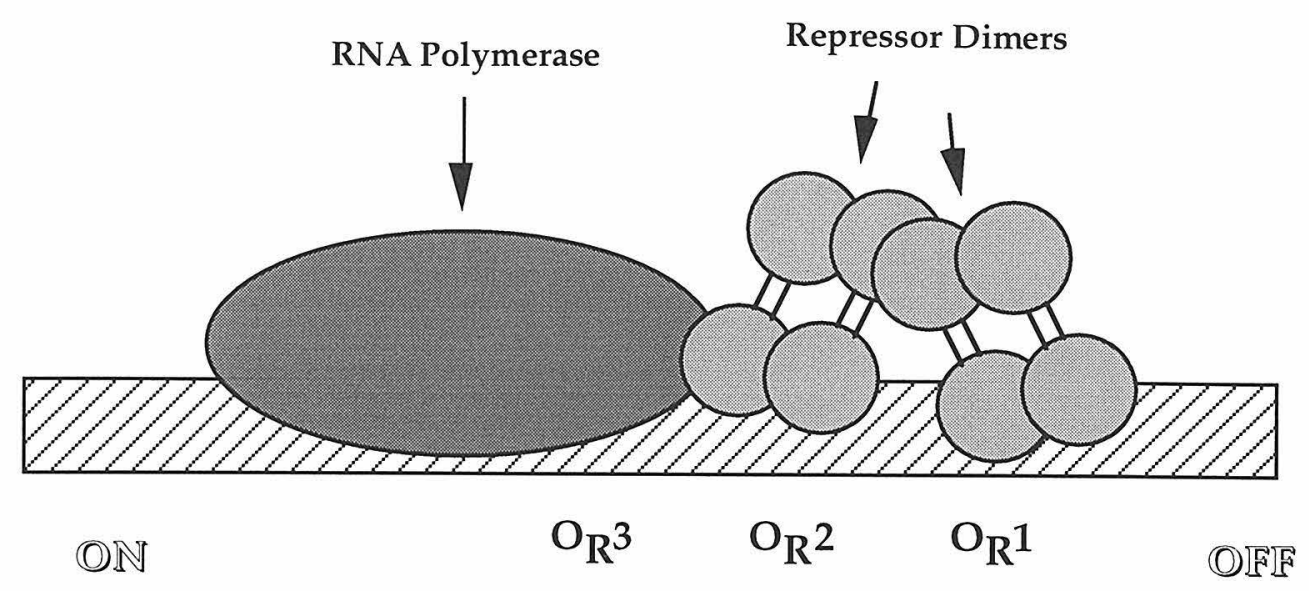

Figure 1.11. Schematic diagram of two dimer repressors and RNA polymerase bound cooperatively to DNA.

cooperative system by comparing it to the corresponding noncooperative system. ${ }^{36 a}$ As shown in Figure 1.12A, repression is maintained in a lysogen over the first two- or three-fold drop in repressor concentration from an initial high level. This ensures that lysogens are not accidentally induced by possible fluctuations in repressor concentration. However, when the repressor concentration drops by a mere factor of five, repression is decreased by $50 \%$. A noncooperative system in which the promoter is controlled by a single repressor-operator interaction would react much more sluggishly to changes in ligand concentration. Ptashne has also showed how the cooperative binding of dimer repressor molecules to two sites on DNA increases the efficiency of repressor binding, compared with binding to a single site (Figure 1.12B). If one assumes that each repressor binds to a single site with a free energy of $-10 \mathrm{kcal} \bullet \mathrm{mol}^{-1}$, and that the interaction energy between repressors bound to adjacent sites is $-2 \mathrm{kcal} \bullet \mathrm{mol}^{-1}, 30$ and 100 times more repressor would be required in the single-site case compared with the two-site system to 
A

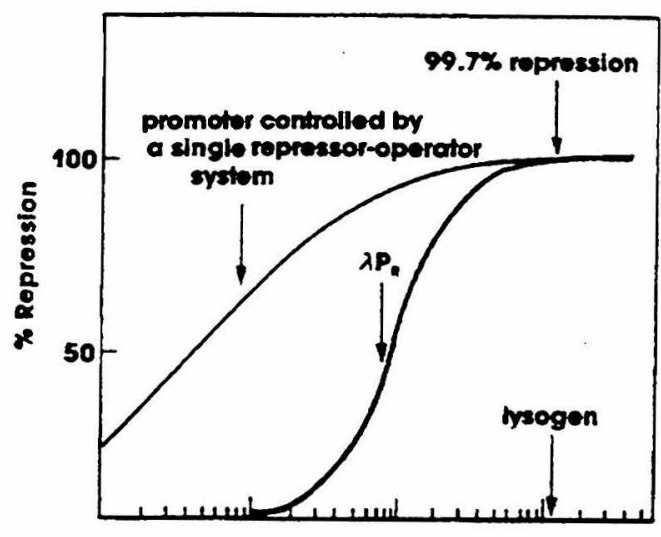

Repressor concentration

B

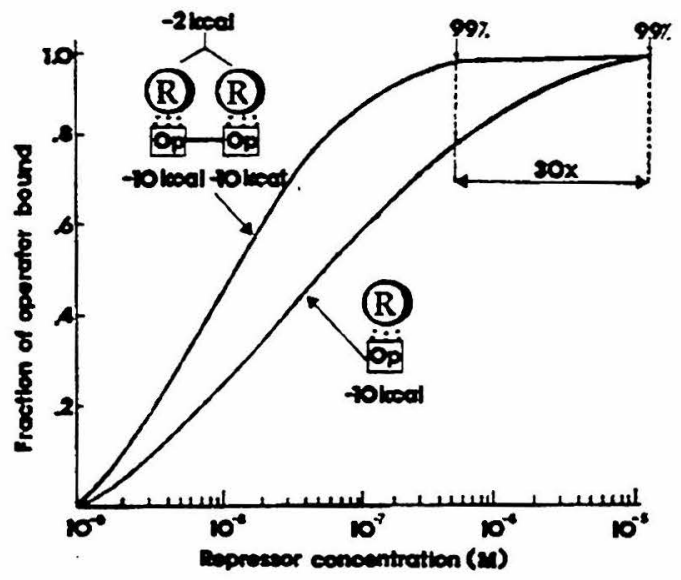

Figure 1.12. (A) Repression as a function of repressor concentration in a cooperative vs. noncooperative system. The cooperative system is much more sensitive to changes in repressor concentration than the noncooperative one. (B) Binding affinity of a ligand (repressor) to its target site (operator site) in a cooperative vs. noncooperative system. The ligand concentration required for $99 \%$ occupation of the target site drops by a factor of 30 when two ligands interact cooperatively. (Taken from Ptashne, M. A Genetic Switch; Blackwell Scientific Publications and Cell Press: Palo Alto, CA, 1986). 
reach $99 \%$ and $99.9 \%$ level occupancy, respectively. This observation stems form the fact that cooperativity raises the ratio of specific to nonspecific binding by increasing the affinity of individual ligands to adjacent sites on DNA via cooperative ligand-ligand interactions.

In the past six years there has been a considerable interest in exploiting the principles of cooperativity in systems involving triple-helical complexes. In 1989, Strobel and Dervan reported the first example of a cooperative system in which two pyrimidine oligodeoxyribonucleotides 9 nucleotides in length bind cooperatively to adjacent homopurine sites on bacteriophage $\lambda$ genomic DNA by triple helix formation. ${ }^{41}$ Stronger cooperative interactions were obtained by the addition of a dimerization domain capable of forming a short WatsonCrick duplex to the juxtaposed 5'- and 3'-termini of two oligonucleotides bound to adjacent DNA sites, leading to the formation of a Y-shaped triplehelical complex (Figure 1.13). ${ }^{42 a, c}$ In another study, Distefano and Dervan showed that the stability of the dimerization could be enhanced by the addition of a small molecule such as echinomycin targeted to the WatsonCrick minihelix. ${ }^{42 \mathrm{~b}}$ This ligand-promoted dimerization of oligonucleotides may be thought of as analogous to the naturally occurring dimerization of proteins regulated by additional protein cofactors. Luebke and Dervan demonstrated that two oligonucleotides bound to adjacent sites on a DNA template are capable of being ligated by a phosphodiester or a pyrophosphate linkage by activation of the 5 '-terminal phosphate of one oligonucleotide with $\mathrm{BrCN}$, imidazole, and $\mathrm{NiCl}_{2} \cdot{ }^{43}$ Cooperative interactions have been invoked in the self-replication of oligonucleotides on a double-stranded DNA template by triple helix formation. ${ }^{39 b, c}$ Cooperativity was also used to juxtapose two double-helical DNA fragments upon binding to a triple helix forming oligonucleotide, and ligate one or both strands by activation of 


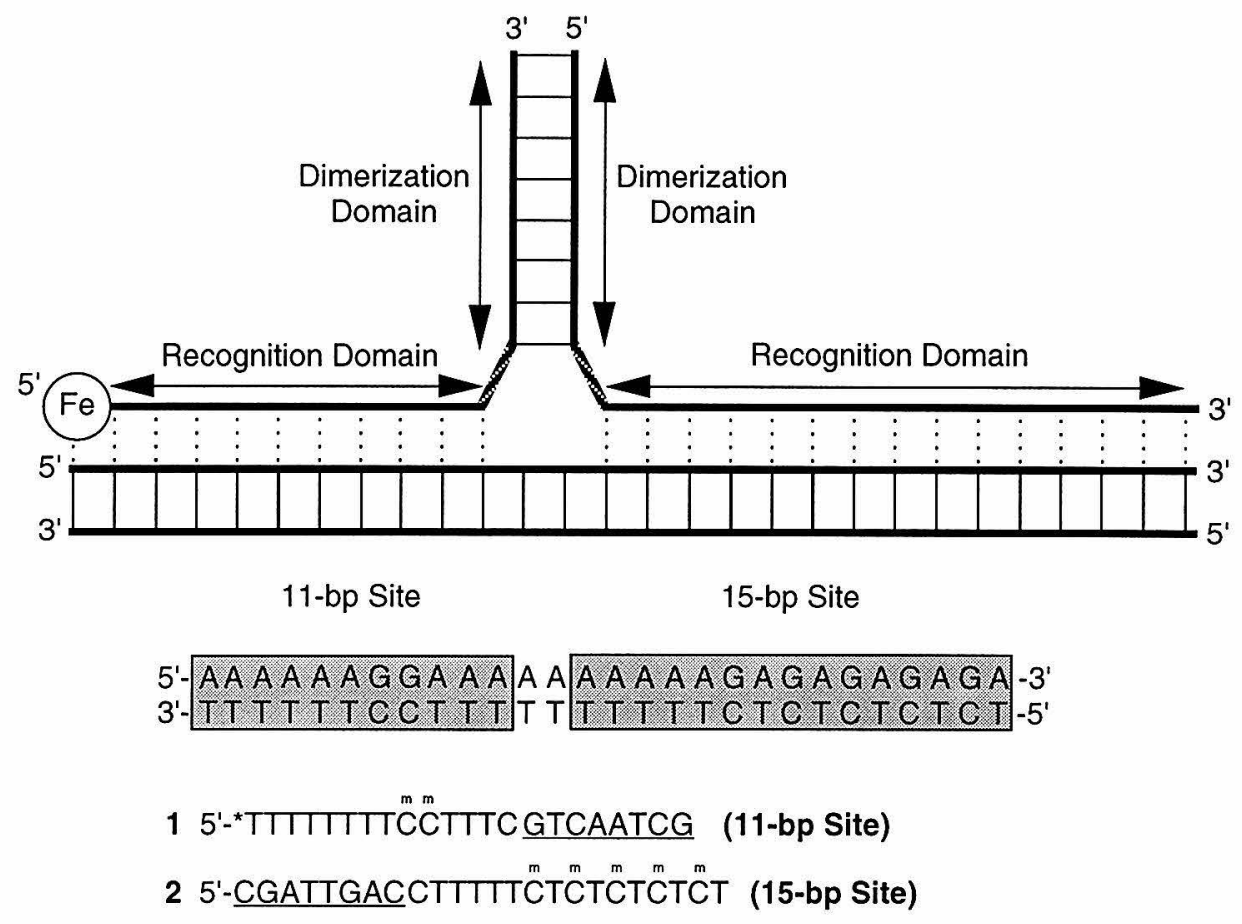

Figure 1.13. Schematic diagram of a Y-shaped triple-helical complex composed of two oligonucleotides, 1 and 2 , binding cooperatively to double-helical DNA through the formation of a Watson-Crick minihelix. 
the 5'-phosphate with $\mathrm{N}$-cyanoimidazole. ${ }^{44}$ Froehler et al. observed the cooperative binding of oligonucleotides with a $3^{\prime}-3^{\prime}$ internucleotide junction to opposite strands of duplex DNA by triple helix formation. ${ }^{45}$ Finally, pyrimidine oligodeoxyribonucleotides were found to bind cooperatively to DNA by triple helix formation in the presence of intercalators such as benzo[e]pyridoindole derivatives. ${ }^{46}$

Description of Thesis Work. This thesis describes studies designed to gain a deeper understanding of the phenomenon of cooperative binding of oligonucleotides to double-helical DNA by triple helix formation. Chapter Two illustrates experiments carried out to elucidate the origins of the cooperative binding of two pyrimidine oligodeoxyribonucleotides to adjacent sites on DNA. ${ }^{47}$ These experiments were the first to suggest that base stacking forces between the terminal bases at the triplex junction are greatly responsible for the observed cooperative interaction energy. Chapter Three reports the rigorous measurement of the energetics of the cooperative binding of two 11mer oligonucleotides to DNA by triple helix formation by quantitative affinity cleavage titrations as a function of sequence composition at the junction. ${ }^{47 b}$ In addition, quantitative studies on the effect of mismatches on cooperativity are described. Results from these experiments demonstrated that a cooperative system is more sensitive to base mismatches than a noncooperative one. ${ }^{47 b}$ Addendums to both Chapters Two and Three describe unpublished experiments on the phenomenon of cooperativity as a function of sequence composition at the triplex junction.

Chapter Four focuses on the synthetic strategies designed to increase the magnitude of cooperative interactions between pyrimidine oligonucleotides bound to abutting sites on DNA. It was reasoned that strong cooperative interactions would allow short $(<11 \mathrm{nt})$ oligonucleotides to bind to DNA. 
The positive implications of this observation are two-fold: 1) a system in which short oligonucleotides bind to DNA would presumably be more specific than one in which longer oligonucleotides bind to DNA, and 2) the use of short oligonucleotides could presumably facilitate the application of cooperativity in therapeutics, as short, low molecular weight oligonucleotides could be more amenable to cell penetration and less toxic than longer, higher molecular weight ones. The described experiments show that the incorporation of nonnatural bases such as 5-(1-propynyl)-2'-deoxyuridine into pyrimidine oligonucleotides increases cooperativity dramatically, allowing 8mers to bind to abutting sites on DNA at micromolar concentrations. ${ }^{48 a}$ In addition, the first example in which three oligonucleotides as short as 6mers bind cooperatively to DNA by triple helix formation is described. ${ }^{48 b}$

Chapter Five describes the cooperative binding of purine-rich oligonucleotides to adjacent sites on DNA, and confirms that base stacking is greatly responsible for the observed cooperative interactions. ${ }^{49}$

Chapters Six and Seven report studies not related to cooperativity. Chapter Six describes the synthesis of oligonucleotide analogs containing 5-(1propynyl)- and/or 2'-O-allyl-modified pyrimidine bases. Our goal was the determination of the energetics of triple helix formation by these oligonucleotide analogs and by the corresponding 2'-O-methyl analogs as well, with the hope of gaining a further understanding of how substituents at the 5- and 2'-position of oligonucleotides affect the stability of triple helices. Chapter Seven describes the progress towards the synthesis of a novel base, $\mathrm{N}^{7}$-2'-deoxyisoinosine, designed to recognize AT base pairs within a parallel isomorphous N7-purine motif. A description of this new motif is presented in the introduction of this chapter. 


\section{References and Notes}

1. Saenger, W. Principles of Nucleic Acid Structure; Springer-Verlag; New York, 1984.

2. (a) Schultz, P. G.; Taylor, J. S.; Dervan, P. B. J. Am. Chem. Soc. 1982, 104, 6861. (b) Vandyke, M. W.; Hertzberg, R. P.; Dervan, P. B. Proc. Natl. Acad. Sci. USA 1982, 79, 5470. (c) Schultz, P. G.; Dervan, P. B. Proc. Natl. Acad. USA 1983, 80, 6834. (d) Schultz, P. G.; Dervan, P. B. J. Am. Chem. Soc. 1983, 105, 7748. (e) Schultz, P. G.; Dervan, P. B. J. Biomol. Struct. Dyn. 1984, 1, 1133. (f) Taylor, J. S.; Schultz, P. G.; Dervan, P. B. Tetrahedron 1984, 40, 457. (g) Younquist, R. S.; Dervan, P. B. J. Am. Chem. Soc. 1985, 107, 5528. (h) Griffin, J. H.; Dervan, P. B. J. Am. Chem. Soc. 1986, 108, 5008. (i) Younquist, R. S.; Dervan, P. B. J. Am. Chem. Soc. 1987, 109, 7564. (j) Mrksich, M.; Wade, W. S.; Dwyer, T. J.; Geierstanger, B. H.; Wemmer, D. E.; Dervan, P. B. Proc. Natl. Acad. USA 1992, 89, 7586. (k) Mrksich, M.; Dervan, P. B. J. Am. Chem. Soc. 1993, 115, 9892 . (1) Mrksich, M.; Dervan, P. B. J. Am. Chem. Soc. 1993, 115, 2572. (m) Wade, W. S.; Mrksich, M.; Dervan, P. B. Biochemistry 1993, 32, 11385. (n) Geierstanger, B. H.; Jacobsen, J. P.; Mrksich, M.; Dervan, P. B.; Wemmer, D. E. Biochemistry 1994, 33, 3055. (o) Mrksich, M.; Dervan, P. B. J. Am. Chem. Soc. 1994, 116, 3663. (p) Mrksich, M.; Parks, M. E.; Dervan, P. B. J. Am. Chem. Soc. 1994, 116, 7983. (q) Geierstanger, B. H.; Mrksich, M.; Dervan, P. B.; Wemmer, D. E. Science 1994, 266, 646. (r) Mrksich, M.; Dervan, P. B. J. Am. Chem. Soc. 1995, 117, 3325.

3. (a) Sluka, J. P.; Horvath, S. J.; Bruist, M. F.; Simon, M. I.; Dervan, P. B. Science 1987, 238, 1129. (b) Mack, D. P.; Iverson, B. L.; Dervan, P. B. J. Am. Chem. Soc. 1988, 110, 7572. (c) Graham, K. S.; Dervan, P. B. J. Biol. 
Chem. 1990, 265, 16534. (d) Mack, D. P.; Dervan, P. B. J. Am. Chem. Soc. 1990, 112, 4604. (e) Mack, D. P.; Sluka, J. P.; Shin, J. A.; Griffin, J. H.; Simon, M. I.; Dervan, P. B. Biochemistry 1990, 29, 6561. (f) Oakley, M. G.; Dervan, P. B. Science 1990, 248, 847. (g) Sluka, J. P.; Horvath, S. J.; Glasgow, A. C.; Simon, M. I.; Dervan, P. B. Biochemistry 1990, 29, 6551. (h) Shin, J. A.; Ebright, R. H.; Dervan, P. B. Nucleic Acids Res. 1991, 19, 5233. (i) Mack, D. P.; Dervan, P. B. Biochemistry 1992, 31, 9399.

4. Felsenfeld, G.; Davies, D. R.; Rich, A. J. Am. Chem. Soc. 1957, 79, 2023.

5. (a) Lipsett, M. N. J. Biol. Chem. 1964, 239, 1256. (b) Howard, F. B.; Frazier, J.; Lipsett, M. N.; Miles, H. T. Biochem. Biophys. Res. Commun. 1964, 17, 93.

6. (a) Morgan, A. R.; Wells, R. D. J. Mol. Biol. 1068, 37, 63. (b) Lee, J. S.; Johnson, D. A.; Morgan, A. R. Nucleic Acids Res. 1979, 6, 3073.

7. (a) Arnott, S.; Bond, P. J. Nature New Biol. 1973, 244, 99. (b) Arnott, S.; Selsing, E. J. Mol. Biol. 1974, 88, 509. (c) Arnott, S.; Bond, P. J.; Selsing, E.; Smith, P. J. C. Nucleic Acids Res. 1976, 3, 2459.

8. (a) de los Santos, C.; Rosen, M.; Patel, D. Biochemistry 1989, 28, 7289. (b) Plum, G. E.; Park, Y. W.; Singleton, S. F.; Dervan, P.B.; Breslauer, K. J. Proc. Natl. Acad. Sci. USA 1990, 87, 9436. (c) Pilch, D. S.; Levenson, C.; Shafer, R. H. Proc. Natl. Acad. Sci. U.S.A. 1990, 87, 1942. (d) Howard, F. B.; Miles, H. T.; Liu, K.; Frazier, J.; Raghunathan, G.; Sasisekharan, V. Biochemistry 1992, 31, 10671. (e) Macaya, R. F.; Schultze, P.; Feigon, J. J. Am. Chem. Soc. 1992, 114, 781. (f) Roberts, R. W.; Crothers, D. M. Science 1992, 258, 1463.

9. Moser, H. E.; Dervan, P. B. Science 1987, 238, 645.

10. Dervan, P. B. Science 1986, 232, 464. 
11. (a) Strobel, S. A. Ph. D. Dissertation, California Institute of Technology, Pasadena, CA, 1992. (b) Dervan, P. B. Biochemistry 1987, 26, 4171.

12. (a) Strobel, S. A.; Moser, H. E.; Dervan, P. B. J. Am. Chem. Soc. 1988, 110, 7927. (b) Strobel, S. A.; Dervan, P. B. Science 1990, 249, 73. (c) Strobel, S. A.; Doucettestamm, L. A.; Riba, L.; Housman, D. E.; Dervan, P. B. Science 1991, 254, 1639.

13. For a recent review on triple helix formation, see: Helene, C. Angew. Chem. Int. Ed. Engl. 1993, 32, 666.

14. (a) Maher, L. J. III; Dervan, P. B.; Wold, B. J. Biochemistry 1990, 29, 8820. (b) Rougee, M.; Faucon, B.; Mergny, J. L.; Barcelo, F.; Giovannangeli, C.; Montenay-Garestier, T.; Helene, C. Biochemistry 1992, 111, 9269.

15. (a) Manzini, G.; Xodo, L. E.; Gaparotto, D.; Quadrifoglio, F.; van der Marel, G. A.; van Boom, J. H. J. Mol. Biol. 1990, 213, 833. (b) Roberts, R. W.; Crothers, D. M. Proc. Natl. Acad. Sci. USA 1991, 88, 9397. (c) Xodo, L. E.; Manzini, G.; Quadrifoglio, F. Nucleic Acids Res. 1990, 18, 3557. (d) Pilch, D. S.; Brousseau, R.; Shafer, R. H. Nucleic Acids Res. 1990, 18, 5743. (e) Ohms, J.; Ackermann, T. Biochemistry 1990, 29, 5237.

16. (a) Singleton, S. F.; Dervan, P. B. Biochemistry 1992, 31, 10995. (b) Singleton, S. F.; Dervan, P. B. Biochemistry 1993, 32, 13171. (c) Singleton, S. F.; Dervan, P. B. J. Am. Chem. Soc. 1994, 116, 10376.

17. (a) Best, G. C.; Dervan, P. B. J. Am. Chem. Soc. 1995, 117, 1187. (b) Best, G. C.; Dervan, P. B. Manuscript in preparation.

18. (a) Cooney, M.; Czernuszewics, G.; Postel, E. H.; Flint, S. J.; Hogan, M. E. Science 1988, 241, 456. (b) Beal, P. A.; Dervan, P. B. Science 1991, 251, 1360. (c) Durland, R. H.; Kessler, D. J.; Gunnell, S.; Duvic, M.; Pettitt, B. M.; Hogan, M. E. Biochemistry 1991, 30, 9246. (d) Pilch, D. S.; Levenson, C.; Shafer, R. H. Biochemistry 1991, 30,6081. (e) Radhakrishnan, P.; de 
los Santos, C.; Patel, D. J. J. Mol. Biol. 1991, 221, 1403. (f) Beal, P. A.; Dervan, P. B. Nucl. Acids Res. 1992, 20, 2773.

19. Greenberg, W. A.; Dervan, P. B. J. Am. Chem. Soc. 1995, 117, 5016.

20. (a) Griffin, L. C.; Dervan, P. B. Science 1989, 245, 967. (b) Kiessling, L. C, Griffin, L. C.; Dervan, P. B. Biochemistry 1992, 2829.

21. Griffin, L. C.; Kiessling, L. C.; Beal, P. B.; Gillespie, P.; Dervan, P. B. J. Am. Chem. Soc. 1992, 114, 7976. (b) Koshlap, K. M.; Gillespie, P.; Dervan, P. B.; Feigon, J. J. Am. Chem. Soc. 1993, 115, 7908.

22. Stilz, H. U.; Dervan, P. B. Biochemistry 1993, 32, 2177.

23. Greenberg, W. A. Unpublished data.

24. Hunziker, J.; Priestley, E. S.; Brunar, H.; Dervan, P. B. J. Am. Chem. Soc. $1995,117,2661$.

25. Horne, D. A.; Dervan, P. B. J. Am. Chem. Soc. 1991, 112, 2435.

26. Rao, B. J.; Dutriex, M.; Radding, C. N. Proc. Natl. Acad. Sci. USA 1991, 88,2984 .

27. Dreyer, G. B.; Dervan, P. B. Proc. Natl. Acad. Sci. USA 1985, 82, 968.

28. Singleton, S. F.; Dervan, P. B. J. Am. Chem. Soc. 1992, 114, 6957.

29. (a) Brenowitz, M.; Senear, D.; Shea, M.; Ackers, G. K. Proc. Natl. Acad. Sci. USA 1986, 83, 8462. (b) Brenowitz, M.; Senear, D.; Shea, M.; Ackers, G. K. Methods in Enzym. 1986, 130, 132.

30. (a) Maher, L. J. III; Wold, B. J.; Dervan, P. B. Science 1989, 245, 725. (b) Maher, L. J. III; Dervan, P. B.; Wold, B. J. Biochemistry 1992, 31, 70.

31. (a) Grigoriev, M.; Praseuth, D.; Robin, P.; Hemar, A.; SaisonBehmoaras, T.; Dautry-Varsat, A.; Nguyen, T. T.; Helene, C.; HarelBellan, A. J. Biol. Chem. 1992, 267, 3389. (b) Duval-Valentin, G.; Thuong, N. T.; Helene, C. Proc. Natl. Acad. Sci. USA 1992, 89, 504. 
32. (a) Ono, A.; Ts'o, P. O. P. J. Am. Chem. Soc. 1991, 113, 4032. (b) Krawczyk, S. H.; Milligan, J. F.; Wadwani, S.; Moulds, C.; Froehler, B. C.; Matteucci, M. D. Proc. Natl. Acad. Sci. USA 1992, 89, 376. (c) Miller, P. S.; Bhan, P.; Cushman, C. D.; Trepane, C. Biochemistry 1992, 31, 6788. (d) Koh, J. S.; Dervan, P. B. J. Am. Chem. Soc. 1992, 114, 1470. (e) Radhakrishnan, I.; Patel, D. J.; Priestley, E. S.; Nash, H. M.; Dervan, P. B. Biochemistry 1993, 32, 11228. (f) Priestley, E. S.; Dervan, P. B. J. Am. Chem. Soc. 1994, 117, 4761. (g) von Krosigk, U.; Benner, S. A. J. Am. Chem. Soc. 1995, 117, 5361.

33. Gee, J. E.; Revankar, G. R.; Sudhakar Rao, T.; Hogan, M. E. Biochemistry 1995, 2042.

34. (a) Latimer, L. J. P.; Hampel, K.; Lee, J. S. Nucleic Acids Res. 1989, 17, 1549. (b) Callahan, D. E.; Trepane, T. L.; Miller, P. S.; Ts'o, P. O. P.; Kan, L. S. Biochemistry 1991, 30, 1650. (c) Miller, P. S.; Fang, K. N.; Kondo, N. S.; Ts'o, P. O. J. Am. Chem. Soc. 1971, 93, 6657. (d) Jones, R. J.; Lin, K.-Y.; Milligan, J. F.; Wadwani, S.; Matteucci, M. D. J. Org. Chem. 1993, 58, 2983.

35. Helene, C. Pure and Appl. Chem. 1994, 66, 663.

36. (a) Ptashne, M. A Genetic Switch; Blackwell Scientific Publications and Cell Press: Palo Alto, CA, 1986. (b) Cantor, C. R.; Schimmel, P. R. Biophysical Chemistry Part III: The Behavior of Biological Macromolecules; W. H. Freeman and Co.: New York, N. Y., 1980. (c) Hill, T. L. Cooperativity Theory in Biochemistry: Steady State and Equilibrium Systems; Springer-Verlag: New York, N. Y., 1985. (d) Adhya, S. Annual Reviews in Genetics 1989, 23, 227.

37. Stryer, L. Biochemistry; W. H. Freeman and Co.: New York, N. Y., 1988. 
38. Austin, D. J.; Crabtree, G. R.; Schreiber, S. L. Chemistry and Biology 1995, 3, 131 .

39. (a) Springgate, M. W.; Poland, D. Biopolymers 1973, 12, 2241. (b) Kanavarioti, A. J. Theor. Biol. 1992, 158, 207. (c) Li, T.; Nicolau, K. C. Nature 1994, 369, 218. (d) Ellington, A. D. Origins Life Evol. Biosphere In press.

40. Kieleczawa, J.; Dunn, J. J.; Studier, F. W. Science 1992, 258, 1787.

41. Strobel, S. A.; Dervan, P. B. J. Am. Chem. Soc. 1989, 111, 6956.

42. (a) Distefano, M. D.; Shin, J. A.; Dervan, P. B. J. Am. Chem. Soc. 1991, 113, 5901. (b) Distefano, M. D.; Dervan, P. B. J. Am. Chem. Soc. 1992, 114, 11006. (c) Distefano, M. D.; Dervan, P. B. Proc. Natl. Acad. Sci. USA $1993,90,1179$.

43. (a) Luebke, K. J.; Dervan, P. B. J. Am. Chem. Soc. 1989, 111, 8733. (b) Dolinnaya, N. G.; Pyatrauskene, O. V.; Shabarova, Z. A. FEBS Lett. 1991, $284,232$.

44. (a) Luebke, K. J.; Dervan, P. B. J. Am. Chem. Soc. 1991, 113, 7447. (b) Luebke, K. J.; Dervan, P. B. Nucleic Acids Res. 1992, 20, 3005.

45. Froehler, B. C.; Terhorst, T.; Shaw, J.-P.; McCurdy, S. C. Biochemistry 1992, 31, 1603.

46. Mergny, J. L.; Duval-Valentin, G.; Nguyen, C. H.; Perrouault, L.; Faucon, B.; Rougee, M.; Monteney-Garestier, T.; Bisagni, E.; Helene, C. Science 1992, 256, 1681.

47. (a) Colocci, N.; Distefano, M. D.; Dervan, P. B. J. Am. Chem. Soc. 1993, 115, 4468. (b) Colocci, N.; Dervan, P. B. J. Am. Chem. Soc. 1995, 117, 4781.

48. (a) Colocci, N.; Dervan, P. B. J. Am. Chem. Soc. 1994, 116, 785. (b) Colocci, N.; Dervan, P. B. Manuscript in preparation.

49. Colocci, N.; Dervan, P. B. Nucleic Acids Res. Manuscript submitted. 


\section{CHAPTER TWO:}

\section{Cooperative Oligonucleotide-Directed Triple Helix Formation at Adjacent DNA Sites.}

\section{Introduction}

Cooperative interactions between proteins bound to DNA are essential for the regulation of gene expression. ${ }^{1}$ These cooperative interactions serve to increase the sequence specificity of DNA-binding proteins as well as the sensitivity of the binding equilibrium to concentration changes. ${ }^{2}$ When cooperative interactions occur between two (or more) ligands bound at neighboring sites on DNA, the specific binding of each ligand is enhanced.

Oligodeoxyribonucleotide-directed triple helix formation is a powerful method for the sequence-specific recognition of double-helical DNA. ${ }^{3}$ To date, at least two classes of triple helix forming oligonucleotides have been identified. In one class, pyrimidine oligonucleotides bind in the major groove of double-helical DNA parallel to purine tracts by Hoogsteen hydrogen bond formation. ${ }^{3 a}$ Specificity is derived from thymine $(\mathrm{T})$ recognition of adenine-thymine base pairs $(\mathrm{T} \bullet \mathrm{AT}$ base triplet) and protonated cytosine $(\mathrm{C}+)$ recognition of guanine-cytosine base pairs ( $C+G C$ base triplet). ${ }^{4}$ In another class of triple-helical structures, purine-rich oligonucleotides bind in the major groove antiparallel to the WatsonCrick purine strand. ${ }^{3 c, 3 e}$ In this case, specificity is derived from $G$ recognition of GC base pairs ( $\bullet \cdot G C$ base triplet) and A or T recognition of AT base pairs $\left(\mathrm{A} \bullet \mathrm{AT}\right.$ and $\mathrm{T} \bullet \mathrm{AT}$ base triplets). ${ }^{5}$

It has been demonstrated that oligonucleotides can bind cooperatively by triple helix formation to adjacent purine sites on double-helical DNA. ${ }^{6}$ For two 9-nt 
oligonucleotides bound to adjacent 9-bp sites on an 18-bp purine tract, the binding enhancement at $\mu \mathrm{M}$ concentration was observed to be a factor of 3.5. ${ }^{6}$ Likely the adjacent sites were not fully occupied, and this qualitative observation is a minimum value. Cooperativity in oligonucleotide-directed sequence-specific recognition of DNA by triple helix formation can be dramatically enhanced by the addition of discrete dimerization domains to oligonucleotides. ${ }^{7}$ However, the maximum enhancement possible for the simplest case, involving directly abutting sites occupied by triple helix forming oligonucleotides, has yet to be determined.

We report here the energetics of cooperative binding of pyrimidine oligodeoxyribonucleotides to adjacent sites on DNA by triple helix formation measured using quantitative affinity cleavage titrations. ${ }^{8}$ We find that pyrimidine oligonucleotides bind cooperatively to abutting purine sites on doublehelical DNA. The equilibrium association constant of an oligonucleotide bound to an 11-bp site is measured in the absence and presence of a second oligonucleotide occupying an adjacent, directly abutting site. The binding affinity of an $11 \mathrm{mer}$ in the presence of a neighboring bound pyrimidine oligonucleotide is enhanced by a factor of 20 at $24^{\circ} \mathrm{C}$ and $\mathrm{pH} 7.0(25 \mathrm{mM}$ TrisOAc, $10 \mathrm{mM} \mathrm{NaCl}, 1$ mM spermine).

\section{Results}

The binding of oligonucleotides 1 and 2 to adjacent sites A and B on doublehelical DNA (D) forms the binary complexes 1.D and 2.D, respectively, and the binding of either 1 to $2 \cdot \mathrm{D}$ or 2 to $1 \cdot \mathrm{D}$ forms the ternary complex 1.2.D (Figure 2.1): 


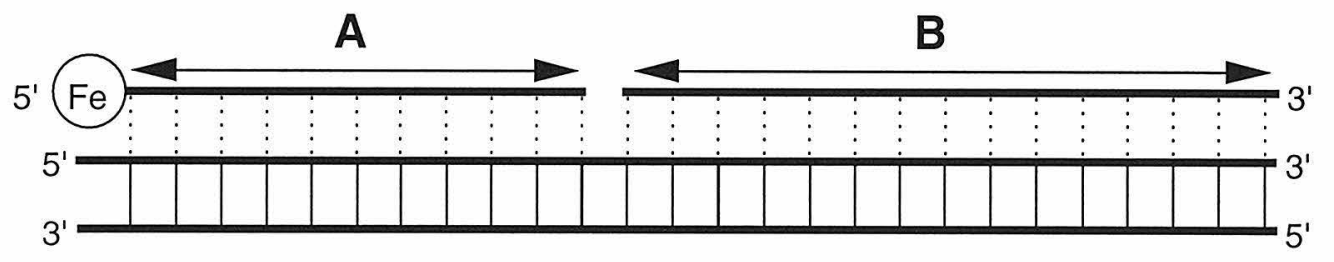

11-bp Site A 15-bp Site B

5'- A A A A A A G A A A A A A A A G A G A A G A GA - 3'

3'- T T T T T T C C T T T T T T T TCT C T C T C T C T. $5{ }^{\prime}$

$1 \quad 5^{1-*}$ TTTTTTC ${ }^{m} \mathrm{~m}$ TTT

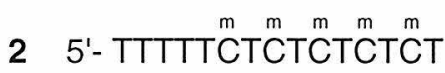

Figure 2.1 Schematic representation of a complex composed of two triple helix forming oligonucleotides binding at adjacent sites on double-helical DNA. Thick solid lines represent the DNA backbone of the target site and associated oligonucleotides. Thin solid lines represent Watson-Crick hydrogen bonds while dashed lines indicate Hoogsteen hydrogen bonds. Binding of the oligonucleotides is assessed by affinity cleavage using $\mathrm{T}^{*}$. 


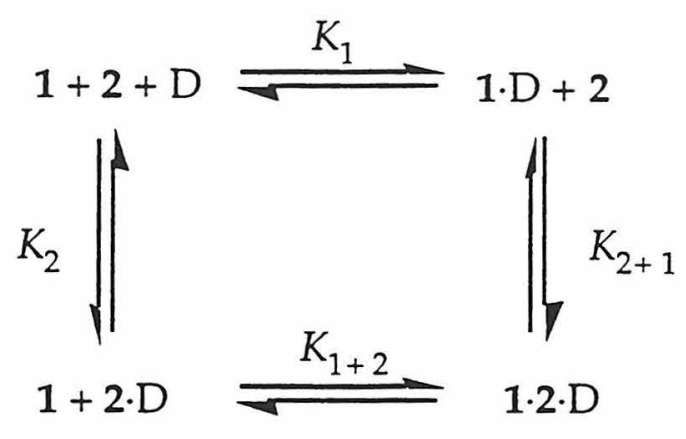

Experiments were designed to measure $K_{1}$, the binding of oligonucleotide 1 to site $\mathrm{A}$ alone, and $K_{1+2}$, the binding of the same oligonucleotide 1 to site $\mathrm{A}$ in the presence of oligonucleotide 2 bound to neighboring site $B$. This allowed us to determine the energetics of binding as a function of the occupancy of a neighboring site.

Affinity cleavage reactions. Oligodeoxyribonucleotide 1, equipped with thymidine-EDTA at the $5^{\prime}$-position, ${ }^{9}$ was allowed to equilibrate with an 850-bp 3'-32P-end-labeled duplex DNA fragment at $24^{\circ} \mathrm{C}$ and pH 7.0 $(25 \mathrm{mM}$ TrisOAc, $10 \mathrm{mM} \mathrm{NaCl}, 1 \mathrm{mM}$ spermine) for $24 \mathrm{~h}$ followed by addition of dithiothreitol (DTT) to initiate cleavage. After $6 \mathrm{~h}$ the reactions were stopped by ethanol precipitation, and the products were separated by denaturing polyacrylamide gel electrophoresis (Figure 2.2). The small amount of cleavage in a reaction containing 1 alone at $100 \mathrm{nM}$ concentration indicates that 1 binds to the $11-\mathrm{bp}$ target site weakly under these conditions (Figure 2.2, Lane 2). However, oligonucleotide 1 at the same concentration $(100 \mathrm{nM})$ in the presence of $1.0 \mu \mathrm{M}$ concentration of oligonucleotide 2 produces a dramatic increase in cleavage (Figure 2.2, Lane 3).

Cooperative Binding of $11 \mathrm{mer}+15 \mathrm{mer}$ at Directly Abutting Sites. To measure the magnitude of the cooperative enhancement, quantitative affinity 
Figure 2.2. Autoradiogram of an $8 \%$ denaturing polyacrylamide gel of reaction products from affinity cleavage reactions with oligonucleotides $\mathbf{1}$ and 2 and a 32P-labeled restriction fragment from pMD5152 containing the target site shown in Figure 2.1. The reactions were performed at $24^{\circ} \mathrm{C}$ in $10 \mathrm{mM} \mathrm{NaCl}, 1 \mathrm{mM}$ spermine, $25 \mathrm{mM}$ Tris-Acetate, $\mathrm{pH}$ 7.0. Oligonucleotide 1 and 2 are present at $100 \mathrm{nM}$ and $1 \mu \mathrm{M}$ concentrations, respectively. Lane 1, "A" specific sequencing reaction performed on $32 \mathrm{P}$-labeled restriction fragment; Lane 2, oligonucleotide 1; Lane 3, oligonucleotides 1 and 2; Lane 4, no oligonucleotide. 


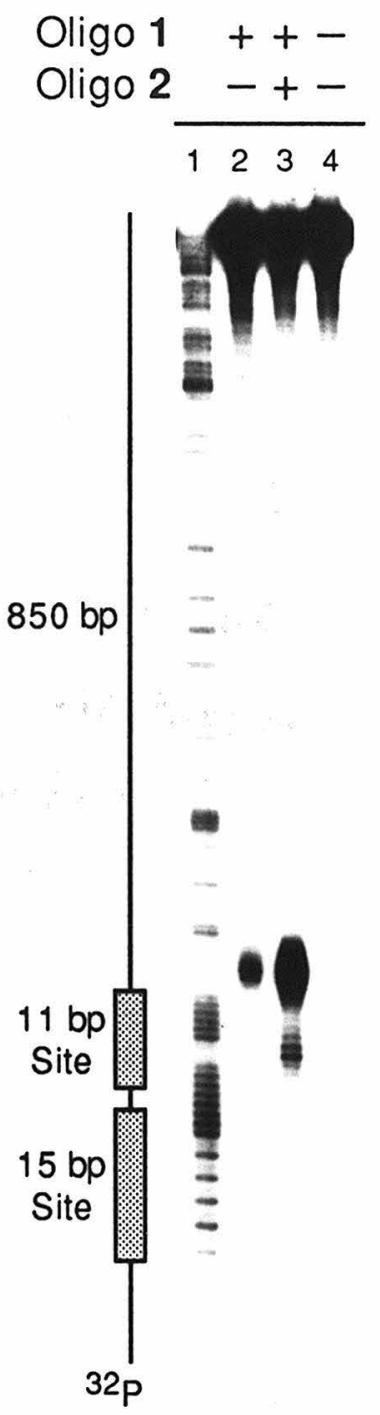


Figure 2.3. Autoradiogram of an $8 \%$ denaturing polyacrylamide gel of reaction products from affinity cleavage reactions with oligonucleotide 1 and a $32 \mathrm{P}$ labeled restriction fragment from pMD5152 containing the target site shown in Figure 2.1. The reactions were performed at $24^{\circ} \mathrm{C}$ in $10 \mathrm{mM} \mathrm{NaCl}, 1 \mathrm{mM}$ spermine, $25 \mathrm{mM}$ Tris-Acetate, pH 7.0. Lanes 1 and 17, "A" specific sequencing reaction performed on ${ }^{32} \mathrm{P}$-labeled restriction fragment; Lanes 2-15, DNA affinity cleavage reaction products produced by 1 at various concentrations: $1 \mathrm{nM}$ (Lane 2); $2 \mathrm{nM}$ (Lane 3); $5 \mathrm{nM}$ (Lane 4); $10 \mathrm{nM}$ (Lane 5); $20 \mathrm{nM}$ (Lane 6); $50 \mathrm{nM}$ (Lane 7); $100 \mathrm{nM}$ (Lane 8); $200 \mathrm{nM}$ (Lane 9); $500 \mathrm{nM}$ (Lane 10); $1 \mu \mathrm{M}$ (Lane 11); $2 \mu \mathrm{M}$ (Lane 12); $5 \mu \mathrm{M}$ (Lane 13); $10 \mu \mathrm{M}$ (Lane 14); $20 \mu \mathrm{M}$ (Lane 15); no oligonucleotide (Lane 16). 


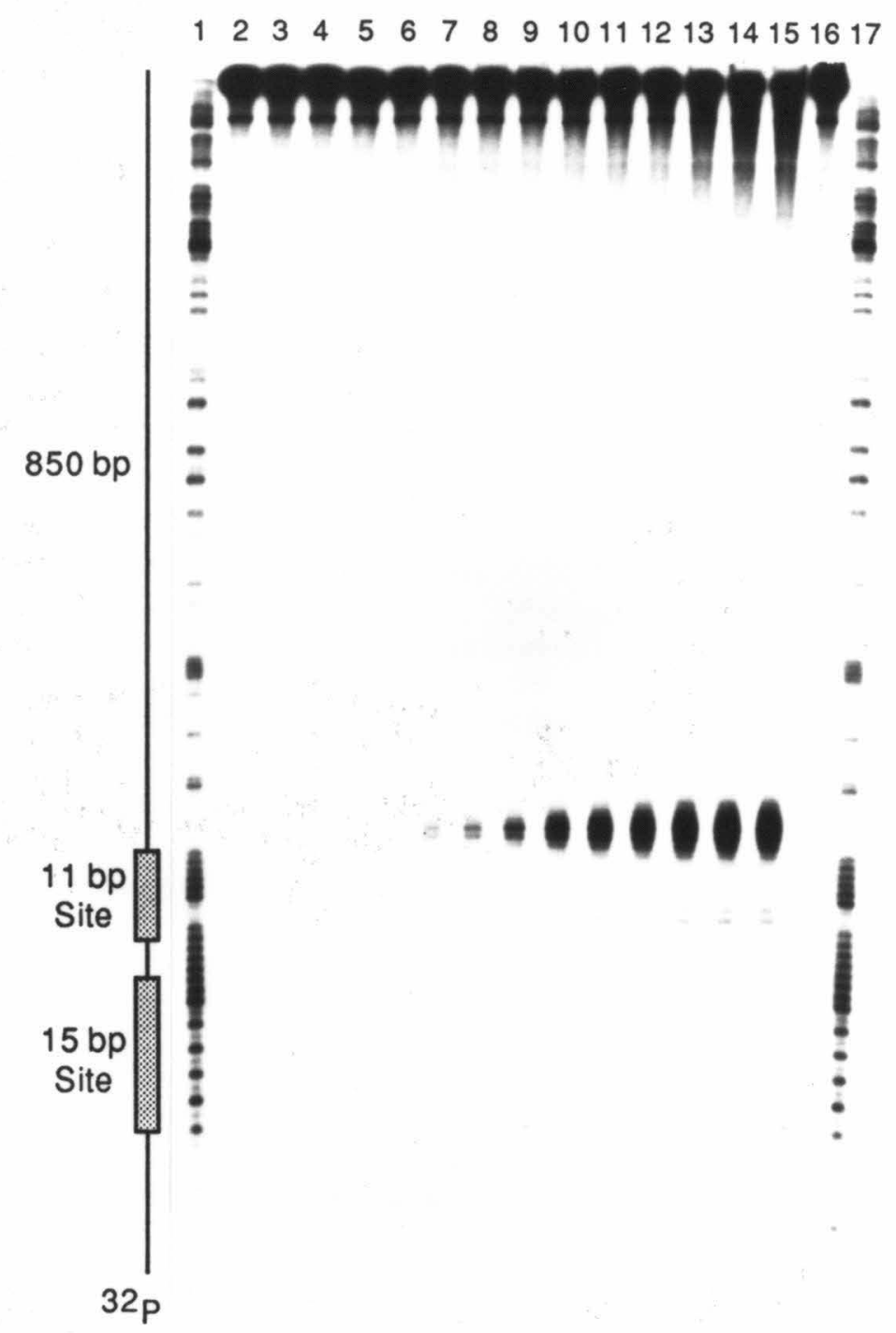


Table 2.1: Equilibrium Association Constants for Two Triple Helix Forming Oligonucleotides Binding at Adjacent Sites on $\mathrm{DNA}^{a}$

\begin{tabular}{|c|c|c|}
\hline Oligonucleotide & $K\left(\mathrm{M}^{-1}\right)$ & $\Delta \mathrm{G}\left(\mathrm{kcal} \cdot \mathrm{mol}^{-1}\right)$ \\
\hline 1 & $1.2( \pm 0.3) \times 10^{6}$ & $-8.2( \pm 0.2)$ \\
\hline $1+2(1 \mu \mathrm{M})$ & $2.3( \pm 0.5) \times 10^{7}$ & $-10.0( \pm 0.2)$ \\
\hline $1+4(1 \mu \mathrm{M})$ & $2.4( \pm 0.2) \times 10^{7}$ & $-10.0( \pm 0.1)$ \\
\hline \multicolumn{3}{|c|}{$\begin{array}{l}a \text { Values reported in the table are mean values measured from affinity cleavage } \\
\text { titration experiments performed in Association buffer }(10 \mathrm{mM} \mathrm{NaCl}, 1 \mathrm{mM} \\
\left.\text { spermine, } 25 \mathrm{mM} \text { Tris-acetate, } \mathrm{pH} 7.0,24^{\circ} \mathrm{C}\right) \text {. }\end{array}$} \\
\hline
\end{tabular}

cleavage titrations were performed over an extensive concentration range (Figure 2.3). The extent of cleavage for each reaction is determined by phosphorimaging analysis ${ }^{10}$ and an equilibrium association constant, $K$, is obtained by fitting a Langmuir binding isotherm to the experimental data (Figure 2.4). ${ }^{8}$ Quantitative affinity cleavage titrations were carried out with 1 alone and with 1 in the presence of oligonucleotide 2 at a concentration sufficient to saturate the nearby 15-bp site $\left(24^{\circ} \mathrm{C}, \mathrm{pH} 7.0\right)$. The equilibrium constant for 3 , an oligonucleotide with the same sequence as 2 but containing $\mathrm{T}^{*}$ targeted to the 15-bp site $\mathrm{B}$ was found to be $1.3( \pm 0.3) \times 10^{7} \mathrm{M}^{-1}$. As the substitution of $\mathrm{T}^{*}$ for $\mathrm{T}$ has a negligible influence on the binding affinity, ${ }^{8}$ we estimate that the 15-bp site should be $93 \%$ occupied by oligonucleotide 2 at $1 \mu \mathrm{M}$ concentration.

Analysis of cleavage data yielded equilibrium association constants of 1.2 ( \pm $0.3) \times 10^{6} \mathrm{M}^{-1}$ for 1 binding alone $\left(K_{1}\right)$ and $2.3( \pm 0.5) \times 10^{7} \mathrm{M}^{-1}$ for 1 in the presence of $1.0 \mu \mathrm{M} 2\left(K_{1+2}\right)$ (Table 2.1, Figure 2.4). The binding enhancement $K_{1+2} / K_{1}$ is a factor of 20 . The free energies of binding $(\Delta G)$ at the 11-bp site for oligonucleotide 1 in the absence and presence of oligonucleotide 2 are $-8.2( \pm 0.2)$ and $-10.0( \pm 0.2) \mathrm{kcal} \cdot \mathrm{mol}^{-1}$, respectively, and the minimum free energy of interaction, $\Delta \mathrm{G}_{1+2}-\Delta \mathrm{G}_{1}$, is $-1.8( \pm 0.3) \mathrm{kcal} \cdot \mathrm{mol}^{-1}$. 


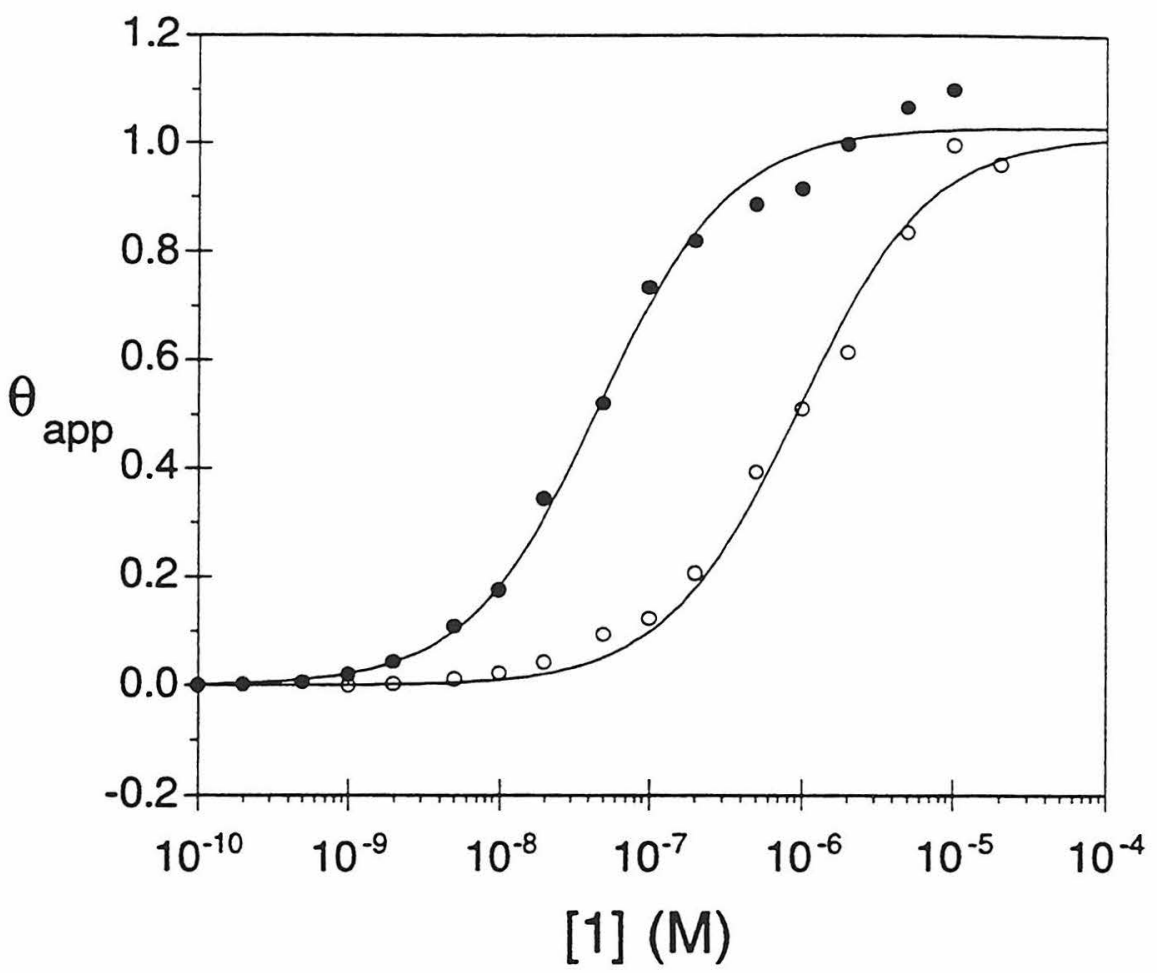

Figure 2.4. Binding isotherms obtained for oligonucleotide 1 alone (o), and in the presence of $1.0 \mu \mathrm{M}$ oligonucleotide $2(\bullet)$, using quantitative affinity cleavage titration. A theoretical binding curve represented by the Langmuir equation 7 (see Experimental Section) was used to fit the experimental data using $I_{\text {sat }}$ and $K$ as adjustable parameters. Five (in the case of oligonucleotide 1) to six (in the case of oligonucleotide 1 in the presence of oligonucleotide 2) complete data sets were used to determine each association constant. The data points were divided by Isat to obtain $\theta_{\mathrm{app}}$. Each data point represents the average of 5 to 6 individual experiments. 
The Effect of a One Base Pair Gap Between Adjacent Sites. Quantitative affinity cleavage titrations were used to obtain isotherms for 1 binding in the presence and absence of 2 when the binding sites A and B are separated by one base pair (Figures 2.5 and 2.6). The association constants for the binding of 1 in the absence and presence of oligonucleotide 2 are $K_{1}=2.9( \pm 0.2) \times 10^{6} \mathrm{M}^{-1}$ and $K_{1+2}=2.5( \pm 0.3) \times 10^{6} \mathrm{M}^{-1}$ (Table 2.2). When the binding sites for the two oligonucleotides are separated by one base pair there is no enhancement of the binding of 1 in the presence of 2 .

Table 2.2: Equilibrium Association Constants for Two Triple Helix Forming Oligonucleotides Binding on DNA where the Target Sites are Separated by One Base Pair ${ }^{a}$

\begin{tabular}{lcc}
\hline \multicolumn{1}{c}{ Oligonucleotide } & $K\left(\mathrm{M}^{-1}\right)$ & $\Delta \mathrm{G}\left(\mathrm{kcal} \bullet \mathrm{mol}^{-1}\right)$ \\
\hline $\mathbf{1}$ & $2.9( \pm 0.2) \times 10^{6}$ & $-8.8( \pm 0.1)$ \\
$\mathbf{1}+\mathbf{2}(1 \mu \mathrm{M})$ & $2.5( \pm 0.3) \times 10^{6}$ & $-8.7( \pm 0.1)$ \\
\hline a Values reported in the table are mean values measured from affinity cleavage \\
titration experiments performed in Association buffer $(10 \mathrm{mM} \mathrm{NaCl}, 1 \mathrm{mM}$ \\
spermine, 25 mM Tris-Acetate, $\left.\mathrm{pH} 7.0,24^{\circ} \mathrm{C}\right)$.
\end{tabular}

Cooperative Binding of $11 \mathrm{mer}+11 \mathrm{mer}$ at Directly Abutting Sites. The equilibrium binding constants for the binding of oligonucleotide 1 in the absence and presence of the $11 \mathrm{mer}$ oligonucleotide 4 at $1.0 \mu \mathrm{M}$ concentration to DNA are $K_{1}=1.2( \pm 0.3) \times 10^{6} \mathrm{M}^{-1}$ and $K_{1+4}=2.4( \pm 0.2) \times 10^{7} \mathrm{M}^{-1}$ (Figures 2.7 and 2.8). This is a 20 -fold increase in the binding of oligonucleotide 1 in the presence of the 11 mer oligonucleotide 4 (Table 2.1). The equilibrium binding constant of 5 , an oligonucleotide with the same sequence as 4 but containing $\mathrm{T}^{*}$ at the $3^{\prime}$-end, to the 11-bp site was shown to be $1.4( \pm 0.5) \times 10^{6} \mathrm{M}^{-1}$. Therefore, at $1 \mu \mathrm{M}$ concentration, the 11-bp site should be $58 \%$ occupied by oligonucleotide 4 in the absence of bound $1 .^{8}$ 


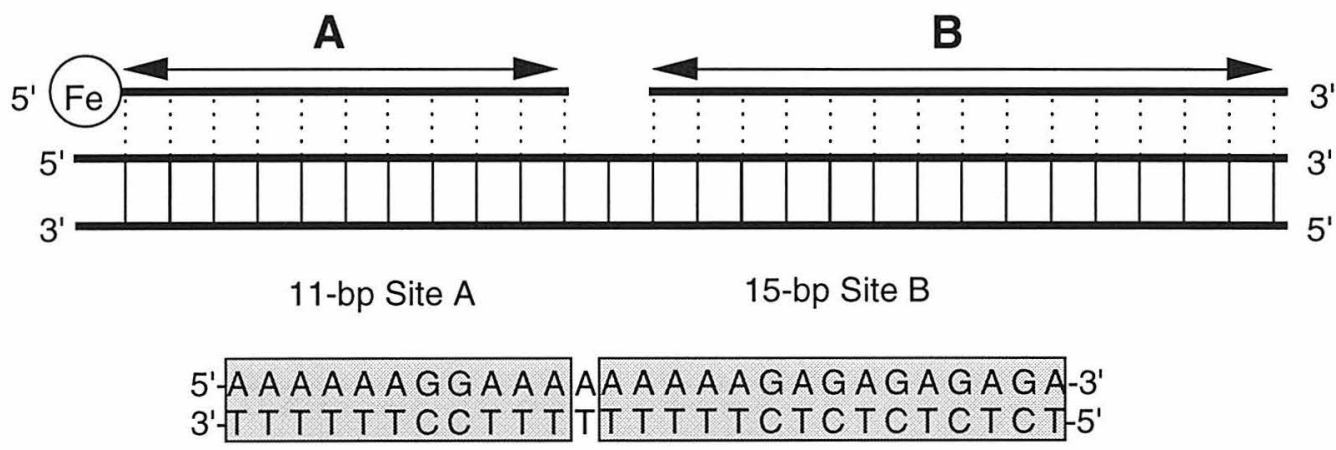

15 5-* TTTTTTC $\stackrel{m}{m}$ TTT

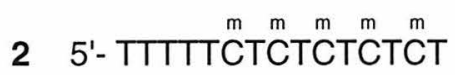

Figure 2.5. Schematic representation of a complex composed of two triple helix forming oligonucleotides binding on double-helical DNA where the two target sites are separated by one base pair. Thick solid lines represent the DNA backbone of the target site and associated oligonucleotides. Thin solid lines represent Watson-Crick hydrogen bonds while dashed lines indicate Hoogsteen hydrogen bonds. 


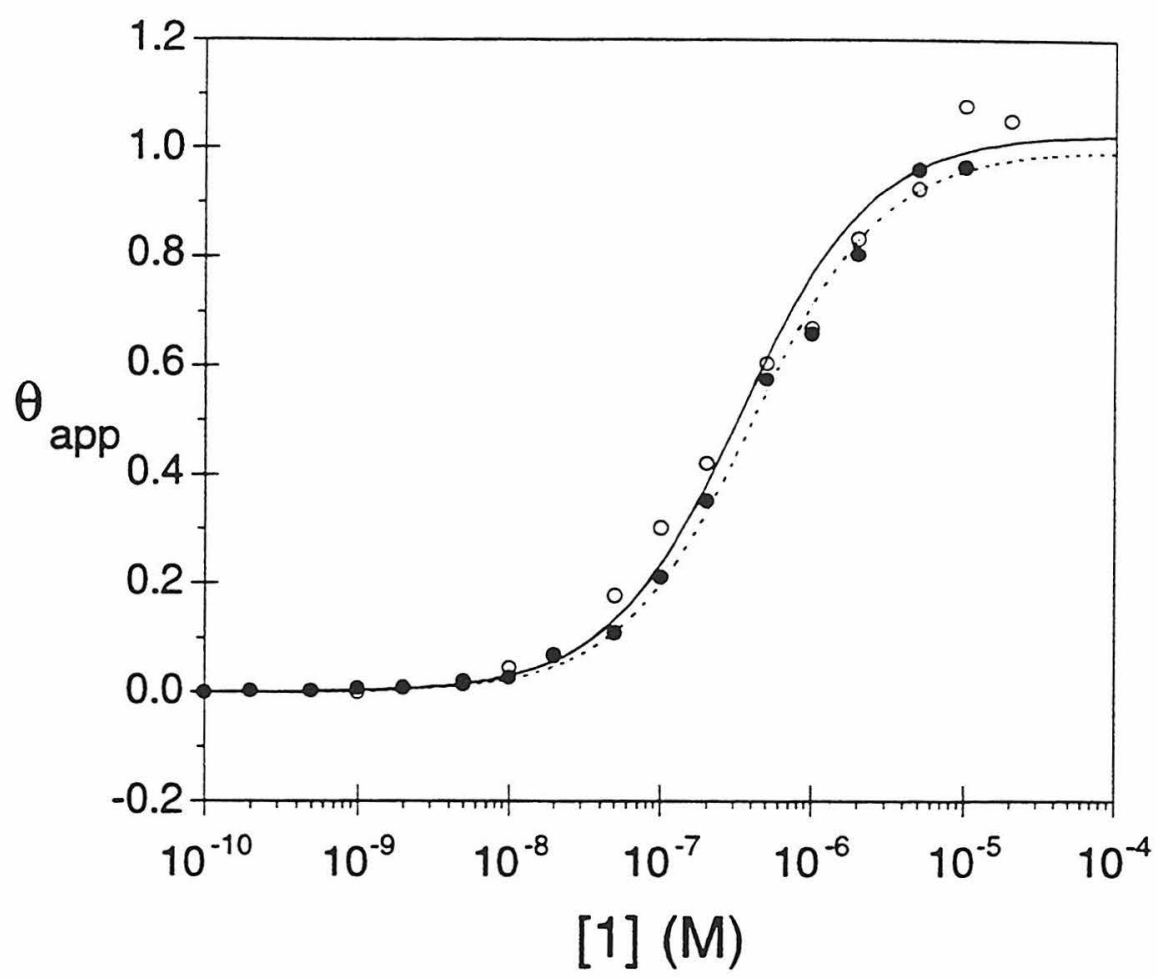

Figure 2.6. Binding isotherms obtained for oligonucleotide 1 alone (o), and in the presence of $1.0 \mu \mathrm{M}$ oligonucleotide $2(\bullet)$ bound to DNA where the two target sites are separated by one base pair. The solid sigmoidal curve represents the titration binding isotherm obtained for oligonucleotide 1 alone; the dashed sigmoidal curve represents the titration binding isotherm obtained for oligonucleotide 1 in the presence of oligonucleotide 2 . The data shown was obtained using the quantitative affinity cleavage titration method as described above (see Figure 2.4). 


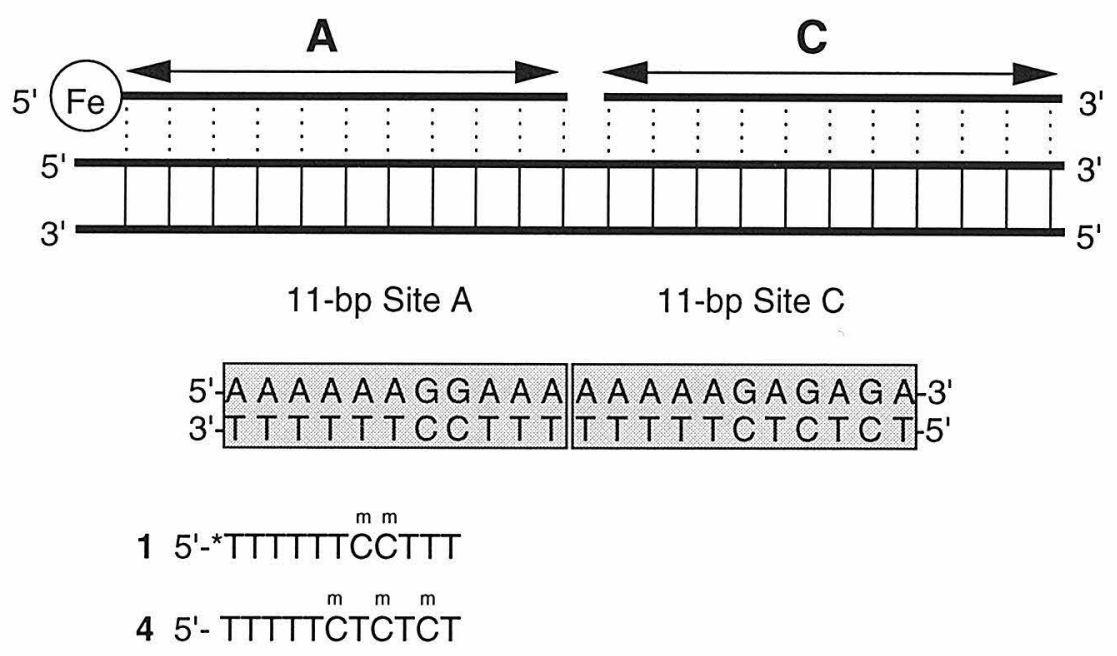

Figure 2.7. Schematic representation of a complex composed of two 11-nt triple helix forming oligonucleotides binding at adjacent sites on doublehelical DNA. Thick solid lines represent the DNA backbone of the target site and associated oligonucleotides. Thin solid lines represent WatsonCrick hydrogen bonds while dashed lines indicate Hoogsteen hydrogen bonds. 


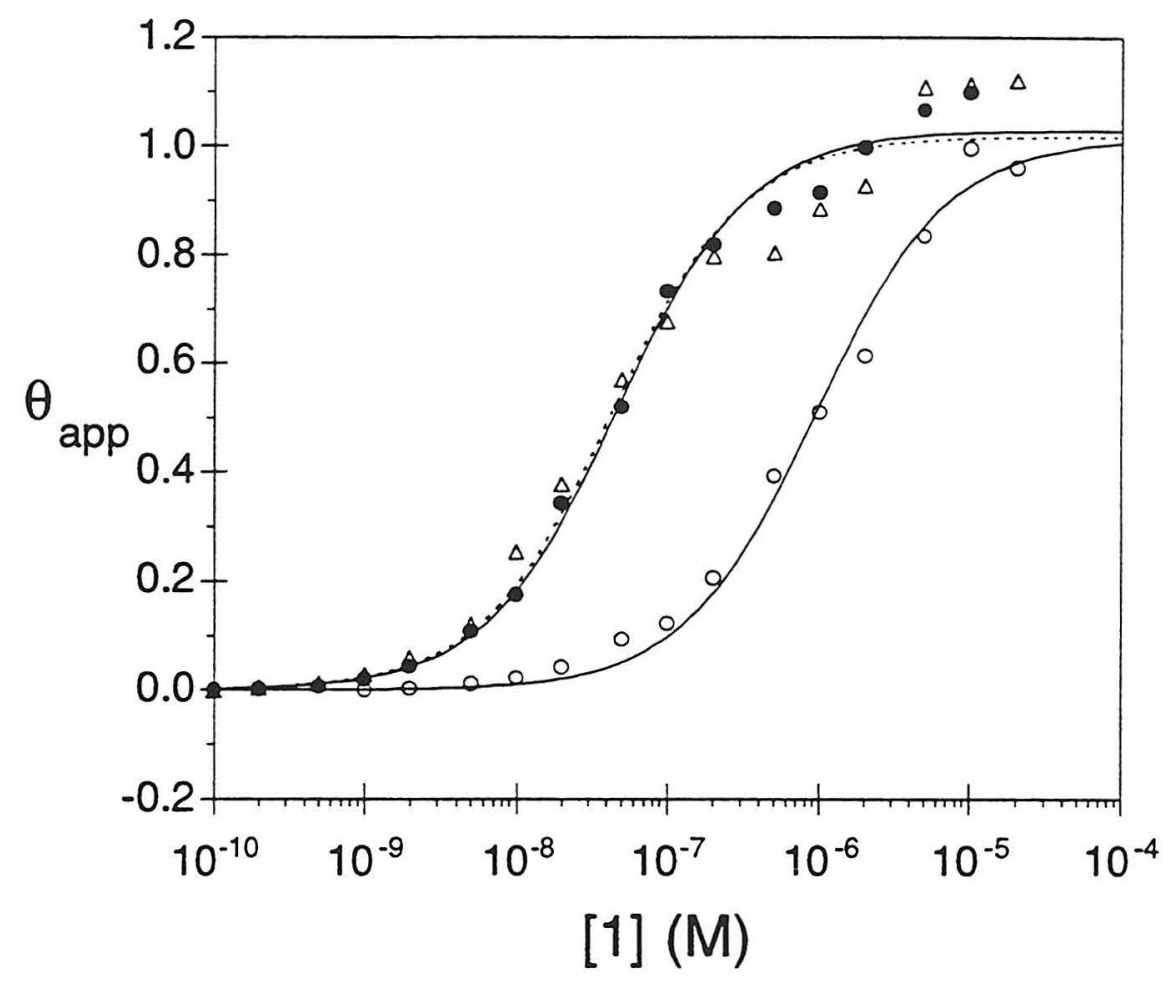

Figure 2.8. Binding isotherms obtained for oligonucleotide 1 alone (o), in the presence of $1.0 \mu \mathrm{M}$ oligonucleotide $2(\bullet)$, and in the presence of $1.0 \mu \mathrm{M}$ oligonucleotide $4(\Delta)$. The solid sigmoidal curves represent the titration binding isotherm obtained for oligonucleotide $\mathbf{1}$ alone, and oligonucleotide $\mathbf{1}$ in the presence of oligonucleotide 2; the dashed sigmoidal curve represents the titration binding isotherm obtained for oligonucleotide 1 in the presence of oligonucleotide 4 . 


\section{Discussion}

There is a 20 -fold difference in the association constants for the binding of 1 in the absence versus the presence of oligonucleotide 2 at $1.0 \mu \mathrm{M}$ concentration (Table 2.1). In the presence of $1 \mu \mathrm{M}$ concentration of 2 , the 15 -bp site is at least 93\% saturated with the adjacent 11-bp site being unoccupied. The observed 1.8 $\mathrm{kcal} \bullet \mathrm{mol}^{-1}$ energy difference represents the minimum free energy of interaction between 1 and 2. To determine the full magnitude of cooperativity between 1 and 2, a model which takes into account the extent of occupation of the adjacent 15-bp site allows calculation of the total cooperative interaction energy.

Heterodimeric Cooperative Systems. Hill has derived a grand partition function $(\xi)$ for a heterodimeric cooperative system in which two different ligands, $\mathrm{L}_{\mathrm{A}}$ and $\mathrm{L}_{\mathrm{B}}$, bind uniquely to two distinct sites and each ligand perturbs the binding equilibrium at the noncognate site: ${ }^{2 b}$

$\xi=1+K_{A}\left[L_{A}\right]+K_{B}\left[L_{B}\right]+y K_{A}\left[L_{A}\right] K_{B}\left[L_{B}\right]$

where $K_{\mathrm{A}}$ and $K_{\mathrm{B}}$ are equilibrium association constants for $\mathrm{L}_{\mathrm{A}}$ and $\mathrm{L}_{\mathrm{B}}$ binding in the absence of each other, and $y$ is related to the interaction energy, $E_{c o o p}$, between $L_{A}$ and $L_{B}$ by:

$y=\exp \left(-E_{\text {coop }} / R T\right)$

The fractional occupancy of site $\mathrm{A}$ by $\mathrm{L}_{\mathrm{A}}$ is given by:

$$
\theta_{\mathrm{A}}=\left[\mathrm{L}_{\mathrm{A}}\right] \frac{\partial \ln \xi}{\partial\left[\mathrm{LA}_{\mathrm{A}}\right]}=\frac{\Phi K_{\mathrm{A}}\left[\mathrm{L}_{\mathrm{A}}\right]}{1+\Phi K_{\mathrm{A}}\left[\mathrm{LA}_{\mathrm{A}}\right]}
$$

where 
$\Phi=\frac{1+y K_{B}\left[L_{B}\right]}{1+K_{B}\left[L_{B}\right]}$

Equations 2 and 4 can be combined and rearranged to give the following expression for the interaction energy:

$$
E_{\text {coop }}=-R T \ln \frac{\Phi\left(1+K_{B}\left[L_{B}\right]\right)-1}{K_{B}\left[L_{B}\right]}
$$

\section{Energetics of Cooperatively Binding Oligonucleotides: $11 \mathrm{mer}+15 \mathrm{mer}$.}

This simple model requires that two conditions be satisfied: the ligands do not interact in solution, and, under experimental conditions chosen, $\mathrm{L}_{\mathrm{A}}$ does not bind to site $B$ and $L_{B}$ does not bind to site $A$. The sequences of the 11- and 15-bp sites were chosen to maximize the binding specificities of oligonucleotides 1 and 2 for their designated sites. For oligonucleotide 1 at $\leq 20 \mu \mathrm{M}$ concentrations, there was no detectable cleavage in the 15-bp target site region, evidence that 1 has low affinity for the 15 -bp site. For oligonucleotide 2 , at $\leq 1.0 \mu \mathrm{M}$, there was no detectable binding in the 11 -bp target site region. Since 1 and 2 do not dimerize significantly in solution and since neither oligonucleotide shows any detectable affinity for its noncognate site under the conditions chosen, ${ }^{11,12}$ the model described above can be reliably used to determine $\mathrm{E}_{\text {coop. }}$. For the cooperatively binding oligonucleotides described here $\mathrm{L}_{\mathrm{A}}$ is oligonucleotide 1 , site $\mathrm{A}$ is the 11bp site and $K_{A}$ is $K_{1}$. Similarly, $L_{B}$ is oligonucleotide 2 , site $B$ is the 15 -bp site and $K_{\mathrm{B}}$ is $K_{2}$. Comparison of the Langmuir expression (see below Experimental Section, equation 7) and equation 3 shows that $K_{1+2}$ in the former equals $\Phi K_{1}$ in the latter. Thus, $\Phi_{1.0}=K_{1+2} / K_{1}=20$ where $\Phi_{1.0}$ is the value of $\Phi$ when [2] = 1.0 $\mu \mathrm{M}$. Substitution of the values $20( \pm 6), 1.3( \pm 0.3) \times 10^{7} \mathrm{M}^{-1}$, and $1.0( \pm 0.1) \times 10^{-6}$ 
$\mathrm{M}$ for $\Phi, K_{2}$, and [2], respectively, in equation 5 affords a value of $-1.8( \pm 0.2)$ $\mathrm{kcal} \bullet \mathrm{mol}^{-1}$ for $\mathrm{E}_{\mathrm{coop}}$ between the $11 \mathrm{mer} 1$ and the $15 \mathrm{mer} 2$. The correspondence of this value with $\Delta \mathrm{G}_{1+2}-\Delta \mathrm{G}_{1}=-1.8 \mathrm{kcal} \bullet \mathrm{mol}^{-1}$ can be explained by the fact that the 15-bp site is likely fully saturated (>93\% occupied) by oligonucleotide 2 in the presence of 1 .

Energetics of Cooperatively Binding Oligonucleotides: $11 \mathrm{mer}+11 \mathrm{mer}$. Under the conditions used for quantitative affinity cleavage titrations, and in the absence of any cooperative energetic benefit, oligonucleotide 4 at $1 \mu \mathrm{M}$ concentration occupies the 11-bp site $58 \%$. For the cooperatively binding oligonucleotides described here $\mathrm{L}_{\mathrm{A}}$ is oligonucleotide 1 , site $\mathrm{A}$ is the 11-bp site and $K_{\mathrm{A}}$ is $K_{1}$. Similarly, $\mathrm{L}_{\mathrm{B}}$ is oligonucleotide 4 , site $\mathrm{B}$ is the designated 11-bp site and $K_{\mathrm{B}}$ is $K_{5}$. Substitution of the values $20( \pm 5), 1.4( \pm 0.5) \times 10^{6} \mathrm{M}^{-1}$, and $1.0( \pm 0.1) \times 10^{-6} \mathrm{M}$ for $\Phi, K_{5}$, and [4], respectively, in equation 5 affords a value of $-2.1( \pm 0.2)$ $\mathrm{kcal} \bullet \mathrm{mol}^{-1}$ for $E_{\text {coop }}$ between the $11 \mathrm{mers} 1$ and 4 . This value is the same within experimental uncertainty as that obtained when 11mer 1 and 15 mer 2 fully saturate the adjacent sites on DNA. This suggests that the binding site of oligonucleotide 4 is more than $58 \%$ occupied at $1 \mu \mathrm{M}$ concentration and likely saturated due to the binding of oligonucleotide 1 to its designated site A. From quantitative affinity cleavage titrations, we found that the binding of $11 \mathrm{mer} 1$ to its site is increased 20-fold in the presence of directly abutting oligonucleotide 4 . In the presence of $1 \mu \mathrm{M} 1$, the occupancy level of oligonucleotide 4 at site $B$ is calculated to be $97 \%$.

Origin of Cooperative Binding Forces. Two oligonucleotides bind cooperatively to duplex DNA with an interaction energy of $1.8-2.1 \mathrm{kcal} \bullet \mathrm{mol}^{-1}$. Potential sources for this cooperative interaction energy include propagation of a conformational transition between adjacent sites and base stacking of the terminal thymines. Early fiber diffraction studies, ${ }^{13 a}$ and chemical footprinting 
experiments ${ }^{13 b, 13 c}$ are consistent with a $\mathrm{B}$ - to $\mathrm{A}^{\prime}$-form conformational change upon formation of a triple-helical complex. However, IR, CD and NMR studies suggest that DNA triplexes contain structural features of both A- and B- conformations. ${ }^{14}$ One would anticipate that triplex formation at site $\mathrm{A}$ would be facilitated by a structural transition at site B. Because the cooperative enhancement was not observed when triple helix binding sites were separated by one base pair, our data suggests that either there are no significant propagated structural changes beyond the immediately neighboring base pair, or that a one base pair gap creates a junction that prevents the propagation.

The free energy of base stacking, which arises from induced dipole interactions, ${ }^{15}$ and hydrophobic forces ${ }^{16}$ has been shown to range from -0.5 $\mathrm{kcal} \bullet \mathrm{mol}^{-1}$ to $-3 \mathrm{kcal} \cdot \mathrm{mol}^{-1}$ for monomer nucleosides associating in aqueous solution, depending on solution, salt conditions, nucleoside identity, concentration, and temperature. ${ }^{15}$ To date, no value for the free energy change associated with stacking interactions between contiguous bases of a triple helix forming oligonucleotide has been reported. The structure at the interface of oligonucleotides 1 and 2 bound on neighboring sites is likely similar to that of the corresponding contiguous triplex. The $1.8-2.1 \mathrm{kcal} \bullet \mathrm{mol}^{-1}$ interaction energy between oligonucleotides 1 and 2 when binding to adjacent sites on DNA at $24{ }^{\circ} \mathrm{C}$ and pH 7.0 (25 mM TrisOAc, $10 \mathrm{mM} \mathrm{NaCl}, 1 \mathrm{mM}$ spermine) may reflect a significant contribution from a T-T stack in the third strand of triple helices. ${ }^{17}$ Under these conditions, if this is true, we would anticipate that the $1.8-2.1 \mathrm{kcal} \bullet \mathrm{mol}^{-1}$ cooperative effect is sequence dependent. The energetics of a CT, TC and CC stack at the junction will be necessary to answer this question (see Chapter Three).

Implications. Pyrimidine oligodeoxyribonucleotides can bind cooperatively to abutting sites on double-helical DNA with an interaction energy of 1.8-2.1 
$\mathrm{kcal} \bullet \mathrm{mol}^{-1}$ for TAT triplets at the triple helix junction (Figure 2.9). Thus, for oligonucleotide-directed sequence specific recognition of DNA, cooperative interactions may allow for significant reduction in the length of oligonucleotides with little decrease in the binding affinity or specificity. 


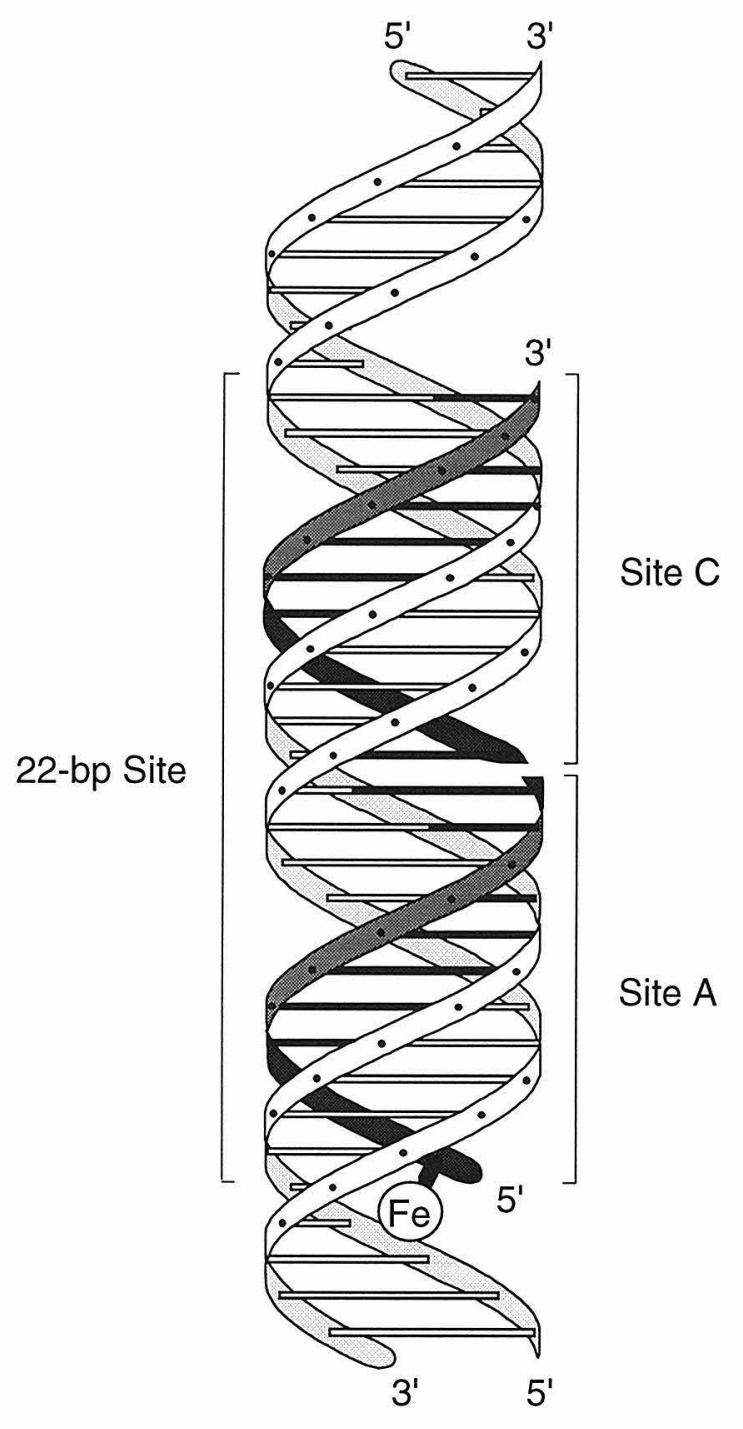

Figure 2.9. Ribbon model of oligonucleotides 1 and 4 bound at adjacent sites on duplex DNA by triple helix formation. The Watson-Crick duplex strands are shown as white ribbons, and the triple helix forming oiligonucleotides are shown as dark ribbons. 


\section{Addendum to Chapter Two:}

\section{Influence of Terminal Phosphates at the \\ Triplex Junction on Cooperativity}

In addition to induced conformational changes and base stacking, we cannot rule out that hydrogen bonding between hydroxyl groups on the terminal sugars may be responsible for the observed cooperativity, although the energetic contribution of such bonds in the aqueous environment are likely small. In an effort to determine the effect of hydrogen bonding between the hydroxyl groups of the terminal sugars on cooperativity, quantitative affinity cleavage titrations were carried out with oligonucleotide 1 binding to site $\mathrm{A}$ in the absence and presence of the $5^{\prime}$-phosphate derivative of 2 (oligonucleotide 6 ) at $1 \mu \mathrm{M}$, and with the $3^{\prime}$-phosphate derivative of 1 (oligonucleotide 7 ) binding to site $A$ in the absence and presence of $1 \mu \mathrm{M} 2$ (Figure 2.10). The binding constants of oligonucleotide 1 binding to site $\mathrm{A}$ in the absence and presence of $1 \mu \mathrm{M} 6$ are $K_{1}=$ $1.2( \pm 0.3) \times 10^{6} \mathrm{M}^{-1}$ and $K_{1+6}=1.1( \pm 0.3) \times 10^{7} \mathrm{M}^{-1}$, respectively, and the binding enhancement is $K_{1+6} / K_{1}=9.6$ (Table 2.3). The binding constants of oligonucleotide 7 binding to site $A$ in the absence and presence of $1 \mu \mathrm{M} 2$ are $K_{7}=5.1( \pm 0.7)$ $\times 10^{6} \mathrm{M}^{-1}$ and $K_{7+2}=3.1( \pm 0.7) \times 10^{7} \mathrm{M}^{-1}$, respectively, and the binding enhancement is $K_{7+2} / K_{7}=6.1$ (Table 2.3). These results suggest that replacing the $5^{\prime}-\mathrm{OH}$ of oligonucleotide 2 or the $3^{\prime}-\mathrm{OH}$ of 1 with a phosphate group decreases the binding enhancements arising from cooperativity. Nonetheless, it is important to note that replacement of the terminal hydroxyl with phosphate groups still allows for hydrogen bonding between the sugars located at the triplex junction. Further studies should be carried out to determine conclusively 


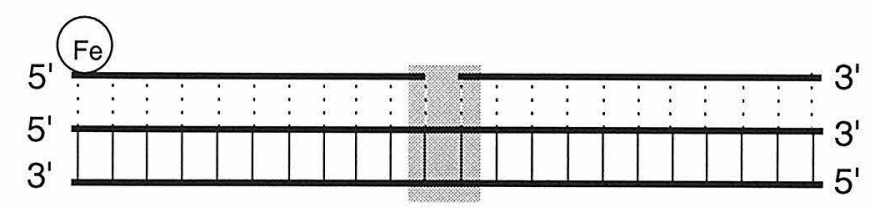

\section{A}

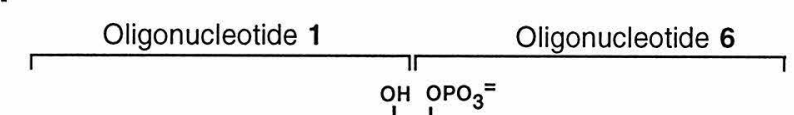

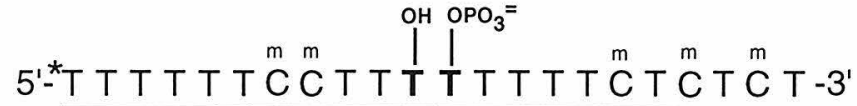

5'- A A A A A A G G A A A A A A A G A G A G A - 3 '

3'- T T T T T T C C T T T T T T T T C T C T C T $-5^{\prime}$

Site $\mathbf{A}$

Site C

\section{B}

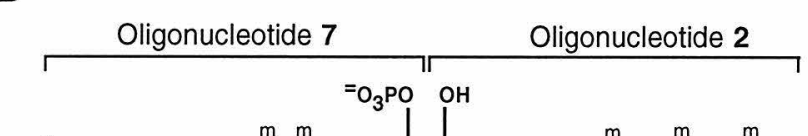

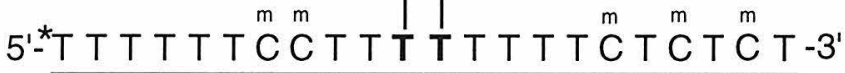

$5^{\prime}$ - A A A A A G G A A A A A A A G A G A GA $-3^{\prime}$

$3^{\prime}$ - T T T T T T C C T T T T T T T T C T C T C T $-5^{\prime}$

Site $\mathbf{A}$

Site C

Figure 2.10. Schematic representation of a complex composed of two triple helix forming oligonucleotides binding at adjacent sites on DNA in the presence of a phosphate group at the 3 -side (A) or 5'-side (B) of the triplex junction. ${ }^{\mathrm{m}} \mathrm{C}$ designates 5-methyl-2'-deoxycytidine. 
Table 2.3: Equilibrium Association Constants for Two Triple Helix Forming Oligonucleotides Binding to DNA in the Presence of Phosphate Groups at the Triplex Junction ${ }^{a}$

\begin{tabular}{llc}
\hline \multicolumn{1}{c}{ Oligonucleotide } & $K\left(\mathrm{M}^{-1}\right)$ & $K_{11+11} / K_{11}$ \\
\hline $\mathbf{1}$ & $1.2( \pm 0.3) \times 10^{6}$ & \\
$1+6(1 \mu \mathrm{M})$ & $1.1( \pm 0.3) \times 10^{7}$ & 9.2 \\
\hline 7 & $5.1( \pm 0.7) \times 10^{6}$ & 6.1 \\
$7+2(1 \mu \mathrm{M})$ & $3.1( \pm 0.7) \times 10^{7}$ & \\
\hline a Values reported in the table are mean values measured from affinity cleavage \\
titration experiments performed in Association buffer $(10 \mathrm{mM} \mathrm{NaCl}, 1 \mathrm{mM}$ \\
spermine, $25 \mathrm{mM}$ Tris-Acetate, $\left.\mathrm{pH} 7.0,24^{\circ} \mathrm{C}\right)$.
\end{tabular}

the effects on cooperativity of hydrogen bonding between the terminal sugars of oligonucleotides bound at adjacent sites on DNA. 


\section{Experimental Section}

General. E. coli JM110 was obtained from Stratagene. Qiagen plasmid kits were purchased from Qiagen Inc. Sonicated, deproteinized calf thymus DNA was purchased from Pharmacia. Nucleotide triphosphates were obtained from Pharmacia. Nucleotide triphosphates labeled with ${ }^{32} \mathrm{P}(\geq 3000 \mathrm{Ci} / \mathrm{mmol})$ were purchased from Amersham. Restriction endonucleases were purchased from New England Biolabs, and used according to the suggested protocol in the provided buffer. Thymidine and 5-methyl-2'-deoxycytidine phosphoramidites were obtained from $A B I$ and Cruachem, respectively. Sephadex resins were obtained from Pharmacia. Sequenase Version 2.0 was obtained from United States Biochemical.

Construction of pMD5152 and pMD5354. These plasmids were prepared by standard methods. ${ }^{18}$ Briefly, pMD5152 was prepared by hybridization of two synthetic oligonucleotides, $5^{\prime}$-d(ACGTTCCTAAAAAAGGAAAAAAAAGAGAGAGAGATCTG)-3' and 5'-d(GATCCAGATCTCTCTCTCTTTTTTTTCCTTTTTTAGGA)-3', followed by ligation of the resulting duplex with pUC18 DNA previously digested with HindIII and BamHI; this ligation mixture was used to transform E. coli JM110 (Stratagene). Plasmid DNA from ampicillin resistant, white colonies was isolated and the presence of the desired insert confirmed by restriction analysis and Sanger sequencing. Preparative isolation of plasmid DNA was performed using a Qiagen plasmid kit. Plasmid pMD5354 was prepared using a similar procedure with the oligonucleotides $5^{\prime}$-d(AGCTTCCTAAAAAAGGAAAAAAAAAGAGAGAGAGATCTG)-3' and 5'-d(GATCCAGATCTCTCTCTCTTTTTTTTTCCTTTTTTAGGA)-3'.

Oligonucleotide Preparation. Oligonucleotides were synthesized by standard automated solid-support chemistry on an Applied Biosystems Model 380B DNA synthesizer using $\mathrm{O}$-cyanoethyl- $\mathrm{N}, \mathrm{N}$-diisopropyl phosphoramidites. ${ }^{19}$ 
The phosphoramidite of thymidine-EDTA $\left(\mathrm{T}^{*}\right)$ was prepared according to published procedures. ${ }^{9}$ Controlled pore glass derivatized with $\mathrm{T}^{*}$ was prepared as described by Strobel. ${ }^{20}$ Oligonucleotides 6 (the 5 -phosphate derivative of oligonucleotide 2) and 7 (the 3'-phosphate derivative of oligonucleotide 1) were synthesized by incorporation of the chemical 5'-and 3'-phosphorylation reagent 2-[2-(dimethoxytrityloxy)ethyl-(2-cyanoethyl)-( $N, N$-diisopropyl)-phosphoramidite purchased from Glen Research. Oligonucleotides 1, 3, 5, and 7 containing $\mathrm{T}^{*}$ were deprotected with $0.1 \mathrm{~N} \mathrm{NaOH}$ at $55^{\circ} \mathrm{C}$ for $24 \mathrm{~h}$, neutralized with glacial acetic acid, desalted on Pharmacia Sephadex (G-10-120) spin columns, and dried in vacuo. Oligonucleotides 2,4 , and 6 were deprotected with concentrated ammonium hydroxide at $55^{\circ} \mathrm{C}$ for $24 \mathrm{~h}$, and dried in vacuo. The crude 5 terminal-dimethoxytrityl protected oligonucleotides were purified by reverse phase FPLC on a ProRPC 10/10 $\left(\mathrm{C}_{2}-\mathrm{C}_{8}\right)$ column (Pharmacia LKB) and a gradient of $0-40 \% \mathrm{CH}_{3} \mathrm{CN}$ in $0.1 \mathrm{M}$ triethylammonium acetate, $\mathrm{pH} 7.0$, detritylated in $80 \%$ $\mathrm{AcOH}$, and chromatographed a second time. Triethylammonium acetate was removed via repeated resuspensions of the oligonucleotides in water followed by lyophilization. Oligonucleotide concentrations were determined by UV absorbance at $260 \mathrm{~nm}$ using extinction coefficients $\left(\mathrm{M}^{-1} \mathrm{~cm}^{-1}\right)$ of $8800\left(\mathrm{~T}\right.$ and $\left.\mathrm{T}^{*}\right)$ and $5700\left(\mathrm{~m}_{\mathrm{C}}\right)$.

Preparation of Labeled Restriction Fragment. The 3'-32P-labeled duplex was prepared by digestion of the plasmid pMD5152 (or pMD5354) with EcoRI, followed by treatment with $\alpha-32$ P-dATP and $\alpha-32$ P-TTP in the presence of Sequenase. To remove nonincorporated radioactivity, the fragment was passed through a Pharmacia NICK column. The DNA was then digested with XmnI, followed by separation of the resulting products on a $5 \%$ nondenaturing polyacrylamide gel (19:1, monomer/bis). The gel band corresponding to the desired 850-bp fragment (851-bp for pMD5354) was visualized by auto- 
radiography, excised, crushed, and soaked in $10 \mathrm{mM}$ Tris, pH 8.0, and $20 \mathrm{mM}$ EDTA, at $37^{\circ} \mathrm{C}$ for $12 \mathrm{~h}$. The resulting suspension was filtered through a $0.45-\mu \mathrm{m}$ filter, and the eluted DNA present in the supernatant was precipitated with $\mathrm{NaOAc} / \mathrm{EtOH}$. The DNA pellet was washed with $70 \% \mathrm{EtOH}$, dried in vacuo, resuspended in TE buffer (10 mM Tris, pH 8.0, 1 mM EDTA), extracted five times with phenol, twice with $24: 1 \mathrm{CHCl}_{3}$ /isoamyl alcohol, and reprecipitated with $\mathrm{NaOAc} / \mathrm{EtOH}$. The DNA pellet was washed with $70 \% \mathrm{EtOH}$, dried in vacuo, and resuspended in $25 \mathrm{mM}$ Tris-acetate, $100 \mathrm{mM} \mathrm{NaCl}, \mathrm{pH} 7.0$ at a final activity of $100,000 \mathrm{cpm} / \mu \mathrm{L}$, and was stored at $-20^{\circ} \mathrm{C}$.

Quantitative Affinity Cleavage Titrations. In a typical experiment, a $5 \mathrm{nmol}$ aliquot of the desired oligonucleotide-EDTA was dissolved in $50 \mu \mathrm{L}$ of aqueous $200 \mu \mathrm{M} \mathrm{Fe}\left(\mathrm{NH}_{4}\right)_{2}\left(\mathrm{SO}_{4}\right)_{2} \bullet 6 \mathrm{H}_{2} \mathrm{O}$ to produce a solution that was $100 \mu \mathrm{M}$ in oligonucleotide. This solution was then diluted serially to yield $100 \mu \mathrm{M}, 10 \mu \mathrm{M}, 1 \mu \mathrm{M}$, $100 \mathrm{nM}, 10 \mathrm{nM}$, and $1 \mathrm{nM}$ solutions. The appropriate volume of these solutions was then distributed among 15-17 $1.5 \mathrm{~mL}$ microcentrifuge tubes at the appropriate concentrations. A stock solution containing labeled target DNA, TrisAcetate buffer, $\mathrm{NaCl}$, calf thymus DNA, the second oligonucleotide where needed, and water, was distributed to each reaction tube in $12 \mu \mathrm{L}$ aliquots, and the appropriate volume of water and $4 \mu \mathrm{L}$ of $10 \mathrm{mM}$ spermine were added to each tube to bring the total volume to $36 \mu \mathrm{L}$. The oligonucleotide-EDTA $\bullet \mathrm{Fe}$ (II) and the DNA were allowed to equilibrate for $24 \mathrm{~h}$ at $24^{\circ} \mathrm{C}$. The cleavage reactions were initiated by the addition of $4 \mu \mathrm{L}$ of a $40 \mathrm{mM}$ aqueous DTT solution to each tube. Final reaction conditions in $40 \mu \mathrm{L}$ of Association buffer were 25 $\mathrm{mM}$ TrisOAc at $\mathrm{pH} 7.0,10 \mathrm{mM} \mathrm{NaCl}, 1 \mathrm{mM}$ spermine, $100 \mu \mathrm{M}$ bp calf thymus DNA, $4 \mathrm{mM}$ DTT, and approximately 10,000 cpm labeled DNA. The reactions were incubated for $6 \mathrm{~h}$ at $24{ }^{\circ} \mathrm{C}$. Cleavage reactions were terminated by $\mathrm{NaOAc} / \mathrm{EtOH}$ precipitation and the reaction tubes were then stored at $-20^{\circ} \mathrm{C}$ for 
30 minutes before centrifugation. The DNA cleavage products were washed with $70 \%$ aqueous $\mathrm{EtOH}$, dissolved in $50 \mu \mathrm{L}$ of water, and dried in vacuo. The DNA was then resuspended in $10 \mu \mathrm{L}$ of formamide-TBE loading buffer, heated at $55^{\circ} \mathrm{C}$ for 10 minutes to effect dissolution, and transferred to a new tube. The Cerenkov radioactivity of the solutions was measured with a scintillation counter, followed by dilution to the same $\mathrm{cpm} / \mu \mathrm{L}$ with more formamide-TBE buffer. The DNA was denatured at $95^{\circ} \mathrm{C}$ for 3 minutes, and $5 \mu \mathrm{L}$ from each sample were loaded onto a $8 \%$ denaturing polyacrylamide gel.

Construction of Titration Binding Isotherms. Gels were exposed to photostimulable storage phosphor imaging plates (Kodak Storage Phosphor Screen S0230 obtained from Molecular Dynamics) in the dark at $24{ }^{\circ} \mathrm{C}$ for $5-12$ h. ${ }^{12}$ A Molecular Dynamics 400S PhosphorImager was used to obtain data from the phosphorimaging screens. Rectangles of the same dimensions were drawn around the cleavage bands at the target and at the references sites. The ImageQuant v. 3.0 program running on an AST Premium 386/33 computer was used to integrate the volume of each rectangle.

Affinity Cleavage Titration Fitting Procedure. A detailed description of the affinity cleavage titration procedure has been published. ${ }^{8}$ The relative cleavage efficiencies at the target site for each oligonucleotide concentration were determined by using the following equation:

$I_{\text {site }}=I_{\text {tot }}-\lambda I_{\text {ref }}$

where $I_{\text {tot }}$ and $I_{\text {ref }}$ are the intensities of the cleavage bands at the target site and at the reference site, respectively, and $\lambda$ is a scaling parameter defined as the ratio Itot/Iref at the lowest oligonucleotide concentration. A theoretical binding curve, represented by equation 7 where $I_{\text {sat }}$ is the apparent maximum cleavage, 
$K_{i}$ the equilibrium association constant for oligonucleotide $i$, and [O] tot the oligonucleotide-EDTA concentration, was used to fit the experimental data using $I_{\text {sat }}$ and $K_{i}$ as adjustable parameters:

$I_{\text {fit }}=I_{\text {sat }} \frac{K_{i}[O]_{\text {tot }}}{1+K_{i}[O]_{\text {tot }}}$

KaleidaGraph software (version 2.1, Abelweck Software) running on a Macintosh IIfx computer was used to minimize the difference between Ifit and Isite for all data points. All values reported in the text are the means of three to six experimental observations \pm SEM, unless otherwise indicated. For graphical representation and comparison, $I_{\text {site }}$ values were converted to apparent fractional occupancies $\left(\theta_{\mathrm{app}}\right)$ by dividing $I_{\text {site }}$ by $I_{\text {sat }}$. 


\section{References and Notes}

1. Ptashne, M. A Genetic Switch; Blackwell Scientific Publications and Cell Press: Palo Alto, CA, 1986.

2. (a) Cantor, C. R.; Schimmel, P. R. Biophysical Chemistry Part III: The Behavior of Biological Macromolecules; W. H. Freeman and Co.: New York, N. Y., 1980. (b) Hill, T. L. Cooperativity Theory in Biochemistry: Steady State and Equilibrium Systems; Springer-Verlag: New York, N. Y., 1985. (c) Adhya, S. Annual Reviews in Genetics 1989, 23, 227.

3. (a) Moser, H. E.; Dervan, P. B. Science 1987, 238, 645. (b) Le Doan, T.; Perrouault, L.; Praseuth, D.; Habhoub, N.; Decout, J.-L.; Thuong, N. T.; Lhomme, J.; Helene, C. Nucleic Acids Res. 1987, 15, 7749. (c) Cooney, M.; Czernuszewics, G.; Postel, E. H.; Flint, S. J.; Hogan, M. E. Science 1988, 241, 456. (d) Maher III, L. J.; Wold, B. J.; Dervan, P. B. Science 1989, 245, 725. (e) Beal, P. A.; Dervan, P. B. Science 1991, 251, 1360. (f) Strobel, S. A.; DoucetteStamm, L. A.; Riba, L.; Housman, D. E.; Dervan, P. B. Science 1991, 254, 1639. (g) Maher III, L. J.; Dervan, P. B.; Wold, B. J. Biochemistry 1992, 31, 70.

4. (a) Felsenfeld, G.; Davies, D. R.; Rich, A. J. Am. Chem. Soc. 1957, 79, 2023.

(b) Howard, F. B.; Frazier, J.; Lipsett, M. N.; Miles, H. T. Biochem. Biophys. Res. Commun. 1964, 17, 93. (c) Rajagopal, P.; Feigon, J. Nature 1989, 339, 637. (d) Radhakrishnan, I.; Gao, X.; de los Santos, C.; Live, D.; Patel, D. J. Biochemistry 1991, 30, 9022.

5. (a) Durland, R. H.; Kessler, D. J.; Gunnell, S.; Duvic, M.; Pettitt, B. M.; Hogan, M. E. Biochemistry 1991, 30, 9246. (b) Pilch, D. S.; Levenson, C.; Shafer, R. H. Biochemistry 1991, 30, 6081. (c) Radhakrishnan, P.; de los Santos, C.; Patel, D. J. J. Mol. Biol. 1991, 221, 1403. (d) Beal, P. A.; Dervan, P. B. Nucleic Acids Res. 1992, 20, 2773. 
6. Strobel, S. A.; Dervan, P. B. J. Am. Chem. Soc. 1989, 111, 6956.

7. (a) Distefano, M. D.; Shin, J. A.; Dervan, P. B. J. Am. Chem. Soc. 1991, 113, 5901. (b) Distefano, M. D.; Dervan, P. B. J. Am. Chem. Soc. 1992, 114, 11006.

(c) Distefano, M. D.; Dervan, P. B. Proc. Natl. Acad. Sci. USA 1993, 90, 1179.

8. (a) Singleton, S. F.; Dervan, P. B. J. Am. Chem. Soc. 1992, 114, 6956. (b) Singleton, S. F.; Dervan, P. B. Biochemistry 1992, 31, 10995.

9. Dreyer, G. B.; Dervan, P. B. Proc. Natl. Acad. Sci. USA 1985, 82, 968.

10. Johnston, R. F.; Pickett, S. C.; Barker, D. L. Electrophoresis 1990, 11, 355.

11. In a heterodimeric cooperative system, intersite competition may reduce the apparent magnitude of cooperative binding. In order to achieve the maximum cooperative interaction, it is necessary to choose an oligonucleotide concentration that is sufficiently high to allow saturation at the designated target site, and sufficiently low to prevent competitive binding at noncognate sites. An increase in oligonucleotide 2 concentration from $1.0 \mu \mathrm{M}$ to $50 \mu \mathrm{M}$ caused a 5.5-fold decrease in the binding of the 1-2 complex. Similarly, an increase in the concentration of oligonucleotide 4 from $1.0 \mu \mathrm{M}$ to $50 \mu \mathrm{M}$ caused a 2.7 -fold decrease in the binding of the $1-4$ complex. These results are consistent with oligonucleotides 2 and 4 occupying site A when present at very high concentrations.

12. An approximate binding constant of $4.2 \times 10^{5} \mathrm{M}^{-1}$ was determined by quantitative affinity cleavage titration for 3 binding to site $\mathrm{A}$. This value suggests that at $1.0 \mu \mathrm{M}$, site $\mathrm{A}$ is ca. 30\% occupied by 2 .

13. (a) Arnott, S.; Selsing, E. J. Mol. Biol. 1974, 88, 509. (b) Collier, D. A.; Mergny, J. L., Thuong, N. T.; Helene, C. Nucleic Acids Res. 1991, 19, 4219. (c) Povsic, T. J. Ph. D. Dissertation, California Institute of Technology, Pasadena, CA, 1992. 
14. (a) Howard, F. B.; Miles, H. T.; Liu, K.; Frazier, J.; Raghunathan, G.; Sasisekharan, V. Biochemistry 1992, 31, 10671. (b) Macaya, R. F.; Schultze, P.; Feigon, J. J. Am. Chem. Soc. 1992, 114, 781. (c) de los Santos, C.; Rosen, M.; Patel, D. Biochemistry 1989, 28, 7289. (d) Roberts, R. W.; Crothers, D. M. Science 1992, 258, 1463. (e) Plum, G. E.; Park, Y. W.; Singleton, S. F.; Dervan, P.B.; Breslauer, K. J. Proc. Natl. Acad. Sci. USA 1990, 87, 9436. (f) Pilch, D. S.; Levenson, C.; Shafer, R. H. Proc. Natl. Acad. Sci. USA 1990,87, 1942.

15. (a) Sowers, L. C.; Shaw, B. R.; Sedwick, W. D. Biochem. Biophys. Res. Commun. 1987, 148, 790. (b) DeVoe, H.; Tinoco, I. J. Mol. Biol. 1962, 4, 500. (c) Sanyal, N. K.; Roychoudhury, M.; Ruhela, K. R.; Tiwari, S. N. J. Comput. Chem. 1986, 8, 604. (d) Ornstein, R. L.; Rein, R.; Breen, D. L.; MacElroy, R. D. Biopolymers 1978, 17, 2341. (e) Broom, A. D.; Schweizer, M. P.; Ts'o, P. O. P. J. Am. Chem. Soc. 1967, 89, 3612. (f) Ts'o, P. O. P. Molecular Associations in Biology; Academic Press: New York, N. Y., 1968, pp 39-75. (g) Nakano, N. I.; Igarishi, S. J. Biochemistry 1970, 9, 577. (h) Breslauer, K. J.; Frank, R.; Blocker, H.; Marky, L. A. Proc. Natl. Acad. Sci. USA 1986, 83, 3746. (i) Delcourt, S. G.; Blake, R. D. J. Biol. Chem. 1991, 266, 15160.

16. (a) Herskovitz, T. T. Arch. Biochem. Biophys. 1962, 97, 474. (b) Herskovitz, T. T. Biochemistry 1963, 2, 335.

17. For previous studies on the cooperative binding of short oligomers to adjacent sites on complementary single-stranded polymers by WatsonCrick hydrogen bond formation, see: (a) Pitha, P. M.; Ts'o, P. O. P. Biochemistry 1969, 8, 5206. (b) Springgate, M. W.; Poland, D. Biopolymers 1973, 12, 2241. (c) Maher, L. J.; Dolnick, B. J. Nucleic Acids Res. 1988, 16, 3341. 
18. Sambrook, J.; Fritsch, E. F.; Maniatis, T. Molecular Cloning; 2nd ed.; Cold Spring Harbor Laboratory Press: New York, N. Y., 1989.

19. Gait, M. J. (Ed.) Oligonucleotide Synthesis: A Practical Approach; IRL Press: Oxford, 1984.

20. Strobel, S. A. Ph. D. Dissertation, California Institute of Technology, Pasadena, CA, 1992. 


\section{CHAPTER THREE:}

\section{Cooperative Triple Helix Formation at Adjacent DNA Sites: Sequence Composition Dependence at the Junction}

\section{Introduction}

Cooperative interactions between proteins bound to DNA are essential for the regulation of gene expression. These cooperative interactions serve to increase the sequence specificity of DNA-binding proteins as well as the sensitivity of the binding equilibrium to concentration changes. ${ }^{1}$ When cooperative interactions occur between two (or more) oligonucleotides bound at neighboring sites on double-helical DNA, the specific binding of each oligonucleotide is enhanced.2,3 Pyrimidine oligodeoxyribonucleotides 11 nucleotides (nt) in length are known to bind cooperatively to abutting sites on double-helical DNA by triple helix formation, resulting in a $1.8 \mathrm{kcal} \cdot \mathrm{mol}^{-1}$ interaction energy between the oligonucleotides. ${ }^{2 \mathrm{~b}}$ This interaction energy likely arises from $\pi$-stacking between the thymines at the triple-helical junction. An increase in cooperativity between triple helix forming oligonucleotides was achieved by the use of modified bases such as 5-(1-propynyl)-2'-deoxyuridine, which allow greater stacking interactions in the third strand (see Chapter Four). ${ }^{2 c, 4}$ Even stronger cooperative interactions were obtained by the addition of dimerization domains to oligonucleotides such as those capable of forming a short Watson-Crick helix or intercalators. 3,5

The nature of the cooperative interactions between triple helix forming oligonucleotides binding to adjacent sites on DNA is still not well understood. A one base-pair gap between the adjacent triple helix sites abolishes cooperativity, suggesting that cooperative interactions largely arise from stacking between the 
bases at the triplex junction. ${ }^{2}$ Based on these results, the interaction energy between cooperatively binding oligonucleotides should depend on the nature of the base stack at the junction. Here we report the energetics of cooperative binding of pyrimidine oligodeoxyribonucleotides to adjacent sites on DNA by triple helix formation as a function of sequence composition at the junction (base stacks 5'-TT-3', 5'-mCT-3', 5'-TmC-3', and 5'-mC ${ }^{m} \mathrm{C}-3^{\prime}$ ) (mC designates 5-methyl2'-deoxycytidine). The equilibrium association constants of four oligonucleotides binding to four 11-bp sites paired as four different neighbors are measured in the absence and presence of a second 11mer oligonucleotide occupying an adjacent, directly abutting site by quantitative affinity cleavage titrations (QACT). ${ }^{6}$ The effect of a single base mismatch at the junction on the cooperative energy between two triple helix forming oligonucleotides reveals that hydrogen bonding between the third strand and the target site is important for proper base stacking in the third strand. Finally, we determine the equilibrium association constant of a 22mer oligonucleotide targeted to two abutting 11-bp sites in the presence and absence of a single-base mismatch. This data allows us to compare the sensitivity to single-base mismatches of oligonucleotides binding cooperatively to DNA with that of a longer oligonucleotide binding noncooperatively to the same two abutting sites on DNA.

\section{Results}

A system was designed to allow determination of the interaction energies

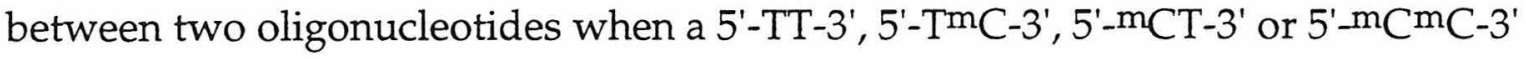
stack is formed at the junction (Figure 3.1). Two 11-nt oligodeoxyribonucleo-

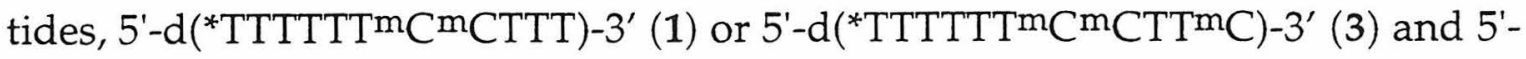

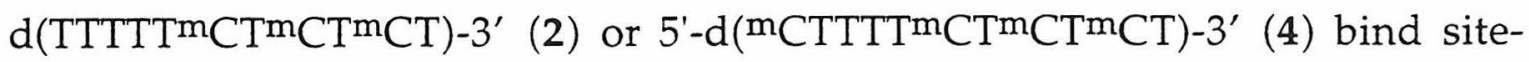

specifically to adjacent sites A (or C) and B (or D) on an 850-bp 3'-32P-end-labeled 
Figure 3.1. Schematic representation of a complex composed of two triple helix forming oligonucleotides binding at adjacent sites on double-helical DNA wherein a 5'-TT-3' (A), 5'-TmC-3' (B), 5'-mCT-3' (C), or a 5'-mCmC-3' (D) stack is formed. Thick solid lines represent the DNA backbone of the target site and associated oligonucleotides. Thin solid lines represent Watson-Crick hydrogen bonds while dashed lines indicate Hoogsteen hydrogen bonds. Binding of each oligonucleotide is assessed by affinity cleavage. ${ }^{6}$ 


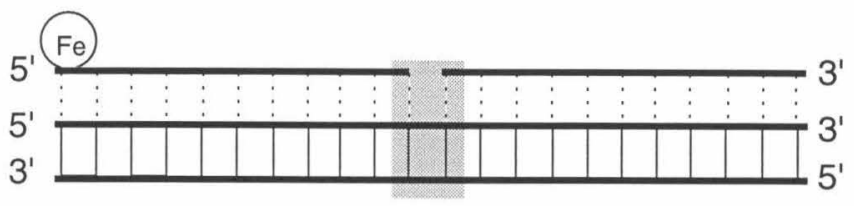

A

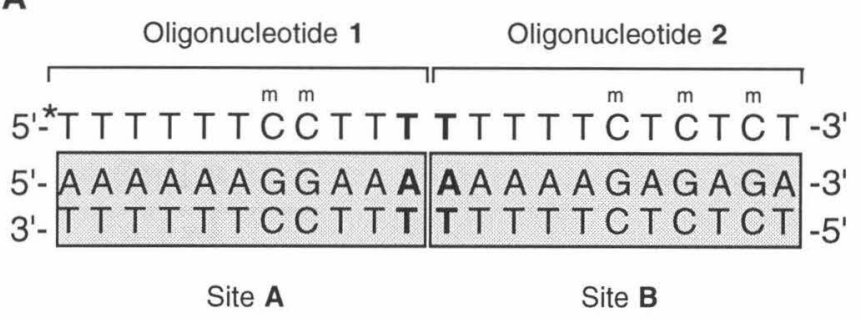

B

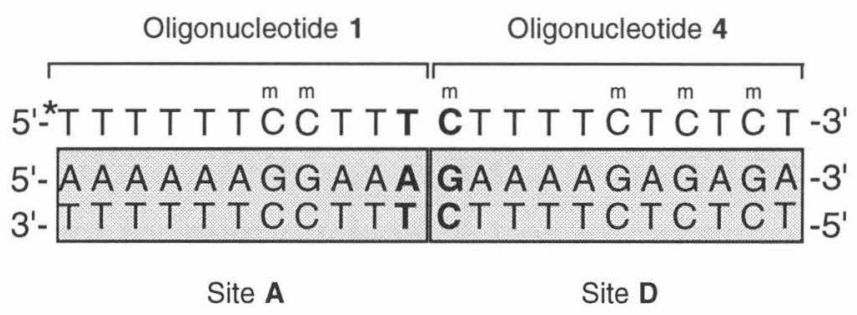

C

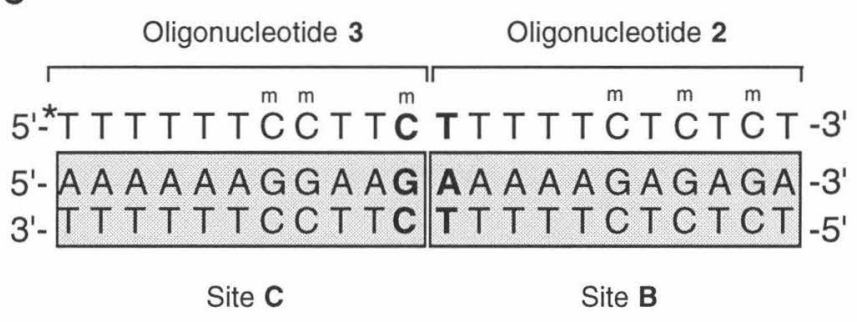

D

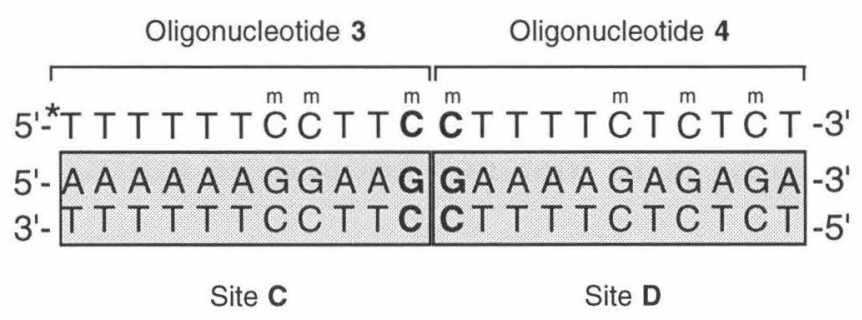


duplex DNA fragment $\left(24^{\circ} \mathrm{C}, \mathrm{pH} 7.0\right)$. Thymidine-EDTA $\left(\mathrm{T}^{*}\right)^{7,8}$ was incorporated at the $5^{\prime}$-terminus of oligonucleotides 1 and 3 to allow determination of their equilibrium association constants to site $\mathrm{A}$ and $\mathrm{C}$, respectively, in the absence or presence of 2 or $\mathbf{4}$, using the QACT method.6 The cooperative interaction energy $E_{\text {coop }}$ is determined from the experimental data through the following expression, as described in Chapter Two:

$\mathrm{E}_{\text {coop }}=-\mathrm{RT} \ln \frac{\Phi\left(1+K_{\mathrm{B}}\left[\mathrm{LB}_{\mathrm{B}}\right]\right)-1}{K_{\mathrm{B}}\left[\mathrm{LB}_{\mathrm{B}}\right]}$

For the cooperatively binding oligonucleotides described $\mathrm{L}_{\mathrm{B}}$ is oligonucleotide 2 or 4 , and $K_{\mathrm{B}}$ is the association constant of 2 or 4 to its respective site. As explained in Chapter Two, $\Phi=K_{\mathrm{A}+\mathrm{B}} / K_{\mathrm{A}}$, where $K_{\mathrm{A}+\mathrm{B}}$ is the equilibrium association constant for oligonucleotide $\mathbf{1}$ or $\mathbf{3}$ binding to its respective site in the presence of oligonucleotide 2 or 4 . For ease of discussion, duplex DNA containing a $5^{\prime}-\mathrm{AA}-3^{\prime}, 5^{\prime}-\mathrm{AG}-3^{\prime}, 5^{\prime}-\mathrm{GA}-3^{\prime}$, or $5^{\prime}-\mathrm{GG}-3^{\prime}$ sequence at the triplex junction site will be referred to as the AA, AG, GA or GG DNA fragments, respectively.

Cooperative Binding of Two 11mers in the Presence of a 5'-TT-3' Stack. Analysis of cleavage data performed on the AA DNA fragment yielded equilibrium association constants of $1.3 \times 10^{6} \mathrm{M}^{-1}$ for 1 binding alone $\left(K_{1, \mathrm{AA}}\right)$ and $1.5 \mathrm{x}$ $10^{7} \mathrm{M}^{-1}$ for 1 binding in the presence of $5.0 \mu \mathrm{M} 2\left(K_{1+2, \mathrm{AA}}\right)$ (Table 3.1, Figure 3.1A). The equilibrium association constant of 5 , an oligonucleotide with the same sequence as 2 but containing $\mathrm{T}^{*}$ at the $3^{\prime}$-end targeted to the 11-bp site $\mathrm{B}$, was found to be $2.8 \times 10^{6} \mathrm{M}^{-1}$. The binding enhancement $K_{1+2, \mathrm{AA}} / K_{1, \mathrm{AA}}$ is a factor of 12. Substitution of the values $12,2.8 \times 10^{6} \mathrm{M}^{-1}$, and $5 \times 10^{-6} \mathrm{M}^{-1}$ for $\Phi$, 
Table 3.1: Equilibrium Association Constants for Two Triple Helix Forming Oligonucleotides Binding at Adjacent Sites on DNA as a Function of Four Different Base Stacks ${ }^{a}$

\begin{tabular}{|c|c|c|c|c|}
\hline Stack & $\begin{array}{c}\text { Oligo- } \\
\text { nucleotide }\end{array}$ & $\begin{array}{c}K \\
\left(M^{-1}\right) \\
\end{array}$ & $K_{11+11} / K_{11}$ & $\begin{array}{c}\mathrm{E}_{\mathrm{coop}} \\
\left(\mathrm{kcal} \bullet \mathrm{mol}^{-1}\right)\end{array}$ \\
\hline $5^{\prime}-\mathrm{TT}-3^{\prime}$ & $\begin{array}{l}1 \\
1+2(5 \mu \mathrm{M})\end{array}$ & $\begin{array}{l}1.3( \pm 0.2) \times 10^{6} \\
1.5( \pm 0.2) \times 10^{7}\end{array}$ & $12( \pm 2)$ & $1.5( \pm 0.1)$ \\
\hline $5^{\prime}-\mathrm{T} \underline{\mathrm{C}}-3^{\prime}$ & $\begin{array}{l}1 \\
1+4(5 \mu \mathrm{M})\end{array}$ & $\begin{array}{l}4.6( \pm 0.8) \times 10^{6} \\
2.8( \pm 0.3) \times 10^{8}\end{array}$ & $61( \pm 12)$ & $2.5( \pm 0.2)$ \\
\hline $5^{\prime}-\underline{C}$ - $-3^{\prime}$ & $\begin{array}{l}3 \\
3+2(5 \mu \mathrm{M})\end{array}$ & $\begin{array}{l}1.1( \pm 0.1) \times 10^{6} \\
1.4( \pm 0.2) \times 10^{8}\end{array}$ & $127( \pm 21)$ & $2.9( \pm 0.1)$ \\
\hline $5^{\prime}-\underline{\mathrm{CC}}-3^{\prime}$ & $\begin{array}{l}3 \\
3+4(5 \mu \mathrm{M})\end{array}$ & $\begin{array}{l}1.9( \pm 0.7) \times 10^{6} \\
3.2( \pm 0.3) \times 10^{7}\end{array}$ & $17( \pm 6)$ & $1.7( \pm 0.2)$ \\
\hline
\end{tabular}

$a$ Values reported in the table are mean values measured from affinity cleavage titration experiments performed in Association buffer (10 $\mathrm{mM}$ Bis-Tris $\bullet \mathrm{HCl}, 10 \mathrm{mM} \mathrm{NaCl}, 250 \mu \mathrm{M}$ spermine, $\left.\mathrm{pH} 7.0,24^{\circ} \mathrm{C}\right) . \underline{\mathrm{C}}$ designates 5-methyl-2'-deoxycytidine.

$K_{\mathrm{B}}$, and $\left[\mathrm{L}_{\mathrm{B}}\right]$, respectively, in equation 1 affords a value of $1.5 \mathrm{kcal} \bullet \mathrm{mol}^{-1}$ for $\mathrm{E}_{\text {coop }}$ between oligonucleotides 1 and 2 .

Cooperative Binding of Two 11 mers in the Presence of a $5^{\prime}-\mathrm{T}^{\mathrm{m}} \mathrm{C}-3^{\prime}$ Stack. Analysis of cleavage data performed on the AG DNA fragment yielded equilibrium association constants of $4.6 \times 10^{6} \mathrm{M}^{-1}$ for 1 binding alone $\left(K_{1, \mathrm{AG}}\right)$ and $2.8 \times 10^{8} \mathrm{M}^{-1}$ for 1 binding in the presence of $5.0 \mu \mathrm{M} 4\left(K_{1+4, A G}\right)$ (Table 3.1, Figure 3.1B). The equilibrium association constant of 6 , an oligonucleotide with the same sequence as 4 but containing $\mathrm{T}^{*}$ at the $3^{\prime}$-end targeted to the 11-bp site $\mathrm{B}$, was found to be $5.4 \times 10^{6} \mathrm{M}^{-1}$. The binding enhancement $K_{1+4, A G} / K_{1, A G}$ is a factor of 61 . Substitution of the values $61,5.4 \times 10^{6} \mathrm{M}^{-1}$, and $5 \times 10^{-6} \mathrm{M}^{-1}$ for $\Phi$, $K_{\mathrm{B}}$, and $\left[\mathrm{L}_{\mathrm{B}}\right]$, respectively, in equation 1 affords a value of $2.5 \mathrm{kcal} \bullet \mathrm{mol}^{-1}$ for $\mathrm{E}_{\mathrm{coop}}$ between oligonucleotides 1 and 4 . 
Cooperative Binding of Two 11 mers in the Presence of a 5'-mCT-3' Stack. Analysis of cleavage data performed on the GA DNA fragment yielded equilibrium association constants of $1.1 \times 10^{6} \mathrm{M}^{-1}$ for 3 binding alone $\left(K_{3, \mathrm{GA}}\right)$ and $1.4 \times 10^{8} \mathrm{M}^{-1}$ for 3 binding in the presence of $5.0 \mu \mathrm{M} 2\left(K_{3+2, \mathrm{GA}}\right)$ (Table 3.1, Figure 3.1C). The equilibrium association constant of 5 was found to be $4.3 \times 10^{6} \mathrm{M}^{-1}$. The binding enhancement $K_{3+2, \mathrm{GA}} / K_{3, \mathrm{GA}}$ is a factor of 127 . Substitution of the values $127,4.3 \times 10^{6} \mathrm{M}^{-1}$, and $5 \times 10^{-6} \mathrm{M}^{-1}$ for $\Phi, K_{\mathrm{B}}$, and [ $\left.\mathrm{L}_{\mathrm{B}}\right]$, respectively, in equation 1 affords a value of $2.9 \mathrm{kcal} \bullet \mathrm{mol}^{-1}$ for $\mathrm{E}_{\text {coop }}$ between oligonucleotides 3 and 2.

Cooperative Binding of Two 11 mers in the Presence of a $5^{\prime}-m^{m}{ }^{m} \mathrm{C}-3^{\prime}$ Stack. Analysis of cleavage data performed on the GG DNA fragment yielded equilibrium association constants of $1.9 \times 10^{6} \mathrm{M}^{-1}$ for 3 binding alone $\left(K_{3, G G}\right)$ and $3.2 \times 10^{7} \mathrm{M}^{-1}$ for 3 binding in the presence of $5.0 \mu \mathrm{M} 4\left(K_{3+4, G G)}\right.$ (Table 3.1, Figure 3.1D). The equilibrium association constant of 6 was found to be $7.1 \times 10^{6} \mathrm{M}^{-1}$. The binding enhancement $K_{3+4, G G} / K_{3, G G}$ is a factor of 17 . Substitution of the values $17,7.1 \times 10^{6} \mathrm{M}^{-1}$, and $5 \times 10^{-6} \mathrm{M}^{-1}$ for $\Phi, K_{B}$, and [ $\left.L_{B}\right]$, respectively, in equation 1 affords a value of $1.7 \mathrm{kcal} \cdot \mathrm{mol}^{-1}$ for $\mathrm{E}_{\text {coop }}$ between oligonucleotides 3 and 4 .

Binding of a 22mer Oligonucleotide Targeted to Two Abutting 11-bp Sites on DNA. The equilibrium association constant of a $22 \mathrm{mer}$ oligonucleotide with sequence $5^{\prime}-\mathrm{d}\left(\right.$ TTTTTT $\left.^{\mathrm{m}} \mathrm{C}^{\mathrm{m}} \mathrm{CTTTTTTTT}{ }^{\mathrm{m}} \mathrm{CT}^{\mathrm{m}} \mathrm{CT}^{\mathrm{m}} \mathrm{CT}^{*}\right)-3^{\prime}$ targeted to sites $\mathrm{A}$ and B (Figure 3.1A) was found to be $1.4 \times 10^{8} \mathrm{M}^{-1}$. The affinity of the $22 \mathrm{mer}$ is therefore ca. one order of magnitude higher than that of 11 mer oligonucleotide 1 binding to site $\mathrm{A}$ in the presence of 2 bound to site $\mathrm{B}$.

Effect of Mismatches on a 5'-TT-3' Stack. Due to the right-handed nature of DNA, we would expect a hydrogen-bond mismatch to affect a stack at the triplex junction differently depending on whether the mismatch is on the $5^{\prime}$ - or $3^{\prime}$ - side 
of the junction. We investigated the effect of mismatches on both sides of the junction on cooperativity. To determine the effect of a mismatch on the $5^{\prime}$-side of the junction on cooperative interactions involving a $5^{\prime}-\mathrm{TT}-3^{\prime}$ stack, we measured the association constants for oligonucleotide $\mathbf{1}$ binding to site A alone ( $\left.K_{1, \mathrm{GA}}\right)$ and in the presence of $5.0 \mu \mathrm{M} 2\left(K_{1+2, G A}\right)$ on the non-complementary GA DNA fragment (Figure 3.2A). In this case, a T•GC mismatch is formed at the $3^{\prime}$-end of oligonucleotide 1 . We found that the binding enhancement $K_{1+2, \mathrm{GA}} / K_{1, \mathrm{GA}}$ is a factor of 2.5, and little cooperativity was observed (Table 3.2). Analysis of Table 3.2 shows that the association constant of 1 binding in the presence of 2 is lowered by a factor of 29 from $1.5 \times 10^{7} \mathrm{M}^{-1}$ in the absence of any mismatch to $5.2 \times 10^{5} \mathrm{M}^{-1}$ in the presence of a mismatch. $9 \mathrm{a}$ To determine the effect of a mismatch on the $3^{\prime}$-side of the junction on a $5^{\prime}-\mathrm{TT}-3^{\prime}$ stack, we measured the association constants for oligonucleotide 1 binding to site $\mathrm{A}$ alone $\left(K_{1, \mathrm{AG}}\right)$ and in the presence of $5.0 \mu \mathrm{M} 2\left(K_{1+2, A G)}\right.$ on the non-complementary AG DNA fragment (Figure 3.2B). In this case, a $\mathrm{T} \bullet \mathrm{GC}$ mismatch is formed at the 5 '-end of oligonucleotide 3 , and no cooperativity was observed (Table 3.2). $9 \mathrm{~b}$

Effect of Mismatches on a 5'-mCT-3' Stack. We also investigated the effect of mismatches on cooperative interactions involving the very strong $5^{\prime}$-m CT- $3^{\prime}$ stack. To determine the effect of a mismatch on the 5 -side of the junction, we measured the association constants for oligonucleotide 3 binding to site $\mathrm{A}$ alone $\left(K_{3, \mathrm{AG}}\right)$ and in the presence of $5.0 \mu \mathrm{M} 4\left(K_{3+4, \mathrm{AG}}\right)$ on the non-complementary $\mathrm{AG}$ DNA fragment (Figure 3.2C). A $\mathrm{m} C \bullet A T$ mismatch is formed at the 3 '-end of oligonucleotide 3. The binding enhancement $K_{3+4, A G} / K_{3, A G}$ is a factor of 17 , corresponding to an $\mathrm{E}_{\mathrm{coop}}$ of $1.7 \mathrm{kcal} \bullet \mathrm{mol}^{-1}$ (Table 3.3). ${ }^{9 \mathrm{c}}$ To determine the effect of a mismatch on the $3^{\prime}$-side of the junction on a $5^{\prime}-\mathrm{mCT}-3^{\prime}$ stack, we measured the association constants for oligonucleotide 3 binding to site $\mathrm{A}$ alone $\left(K_{3, \mathrm{GG}}\right)$ and in the presence of $5.0 \mu \mathrm{M} 4\left(K_{3+4, G G)}\right.$ on the non-complementary GG 
Figure 3.2. Schematic representation of a complex composed of two triple helix forming oligonucleotides binding at adjacent sites on double-helical DNA in the presence of a single-base mismatch at the triplex junction. (A) A 5'-TT-3' stack is formed at the junction in the presence of a $\mathrm{T} \bullet \mathrm{GC}$ mismatch on the 5 - side of the junction. (B) A 5'-TT-3' stack is formed at the junction in the presence of a $\mathrm{T} \bullet \mathrm{GC}$ mismatch on the 3'- side of the junction. (C) A 5'-mCT-3' stack is formed at the junction in the presence of a $\mathrm{mC} \cdot \mathrm{AT}$ mismatch on the 5 - side of the junction. (D) A 5'-mCT-3' stack is formed at the junction in the presence of a T $\bullet$ GC mismatch on the 3 '- side of the junction. Thick solid lines represent the DNA backbone of the target site and associated oligonucleotides. Thin solid lines represent Watson-Crick hydrogen bonds while dashed lines indicate Hoogsteen hydrogen bonds. Binding of the oligonucleotides is assessed by affinity cleavage. ${ }^{6}$ 


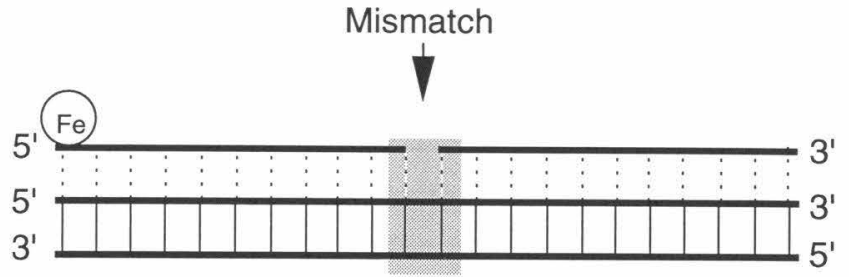

\section{5'-TT-3' Stack:}

A

Oligonucleotide 1

Oligonucleotide 2

5'- ${ }^{\prime *}$ T T T T T $\stackrel{m}{C} \stackrel{m}{C}$ T T T T T T T T $\stackrel{m}{C}$ T $\stackrel{m}{C}$ T $\stackrel{m}{C}$ T - $3^{\prime}$

5'- A A A A A A G G A A G A A A A A G A G A GA - 3 '

3'- T T T T T T C C T T C T T T T T C T C T C T $-5^{\prime}$

Site C

Site B

B

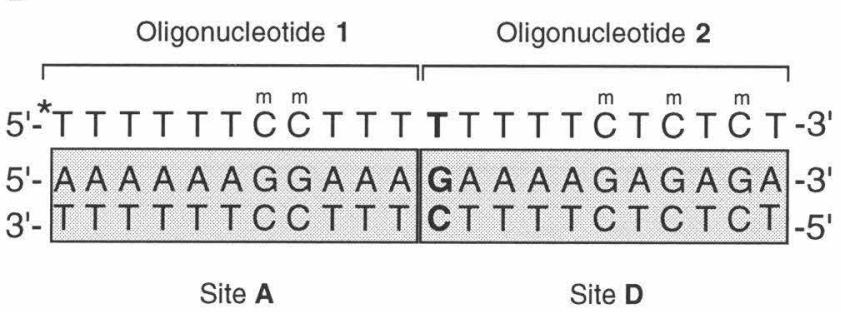

5'-mCT-3' Stack:

C

\begin{tabular}{|c|c|}
\hline Oligonucleotide 3 & Oligonucleotide 2 \\
\hline $5^{\prime}{ }^{*} T T T T T$ T $\stackrel{m}{C} \stackrel{m}{C} T T \stackrel{m}{c}$ & $\mathrm{~T} T \mathrm{~T} T \mathrm{~T} \stackrel{\mathrm{m}}{\mathrm{C}} \mathrm{T} \stackrel{\mathrm{m}}{\mathrm{C}} \mathrm{T} \stackrel{\mathrm{m}}{\mathrm{C}} \mathrm{T}$ \\
\hline $5^{\prime}-\mathrm{A} A \mathrm{~A}$ A A A G G A A & A A A A A A G A G A \\
\hline 3'- T T T T T T C C T T T & T T T T T C TC TCT \\
\hline
\end{tabular}

D

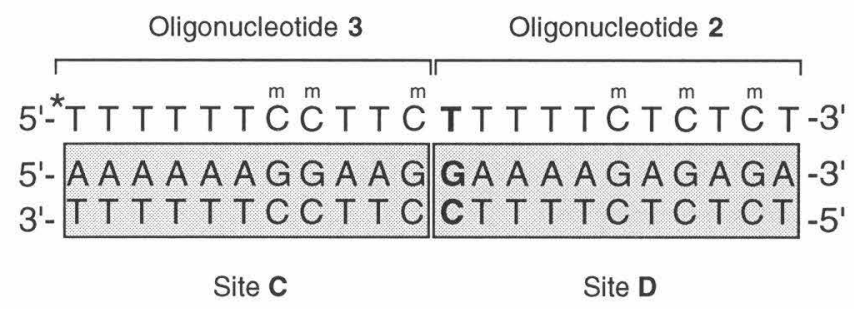


Table 3.2: Effect of Mismatches on a 5'-TT-3' Stack: Equilibrium Association Constants for Two Triple Helix Forming Oligonucleotides Binding at Adjacent Sites on DNA in the Presence of a Mismatch at the Junction ${ }^{a}$

\begin{tabular}{|c|c|c|c|c|}
\hline Mismatch & $\begin{array}{c}\text { Oligo- } \\
\text { nucleotide }\end{array}$ & $\begin{array}{c}K \\
\left(M^{-1}\right) \\
\end{array}$ & $K_{11+11} / K_{11}$ & $\begin{array}{c}\mathrm{E}_{\mathrm{coop}} \\
\left(\mathrm{kcal} \bullet \mathrm{mol}^{-1}\right)\end{array}$ \\
\hline $\begin{array}{l}5^{\prime}-\mathrm{T} \text { T-3' } \\
5^{\prime}-\mathrm{GA}-3^{\prime} \\
3^{\prime}-\mathrm{CT}-5^{\prime}\end{array}$ & $\begin{array}{l}1 \\
1+2(5 \mu \mathrm{M})\end{array}$ & $\begin{array}{l}2.1( \pm 0.2) \times 10^{5} \\
5.2( \pm 1.2) \times 10^{5}\end{array}$ & $2.5( \pm 0.8)$ & $0.6( \pm 0.2)$ \\
\hline $\begin{array}{l}5^{\prime}-\mathrm{TT}-3^{\prime} \\
5^{\prime}-\mathrm{AG}-3^{\prime} \\
3^{\prime}-\mathrm{TC}-5^{\prime}\end{array}$ & $\begin{array}{l}1 \\
1+2(5 \mu \mathrm{M})\end{array}$ & $\begin{array}{l}4.6( \pm 0.8) \times 10^{6} \\
5.3( \pm 0.6) \times 10^{6}\end{array}$ & $1.0( \pm 0.9)$ & 0 \\
\hline \multicolumn{5}{|c|}{$\begin{array}{l}\text { a Values reported in the table are mean values measured from } \\
\text { affinity cleavage titration experiments performed in Association } \\
\text { buffer ( } 10 \mathrm{mM} \text { Bis-Tris } \bullet \mathrm{HCl}, 10 \mathrm{mM} \mathrm{NaCl}, 250 \mu \mathrm{M} \text { spermine, } \mathrm{pH} \text { 7.0, } \\
\left.24^{\circ} \mathrm{C}\right) \text {. }\end{array}$} \\
\hline
\end{tabular}

DNA fragment (Figure 3.2D). In this case, a T•GC mismatch is formed at the 5'end of oligonucleotide 4, and no cooperativity was observed.9d Analysis of Table 3.3 reveals that the association constant of 3 binding in the presence of 2 is lowered by a factor of 64 from $1.4 \times 10^{8} \mathrm{M}^{-1}$ in the absence of any mismatch to 2.2 $x 10^{6} \mathrm{M}^{-1}$ in the presence of the mismatch.

Effect of Mismatches on the Binding of a 22mer targeted to sites A and B. The sensitivity to single-base mismatches of a noncooperative system compared to that of a cooperative one was examined. The sensitivity to single-base mismatches of the cooperative binding of two 11mers 1 and 2 targeted to sites $C$ and $\mathrm{B}$, respectively (Figure 3.2A) was compared to the binding of the corresponding 22 mer oligonucleotide with sequence $5^{\prime}-\mathrm{d}\left(\right.$ TTTTTT $^{\mathrm{m}} \mathrm{C}^{\mathrm{m}} \mathrm{CTTTTTTTT} \mathrm{CTT}^{\mathrm{m}} \mathrm{CT}$ mCT*)-3' targeted to the 22-bp site $(B+C)$. In both cases, a $\cdot \bullet G C$ mismatch is present at the 3 '-end of site $C$. The association constants of the 22 mer in the 
Table 3.3: Effect of Mismatches on a 5'-mCT-3' Stack: Equilibrium Association Constants for Two Triple Helix Forming Oligonucleotides Binding at Adjacent Sites on DNA in the Presence of a Mismatch at the Junction ${ }^{a}$

\begin{tabular}{|c|c|c|c|c|}
\hline Mismatch & $\begin{array}{c}\text { Oligo- } \\
\text { nucleotide }\end{array}$ & $\begin{array}{c}K \\
\left(M^{-1}\right) \\
\end{array}$ & $K_{11+11} / K_{11}$ & $\begin{array}{c}\mathrm{E}_{\mathrm{coop}} \\
\left(\mathrm{kcal} \bullet \mathrm{mol}^{-1}\right)\end{array}$ \\
\hline $\begin{array}{l}5^{\prime}-\text { CT-3' } \\
5^{\prime}-\mathbf{A A}-3^{\prime} \\
3^{\prime}-\text { TT-5' }\end{array}$ & $\begin{array}{l}3 \\
3+2(5 \mu \mathrm{M})\end{array}$ & $\begin{array}{l}1.3( \pm 0.1) \times 10^{5} \\
2.2( \pm 0.4) \times 10^{6}\end{array}$ & $17( \pm 3)$ & $1.7( \pm 0.1)$ \\
\hline $\begin{array}{l}\text { 5'-CT-3' } \\
5^{\prime}-\mathrm{GG}-3^{\prime} \\
3^{\prime}-\mathrm{CC}-5^{\prime}\end{array}$ & $\begin{array}{l}3 \\
3+2(5 \mu \mathrm{M})\end{array}$ & $\begin{array}{l}1.9( \pm 0.7) \times 10^{6} \\
1.3( \pm 0.1) \times 10^{6}\end{array}$ & $1.0( \pm 0.5)$ & 0 \\
\hline \multicolumn{5}{|c|}{$\begin{array}{l}\text { a Values reported in the table are mean values measured from } \\
\text { affinity cleavage titration experiments performed in Association } \\
\text { buffer ( } 10 \mathrm{mM} \text { Bis-Tris } \bullet \mathrm{HCl}, 10 \mathrm{mM} \mathrm{NaCl}, 250 \mu \mathrm{M} \text { spermine, } \mathrm{pH} \text { 7.0, } \\
\left.24^{\circ} \mathrm{C}\right) \text {. } \mathrm{C} \text { designates 5-methyl-2'-deoxycytidine. }\end{array}$} \\
\hline
\end{tabular}

absence and presence of the $\mathrm{T} \bullet \mathrm{GC}$ mismatch are $1.8 \times 10^{8} \mathrm{M}^{-1}$ and $7.2 \times 10^{7} \mathrm{M}^{-1}$, respectively. The association constants of oligonucleotide 1 binding cooperatively in the presence of $\mathbf{2}$ in the absence and presence of the same mismatch are $1.5 \times 10^{7} \mathrm{M}^{-1}$ and $5.2 \times 10^{5} \mathrm{M}^{-1}$, respectively, as mentioned above.

\section{Discussion}

Two pyrimidine oligonucleotides bind cooperatively to adjacent sites on double-helical DNA with an interaction energy ranging from $1.5 \mathrm{kcal} \bullet \mathrm{mol}^{-1}$ to $2.9 \mathrm{kcal} \bullet \mathrm{mol}^{-1}$, depending on the sequence composition at the triplex junction (Table 3.1). Cooperative interactions may arise from propagation of a conformational transition between adjacent sites and from base stacking of the terminal bases. Previous experiments show that when the two target sites are separated by one base pair, no cooperativity is observed, suggesting that base stacking is 
the major contributor to the cooperative interaction energy. $2 b$ The experimental results reported here are consistent with this model.

Base stacking is dominated by electrostatic, polarization, and dispersion forces. ${ }^{10}$ According to optimized potential calculations, dispersion and polarization interactions determine the magnitude of the total interaction energy, whereas electrostatic forces determine orientational preferences. $10 \mathrm{~d}$ In an attempt to explain the differences in interaction energies observed when cooperatively binding oligonucleotides interact through different base stacks, the electrostatic potentials of protonated N1-methyl-5-methylcytosine $\left(\mathrm{Nm}_{\mathrm{C}}\right)$ andN1methylthymine $(\mathrm{Nm} \mathrm{T})$, model compounds of the protonated 5-methylcytosine and thymine, respectively, were analyzed using the program Spartan. ${ }^{11}$ These calculations do not take into account the change in charge distribution of the bases due to hydrogen bonding to the purine strand. The AM1 electrostatic potentials were calculated at the semi-empirical level and mapped onto the electron-density surface of each molecule (Figure 3.3). Regions of electrostatic potential greater than or equal to $155.3\left(\mathrm{kcal}^{\circ} \mathrm{mol}^{-1}\right)$ for $\mathrm{NmC}$ and 36.14 $\left(\mathrm{kcal} \bullet \mathrm{mol}^{-1}\right)$ for $\mathrm{NmT}$ are shown in blue, and regions of electrostatic potential less than or equal to 22.25 for $\mathrm{NmC}$ and -65.51 for $\mathrm{NmT}$ are shown in red. The lower and higher end of the color scale were chosen such as to highlight the charge distributions in the two molecules, and therefore the scale values in the two molecules are different. On the basis of these scale values, $\operatorname{NmC}(22.25 \rightarrow 155.3)$ is more polarized than $\mathrm{NmT}(-65.51 \rightarrow 36.14)$. NmC contains a region of low electrostatic potential (electron-deficient) localized around the protonated nitrogen, and a region of high positive electrostatic potential (electron-rich) localized on the carbonyl oxygen. $\mathrm{Nm} \mathrm{T}$ contains an electron-deficient region extending over half of its ring opposite to the two carbonyl groups. 
Figure 3.3. Representation of the calculated AM1 electrostatic potential surfaces of model compounds N1-methyl-5-methylcytidine $\left(\mathrm{Nm}_{\mathrm{C}}\right)$ and N1-methylthymidine $(\mathrm{Nm} T)$. The range of electrostatic potential values calculated for each molecule are shown under the surfaces. Electrostatic potentials values are shown colorimetrically, and range from 22.25 (red) to 155.3 (blue) $\mathrm{kcal}^{\bullet} \mathrm{mol}^{-1}$ for $\mathrm{NmC}^{-}$ and from -65.51 (red) to 36.14 (blue) $\mathrm{kcal} \cdot \mathrm{mol}^{-1}$ for ${ }^{\mathrm{Nm}} \mathrm{T}$. 

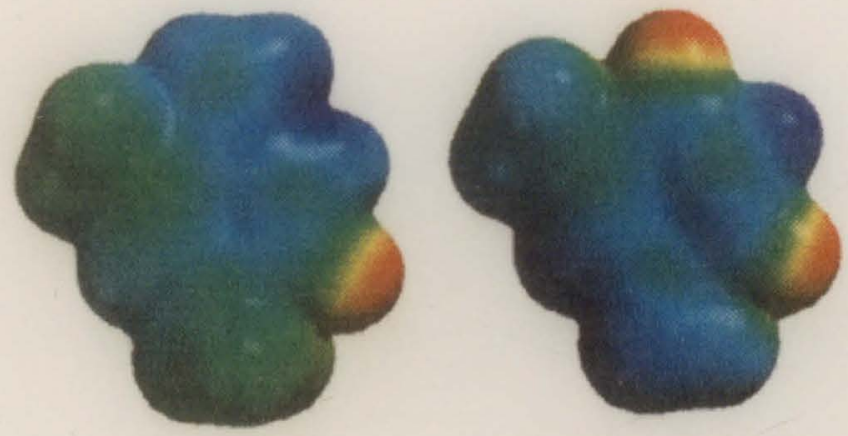

$(22.25 \longrightarrow 155.3)$

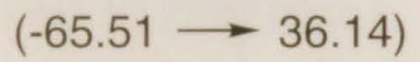

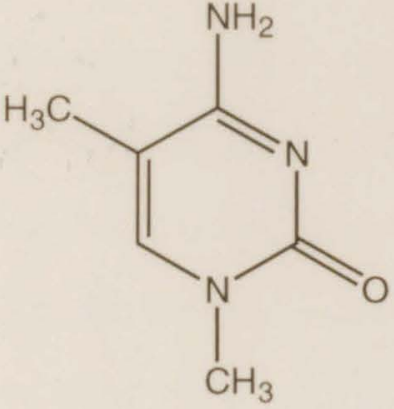

${ }^{\mathrm{Nm}} \mathrm{C}$

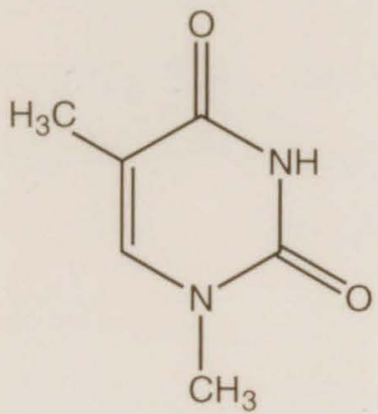

NmT 
The four base stacking configurations $5^{\prime}-\mathrm{TT}-3^{\prime}, 5^{\prime}-\mathrm{Tm}_{\mathrm{C}}-3^{\prime}, 5^{\prime}-\mathrm{m}_{\mathrm{CT}}-3^{\prime}$ and $5^{\prime}-$ ${ }^{m}{ }^{m} \mathrm{C}-3^{\prime}$ drawn on the basis of the structure proposed for DNA triple helix $(\mathrm{T} \bullet \mathrm{AT})_{n}$ are shown in Figure 3.4.12 These base stacks are characterized by four different charge-charge interactions, depending on the electrostatic distribution of the individual bases, and the relative positioning of the bases with respect to each other. Our data suggests that the weakest interactions are a $5^{\prime}-\mathrm{m}^{\mathrm{m}} \mathrm{m} C-3^{\prime}$ and a 5'-TT-3' stack, which are comparable (Table 3.1). Although we usually depict $\mathrm{m}_{\mathrm{C}}$ as protonated when bound to DNA in a triple-helical complex, under the conditions used ( $\mathrm{pH}$ 7.0) it may not be protonated at every position. An analysis of the electronic distribution of ${ }^{\mathrm{Nm} C}$ and $\mathrm{Nm} T$ reveals that there are no favorable charge-charge interactions in a $5^{\prime}-\mathrm{m}^{\mathrm{m}} \mathrm{C}-3^{\prime}$ or $5^{\prime}-\mathrm{TT}-3^{\prime}$ stack. The 1.5-1.7 $\mathrm{kcal} \bullet \mathrm{mol}^{-1}$ cooperative energy observed when either a $5^{\prime} \mathrm{m}_{\mathrm{C}} \mathrm{m} \mathrm{C}-3^{\prime}$ or a $5^{\prime}-\mathrm{TT}-3^{\prime}$ stack is formed may reflect generally favorable polarization interactions between the two bases across the junction.

Stronger interaction energies between two oligonucleotides binding to adjacent sites on DNA are observed when a $5^{\prime}-\mathrm{T}^{\mathrm{m}} \mathrm{C}-3^{\prime}$ or a $5^{\prime}-\mathrm{m} \mathrm{CT}-3^{\prime}$ stack is formed at the junction (Table 3.1). An analysis of the electronic distribution of ${ }^{N m} \mathrm{~T}$ and ${ }^{N m} \mathrm{C}$ reveals that in both $5^{\prime}-\mathrm{T}^{\mathrm{m}} \mathrm{C}-3^{\prime}$ and $5^{\prime}-\mathrm{m}_{\mathrm{CT}}-3^{\prime}$ stacks, there may be a favorable charge-charge interaction between the electron-deficient exocyclic amino group on $\mathrm{m}_{\mathrm{C}}$ and the electron-rich $\mathrm{C} 4$ carbonyl group on $\mathrm{T}$. This interaction may explain why cooperative interactions may be stronger when a 5'$\mathrm{T}^{\mathrm{m} C} \mathrm{C}-3^{\prime}$ or a $5^{\prime}-\mathrm{m} \mathrm{CT}-3^{\prime}$ stack is formed rather than a $5^{\prime}-\mathrm{TT}-3^{\prime}$ or $5^{\prime}-\mathrm{m}_{\mathrm{C}} \mathrm{m}_{\mathrm{C}}-3^{\prime}$ stack. A comparison between the $5^{\prime}-\mathrm{T}^{\mathrm{m}} \mathrm{C}-3^{\prime}$ and $5^{\prime}-\mathrm{m} \mathrm{CT}-3^{\prime}$ stacking configurations themselves in terms of the charge distribution of the individual bases and their interactions reveals information about the relative strength of the two stacks. The data suggest that a $5^{\prime}-\mathrm{m} C \mathrm{CT}-3^{\prime}$ stack is significantly stronger than a $5^{\prime}-\mathrm{T}^{\mathrm{m}} \mathrm{C}-3^{\prime}$ stack. In the latter stack, the highly polarized region of ${ }^{m} \mathrm{C}$ faces away from $\mathrm{T}$, 


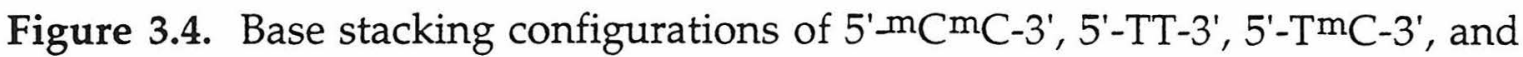
5'-mCT-3' triples drawn on the basis of the structure proposed for DNA triple helix $(\mathrm{T} \bullet \mathrm{AT})_{n}{ }^{12}$ The $\mathrm{C}^{\prime}$ atoms of the deoxyribose sugars are represented by the open circles. The larger filled circles represent methyl groups. The $5^{\prime} \rightarrow 3^{\prime}$ polarity of the strands is indicated by the $\otimes$ symbols (into the plane of the page) and $\odot$ (out of the plane of the page). 
5'-m $\mathrm{C}^{\mathrm{m}} \mathrm{C}-3^{\prime}$ Stack:

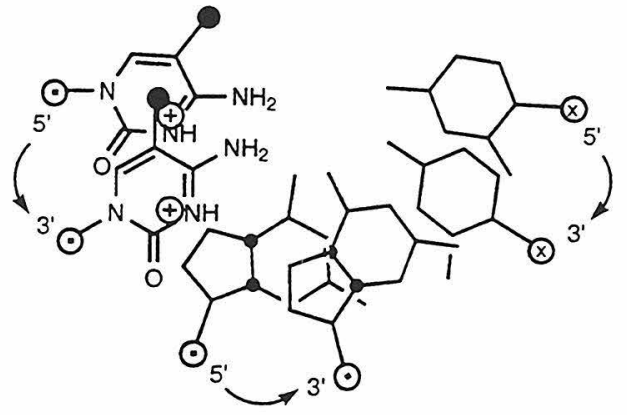

5'-TT-3' Stack:

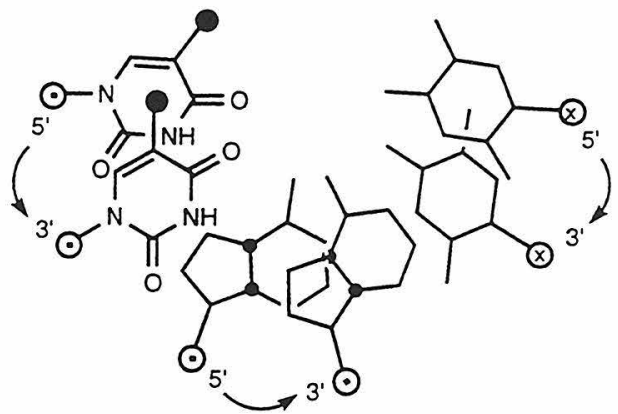

5'-T ${ }^{m} C-3^{\prime}$ Stack:

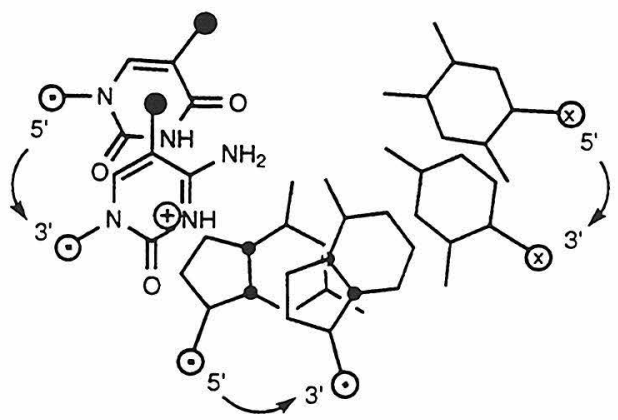

5'-mCT-3' Stack:

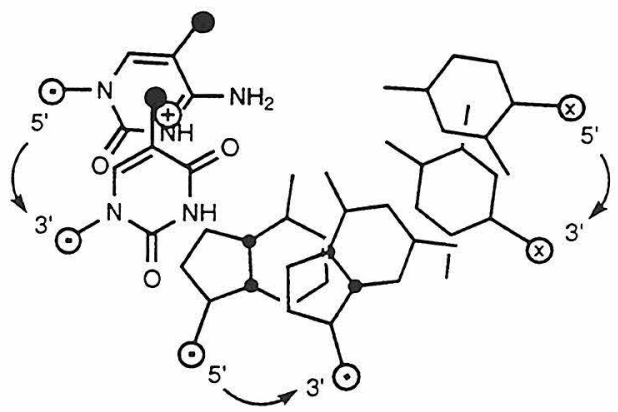


and no strong charge-charge interactions occur. In contrast, in a 5'-mCT-3' stack the highly polarized region of $\mathrm{m}_{\mathrm{C}}$ is located directly above $\mathrm{T}$, allowing the electron-deficient region of $\mathrm{T}$ to interact favorably with the electron-rich oxygen of $\mathrm{m}_{\mathrm{C}}$. In addition, there may be a favorable interaction between the positively charged ring nitrogen of $\mathrm{m} C$ and the electron-rich $\mathrm{C} 4$ carbonyl group of $\mathrm{T}$.

Effect of Mismatches on Cooperativity. Based on experimental data, the cooperative interaction energy between two triple helix forming oligonucleotides likely arises from base stacking at the triplex junction. The question arises as to what degree base stacking is sensitive to hydrogen-bond mismatches at the junction. A mismatch could presumably disrupt base stacking by either preventing a base from aligning favorably with respect to the other base across the junction, disrupting favorable electrostatic interactions, or by changing the electronic distribution of the mismatched base itself. Experiments were carried out to determine the degree to which cooperativity is disrupted by a single-base mismatch on either side of the triplex junction. The effect of a mismatch on cooperativity was examined in the cases where the moderately strong 5'-TT-3' stack and the very strong 5'-mCT-3' stack are formed. In the case of a 5'-TT-3' stack, a T•GC mismatch on the 3'- side of the junction (Figure 3.2A) significantly reduces cooperative interactions, whereas a $T \bullet G C$ mismatch on the 5 -side virtually destroys cooperativity (Figure 3.2B). The disruption of cooperativity may indicate that either the electron distribution or the relative position of $\mathrm{T}$ with respect to the adjacent $\mathrm{T}$ across the junction do not allow stacking between the two bases. In the case of the strong $5^{\prime}-\mathrm{m}_{\mathrm{CT}}-3^{\prime}$ stack, a ${ }^{\mathrm{C}} \mathrm{C} \bullet \mathrm{AT}$ mismatch on the 5 -side of the junction (Figure 3.2C) decreases the cooperative interaction energy between oligonucleotides 3 and 2 by $1.7 \mathrm{kcal} \bullet \mathrm{mol}^{-1}$, whereas a T•GC mismatch on the 3'-side of the junction completely destroys cooperativity (Figure 3.2D). Therefore, in this system, cooperativity is affected differently depending on the 
nature of the mismatch and/or the location of the mismatch with respect to the junction.

Sensitivity of a Cooperative vs. Noncooperative System to Single-Base Mismatches. Analysis of the data shows that the equilibrium association constant of a 22 mer of sequence $5^{\prime}-d\left(\right.$ TTTTTT $\left.^{\mathrm{m}} \mathrm{C}^{\mathrm{m}} \mathrm{CTTTTTTTT}{ }^{\mathrm{m}} \mathrm{CT}^{\mathrm{m}} \mathrm{CT}^{\mathrm{m}} \mathrm{CT}^{*}\right)-3^{\prime}$ in the absence and presence of a T•GC mismatch are $1.8 \times 10^{8} \mathrm{M}^{-1}$ and $7.2 \times 10^{7}$ $\mathrm{M}^{-1}$, respectively. The association constants of 11 mer oligonucleotide 1 binding cooperatively in the presence of $\mathbf{2}$ to the same sites in the absence and presence of the same mismatch are $1.5 \times 10^{7} \mathrm{M}^{-1}$ and $5.2 \times 10^{5} \mathrm{M}^{-1}$, respectively. Therefore, the same mismatch decreases the binding constant of the 22 mer by a factor of 2 , whereas it lowers the association constant of cooperatively binding 11 mer 1 by a factor of 29. This observation suggests that the cooperative system is more specific than the noncooperative one.

Summary. Pyrimidine oligonucleotides bind cooperatively to abutting sites on double-helical DNA with an interaction energy of $1.5-2.9 \mathrm{kcal} \bullet \mathrm{mol}^{-1}$ depending on the sequence of the base stack at the triple helix junction. Base stacking appears to be the major source of the positive cooperativity. Knowledge of the relative strength of base stacks in the third strand of a triple helix may serve as a baseline for the design of artificial cooperative systems containing novel structural domains for stabilizing interactions. 


\section{Addendum to Chapter Three:}

\section{Additional Sequence Composition Effects at the Junction}

The studies described above show that electrostatic rather than hydrophobic forces play a crucial role in the base stacking interactions observed in the cooperative systems that were analyzed. Nonetheless, previous experiments on the cooperative binding of oligonucleotide analogs containing 5-(1-propynyl)modified bases to DNA suggested that hydrophobic $\pi-\pi$ stacking interactions between the propyne-substituted nucleotides at the triplex junction are greatly responsible for the significant increase observed in cooperativity (see Chapter Four). In light of these results, further experiments were carried out with the aim of elucidating the chemical forces majorly responsible for the observed cooperative interactions between oligonucleotides.

\section{Results and Discussion}

Cooperative Binding of Two 11 mers in the Presence of a $5^{\prime}-\mathrm{P} U T-3^{\prime}$ or $5^{\prime}-$ $\mathrm{T}^{\mathrm{P}} \mathrm{U}-3$ ' Stack ( ${ }^{\mathrm{P}} \mathrm{U}=$ 5-(1-Propynyl)-2'-deoxyuridine). The cooperative binding of two 11mer oligonucleotides in the presence of a 5-propynyl-substituted 2'-deoxyuridine located either at the 5'- or 3'-end of the junction was examined. To study the effect on cooperativity of a propynyl-substituted base at the $5^{\prime}$-end of the junction, the equilibrium association constants for oligonucleotide $7\left(5^{\prime}-\mathrm{d}\left({ }^{*}\right.\right.$ TTTT$\left.{ }^{\mathrm{TT}^{\mathrm{m}}}{ }^{\mathrm{C}}{ }^{\mathrm{m}} \mathrm{CTT}{ }^{\mathrm{P}} \mathrm{U}\right)-3^{\prime}$ ) binding to site $\mathrm{A}$ on the AA DNA fragment alone and in the presence of oligonucleotide 2 were measured. Analysis of cleavage data performed on the AA DNA fragment yielded equilibrium association constants of $7.8 \times 10^{5} \mathrm{M}^{-1}$ for 7 binding alone $\left(K_{7, \mathrm{AA}}\right)$ and $1.6 \times 10^{7} \mathrm{M}^{-1}$ for 7 binding in the presence of $5.0 \mu \mathrm{M} 2\left(K_{7+2, \mathrm{AA}}\right)$ (Table 3.4, Figure 3.5A). The binding enhance- 


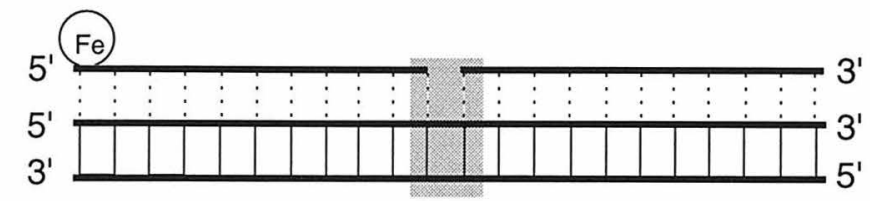

A

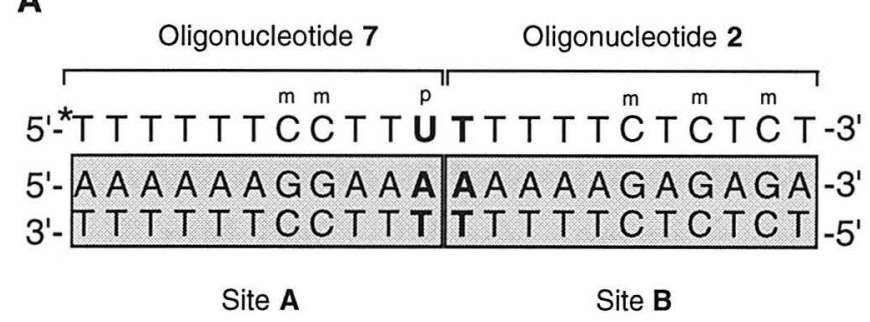

B

\begin{tabular}{|c|c|}
\hline Oligonucleotide 1 & Oligonucleotide 8 \\
\hline 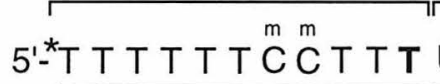 & $\stackrel{p}{\mathrm{U}} T \mathrm{~T} T \mathrm{~T} \stackrel{\mathrm{m}}{\mathrm{C}} \mathrm{T} \stackrel{\mathrm{m}}{\mathrm{C}} \mathrm{T} \stackrel{\mathrm{m}}{\mathrm{C}} \mathrm{T}-3^{\prime}$ \\
\hline $\begin{array}{l}5^{\prime}-\mathrm{A} A \mathrm{~A} A \mathrm{~A} A \mathrm{~A} \\
3^{\prime}-\mathrm{T} T \mathrm{~T} \text { T } \\
\end{array}$ & $\begin{array}{lll}\text { A A A A A G A G A G A } & -3^{\prime} \\
\text { T T T T T C T C T C T } & -5\end{array}$ \\
\hline
\end{tabular}

Figure 3.5. Schematic representation of a complex composed of two triple helix forming oligonucleotides binding at adjacent sites on DNA wherein a 5'-PUT-3' (A) or a 5'-TPU-3' (B) stack is formed at the junction. PU designates 5-(1-propynyl)-2'-deoxyuridine. 
Table 3.4: Equilibrium Association Constants for Two Triple Helix Forming Oligonucleotides Binding at Adjacent Sites on DNA as a Function of a Single 5-(1-Propynyl)-substituted Base at the Junction ${ }^{a}$

\begin{tabular}{|c|c|c|c|c|}
\hline Stack & $\begin{array}{c}\text { Oligo- } \\
\text { nucleotide }\end{array}$ & $\begin{array}{c}K \\
\left(M^{-1}\right)\end{array}$ & $K_{11+11} / K_{11}$ & $\begin{array}{c}\mathrm{E}_{\mathrm{coop}} \\
\left(\mathrm{kcal} \bullet \mathrm{mol}^{-1}\right)\end{array}$ \\
\hline $5^{\prime}-\mathrm{TT}-3^{\prime}$ & $\begin{array}{l}1 \\
1+2(5 \mu \mathrm{M})\end{array}$ & $\begin{array}{l}1.3 \times 10^{6} \\
1.5 \times 10^{7}\end{array}$ & 12 & 1.5 \\
\hline $5^{\prime}-\mathrm{P}_{\mathrm{UT}-3^{\prime}}$ & $\begin{array}{l}7 \\
7+2(5 \mu \mathrm{M}) \\
\end{array}$ & $\begin{array}{l}7.8 \times 10^{5} \\
1.6 \times 10^{7} \\
\end{array}$ & 21 & 1.8 \\
\hline $5^{\prime}-T^{\mathrm{P}} \mathrm{U}-3^{\prime}$ & $\begin{array}{l}1 \\
1+8(5 \mu \mathrm{M})\end{array}$ & $\begin{array}{l}1.3 \times 10^{6} \\
2.8 \times 10^{7}\end{array}$ & 25 & 1.9 \\
\hline \multicolumn{5}{|c|}{$\begin{array}{l}\text { a Values reported in the table are mean values measured from affinity } \\
\text { cleavage titration experiments performed in Association buffer (10 mM } \\
\left.\text { Bis-Tris } \bullet \mathrm{HCl}, 10 \mathrm{mM} \mathrm{NaCl}, 250 \mu \mathrm{M} \text { spermine, } \mathrm{pH} 7.0,24{ }^{\circ} \mathrm{C}\right) .{ }^{\mathrm{P}} \mathrm{U} \\
\text { designates 5-(1-propynyl)-2'-deoxyuridine. }\end{array}$} \\
\hline
\end{tabular}

ment $K_{7+2, \mathrm{AA}} / K_{7, \mathrm{AA}}$ is a factor of 21 . Substitution of the values $21,2.8 \times 10^{6} \mathrm{M}^{-1}$, and $5 \times 10^{-6} \mathrm{M}^{-1}$ for $\Phi, K_{\mathrm{B}}$, and [ $\left.\mathrm{L}_{\mathrm{B}}\right]$, respectively, in equation 1 affords a value of $1.8 \mathrm{kcal} \bullet \mathrm{mol}^{-1}$ for $\mathrm{E}_{\mathrm{coop}}$ between oligonucleotides 7 and 2 .

To study the effect on cooperativity of a propynyl-substituted base at the 3 'end of the junction, the equilibrium association constants for oligonucleotide 1 binding to site A on the AA DNA fragment alone and in the presence of oligonucleotide $8\left(5^{\prime}-\mathrm{d}\left({ }^{\mathrm{P}} \mathrm{UTTTT}{ }^{\mathrm{m}} \mathrm{CT}^{\mathrm{m}} \mathrm{CT} \mathrm{T}^{\mathrm{m}} \mathrm{CT}\right)-3^{\prime}\right)$ were measured. Analysis of cleavage data performed on the AA DNA fragment yielded equilibrium association constants of $1.3 \times 10^{6} \mathrm{M}^{-1}$ for 1 binding alone $\left(K_{1, \mathrm{AA}}\right)$ and $2.8 \times 10^{7} \mathrm{M}^{-1}$ for 1 binding in the presence of $5.0 \mu \mathrm{M} 8\left(K_{1+8, \mathrm{AA}}\right)$ (Table 3.4, Figure 3.5B). The equilibrium association constant of $\mathbf{9}$, an oligonucleotide with the same sequence as 8 but containing $\mathrm{T}^{*}$ at the $3^{\prime}$-end targeted to the 11 -bp site $\mathrm{B}$, was found to be $3.5 \times 10^{6} \mathrm{M}^{-1}$. The binding enhancement $K_{1+8, \mathrm{AA}} / K_{1, \mathrm{AA}}$ is a factor of 25 . 
Substitution of the values $25,3.5 \times 10^{6} \mathrm{M}^{-1}$, and $5 \times 10^{-6} \mathrm{M}^{-1}$ for $\Phi, K_{\mathrm{B}}$, and $\left[\mathrm{L}_{\mathrm{B}}\right.$, respectively, in equation 1 affords a value of $1.9 \mathrm{kcal} \cdot \mathrm{mol}^{-1}$ for $\mathrm{E}_{\mathrm{coop}}$ between oligonucleotides 1 and 8 .

Cooperative Binding of Two 11 mers in the Presence of a $5^{\prime}-m_{C} d U_{-} 3^{\prime}, 5^{\prime}$ $\mathrm{m}_{\mathrm{CT}}-3^{\prime}$, or $5^{\prime}-\mathrm{mC}^{\mathrm{P}} \mathrm{U}-3^{\prime}$ Stack ( ${ }^{\mathrm{d}} \mathrm{U}=2^{\prime}$-Deoxyuridine). Further experiments were carried out to learn more about the importance of hydrophobic $\pi-\pi$ stacking interactions in cooperativity. More specifically, we were interested in studying the relative energetic contributions to cooperative interactions of a series of hydrophobic groups present at the triplex junction. We chose to conduct this study in a system in which a 5'-m $\underline{\mathrm{C}}-\mathrm{3}^{\prime}$ stack, where $\underline{\mathrm{U}}$ designates a uridine derivative, is formed at the triplex junction. Analysis of the stacking configuration of a 5'-m $\underline{\mathrm{U}}-3^{\prime}$ stack reveals that substituents at the 5-position of $\underline{\mathrm{U}}$ are located directly above the heterocyclic portion of $\mathrm{m}_{\mathrm{C}}$ (Figure 3.6). If hydrophobic interactions greatly influence cooperativity, one would anticipate a strong dependence of cooperativity on the nature of the 5-substituent. Hence, experiments were carried out in which a hydrogen, a methyl, or a propynyl group is present at the 5-position of $\underline{U}$ (Figures 3.6 and 3.7).

Cooperative Binding of Two 11 mers in the Presence of a $5^{\prime}-m C^{d} U-3^{\prime}$ Stack. Analysis of cleavage data performed on the GA DNA fragment yielded equilibrium association constants of $1.1 \times 10^{6} \mathrm{M}^{-1}$ for 3 binding alone $\left(K_{3, \mathrm{GA}}\right)$ and $6.2 \times 10^{7} \mathrm{M}^{-1}$ for 3 binding in the presence of $5.0 \mu \mathrm{M} 10\left(5^{\prime}-\mathrm{d}\left(\mathrm{dUTTTT}^{\mathrm{m}} \mathrm{C}\right.\right.$ -

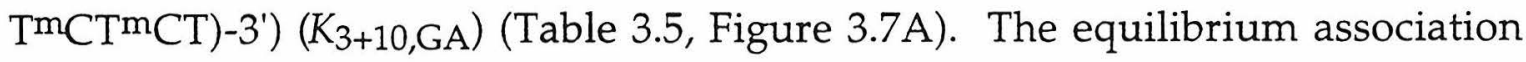
constant of 11 , an oligonucleotide with the same sequence as 10 but containing $\mathrm{T}^{*}$ at the $3^{\prime}$-end targeted to the $11-\mathrm{bp}$ site $\mathrm{B}$, was found to be $1.8 \times 10^{5} \mathrm{M}^{-1}$. The binding enhancement $K_{3+10, \mathrm{GA}} / K_{1, \mathrm{GA}}$ is a factor of 56 . Substitution of the values $56,1.8 \times 10^{5} \mathrm{M}^{-1}$, and $5 \times 10^{-6} \mathrm{M}^{-1}$ for $\Phi, K_{\mathrm{B}}$, and [ $\left.\mathrm{L}_{\mathrm{B}}\right]$, respectively, in equation 1 
$5^{\prime}-{ }^{m} C^{d} U-3 '$ Stack:

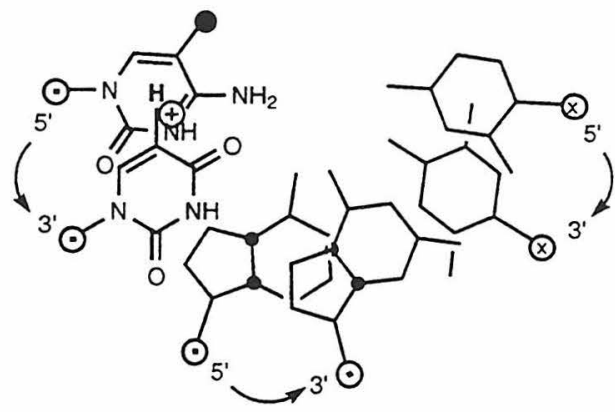

5'-mCT-3' Stack:

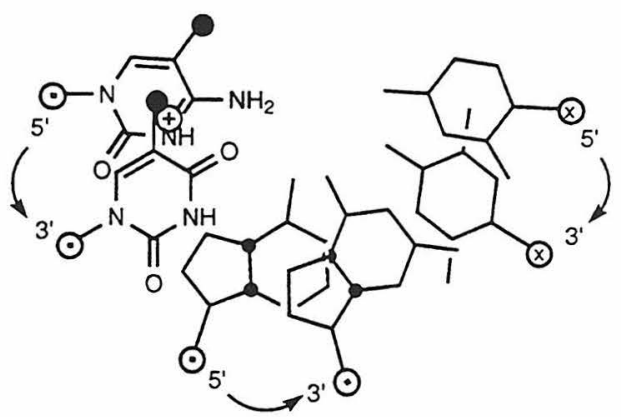

5'-mCPU-3' Stack:

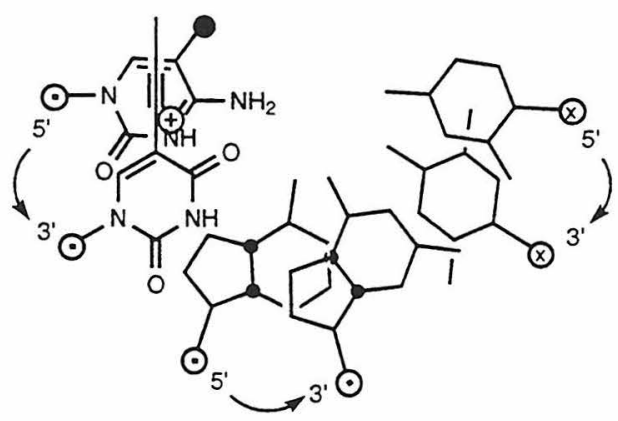

Figure 3.6. Base stacking configurations of $5^{\prime}-\mathrm{m}_{\mathrm{C}} \mathrm{d} U-3^{\prime}, 5^{\prime}-\mathrm{m}_{\mathrm{C}} \mathrm{T}-3^{\prime}$, and $5^{\prime}-\mathrm{m}^{\mathrm{P}}{ }^{\mathrm{P}} \mathrm{U}-3^{\prime}$ triples drawn on the basis of the structure proposed for DNA triple helix $(\mathrm{T} \bullet \mathrm{AT})_{n}{ }^{12}$ The $\mathrm{C}^{\prime}$ atoms of the deoxyribose sugars are represented by the open circles. The larger filled circles represent methyl groups. The $5^{\prime} \rightarrow 3^{\prime}$ polarity of the strands is indicated by the $\otimes$ symbols (into the plane of the page) and $\odot$ (out of the plane of the page). 


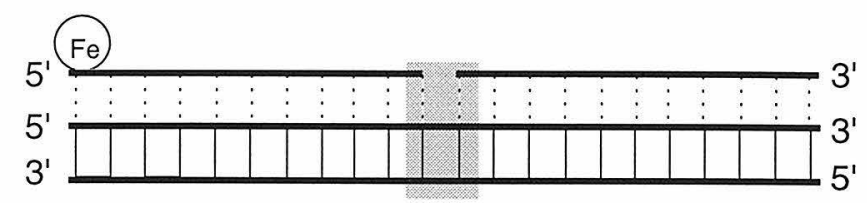

A

\begin{tabular}{|c|c|}
\hline Oligonucleotide 3 & Oligonucleotide 10 \\
\hline \multicolumn{2}{|c|}{ 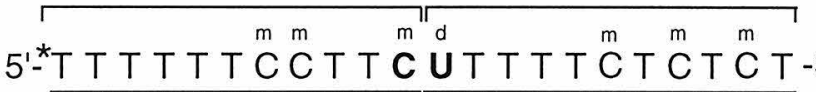 } \\
\hline 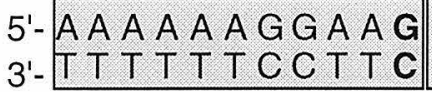 & $\begin{array}{l}\text { AA A A A G A G A GA } \\
\text { T T T T TCTCTCT. }\end{array}$ \\
\hline
\end{tabular}

B

\begin{tabular}{|c|c|}
\hline Oligonucleotide 3 & Oligonucleotide 2 \\
\hline $5^{\prime-*} T T T T T T \stackrel{m}{\mathrm{C}} \stackrel{m}{\mathrm{C}} T \mathrm{~T} \stackrel{\mathrm{m}}{\mathrm{c}}$ & 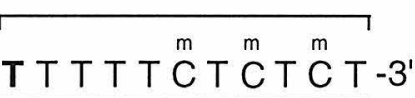 \\
\hline 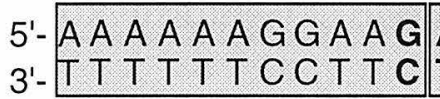 & $\begin{array}{llll}\text { A A A A A G A G A GA } & -3^{\prime} \\
\text { T T T T T C T C T C T } & \\
\end{array}$ \\
\hline
\end{tabular}

C

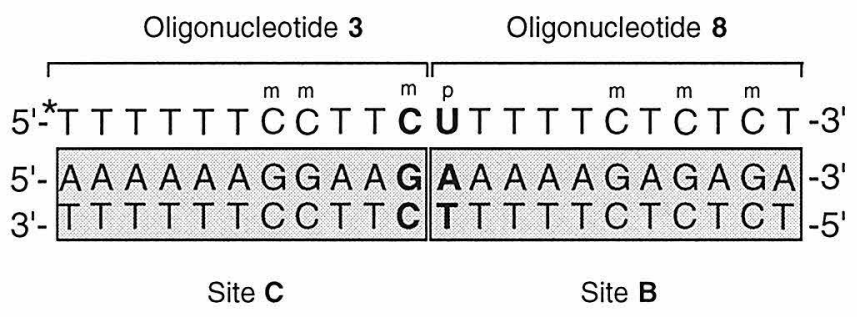

Figure 3.7. Schematic representation of a complex composed of two triple helix forming oligonucleotides binding at adjacent sites on DNA wherein a 5'-mCdU-3' (A), a 5'-mCT-3' (B), or a 5'-mCPU-3' (C) stack is formed at the junction. ${ }^{d} U$ designates 2'-deoxyuridine. PU designates 5-(1-propynyl)-2'deoxyuridine. 
Table 3.5: Equilibrium Association Constants for Two Triple Helix Forming Oligonucleotides Binding at Adjacent Sites on DNA as a Function of a Series of 5-Substituted Bases at the 3'-End of the Junction ${ }^{a}$

\begin{tabular}{|c|c|c|c|c|}
\hline Stack & $\begin{array}{c}\text { Oligo- } \\
\text { nucleotide }\end{array}$ & $\begin{array}{c}K \\
\left(M^{-1}\right) \\
\end{array}$ & $K_{11+11} / K_{11}$ & $\begin{array}{c}\mathrm{E}_{\mathrm{coop}} \\
\left(\mathrm{kcal} \cdot \mathrm{mol}^{-1}\right)\end{array}$ \\
\hline $5^{\prime}-\mathrm{mCd}^{\mathrm{d}} \mathrm{U}-3^{\prime}$ & $\begin{array}{l}3 \\
3+10(5 \mu \mathrm{M})\end{array}$ & $\begin{array}{l}1.1 \times 10^{6} \\
6.2 \times 10^{7}\end{array}$ & 56 & 2.8 \\
\hline $5^{\prime}-\mathrm{mCT}-3^{\prime}$ & $\begin{array}{l}3 \\
3+2(5 \mu \mathrm{M}) \\
\end{array}$ & $\begin{array}{l}1.1 \times 10^{6} \\
1.4 \times 10^{8} \\
\end{array}$ & 127 & 2.9 \\
\hline $5^{\prime}-\mathrm{m}_{C^{\mathrm{P}}}{ }^{\mathrm{U}-3^{\prime}}$ & $\begin{array}{l}3 \\
3+8(5 \mu \mathrm{M})\end{array}$ & $\begin{array}{l}1.1 \times 10^{6} \\
2.2 \times 10^{8}\end{array}$ & 204 & 3.2 \\
\hline
\end{tabular}

a Values reported in the table are mean values measured from affinity cleavage titration experiments performed in Association buffer $(10 \mathrm{mM}$ Bis-Tris $\bullet \mathrm{HCl}, 10 \mathrm{mM} \mathrm{NaCl}, 250 \mu \mathrm{M}$ spermine, $\left.\mathrm{pH} 7.0,24{ }^{\circ} \mathrm{C}\right)$. d $\mathrm{U}$ designates 2'-deoxyuridine; ${ }^{\mathrm{P}} \mathrm{U}$ designates 5-(1-propynyl)-2'-deoxyuridine.

affords a value of $2.8 \mathrm{kcal} \cdot \mathrm{mol}^{-1}$ for $\mathrm{E}_{\mathrm{coop}}$ between oligonucleotides 3 and $\mathbf{1 0}$.

Cooperative Binding of Two 11mers in the Presence of a 5'-mCT-3' Stack. Data pertaining to this system is described in the Results section of this chapter. Briefly, the binding enhancement $K_{3+2, G A} / K_{3, G A}$ is a factor of 127 , and $E_{c o o p}$ between oligonucleotides 3 and 2 is $2.9 \mathrm{kcal} \cdot \mathrm{mol}^{-1}$ (Table 3.5, Figure 3.7B).

Cooperative Binding of Two 11 mers in the Presence of a $5^{\prime}-m C^{p} U-3^{\prime}$ Stack. Analysis of cleavage data performed on the GA DNA fragment yielded equilibrium association constants of $1.1 \times 10^{6} \mathrm{M}^{-1}$ for 3 binding alone $\left(K_{3, G A}\right)$ and $2.2 \times 10^{8} \mathrm{M}^{-1}$ for 3 binding in the presence of $5.0 \mu \mathrm{M} 8\left(K_{3+8, G A}\right)$ (Table 3.5, Figure 3.7C). The equilibrium association constant of 9 was found to be $3.8 \times 10^{6} \mathrm{M}^{-1}$. The binding enhancement $K_{3+8, G A} / K_{1, G A}$ is a factor of 204 . Substitution of the values $204,3.8 \times 10^{6} \mathrm{M}^{-1}$, and $5 \times 10^{-6} \mathrm{M}^{-1}$ for $\Phi, K_{B}$, and [ $\left.\mathrm{L}_{B}\right]$, respectively, in 
equation 1 affords a value of $3.2 \mathrm{kcal} \cdot \mathrm{mol}^{-1}$ for $\mathrm{E}_{\mathrm{coop}}$ between oligonucleotides 3 and 8.

Summary. The results described above indicate that the effect of a propynyl group located at either the 5'- or 3'-end of the triplex junction on the observed interaction energy is significant, although not to a great extent (Table 3.4). ${ }^{13}$ In addition, the cooperative interaction energy between oligonucleotides bound at adjacent DNA sites does not change greatly when the 5-substituent of the base at the 3 '-side of the junction is changed from a hydrogen to a methyl and finally to a propynyl group (Table 3.5). These combined results are consistent with the hypothesis that hydrophobic interactions may not be as important as electrostatic ones to the cooperative binding of oligonucleotides at adjacent DNA sites by triple helix formation. The idea that aromatic stacking interactions in aqueous solutions arise mostly from charge-charge interactions rather than classical hydrophobic effects or dispersion forces has been reported recently. ${ }^{14}$ 


\section{Experimental Section}

General. E. coli JM110 was obtained from Stratagene. Qiagen plasmid kits were purchased from Qiagen Inc. Sonicated, deproteinized calf thymus DNA was purchased from Pharmacia. Nucleotide triphosphates were obtained from Pharmacia. Nucleotide triphosphates labeled with ${ }^{32} \mathrm{P}(\geq 3000 \mathrm{Ci} / \mathrm{mmol})$ were purchased from Amersham. Restriction endonucleases were purchased from New England Biolabs or Boehringer Mannheim, and used according to the suggested protocol in the provided buffer. Thymidine, 5-methyl-2'-deoxycytidine, and 2'-deoxyuridine phosphoramidites were obtained from Glen Research. The 5'-O-DMT-protected phosphoramidite derivative of 5-(1-propynyl)-2'deoxyuridine was synthesized as described (see also Chapter Four). ${ }^{15}$ Sephadex resins were obtained from Pharmacia. Sequenase Version 2.0 was obtained from United States Biochemical.

Construction of pMD5152, pNCAG, pNCGA, and pNCGG. These plasmids were prepared by standard methods. ${ }^{16}$ Briefly, pMD5152 was prepared by hybridization of two synthetic oligonucleotides, $5^{\prime}$-d(ACGTTCCTAAAAAAGGAAAAAAAAGAGAGAGAGATCTG)-3' and $5^{\prime}$-d(GATCCAGATCTCTCTCTCTTTTTTTTCCTTTTTTAGGA)-3', followed by ligation of the resulting duplex with pUC18 DNA previously digested with HindIII and BamHI; this ligation mixture was used to transform E. coli JM110 (Stratagene). Plasmid DNA from ampicillin resistant, white colonies was isolated and the presence of the desired insert confirmed by restriction analysis and Sanger sequencing. Preparative isolation of plasmid DNA was performed using a Qiagen plasmid kit. Similar procedures were used to prepare plasmid pNCAG with the oligonucleotides 5'-d(AGCTTCCTAAAAAAGGAAAGAAAAAGAGAGAGAGATCTG)-3' and 5'-d(GATCCAGATCTCTCTCTCTTTTTCTTTCCTTTTTTAGGA)-3' ${ }^{\prime}$, plasmid pNCGA with the oligonucleotides 5'-d(AGCTTCCTAAAAAAGGAAGAAAAAAGAGAGAGAG- 
ATCTG)-3' and 5'-d(GATCCAGATCTCTCTCTCTTTTTTCTTCCTTTTTTAGGA)-3', and plasmid pNCGG with the oligonucleotides 5'-d(AGCTTCCTAAAAAAGGAAGGAAAAAGAGAGAGAGATCTG)-3' and 5'-d(GATCCAGATCTCTСTCTCTTTTCCTTTCCTTTTTTAGGA)-3'.

Oligonucleotide Preparation. Oligonucleotides were synthesized by standard automated solid-support chemistry on an Applied Biosystems Model 380B DNA synthesizer using O-cyanoethyl- $N, N$-diisopropyl phosphoramidites. ${ }^{17}$ The phosphoramidite of the Amino-Modifier-dT (5'-dimethoxytrityl-5-[Ntrifluoroacetylaminoethyl)-3-acrylimido]-2'-deoxyuridine,3'-[(2-cyanoethyl)( $N, N$-diisopropyl]-phosphoramidite) purchased from Glen Research was incorporated at the 5'-terminus of oligonucleotides 1 and 3 during oligonucleotide synthesis. Controlled pore glass derivatized with thymidineEDTA $\left(T^{*}\right)$ was prepared as described by Strobel. ${ }^{18}$ All oligonucleotides except $5,6,7,9$, and 11 , were deprotected with concentrated ammonium hydroxide at 55 ${ }^{\circ} \mathrm{C}$ for $24 \mathrm{~h}$, and dried in vacuo. Oligonucleotides $5,6,7,9$, and 11 containing $\mathrm{T}^{*}$ at the $3^{\prime}$-end were deprotected with $0.1 \mathrm{~N} \mathrm{NaOH}$ at $55^{\circ} \mathrm{C}$ for $24 \mathrm{~h}$. The crude 5'terminal-dimethoxytrityl protected oligonucleotides were purified by reverse phase FPLC on a ProRPC 10/10 $\left(\mathrm{C}_{2}-\mathrm{C}_{8}\right)$ column (Pharmacia LKB) and a gradient of $0-40 \% \mathrm{CH}_{3} \mathrm{CN}$ in $0.1 \mathrm{M}$ triethylammonium acetate, $\mathrm{pH} 7.0$, detritylated in $80 \%$ $\mathrm{AcOH}$, and chromatographed a second time. Oligonucleotides 1 and 3 containing the Amino-Modifier-dT were dissolved in a $0.4 \mathrm{M} \mathrm{NaHCO}_{3}$ solution, and added to an Eppendorf tube containing $13.6 \mathrm{mg}(50 \mu \mathrm{mol})$ of EDTAmonoanhydride. The reaction mixtures were vortexed at room temperature for 30 minutes, filtered through Centrex, and purified by ion-exchange FPLC on a Mono Q 10/10 column (Pharmacia LKB) and a gradient of 0.2-2 $\mathrm{M} \mathrm{NH}_{4} \mathrm{OAc}, \mathrm{pH}$ 7.0. Oligonucleotides 1 and 3 were desalted on Pharmacia NAP-25 columns and dried in vacuo. All other oligonucleotides were desalted via repeated 
resuspensions of the oligonucleotides in water followed by lyophilization. Concentrations of oligonucleotides not containing 5-(1-propynyl)-2'-deoxyuridine were determined by UV absorbance at $260 \mathrm{~nm}$ using extinction coefficients $\left(\mathrm{M}^{-1} \mathrm{~cm}^{-1}\right)$ of 8800 ( $\mathrm{d} \mathrm{U}, \mathrm{T}$ and $\mathrm{T}^{*}$ derivative from Glen Research's Amino-Modifier-dT) and $5700(\mathrm{~m} C)$. Concentrations of oligonucleotides containing 5-(1-propynyl)-2'-deoxyuridine were determined by UV absorbance at $280 \mathrm{~nm}$ using extinction coefficients $\left(\mathrm{M}^{-1} \mathrm{~cm}^{-1}\right)$ of 6400 ( $\mathrm{T}$ and $\mathrm{T}^{*}$ derivative from Glen Research's Amino-Modifier-dT), 8300 (mC), and 9700 ( $\left.{ }^{\mathrm{P}} \mathrm{U}\right)$.

Preparation of Labeled Restriction Fragment. The 3'-32P-labeled duplex was prepared by digestion of the desired plasmid with EcoRI, followed by treatment with $\alpha-32$ P-dATP and $\alpha-32$ P-TTP in the presence of Sequenase. To remove nonincorporated radioactivity, the fragment was passed through a Pharmacia NICK column. The DNA was then digested with $\mathrm{XmnI}$, followed by separation of the resulting products on a 5\% nondenaturing polyacrylamide gel (19:1, monomer/bis). The gel band corresponding to the desired 850-bp fragment was visualized by autoradiography, excised, crushed, and soaked in $10 \mathrm{mM}$ Tris, $\mathrm{pH}$ 8.0, and $20 \mathrm{mM}$ EDTA, at $37^{\circ} \mathrm{C}$ for $15-18 \mathrm{~h}$. The resulting suspension was filtered through a $0.45-\mu \mathrm{m}$ filter, and the eluted DNA present in the supernatant was precipitated with $\mathrm{NaOAc} / \mathrm{EtOH}$. The DNA pellet was washed with $70 \% \mathrm{EtOH}$, dried in vacuo, resuspended in TE buffer (10 mM Tris, pH 8.0, 1 mM EDTA), extracted four times with phenol, twice with $24: 1 \mathrm{CHCl}_{3} /$ isoamyl alcohol, and reprecipitated with $\mathrm{NaOAc} / \mathrm{EtOH}$. The DNA pellet was washed with $70 \%$ EtOH, dried in vacuo, and resuspended in $10 \mathrm{mM}$ Bis-Tris $\bullet \mathrm{HCl}, 100 \mathrm{mM} \mathrm{NaCl}$, $\mathrm{pH} 7.0$ at a final activity of $100,000 \mathrm{cpm} / \mu \mathrm{L}$, and was stored at $-20^{\circ} \mathrm{C}$.

Quantitative Affinity Cleavage Titrations. In a typical experiment, a $5 \mathrm{nmol}$ aliquot of the desired oligonucleotide-EDTA was dissolved in $50 \mu \mathrm{L}$ of aqueous $200 \mu \mathrm{M} \mathrm{Fe}\left(\mathrm{NH}_{4}\right)_{2}\left(\mathrm{SO}_{4}\right)_{2} \bullet 6 \mathrm{H}_{2} \mathrm{O}$ to produce a solution that was $100 \mu \mathrm{M}$ in 
oligonucleotide. This solution was then diluted serially to yield $100 \mu \mathrm{M}, 10 \mu \mathrm{M}, 1$ $\mu \mathrm{M}, 100 \mathrm{nM}, 10 \mathrm{nM}, 1 \mathrm{nM}$ and $100 \mathrm{pM}$ solutions. The appropriate volume of these solutions was then distributed among 14-16 $1.5 \mathrm{~mL}$ microcentrifuge tubes at the appropriate concentrations. A stock solution containing labeled target DNA, Bis-Tris $\bullet \mathrm{HCl}$ buffer, $\mathrm{NaCl}$, calf thymus DNA, the second oligonucleotide where needed, and water, was distributed to each reaction tube in $12 \mu \mathrm{L}$ aliquots, and the appropriate volume of water and $4 \mu \mathrm{L}$ of $250 \mu \mathrm{M}$ spermine were added to each tube to bring the total volume to $36 \mu \mathrm{L}$. The oligonucleotideEDTA $\bullet \mathrm{Fe}$ (II) and the DNA were allowed to equilibrate for $24 \mathrm{~h}$ at $24^{\circ} \mathrm{C}$. After 21 h, $2 \mu \mathrm{L}$ of $100 \mu \mathrm{M} \mathrm{Fe}\left(\mathrm{NH}_{4}\right)_{2}\left(\mathrm{SO}_{4}\right)_{2} \cdot 6 \mathrm{H}_{2} \mathrm{O}$ were added to each tube. The cleavage reactions were initiated by the addition of $2 \mu \mathrm{L}$ of a $80 \mathrm{mM}$ aqueous DTT solution to each tube. Final reaction conditions in $40 \mu \mathrm{L}$ of Association buffer were 10 $\mathrm{mM}$ Bis-Tris $\bullet \mathrm{HCl}$ at $\mathrm{pH} 7.0,10 \mathrm{mM} \mathrm{NaCl}, 250 \mu \mathrm{M}$ spermine, $100 \mu \mathrm{M}$ bp calf thymus DNA, $4 \mathrm{mM}$ DTT, and approximately 10,000 cpm labeled DNA. The reactions were incubated for $2 \mathrm{~h}$ at $24^{\circ} \mathrm{C}$. Cleavage reactions were terminated by $\mathrm{NaOAc} / \mathrm{EtOH}$ precipitation. The precipitated DNA cleavage products were dissolved in $35 \mu \mathrm{L}$ of water, and dried in vacuo. The DNA was then resuspended in $10 \mu \mathrm{L}$ of formamide-TBE loading buffer, and heated at $55^{\circ} \mathrm{C}$ for 10 minutes to effect dissolution. The Cerenkov radioactivity of the solutions was measured with a scintillation counter. The DNA was denatured at $95^{\circ} \mathrm{C}$ for 3 minutes, and $5 \mu \mathrm{L}$ from each sample were loaded onto a $8 \%$ denaturing polyacrylamide gel.

Construction of Titration Binding Isotherms. Gels were exposed to photostimulable storage phosphor imaging plates (Kodak Storage Phosphor Screen S0230 obtained from Molecular Dynamics) in the dark at $24{ }^{\circ} \mathrm{C}$ for $8-24$ h. ${ }^{19}$ A Molecular Dynamics 400S PhosphorImager was used to obtain data from the phosphorimaging screens. Rectangles of the same dimensions were drawn around the cleavage bands at the target and at the references sites. The 
ImageQuant v. 3.0 program running on an AST Premium 386/33 computer was used to integrate the volume of each rectangle.

Affinity Cleavage Titration Fitting Procedure. For a detailed description of the affinity cleavage titration procedure, see Chapter Two. 6

Electrostatic Potential Calculations. AM1 electrostatic potential surfaces calculations were performed at the semi-empirical level using the program Spartan running on a Silicon Graphics computer. 


\section{References and Notes}

1. (a) Ptashne, M. A Genetic Switch; Blackwell Scientific Publications and Cell Press: Palo Alto, CA, 1986. (b) Cantor, C. R.; Schimmel, P. R. Biophysical Chemistry Part III: The Behavior of Biological Macromolecules; W. H. Freeman and Co.: New York, N. Y., 1980. (c) Hill, T. L. Cooperativity Theory in Biochemistry: Steady State and Equilibrium Systems; Springer-Verlag: New York, N. Y., 1985. (d) Adhya, S. Annual Reviews in Genetics 1989, 23, 227.

2. (a) Strobel, S. A.; Dervan, P. B. J. Am. Chem. Soc. 1989, 111, 6956. (b) Colocci, N.; Distefano, M. D.; Dervan, P. B. J. Am. Chem. Soc. 1993, 115, 4468. (c) Colocci, N.; Dervan, P. B. J. Am. Chem. Soc. 1994, 116, 785.

3. (a) Distefano, M. D.; Shin, J. A.; Dervan, P. B. J. Am. Chem. Soc. 1991, 113, 5901. (b) Distefano, M. D.; Dervan, P. B. J. Am. Chem. Soc. 1992, 114, 11006. (c) Distefano, M. D.; Dervan, P. B. Proc. Natl. Acad. Sci. USA 1993, 90, 1179.

4. Froehler, B. C.; Wadwani, S.; Terhorst, T. J.; Gerrard, S. R. Tetrahedron Lett. $1992,33,5307$.

5. Mergny, J. L.; Duval-Valentin, G.; Nguyen, C. H.; Perrouault, L.; Faucon, B.; Rougée, M.; Montenay-Garestier, T.; Bisagni, E.; Helène, C. Science $1992,256,1681$.

6. (a) Singleton, S. F.; Dervan, P. B. J. Am. Chem. Soc. 1992, 114, 6956. (b) Singleton, S. F.; Dervan, P. B. Biochemistry 1992, 31, 10995. (c) Singleton, S. F.; Dervan, P. B. Biochemistry 1993, 32, 13171. (d) Singleton, S. F.; Dervan, P. B. J. Am. Chem. Soc. 1994, 116, 10376.

7. For syntheses of several modified thymidines with a short linker-EDTA at the 5-position, see (a) Dreyer, G. B.; Dervan, P. B. Proc. Natl. Acad. Sci. USA 
1985, 82, 968. (b) Han, H.; Dervan, P. B. Nucleic Acid Res. 1994, 22, 2837. (c) Glen Research Corporation, 44901 Falcon Place, Sterling, VA 22170.

8. Thymidine-EDTA is designated $\mathrm{T}^{*}$. For details of linker composition see Experimental Section. ${ }^{7}$

9. (a) The association constant of oligonucleotide 5 binding to site $B$ on the GA plasmid was determined to be $4.3( \pm 1.1) \times 10^{6} \mathrm{M}^{-1}$. (b) The association constant of oligonucleotide 5 binding to site D on the AG plasmid was determined to be $5.3( \pm 0.3) \times 10^{5} \mathrm{M}^{-1}$. (c) The association constant of oligonucleotide 5 binding to site $\mathrm{B}$ on the AA plasmid was determined to be $2.8( \pm 0.1) \times 10^{6} \mathrm{M}^{-1}$. (d) The association constant of oligonucleotide 5 binding to site D on the GG plasmid was determined to be $7.1( \pm 0.4) \times 10^{5}$ $\mathrm{M}^{-1}$.

10. (a) Sowers, L. C.; Shaw, B. R.; Sedwick, W. D. Biochem. Biophys. Res. Commun. 1987, 148, 790. (b) DeVoe, H.; Tinoco, I. J. Mol. Biol. 1962, 4, 500. (c) Sanyal, N. K.; Roychoudhury, M.; Ruhela, K. R.; Tiwari, S. N. J. Comput. Chem. 1986, 8, 604. (d) Ornstein, R. L.; Rein, R.; Breen, D. L.; MacElroy, R. D. Biopolymers 1978, 17, 2341. (e) Broom, A. D.; Schweizer, M. P.; Ts'o, P. O. P. J. Am. Chem. Soc. 1967, 89, 3612. (f) Ts'o, P. O. P. Molecular Associations in Biology; Academic Press: New York, N. Y., 1968, pp 39-75. (g) Nakano, N. I.; Igarishi, S. J. Biochemistry 1970, 9, 577. (h) Breslauer, K. J.; Frank, R.; Blocker, H.; Marky, L. A. Proc. Natl. Acad. Sci. USA 1986, 83, 3746. (i) Delcourt, S. G.; Blake, R. D. J. Biol. Chem. 1991, 266, 15160. (j) Herskovitz, T. T. Arch. Biochem. Biophys. 1962, 97, 474. (k) Herskovitz, T. T. Biochemistry $1963,2,335$.

11. Spartan Version 2.0, Wavefunction, Inc., 18401 Von Karman Ave., Suite 210, Irvine, CA 92715. 
12. (a) Arnott, S.; Bond, P. J.; Selsing, E.; Smith, P. J. C. Nucleic Acids Res. 1976, 3, 2459. (b) Saenger, W. Principles of Nucleic Acid Structure; SpringerVerlag: New York, N. Y., 1984.

13. Previous experiments showed that the incorporation of several 5-(1propynyl)-2'-deoxyuridines into 8mer oligodeoxyribonucleotides dramatically increased the cooperativity between them, as compared to that observed between the corresponding unsubstituted oligonucleotides (see Chapter Four). These results might be due to some dependence of cooperativity on the length of the oligonucleotides.

14. Newcomb, L. F.; Gellman, S. H. J. Am. Chem. Soc. 1994, 116, 4993.

15. Froehler, B. C.; Wadwani, S.; Terhorst, T. J.; Gerrard, S. R. Tetrahedron Lett. $1992,33,5307$.

16. Sambrook, J.; Fritsch, E. F.; Maniatis, T. Molecular Cloning; 2nd ed.; Cold Spring Harbor Laboratory Press: New York, N. Y., 1989.

17. Gait, M. J. (Ed.) Oligonucleotide Synthesis: A Practical Approach; IRL Press: Oxford, 1984.

18. Strobel, S. A. Ph. D. Dissertation, California Institute of Technology, Pasadena, CA, 1992.

19. Johnston, R. F.; Pickett, S. C.; Barker, D. L. Electrophoresis 1990, 11, 355. 


\section{CHAPTER FOUR:}

\section{Cooperative Binding of Short Oligonucleotides Containing 5-(1-Propynyl)-2'-deoxyuridine to Adjacent DNA Sites by Triple Helix Formation.}

\section{Introduction}

The design of cooperative domains between DNA binding ligands for modulation of the kinetics and thermodynamics of ligand-nucleic acid interactions is at an early stage of development. ${ }^{1-4}$ Pyrimidine oligodeoxyribonucleotides 11-nt in length are known to bind cooperatively to abutting sites on double-helical DNA by triple helix formation, resulting in a 20-fold increase in the association constant for one oligonucleotide in the presence of the neighboring oligonucleotide. ${ }^{3}$ This $1.8 \mathrm{kcal} \bullet \mathrm{mol}^{-1}$ interaction energy may arise from $\pi$ stacking between the bases at the triple-helical junction. ${ }^{3}$ The incorporation of discrete dimerization domains to oligonucleotides such as those capable of forming a short Watson-Crick helix produces a cooperative interaction and results in a 44-fold enhancement in the association constant of one oligonucleotide in the presence of a neighbor. ${ }^{2}$

An alternative approach to increasing cooperativity by the addition of dimerization domains is the use of modified bases, which could allow greater interactions between bases at the triple-helical junction. It is known that replacing 2 -deoxycytidine in the third strand with 5-methyl-2'-deoxycytidines, and replacing 2 -deoxyuridines with thymidines, 5-ethynyl-2'-deoxyuridines or 5-(1-propynyl)-2'-deoxyuridines increases the stability of triple-helical complexes.5,6 If this enhanced stability is due to increased stacking in the third 
104

strand, one might expect similar effects at triple helix junctions. We report here that two short oligodeoxyribonucleotides containing 5-(1-propynyl)-substituted 2 -deoxyuridine $\left({ }^{\mathrm{P}} \mathrm{U}\right)$ and 5-methyl-2'-deoxycytidine $\left(\mathrm{m}_{\mathrm{C}}\right)$ bind cooperatively to adjacent sites on double-helical DNA at micromolar concentrations (10 mM BisTris $\bullet \mathrm{HCl}$ at $\mathrm{pH} 7.0,10 \mathrm{mM} \mathrm{NaCl}, 1 \mathrm{mM}$ spermine, $24^{\circ} \mathrm{C}$ ) (Figure 4.1). These results prompted the question whether the strong cooperative forces between 8mer oligonucleotides containing 5-(1-propynyl)-modified bases would allow even shorter oligonucleotide analogs to bind cooperatively to three consecutive sites on DNA. We describe here the first example of a system in which three hexamers containing 5-(1-propynyl)-2'-deoxyuridines bind cooperatively to three adjacent sites covering a specific 18-bp region on double-helical DNA by triple helix formation at near micromolar concentrations $(10 \mathrm{mM}$ Bis-Tris $\bullet \mathrm{HCl}$ at $\mathrm{pH}$ 7.0, $10 \mathrm{mM} \mathrm{NaCl}, 1 \mathrm{mM}$ spermine, $24^{\circ} \mathrm{C}$ ) (Figure 4.2).

\section{Results}

Cooperative Binding of Two 8mer Oligonucleotide Analogs Containing 5(1-Propynyl)-2'-deoxyuridine. A system was designed in which two 8-nt oligodeoxyribonucleotides, 1 and 2, bind site-specifically to adjacent sites on an 850-bp 3'-32P-end-labeled duplex DNA fragment via specific Hoogsteen hydrogen bonding ( ${ }^{\mathrm{P}} \mathrm{U} \bullet \mathrm{AT}$ and $\mathrm{m}_{\mathrm{C}}+\mathrm{GC}$ ) (Figure 4.1). Thymidine-EDTA $\left(\mathrm{T}^{*}\right)$ was incorporated at the 5 '-terminus of oligonucleotide 1 to allow thermodynamic analysis of site-specific binding using the quantitative affinity cleavage titration method.7,8 To determine the interaction energy between oligonucleotides 1 and 2 , the equilibrium association constants $K_{1}$ for 1 binding to site $\mathrm{A}$ alone, and $K_{1+2}$ for 1 binding to site $A$ in the presence of $1.0 \mu \mathrm{M} 2$ bound to neighboring site $B$ were measured. 3,8 Analysis of cleavage data yielded equilibrium association constants of $<2 \times 10^{4} \mathrm{M}^{-1}$ for 1 binding alone $\left(K_{1}\right)$ and $8.0( \pm 2.1) \times 10^{5} \mathrm{M}^{-1}$ for 1 in 


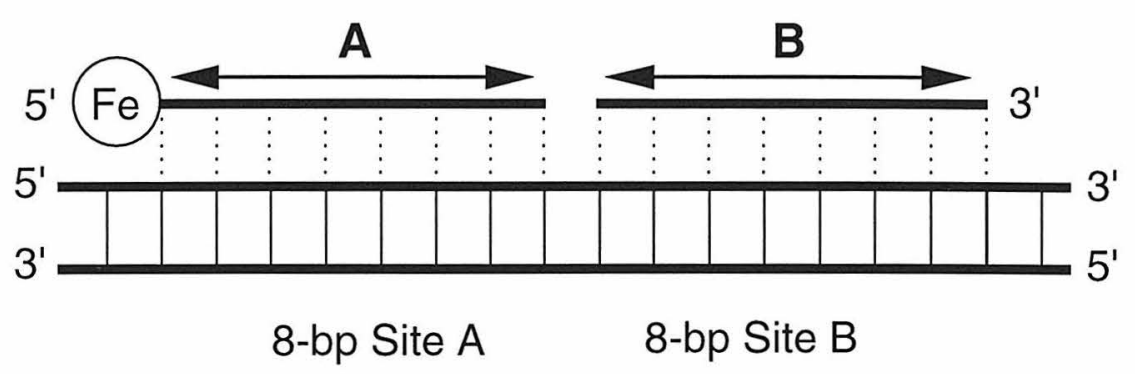

5'-A A A A A G A A A A A A A A A A G A-3'

3'-T T T TT T C C T T T T T T TC T C TC T C T-5'
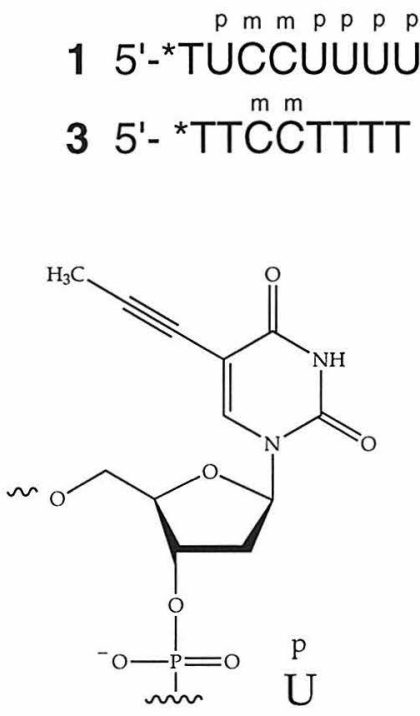

p p p p m p m

2 5'-UUUUCUCT

4 5'- TTTTC ${ }^{m}{ }^{m}{ }^{m} T$

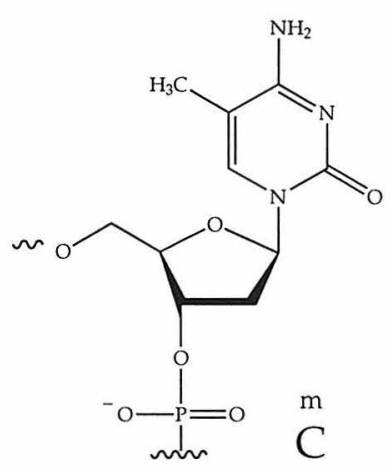

Figure 4.1. Schematic representation of a complex composed of two triple helix forming oligonucleotides binding at adjacent sites on double-helical DNA. Thick solid lines represent the DNA backbone of the target site and associated oligonucleotides. Thin solid lines represent Watson-Crick hydrogen bonds while dashed lines indicate Hoogsteen hydrogen bonds. Binding of the oligonucleotides is assessed by affinity cleavage using $T^{*}$. ${ }^{P} U$ and ${ }^{m} C$ represent 5-(1propynyl)-2'-deoxyuridine and 5-methyl-2'-deoxycytidine nucleotides, respectively. 


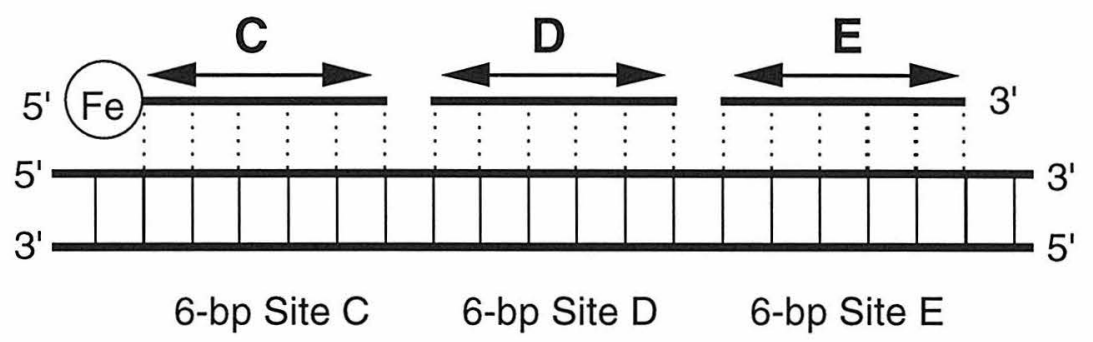

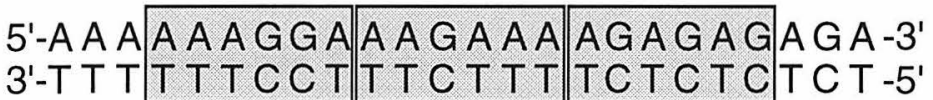

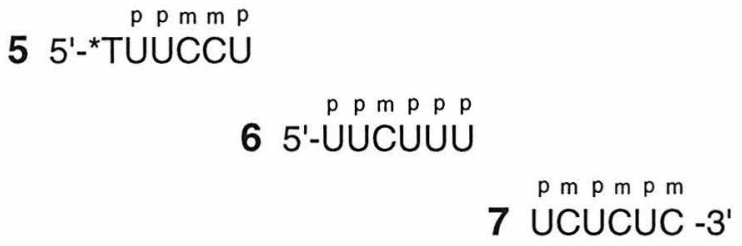

Figure 4.2. Schematic representation of a complex composed of three triple helix forming oligonucleotides binding to adjacent sites on double-helical DNA. PU and ${ }^{m} \mathrm{C}$ designate 5-(1-propynyl)-2'deoxyuridine and 5-methyl-2'-deoxycytidine, respectively. 
Table 4.1: Equilibrium Association Constants for 8mer Modified Triple Helix Forming Oligonucleotides Binding at Adjacent Sites on $\mathrm{DNA}^{a}$

\begin{tabular}{lc}
\hline Oligonucleotide & $K\left(\mathrm{M}^{-1}\right)$ \\
\hline $\mathbf{1}$ & $<2 \times 10^{4}$ \\
$\mathbf{1}+\mathbf{2}(1.0 \mu \mathrm{M})$ & $8.0( \pm 2.1) \times 10^{5}$ \\
$\mathbf{1}+\mathbf{4}(1.0 \mu \mathrm{M})$ & $<2 \times 10^{4}$ \\
3 & $<2 \times 10^{4}$ \\
$3+\mathbf{2}(1.0 \mu \mathrm{M})$ & $9.7( \pm 0.6) \times 10^{4}$ \\
\hline$a$ Values reported in the table are mean values measured \\
from affinity cleavage titration experiments performed in \\
Association buffer $(10 \mathrm{mM}$ Bis-Tris $\bullet \mathrm{HCl}, 10 \mathrm{mM} \mathrm{NaCl}, 1$ \\
mM spermine, $\left.\mathrm{pH} 7.0,24^{\circ} \mathrm{C}\right)$.
\end{tabular}

the presence of $1.0 \mu \mathrm{M} 2\left(K_{1+2}\right)$, resulting in a dramatic binding enhancement $K_{1+2} / K_{1}>40$ (Table 4.1, Figure 4.3). ${ }^{9}$ This corresponds to a cooperative interaction energy of $>4.5 \mathrm{kcal} \cdot \mathrm{mol}^{-1} .10$

For comparison, binding of the corresponding unmodified oligonucleotides 3 and 4, containing a methyl (thymidine) instead of a propynyl group at the 5position of 2'-deoxyuridine, was analyzed under the same conditions (Figure 4.1). Oligonucleotide 3 at $\leq 100 \mu \mathrm{M}$ both in the absence and in the presence of 1.0 $\mu \mathrm{M} 4$ did not produce any observable cleavage, and therefore no cooperativity could be measured.11,12

Cooperative Binding of Three 6mer Oligonucleotide Analogs Containing 5(1-Propynyl)-2'-deoxyuridine. A system was designed in which three hexanucleotides, 5, 6, and 7, bind site-specifically to adjacent sites on an 850-bp 3'-32Pend-labeled duplex DNA fragment via specific Hoogsteen hydrogen bonding $\left(\mathrm{PU} \bullet \mathrm{AT}\right.$ and ${ }^{\mathrm{m}} \mathrm{C}+\mathrm{GC}$ ) (Figure 4.2). $\mathrm{T}^{*}$ was incorporated at the $5^{\prime}$-terminus of 


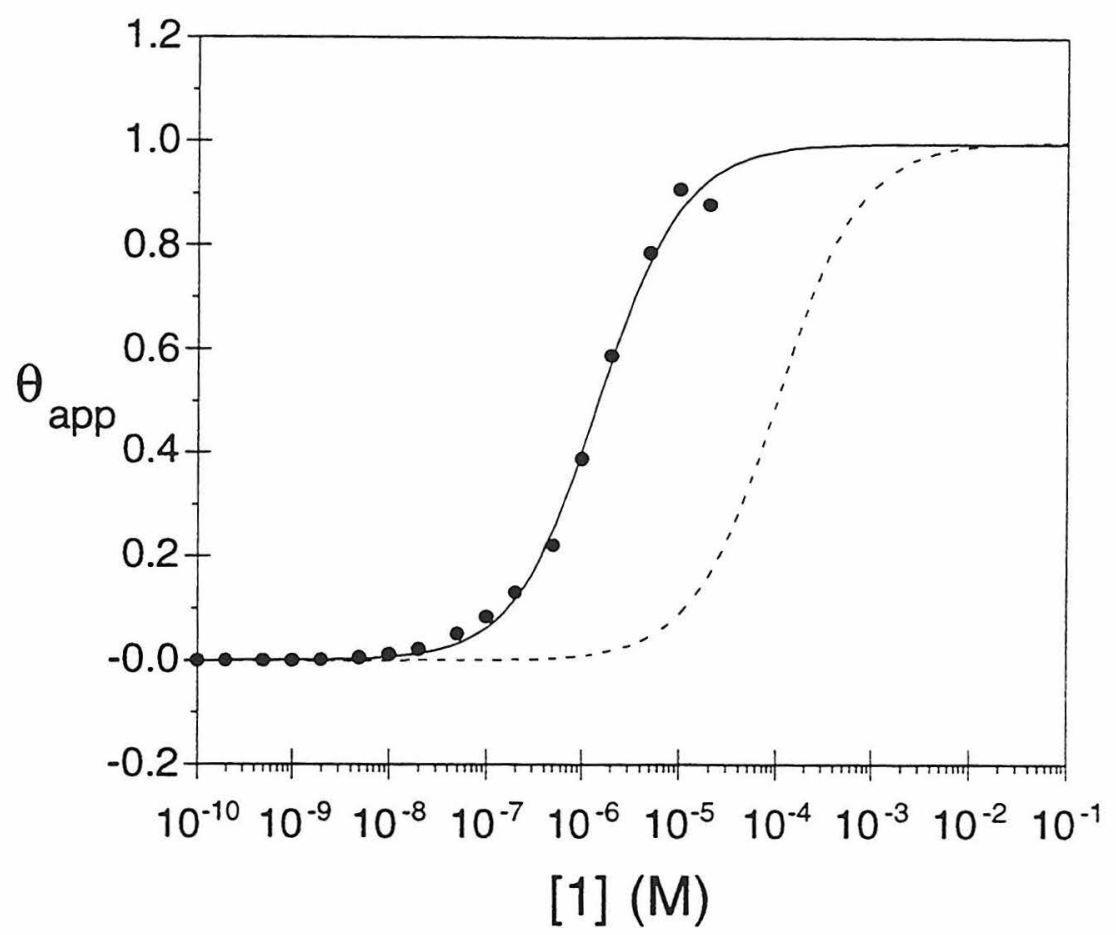

Figure 4.3. Binding isotherms obtained for oligonucleotide 1 alone (dashed line), and in the presence of $1.0 \mu \mathrm{M}$ oligonucleotide 2 bound to DNA $(\bullet)$. The dashed sigmoidal curve represents the theoretical titration binding isotherm obtained for oligonucleotide 1 binding alone; the solid sigmoidal curve represents the titration binding isotherm obtained for oligonucleotide 1 binding in the presence of oligonucleotide 2 . The data shown was obtained using the quantitative affinity cleavage titration method as described in Chapter Two. 
oligonucleotide 5 to allow thermodynamic analysis of site-specific binding using the quantitative affinity cleavage titration method.7,8 Affinity cleavage experiments show that oligonucleotide 5 at $<10 \mu \mathrm{M}$, and in the presence of nonneighboring $7(1.0 \mu \mathrm{M})$ does not produce any observable binding and cleavage (Figure 4.4, Lane 10). Reaction of $1.0 \mu \mathrm{M} 5$ in the presence of $1.0 \mu \mathrm{M} 6$ affords very low levels of binding and cleavage, revealing that some cooperativity occurs between the two adjacent $6 \mathrm{mer}$ oligonucleotides at $1.0 \mu \mathrm{M}$ each (Figure 4.4, Lane 2). Upon addition of $1 \mathrm{nM}$ and $10 \mathrm{nM} 7$, very little cleavage is produced (Figure 4.4, Lanes 3 and 4). Upon addition of $100 \mathrm{nM} \mathrm{7,} \mathrm{a} \mathrm{dramatic}$ increase in cleavage by $6 \mathrm{mer} 5$ occurs (Figure 4.4, Lane 5). At $1.0 \mu \mathrm{M}$ and $10 \mu \mathrm{M}$ 7, further increases in cleavage are observed (Figure 4.4, Lanes 6 and 7). Thus a modest increase in the concentration of $\mathbf{7}$ can significantly increase the affinities of oligonucleotides 5 and 6 for their sites.

To determine the magnitude of the binding enhancements, the equilibrium association constants $K_{5}$ for 5 binding to site $C$ alone, $K_{5+6}$ for 5 binding to site $C$ in the presence of $5.0 \mu \mathrm{M} 6$ bound to neighboring site $D$, and $K_{5+6+7}$ for 5 binding in the presence of both $5.0 \mu \mathrm{M} 6$ and 7 were measured. ${ }^{8}$ Analysis of cleavage data yielded values of $<10^{4} \mathrm{M}^{-1}\left(K_{5}\right), 2.1( \pm 0.2) \times 10^{5} \mathrm{M}^{-1}\left(K_{5+6}\right)$, and $8.9( \pm 0.2) \mathrm{x}$ $10^{5} \mathrm{M}^{-1}\left(K_{5+6+7}\right)$, respectively (Table 4.2$)$. These results show that the presence of $5 \mu \mathrm{M}$ oligonucleotide 6 increases the affinity of 5 for its site at least 21 -fold. The addition of $5 \mu \mathrm{M}$ oligonucleotide 7 further enhances the binding of 5 by a factor of 4.2 .

\section{Discussion}

Possible sources for the cooperative interaction between oligonucleotides containing 5-(1-propynyl)-2'-deoxyuridines include a structural transition between adjacent sites on DNA and increased base stacking between the 
Figure 4.4. Autoradiogram of an $8 \%$ denaturing polyacrylamide gel of reaction products from affinity cleavage reactions with oligonucleotides 5, 6, and 7 and a ${ }^{32} \mathrm{P}$-labeled restriction fragment containing the target sites shown in Figure 4.2. The reactions were performed at $24^{\circ} \mathrm{C}$ in $10 \mathrm{mM}$ Bis-Tris $\cdot \mathrm{HCl}$ at $\mathrm{pH} 7.0,10 \mathrm{mM}$ $\mathrm{NaCl}, 1 \mathrm{mM}$ spermine. Lane 1, A-specific sequencing reaction; lane 2, oligonucleotides 5 and 6 at $1 \mu \mathrm{M}$ each; lane 3, oligonucleotides 5 and 6 at $1 \mu \mathrm{M}$ each, oligonucleotide 7 at $1 \mathrm{nM}$; lane 4 , oligonucleotides 5 and 6 at $1 \mu \mathrm{M}$ each, oligonucleotide 7 at $10 \mathrm{nM}$; lane 5, oligonucleotides 5 and 6 at $1 \mu \mathrm{M}$ each, oligonucleotide 7 at $100 \mathrm{nM}$; lane 6, oligonucleotides 5 and 6 at $1 \mu \mathrm{M}$ each, oligonucleotide 7 at $1 \mu \mathrm{M}$; lane 7 , oligonucleotides 5 and 6 at $1 \mu \mathrm{M}$ each, oligonucleotide 7 at 10 $\mu \mathrm{M}$; lane 8, no oligonucleotides; lane 9, A-specific sequencing reaction; lane 10, oligonucleotides 5 and 7 at $1 \mu \mathrm{M}$ each. 


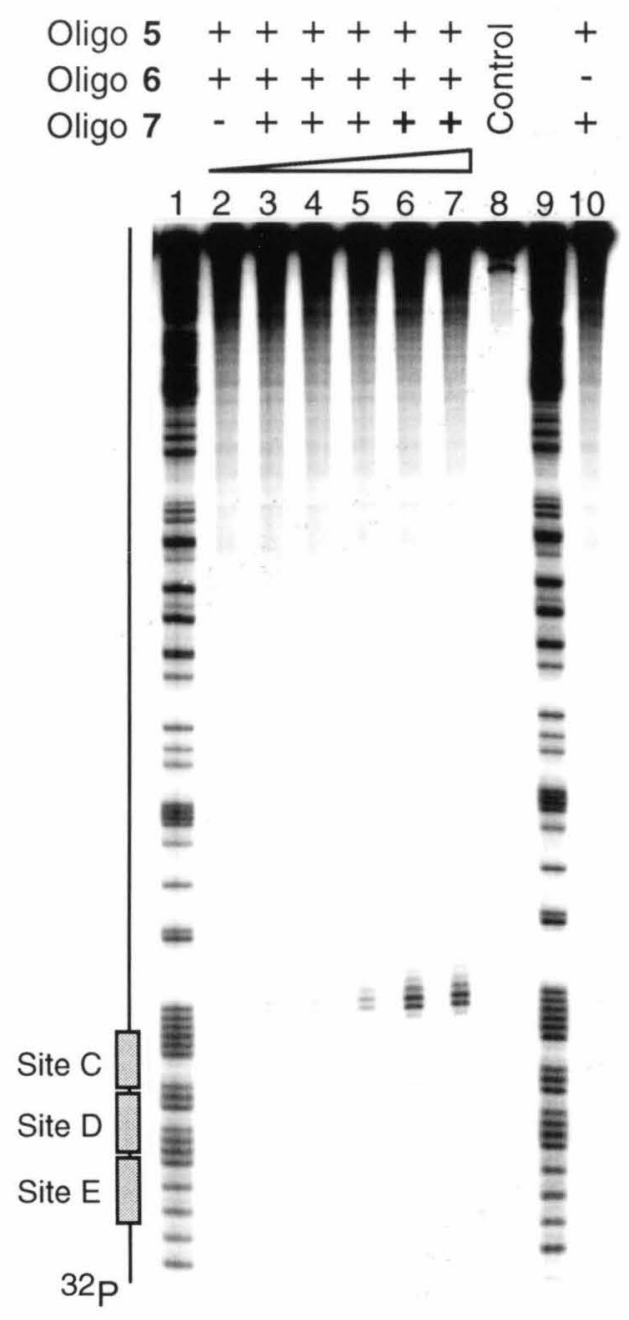


Table 4.2: Equilibrium Association Constants for 6 mer 5 Binding in the Absence and Presence of 6 mers 6 and 7 to DNA by Triple Helix Formation ${ }^{a}$

\begin{tabular}{lc}
\hline Oligonucleotide & $K\left(\mathrm{M}^{-1}\right)$ \\
\hline 5 & $<10^{4}$ \\
$5+6(5.0 \mu \mathrm{M})$ & $2.1( \pm 0.2) \times 10^{5}$ \\
$5+6(5.0 \mu \mathrm{M})+7(5.0 \mu \mathrm{M})$ & $8.9( \pm 0.2) \times 10^{5}$ \\
\hline$a$ Values reported in the table are mean values measured \\
from affinity cleavage titration experiments performed in \\
Association buffer $(10 \mathrm{mM}$ Bis-Tris $\bullet \mathrm{HCl}, 10 \mathrm{mM} \mathrm{NaCl}, 1$ \\
$\mathrm{mM}$ spermine, $\left.\mathrm{pH} 7.0,24^{\circ} \mathrm{C}\right)$.
\end{tabular}

propyne-substituted 2'-deoxyuridines. ${ }^{13,14}$ Additional experiments showing that separation of sites A and B (Figure 4.1) by a one base pair gap abolishes the binding enhancement of oligonucleotide 1 in the presence of oligonucleotide 2 suggest that stacking interactions are likely to play an important role in cooperativity. This idea is supported by experiments indicating that the cooperativity between oligonucleotides bound at adjacent DNA sites is dependent on the sequence composition at the triplex junction (see Chapter Three). ${ }^{15}$

- The right-handed nature of the triplex allows stacking of the propyne group of the base on the $3^{\prime}$-side of the junction onto the $5^{\prime}$-base across the junction, but not the stacking of the propyne group at the $5^{\prime}$-side of the junction onto the 3 adjacent base (Figure 4.5). It is reasonable to believe that a $5^{\prime}-T^{P} U-3^{\prime}$ stack (Figure 4.5A) is more favorable than a $5^{\prime}{ }^{-}{ }^{-}$TT-3' stack (Figure 4.5B) due to greater interactions between delocalized $\pi$-orbitals in the former rather than in the latter. ${ }^{16}$ 

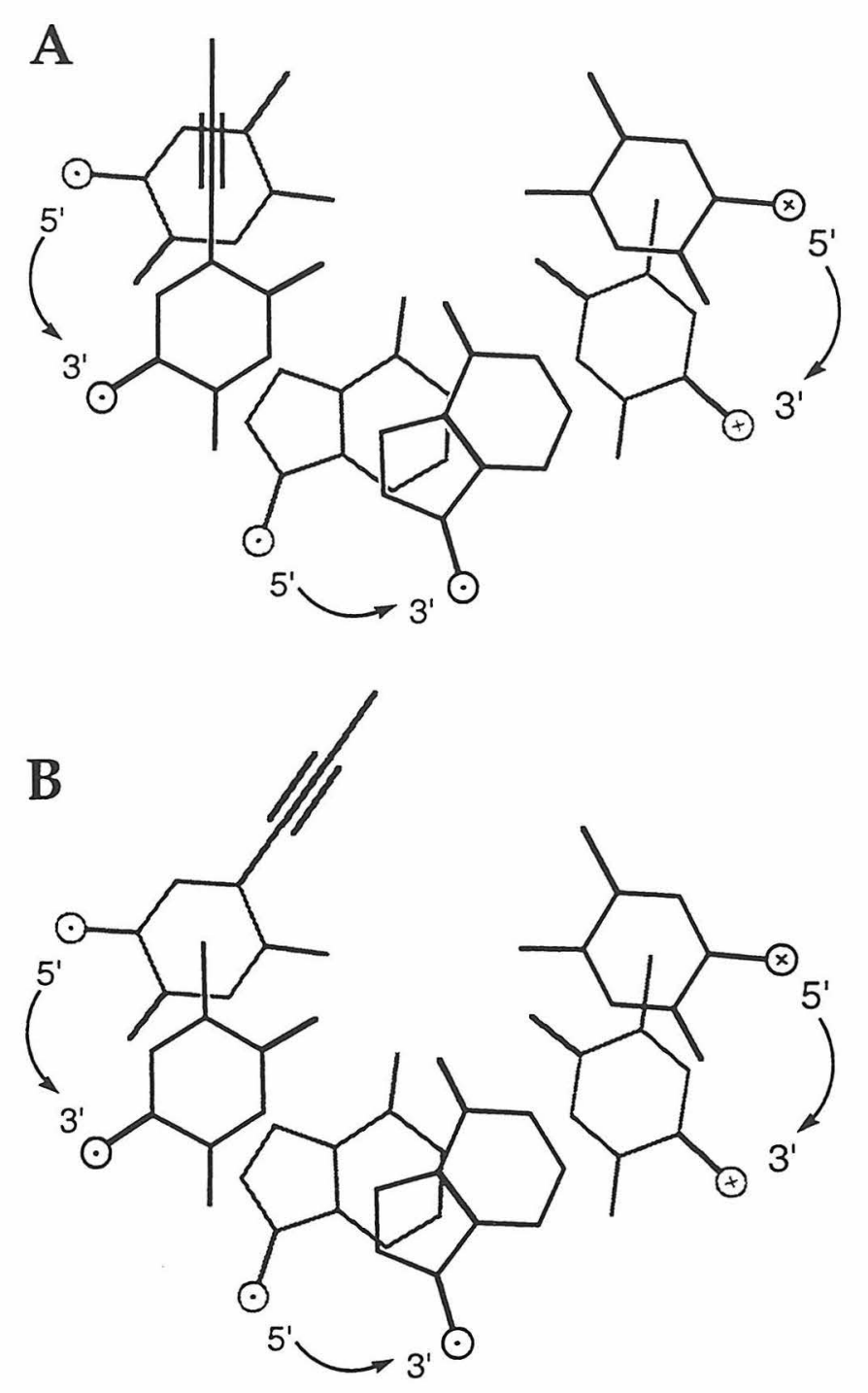

Figure 4.5. Base stacking configuration of two PU•AT triples drawn based on the structure proposed for DNA triple helix $(\mathrm{T} \bullet \mathrm{AT}) n .{ }^{17}$ The $\mathrm{C}^{\prime}$ atoms of the deoxyribose sugars are represented by the open circles. The $5^{\prime} \rightarrow 3^{\prime}$ polarity of the strands is indicated by the symbols $\otimes$ (into the plane of the page) and $\odot$ (out of the plane of the page). 
To test this model, experiments were carried out to determine the interaction energies observed when 5-(1-propynyl)-modified oligonucleotide 1 binds to the $5^{\prime}$-side of the triple-helical junction (site A, Figure 4.1) in the presence of $1.0 \mu \mathrm{M}$ unmodified oligonucleotide 4 bound to the 3 '-side (site B, Figure 4.1), and when unmodified oligonucleotide 3 binds to the $5^{\prime}$-side in the presence of $1.0 \mu \mathrm{M}$ modified oligonucleotide 2 bound to the $3^{\prime}$-side (Figure 4.1). In both cases, site B should be $<2 \%$ occupied by $1.0 \mu \mathrm{M}$ oligonucleotide 2 or 4 in the absence of bound 1 or 3 . Under the titration conditions, modified oligonucleotide 1 at $\leq 20$ $\mu \mathrm{M}$ in the presence of $1.0 \mu \mathrm{M}$ unmodified 4 produced minimal cleavage, and its equilibrium constant for binding to site A could not be measured. In contrast, unmodified oligonucleotide 3 bound to site $\mathrm{A}$ in the presence of $1.0 \mu \mathrm{M}$ modified 2 with an increased association constant $\left(K_{3+2}=9.7( \pm 0.6) \times 10^{4} \mathrm{M}^{-1}\right)$ (Table 4.1). These results are consistent with a model wherein cooperativity between a modified and an unmodified oligonucleotide is dramatically affected by the position $\left(3^{\prime}-\right.$ or $\left.5^{\prime}-\right)$ of the modified oligonucleotide with respect to the triplehelical junction due to two stacking arrangements (Figure 4.5). This suggests that some significant contribution to the interaction energy between $\mathbf{1}$ and $\mathbf{2}$ originates from stacking between the modified bases at the triplex junction. It is reasonable to believe that the same phenomenon occurs in the trimeric cooperative system described. Thus, according to this model, the binding of oligonucleotide 7 to site $\mathrm{E}$ enhances the binding of 6 to site $\mathrm{D}$ through $\pi$-stacking interactions, which in turn enhances the binding of 5 to its site (Figures 4.2 and 4.6). This model is supported by experiments described above wherein increasing concentrations of 7 in the presence of a constant concentration of 5 and 6 lead to greater cleavage by 5 .

Implications. Cooperativity can be used to allow modified $8 \mathrm{mer}$ oligonucleotides in the molecular weight range of 2500 to bind to adjacent sites 


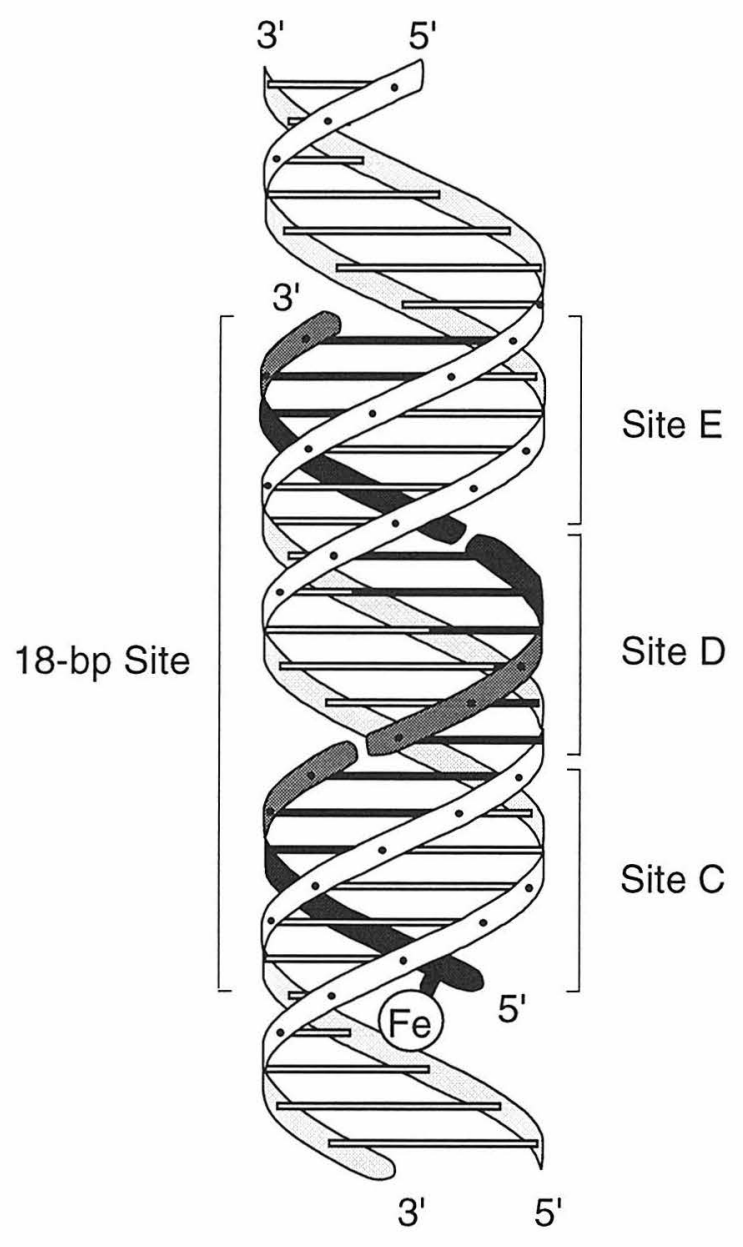

Figure 4.6. Ribbon model of oligonucleotides 5, 6, and 7 bound at adjacent sites on duplex DNA by triple helix formation. The WatsonCrick duplex strands are shown as white ribbons, and the triple helix forming oligonucleotides are shown as dark ribbons. 
on double-helical DNA at micromolar concentrations. In addition, it allows even shorter (MW 1600) oligonucleotides to bind to three adjacent sites on DNA (Figure 4.6). These findings carry several important implications. First of all, the use of cooperativity has allowed us to design a system in which three ligands bind cooperatively to DNA. The functioning of many biological systems relies on the cooperative interactions between two or more ligands, as these can lead to highly specific DNA-protein binding interactions and, as a result, to the highly efficient control of gene expression. This principle is exemplified by the natural trimeric phage $\lambda$ repressor system, in which cooperative interactions occur between proteins bound to three tandem operator sites. ${ }^{18}$ The nucleic acid system described here could presumably be highly specific as well. Studies on the cooperative binding of oligonucleotides to DNA have shown that a cooperative system in which two oligonucleotides bind to DNA is more sensitive to single-base mismatches than the corresponding noncooperative system in which a longer oligonucleotide binds to DNA (see Chapter Three). ${ }^{15}$ On this basis, it is reasonable to believe that even higher specificities could be achieved in systems in which still shorter oligonucleotides bind to DNA.

In addition to leading to higher specificities, cooperative interactions between short oligonucleotides may facilitate the application of cooperativity in therapeutics, as low molecular weight oligonucleotides are presumably more amenable to cell penetration and are less toxic than longer, higher molecular weight ones.

\section{Experimental Section}

General. E. coli JM110 was obtained from Stratagene. Qiagen plasmid kits were purchased from Qiagen Inc. Sonicated, deproteinized calf thymus DNA was purchased from Pharmacia. Nucleotide triphosphates were obtained from 
Pharmacia. Nucleotide triphosphates labeled with $32 \mathrm{P}(\geq 3000 \mathrm{Ci} / \mathrm{mmol})$ were purchased from Amersham. Restriction endonucleases were purchased from New England Biolabs, and used according to the suggested protocol in the provided buffer. Thymidine and 5-methyl-2'-deoxycytidine phosphoramidites were obtained from ABI and Cruachem, respectively. The 5'-O-DMT-protected 5-(1-propynyl)-2'-deoxyuridine phosphoramidite derivative (now commercially available) (Figure 4.7) and controlled pore glass derivatized with 5-(1-propynyl)2'-deoxyuridine (Figure 4.8) were synthesized according to published procedures (see below). Sephadex resins were obtained from Pharmacia. Sequenase Version 2.0 was obtained from United States Biochemical.

5-(1-Propynyl)-2'-deoxyuridine (II). A mixture of 5-iodo-2'-deoxyuridine (3.54 g, $10.0 \mathrm{mmol})$, CuI (0.38 g, $2.0 \mathrm{mmol})$, tetrakis(triphenylphosphine)palladium (0) $(1.16 \mathrm{~g}, 1.0 \mathrm{mmol})$, and triethylamine $(3.0 \mathrm{~mL}, 21 \mathrm{mmol})$ in dry DMF (50 mL) was stirred under argon. Propyne (see below) was bubbled through the mixture for $6.5 \mathrm{~h}$. The mixture was allowed to stir at room temperature for $18 \mathrm{~h}$. To the reaction mixture were added methanol $(28 \mathrm{~mL})$, methylene chloride $(28 \mathrm{~mL})$, and $\mathrm{NaHCO}_{3}(4.1 \mathrm{~g})$. After 30 minutes, the mixture was filtered through Celite, and concentrated in vacuo. The resulting residue was dissolved in $\mathrm{CH}_{2} \mathrm{Cl}_{2}(300 \mathrm{~mL})$, and extracted with water $(3 \times 300 \mathrm{~mL})$. The aqueous layers were combined, and concentrated under reduced pressure. The residue was suspended in acetone, and the resulting precipitate was collected by filtration to give $1.30 \mathrm{~g}$ ( $49 \%$ yield) of product in the form of a white solid. The filtrate was concentrated in vacuo, and crystallized from $98 \% \mathrm{EtOH}$ to give an additional $0.91 \mathrm{~g}$ of pure product ( $34 \%$ yield). The mother liquor was concentrated in vacuo, and purified through flash chromatography (100\% EtOAc) to afford $0.17 \mathrm{~g}$ ( $6.4 \%$ yield) of product. The total yield was $2.38 \mathrm{~g}$ ( $89 \%$ yield). ${ }^{1} \mathrm{H}$ NMR (DMSO) d $1.94(\mathrm{~s}, 3 \mathrm{H}), 2.06(\mathrm{~m}, 2 \mathrm{H}), 3.50-3.61(\mathrm{~m}, 2 \mathrm{H}), 3.73-3.79(\mathrm{~m}, 1 \mathrm{H})$, 

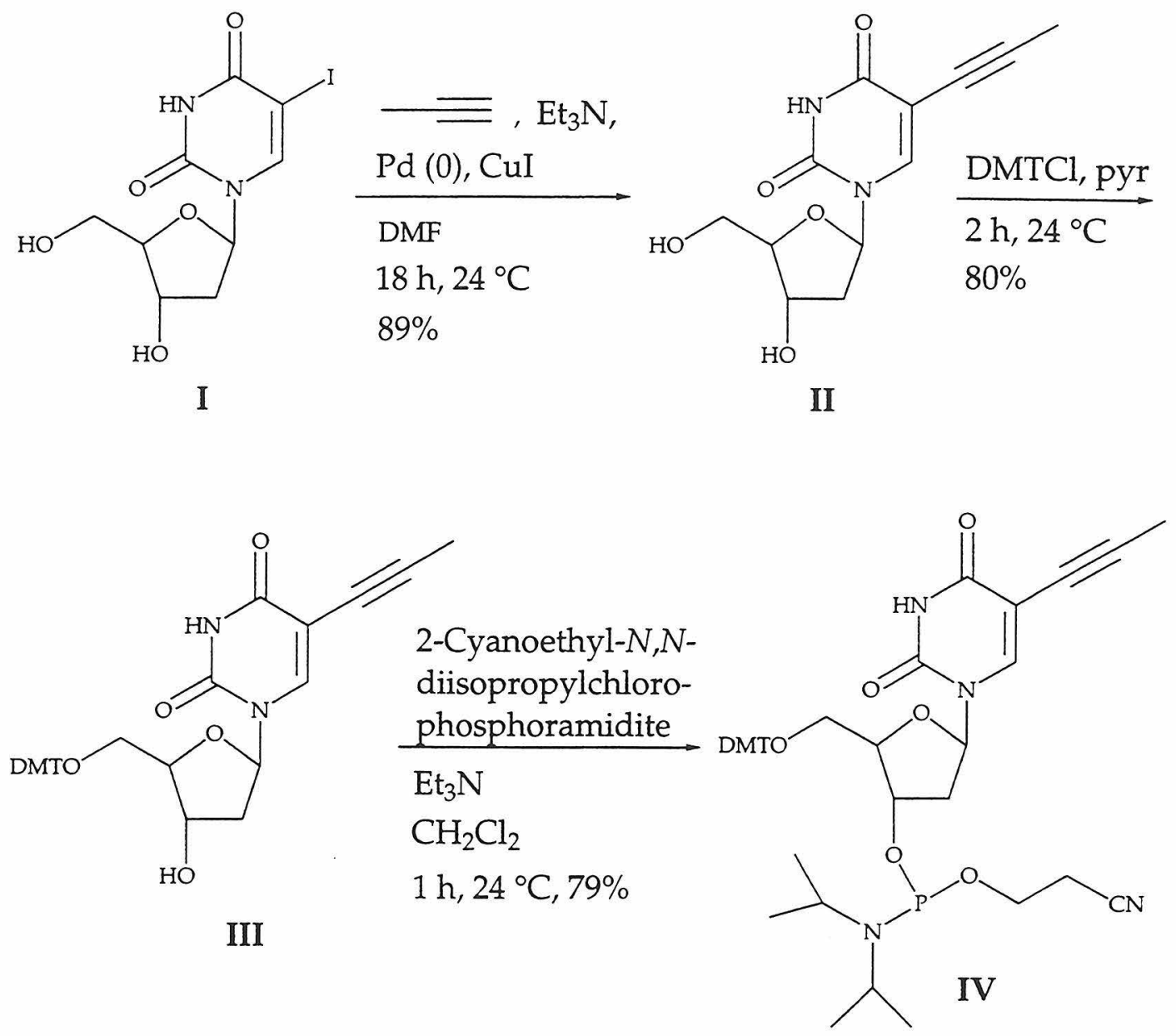

Figure 4.7. Synthesis of the 5'-O-DMT-protected 5-(1-propynyl)-2'-deoxyuridine phosphoramidite derivative IV.6a 5-(1-Propynyl)-2'-deoxyuridine (II) was obtained in $89 \%$ yield from the palladium catalyzed coupling of 5-iodo-2'-deoxyuridine (I) with propyne as described by De Clercq. ${ }^{19}$ 

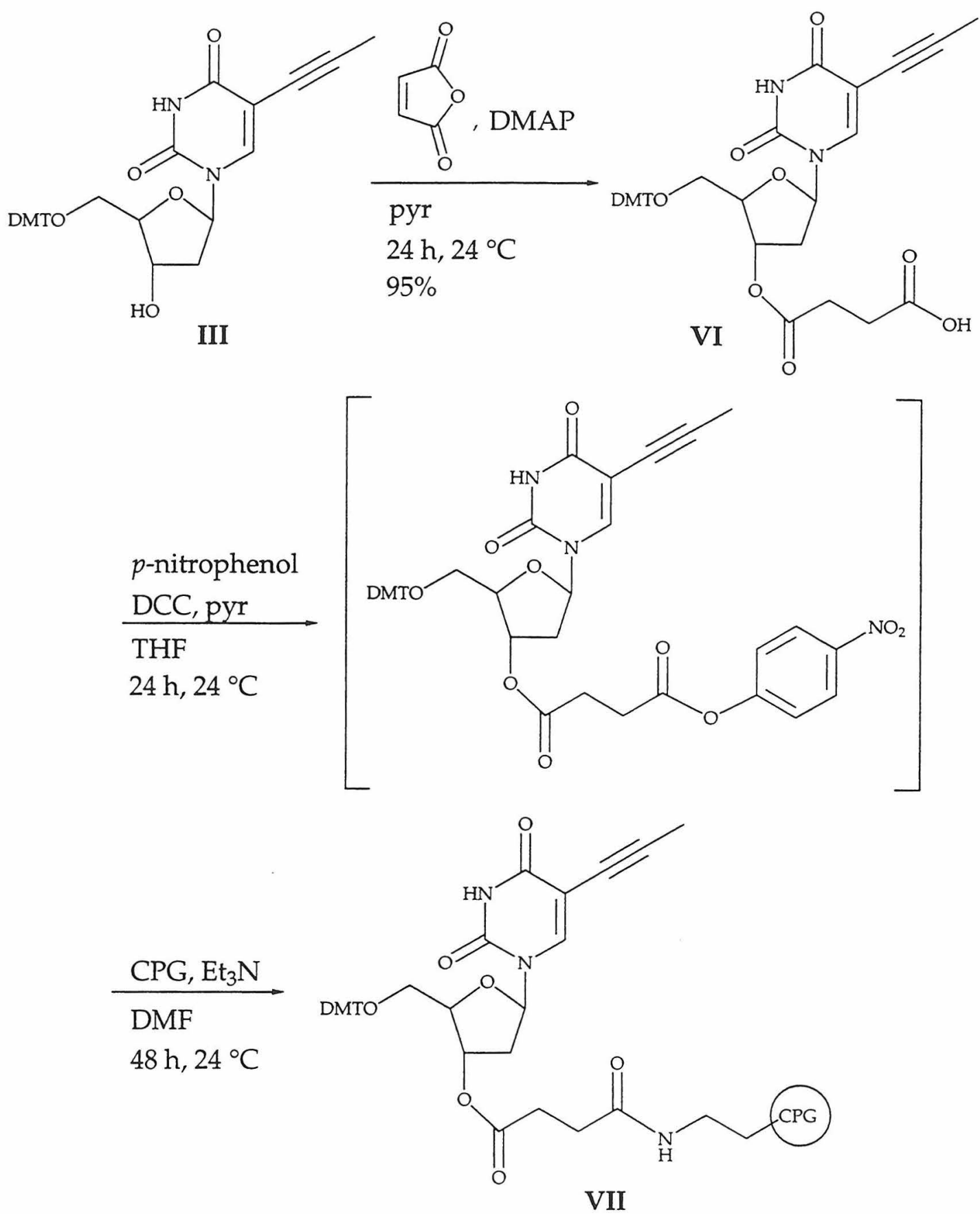

Figure 4.8. Synthesis of controlled pore glass derivatized with 5-(1-propynyl)-2'deoxyuridine (VII). ${ }^{20}$ 
4.16-4.22 (m, 1H), 5.05-5.08 (m, 1H), 5.20-5.23 (m, 1H), $6.07(\mathrm{t}, 1 \mathrm{H}, \mathrm{J}=6.7 \mathrm{~Hz}), 8.07$ (s, 1H), 11.52 (bs, 1H); FABMS m/e (relative intensity) $267.0991(\mathrm{M}+\mathrm{H}, 267.0981$ calcd. for $\mathrm{C}_{12} \mathrm{H}_{15} \mathrm{~N}_{2} \mathrm{O}_{5}$ ).

Propyne. To a refluxing solution of $\mathrm{KOH}(90.0 \mathrm{~g}, 1.6 \mathrm{~mol})$ in dry $\mathrm{nBuOH}(400$ $\mathrm{mL}$ ) was added dropwise 1,2-dibromopropane $(52 \mathrm{~mL}, 0.50 \mathrm{~mol}$ ) over a period of $6 \mathrm{~h}$. The gaseous propyne was bubbled through a pipette into the reaction mixture of 5-iodo-2'-deoxyuridine at room temperature.

5-(1-Propynyl)-5'-O-(4,4'-dimethoxytrityl)-2'-deoxyuridine (III). A solution of 5-(1-propynyl)-2'-deoxyuridine (II) (300 mg, $1.13 \mathrm{mmol}$ ) and dimethoxytrityl chloride $(517 \mathrm{mg}, 1.52 \mathrm{mmol})$ was allowed to stir in dry pyridine $(5.0 \mathrm{~mL})$ under argon at room temperature for $2 \mathrm{~h}$. Methanol $(8 \mathrm{~mL})$ was added, and the solution was stirred at room temperature for $1 \mathrm{~h}$. The solution was concentrated in vacuo, and excess pyridine was removed by coevaporation with heptane. The resulting residue was dissolved in methylene chloride $(200 \mathrm{~mL})$, washed with water $(3 \times 200 \mathrm{~mL})$, dried $\left(\mathrm{Na}_{2} \mathrm{SO}_{4}\right)$, and concentrated in vacuo. Flash chromatography $\left(0-1.5 \% \mathrm{MeOH} / \mathrm{CH}_{2} \mathrm{Cl}_{2}\right)$ afforded $520 \mathrm{mg}(80 \%$ yield $)$ of product in the form of a white solid. ${ }^{1} \mathrm{H}$ NMR $\left(\mathrm{CDCl}_{3}\right) \mathrm{d} 1.74(\mathrm{~s}, 3 \mathrm{H}), 2.31-2.33$ $(\mathrm{m}, 1 \mathrm{H}), 2.48-2.49(\mathrm{~m}, 1 \mathrm{H}), 3.39(\mathrm{~d}, 2 \mathrm{H}, \mathrm{J}=3.0 \mathrm{~Hz}), 3.81(\mathrm{~s}, 6 \mathrm{H}), 4.51(\mathrm{~m}, 1 \mathrm{H})$, $4.57(\mathrm{t}, 1 \mathrm{H}, \mathrm{J}=2.8 \mathrm{~Hz}), 6.34(\mathrm{~m}, 1 \mathrm{H}), 6.86(\mathrm{~d}, 4 \mathrm{H}), 7.23-7.47(\mathrm{~m}, 9 \mathrm{H}), 8.01(\mathrm{~s}, 1 \mathrm{H})$; FABMS m/e (relative intensity) $568.2215(\mathrm{M}+\mathrm{H}, 567.2210$ calcd. for $\mathrm{C}_{33} \mathrm{H}_{33} \mathrm{~N}_{2} \mathrm{O}_{7}$ ).

5-(1-Propynyl)-3'-(2-cyanoethyl- $N, N$-diisopropylphosphoramidite)-5'-O(4,4'-dimethoxytrityl)cytidine (IV). A solution of 5-(1-propynyl)-5'-O-(4,4'dimethoxytrityl)-2'-deoxyuridine (III) $(0.30 \mathrm{~g}, 0.528 \mathrm{mmol})$ in dry $\mathrm{CH}_{2} \mathrm{Cl}_{2}(5 \mathrm{~mL})$ was cooled to $0^{\circ} \mathrm{C}$, and to it were added dry Et $3 \mathrm{~N}(0.22 \mathrm{~mL}, 1.584 \mathrm{mmol})$ and 2 cyanoethyl- $\mathrm{N}, \mathrm{N}$-diisopropylchlorophosphoramidite $(0.18 \mathrm{~mL}, 0.792 \mathrm{mmol})$. The solution was allowed to stir under argon at $0{ }^{\circ} \mathrm{C}$ for 10 minutes, after which it 
was allowed to warm to room temperature. After 50 minutes, it was diluted with $50 \mathrm{~mL}$ of methylene chloride, washed with a saturated solution of $\mathrm{NaHCO}_{3}$ $(2 \times 50 \mathrm{~mL})$, dried $\left(\mathrm{Na}_{2} \mathrm{SO}_{4}\right)$, and concentrated in vacuo. Flash chromatography (1:1 EtOAc/petroleum ether) afforded $0.319 \mathrm{~g}$ (79\% yield) of product in the form of a white foam. FABMS m/e (relative intensity) $769.3354(\mathrm{M}+\mathrm{H}, 769.3366$ calcd. for $\left.\mathrm{C}_{42} \mathrm{H}_{50} \mathrm{~N}_{4} \mathrm{O}_{8} \mathrm{P}\right)$.

5-(1-Propynyl)-3'-succinyl-5'-O-(4,4'-dimethoxytrityl)cytidine (VI). A solution of 5-(1-propynyl)-5'-O-(4,4'-dimethoxytrityl)-2'-deoxyuridine (III) (0.30 $\mathrm{g}, 0.528 \mathrm{mmol})$, succinic anhydride $(0.079 \mathrm{~g}, 0.79 \mathrm{mmol})$, and DMAP $(0.065 \mathrm{~g}$, $0.528 \mathrm{mmol})$ in dry pyridine $(1 \mathrm{~mL})$ was allowed to stir under argon at room temperature for $24 \mathrm{~h}$. The solution was concentrated in vacuo, azeotroped from toluene, and reconcentrated. It was then dissolved in $\mathrm{CH}_{2} \mathrm{Cl}_{2}(30 \mathrm{~mL})$, washed with cold $10 \%$ citric acid $(2 \times 15 \mathrm{~mL})$, and water $(2 \times 15 \mathrm{~mL})$. The aqueous layers were extracted with $\mathrm{CH}_{2} \mathrm{Cl}_{2}$, after which the combined organic layers were dried ( $\left.\mathrm{Na}_{2} \mathrm{SO}_{4}\right)$, and concentrated in vacuo. The solid residue was dissolved in $\mathrm{CH}_{2} \mathrm{Cl}_{2}$ $(3 \mathrm{~mL})$, and precipitated into rapidly stirring hexanes $(125 \mathrm{~mL})$. The precipitate was separated by filtration, and the precipitation process was repeated three times to afford $0.336 \mathrm{~g}$ ( $95 \%$ yield) of slightly impure product in the form of a yellowish foam which was used without further purification.

5-(1-Propynyl)-5'-O-(4,4'-dimethoxytrityl)-2'-deoxyuridine-derivatized CPG (VII). A solution of VI (0.336 g, $0.50 \mathrm{mmol}), p$-nitrophenol $(0.070 \mathrm{~g}, 0.5 \mathrm{mmol})$, dicyclohexylcarbodiimide $(0.258 \mathrm{~g}, 1.25 \mathrm{mmol})$, and dry pyridine $(0.1 \mathrm{~mL})$ in dry THF ( $2.5 \mathrm{~mL})$ was allowed to stir under argon at room temperature for $24 \mathrm{~h}$. The resulting precipitate was isolated by filtration through a Nylon filter, and washed with DMF. It was immediately added to a mixture of CPG (Sigma, 0.61 $\mathrm{g})$ in dry DMF $(1.6 \mathrm{~mL})$, to which dry $\mathrm{Et}_{3} \mathrm{~N}(0.15 \mathrm{~mL})$ was subsequently added. The mixture was allowed to stir at room temperature for $48 \mathrm{~h}$. The derivatized 
CPG was then separated by filtration, washed with DMF ( $3 \times 50 \mathrm{~mL})$, methanol $(3 \times 50 \mathrm{~mL})$, and ether $(3 \times 50 \mathrm{~mL})$, after which it was dried under air and then under vacuum. Nucleotide loadings were determined to be $26 \mu \mathrm{mol} / \mathrm{g}$ of support by a DMT deprotection assay. ${ }^{20}$ The uncoupled amine groups on the CPG were capped by treatment with DMAP $(0.0203 \mathrm{~g})$ and acetic anhydride $(0.4$ $\mathrm{mL})$ in pyridine $(4 \mathrm{~mL})$ for 30 minutes at room temperature. The support was then filtered, washed first with methanol and then with ether, and finally dried in vacuo.

Construction of pMD5152 and pMD5354. These plasmids were prepared by standard methods. ${ }^{21}$ Briefly, pMD5152 was prepared by hybridization of two synthetic oligonucleotides, 5'-d(ACGTTCCTAAAAAAGGAAAAAAAAGAGAGAGAGATCTG)-3' and 5'-d(GATCCAGATCTCTCTCTCTTTTTTTTCCTTTTTTAGGA)-3', followed by ligation of the resulting duplex with pUC18 DNA previously digested with HindIII and BamHI; this ligation mixture was used to transform E. coli JM110 (Stratagene). Plasmid DNA from ampicillin resistant, white colonies was isolated and the presence of the desired insert confirmed by restriction analysis and Sanger sequencing. Preparative isolation of plasmid DNA was performed using a Qiagen plasmid kit. Plasmid pMD5354 (used in the one base pair gap experiment) was prepared using a similar procedure with the oligonucleotides 5'-d(AGCTTCCTAAAAAAGGAAAAAAAAAGAGAGAGAG ATCTG)-3' and 5'-d(GATCCAGATCTCTCTCTCTTTTTTTTTCCTTTTTTAGG A) -3 .

Oligonucleotide Preparation. Oligonucleotides were synthesized by standard automated solid-support chemistry on an Applied Biosystems Model 380B DNA synthesizer using $O$-cyanoethyl- $N, N$-diisopropyl phosphoramidites. ${ }^{22}$ The phosphoramidite of thymidine-EDTA $\left(\mathrm{T}^{*}\right)$ was prepared according to published procedures. ${ }^{7}$ Controlled pore glass derivatized with $\mathrm{T}^{*}$ was prepared 
as described by Strobel. ${ }^{20}$ Oligonucleotides 1,3 , and 5 containing $\mathrm{T}^{*}$ were deprotected with $0.1 \mathrm{~N} \mathrm{NaOH}$ at $55^{\circ} \mathrm{C}$ for $24 \mathrm{~h}$, neutralized with glacial acetic acid, desalted on Pharmacia Sephadex (G-10-120) spin columns, and dried in vacuo. Oligonucleotides $2,4,6$, and 7 were deprotected with concentrated ammonium hydroxide at $55{ }^{\circ} \mathrm{C}$ for $24 \mathrm{~h}$, and dried in vacuo. The crude 5 terminal-dimethoxytrityl protected oligonucleotides were purified by reverse phase FPLC on a ProRPC 10/10 $\left(\mathrm{C}_{2}-\mathrm{C}_{8}\right)$ column (Pharmacia LKB) and a gradient of $0-40 \% \mathrm{CH}_{3} \mathrm{CN}$ in $0.1 \mathrm{M}$ triethylammonium acetate, $\mathrm{pH} 7.0$, detritylated in $80 \%$ $\mathrm{AcOH}$, and chromatographed a second time. Triethylammonium acetate was removed via repeated resuspensions of the oligonucleotides in water followed by lyophilization. Concentrations of oligonucleotides not containing 5-(1propynyl)-2'-deoxyuridine were determined by UV absorbance at $260 \mathrm{~nm}$ using extinction coefficients $\left(\mathrm{M}^{-1} \mathrm{~cm}^{-1}\right)$ of $8800\left(\mathrm{~T}\right.$ and $\left.\mathrm{T}^{*}\right)$ and $5700(\mathrm{~m} \mathrm{C})$. Concentrations of oligonucleotides containing 5-(1-propynyl)-2'-deoxyuridine were determined by UV absorbance at $280 \mathrm{~nm}$ using extinction coefficients ( $\mathrm{M}^{-1}$ $\mathrm{cm}^{-1}$ ) of $6400\left(\mathrm{~T}\right.$ and $\left.\mathrm{T}^{*}\right), 8300\left({ }^{\mathrm{m}} \mathrm{C}\right)$, and $9700\left({ }^{\mathrm{P}} \mathrm{U}\right)$.

HPLC Analysis of Oligonucleotides Containing 5-(1-Propynyl)-2'-deoxyuridine. Oligonucleotides 1 and 2 were subjected to standard enzyme degradation and HPLC analysis for purity confirmation with a Hewlett-Packard 1090 liquid chromatograph using a reverse phase Vydac RP C18 90A pharmaceutical column ( $4.6 \times 250 \mathrm{~mm}, 5 \mu \mathrm{m}$ C18-derivatized gel). Mobile phase A: $20 \mathrm{mM}$ ammonium acetate, $1 \mathrm{mM}$ EDTA in water, $\mathrm{pH}$ 5.0. B: $20 \mathrm{mM}$ ammonium acetate, $1 \mathrm{mM}$ EDTA in $40 \%$ aqueous acetonitrile, $\mathrm{pH}$ 5.0. Flow rate: $1.0 \mathrm{~mL} / \mathrm{min}$. Pressure: $120 \mathrm{bar}$.

Preparation of Labeled Restriction Fragment. This is fully described in the Experimental Section of Chapter Two. 
124

Quantitative Affinity Cleavage Titrations. These are fully described in the Experimental Section of Chapter Two.

Construction of Titration Binding Isotherms. See the Experimental Section of Chapter Two for a detailed description. 


\section{References and Notes}

1. Strobel, S. A.; Dervan, P. B. J. Am. Chem. Soc. 1989, 111, 7286.

2. (a) Distefano, M. D.; Shin, J. A.; Dervan, P. B. J. Am. Chem. Soc. 1991, 113, 5901. (b) Distefano, M. D.; Dervan, P. B. J. Am. Chem. Soc. 1992, 114, 11006. (c) Distefano, M. D.; Dervan, P. B. Proc. Natl. Acad. Sci. USA 1993, 90, 1179.

3. Colocci, N.; Distefano, M. D.; Dervan, P. B. J. Am. Chem. Soc. 1993, 115, 4468.

4. Mergny, J. L.; Duval-Valentin, G.; Nguyen, C. H.; Perrouault, L.; Faucon, B.; Rougée, M.; Montenay-Garestier, T.; Bisagni, E.; Helène, C. Science $1992,256,1681$.

5. (a) Lee, J. S.; Woodsworth, M. L.; Latimer, L. J. P.; Morgan, A. R. Nucleic Acids Res. 1984, 12, 6603. (b) Povsic, T. J.; Dervan, P. B. J. Am. Chem. Soc. 1989, 111, 3059. (c) Povsic, T. J. Ph. D. Dissertation, California Institute of Technology, Pasadena, CA, 1991. (d) Collier, D. A.; Thuong, N. T.; Helène, C. J. Am. Chem. Soc. 1991, 113, 1457.

6. (a) Froehler, B. C.; Wadwani, S.; Terhorst, T. J.; Gerrard, S. R. Tetrahedron Lett. 1992, 33, 5307. For the effect of 5-(1-propynyl)-pyrimidines on duplex stability, see (b) Sagi, J.; Szemzo, A.; Ebinger, K.; Szabolcs, A.; Sagi, G.; Ruff, E.; Otvos, L. Tetrahedron Lett. 1993, 34, 2191.

7. Dreyer, G. B.; Dervan, P. B. Proc. Natl. Acad. Sci. USA 1985, 82, 968.

8. (a) Singleton, S. F.; Dervan, P. B. J. Am. Chem. Soc. 1992, 114, 6956. (b) Singleton, S. F.; Dervan, P. B. Biochemistry 1992, 31, 10995.

9. (a) Under the conditions chosen, oligonucleotide 1 alone at concentrations up to $100 \mu \mathrm{M}$ produced only minimal cleavage. It was therefore assumed that $K_{1}$ is $<2 \times 10^{4} \mathrm{M}^{-1}$. Oligonucleotide $5^{\prime}-\mathrm{d}\left({ }^{\mathrm{P}} U^{\mathrm{P}} \mathrm{U}^{\mathrm{P}} U^{\mathrm{P}} U^{m_{C}}{ }^{\mathrm{P}} U^{\mathrm{m}} \mathrm{CT}{ }^{*}\right)-3^{\prime}$ with the same sequence as 2 but containing $\mathrm{T}^{*}$ at the $3^{\prime}$-end, also produced 
minimal cleavage at $\leq 100 \mu \mathrm{M}$, and its equilibrium constant as well as that of $K_{2}$ were also assumed to be $<2 \times 10^{4} \mathrm{M}^{-1}$. (b) Similar binding constants were obtained for oligonucleotide $\mathbf{1}$ binding to site $\mathrm{A}$ in the presence of 5.0 $\mu \mathrm{M}$ and $10 \mu \mathrm{M} 2$.

10. For the definition of and details on the determination of the cooperative interaction energy $E_{c o o p}$ between two different ligands binding to two distinct sites in a heterodimeric cooperative system, see Chapter Two, reference 3 and references cited therein.

11. For previous studies on the cooperative binding of short unmodified oligomers to adjacent sites on complementary single-stranded DNA, see: (a) Pitha, P. M.; Ts'o, P. O. P. Biochemistry 1969, 8, 5206. (b) Springgate, M. W.; Poland, D. Biopolymers 1973, 12, 2241. (c) Maher, L. J.; Dolnick, B. J. Nucleic Acids Res. 1988, 16, 3341. (d) Kieleczawa, J.; Dunn, J. J.; Studier, F. W. Science 1992, 258, 1787.

12. The equilibrium constant of $3\left(K_{3}\right)$ was assumed to be $<2 \times 10^{4} \mathrm{M}^{-1}$.

13. (a) Sowers, L. C.; Shaw, B. R.; Sedwick, W. D. Biochem. Biophys. Res. Commun. 1987, 148, 790. (b) DeVoe, H.; Tinoco, I. J. Mol. Biol. 1962, 4, 500. (c) Sanyal, N. K.; Roychoudhury, M.; Ruhela, K. R.; Tiwari, S. N. J. Comput. Chem. 1986, 8, 604. (d) Ornstein, R. L.; Rein, R.; Breen, D. L.; MacElroy, R. D. Biopolymers 1978, 17, 2341. (e) Broom, A. D.; Schweizer, M. P.; Ts'o, P. O. P. J. Am. Chem. Soc. 1967,89, 3612. (f) Ts'o, P. O. P. Molecular Associations in Biology; Academic Press: New York, N. Y., 1968, pp 39-75. (g) Nakano, N. I.; Igarishi, S. J. Biochemistry 1970, 9, 577. (h) Breslauer, K. J.; Frank, R.; Blocker, H.; Marky, L. A. Proc. Natl. Acad. Sci. USA 1986, 83, 3746. (i) Delcourt, S. G.; Blake, R. D. J. Biol. Chem. 1991, 266, 15160.

14. (a) Herskovitz, T. T. Arch. Biochem. Biophys. 1962, 97, 474. (b) Herskovitz, T. T. Biochemistry 1963, 2, 335. 
15. Colocci, N.; Dervan, P. B. J. Am. Chem. Soc. 1995, 117, 4781.

16. It is known that the presence of a large mobile $\pi$-electron system favors stacking between aromatic molecules. For examples, see reference $13 \mathrm{f}$.

17. Raghunathan, G.; Miles, T. H.; Sasisekharan, V. Biochemistry 1993, 32, 455.

18. Ptashne, M. A Genetic Switch; Blackwell Scientific Publications and Cell Press: Palo Alto, CA, 1986.

19. De Clercq, E. D.; Descamps, J.; Balzarini, J.; Giziewicz, J.; Barr, P. J.; Robins, M. J. J. Med. Chem. 1983, 26, 661.

20. Strobel, S. A. Ph. D. Dissertation, California Institute of Technology, Pasadena, CA, 1992.

21. Sambrook, J.; Fritsch, E. F.; Maniatis, T. Molecular Cloning; 2nd ed.; Cold Spring Laboratory Press: New York, N.Y., 1989.

22. Gait, M. J. Oligonucleotide Synthesis: A Practical Approach; IRL Press: Oxford, 1984. 


\section{CHAPTER FIVE:}

\section{Cooperative Binding of Purine-Rich Oligonucleotides to Adjacent DNA Sites by Triple Helix Formation}

\section{Introduction}

Cooperative interactions between DNA-binding proteins have been shown to be important for the regulation of gene expression. ${ }^{1} \quad$ These cooperative interactions result in higher sequence specificity as well as greater sensitivity to concentration changes. ${ }^{1}$ When cooperative interactions occur between two or more oligonucleotides bound at neighboring DNA sites, the specific binding of each oligonucleotide is enhanced. ${ }^{2,3}$ Pyrimidine oligodeoxyribonucleotides 11 nucleotides in length are known to bind cooperatively by triple helix formation to adjacent purine sites on double-helical DNA, resulting in a 12-fold to 127-fold increase in the association constant for one oligonucleotide in the presence of a neighboring bound oligonucleotide depending on the sequence composition at the junction. ${ }^{3 \mathrm{a}, \mathrm{c}}$ This $1.5-2.9 \mathrm{kcal} \bullet \mathrm{mol}^{-1}$ interaction energy likely arises from favorable polarization and charge-charge interactions between the terminal bases at the triple-helical junction. We have subsequently shown that the use of modified bases, such as 5-(1-propynyl)-2'-deoxyuridine, increases cooperativity between oligonucleotides bound to adjacent sites on DNA, presumably due to an increased stacking energy between the modified bases at the triplex junction. ${ }^{3 b}$ The addition of dimerization domains to oligonucleotides such as those capable of forming a short Watson-Crick helix or intercalators were shown to result in strong cooperative interactions as well. ${ }^{2 b-d, 4}$ 
The notion that base stacking is greatly responsible for the observed cooperative interactions is consistent with results indicating that when two pyrimidine oligonucleotides bind on duplex DNA to sites that are separated by one base pair, no cooperativity is observed..$^{3 a, b}$ The finding that cooperative interactions between oligonucleotides bound to double-helical DNA depend on the nature of the base stack at the junction led us to investigate cooperative interactions between purine-rich oligonucleotides bound to abutting DNA sites when a purine-purine stack is formed at the junction. Purine-rich oligonucleotides bind in the major groove antiparallel to the Watson-Crick purine strand through the formation of reverse Hoogsteen hydrogen bonds $(\mathrm{G} \bullet \mathrm{GC}$ and $\mathrm{A} \bullet \mathrm{AT}$ or $\mathrm{T} \bullet \mathrm{AT}$ base triplets). ${ }^{5}$ Here we report the energetics of cooperative binding of purine-rich oligodeoxyribonucleotides to adjacent sites on DNA by triple helix formation when a $5^{\prime}-\mathrm{GG}-3^{\prime}$ stack is formed at the junction. The equilibrium association constant of one oligonucleotide bound to an 11-base pair (bp) homopurine site is measured in the absence and presence of a second oligonucleotide occupying an adjacent 11-bp site by quantitative DNase footprinting titrations. ${ }^{6,7}$ In addition, we determine the equilibrium association constant of the same $11 \mathrm{mer}$ binding in the absence and presence of a second oligonucleotide when the binding sites for the two oligonucleotides are separated by one base pair.

\section{Results}

A system was designed in which two purine-rich oligonucleotides, 1 and 2, bind to abutting sites on a 648-bp 3'-32P-end-labeled duplex DNA fragment at $24{ }^{\circ} \mathrm{C}$ and $\mathrm{pH} 7.0$ (50 mM TrisOAc, $10 \mathrm{mM} \mathrm{NaCl}, 10 \mathrm{mM} \mathrm{MgCl}_{2}$ ) via specific reverse Hoogsteen hydrogen bonding ( $\mathrm{T} \bullet \mathrm{AT}$ and $\mathrm{G} \bullet \mathrm{GC})$ (Figure 5.1). To measure the interaction energy between 1 and 2, the equilibrium association constant $K_{1}$ of 1 binding to site $\mathrm{A}$ alone, $K_{2}$ of 2 binding to site $\mathrm{B}$ alone, and $K_{1+2}$ 


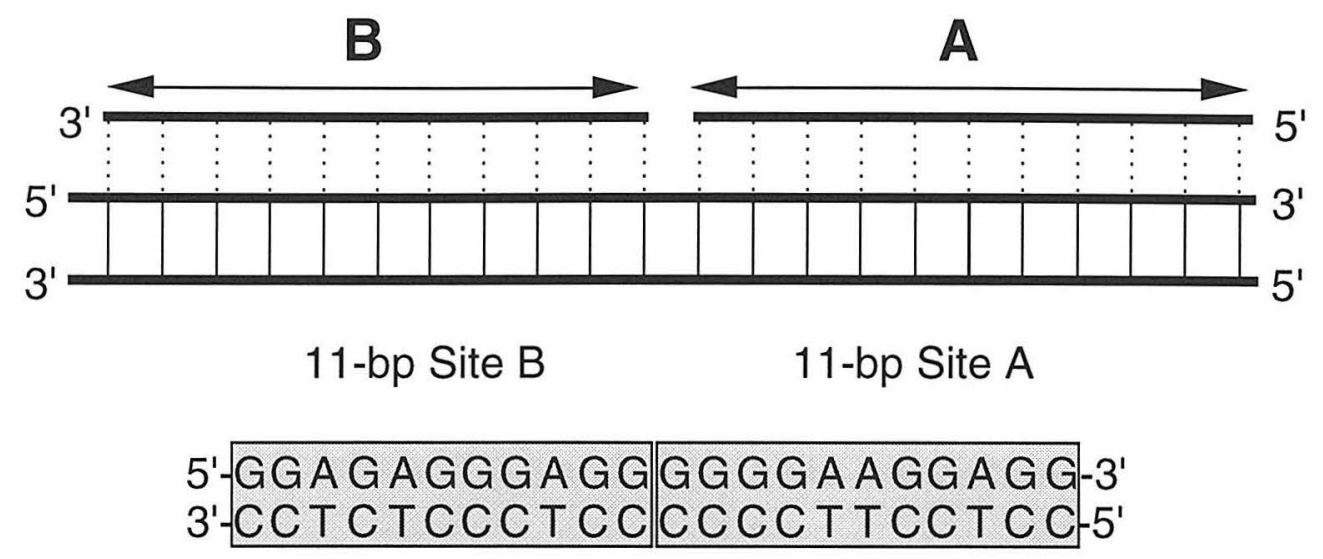

15 - GGTGGTTGGGG

2 5'- GGTGGGTGTGG

Figure 5.1. Schematic representation of a complex composed of two purine-rich triple helix forming oligonucleotides binding at adjacent sites on double-helical DNA. Thick solid lines represent the DNA backbone of the target site and associated oligonucleotides. Thin solid lines represent Watson-Crick hydrogen bonds while dashed lines indicate Hoogsteen hydrogen bonds. Binding of the oligonucleotides is assessed by quantitative DNase footprinting titrations. 
of 1 binding to site $A$ in the presence of $5.0 \mu \mathrm{M} 2$ bound to site $B$ were measured using quantitative DNase footprinting titrations. The cooperative interaction energy $E_{\text {coop }}$ between oligonucleotides 1 and 2 can be determined from the experimental data through the following expression, as described in Chapter Two: ${ }^{3 a}$

$E_{\text {coop }}=-R T \ln \frac{\Phi\left(1+K_{B}\left[L_{B}\right]\right)-1}{K_{B}\left[L_{B}\right]}$

For the cooperatively binding oligonucleotides described here $\mathrm{L}_{B}$ is oligonucleotide 2 , and $K_{\mathrm{B}}$ is the association constant of 2 to its site. As explained in Chapter Two, $\Phi=K_{\mathrm{A}+\mathrm{B}} / K_{\mathrm{A}}$, where $K_{\mathrm{A}+\mathrm{B}}$ and $K_{\mathrm{A}}$ are the association constants of oligonucleotide 1 binding to site $\mathrm{A}$ in the presence and absence of 2, respectively.

Cooperative Binding of Two 11mers in the Presence of a 5'-GG-3' Stack. Analysis of the footprinting data performed on a 648-bp 3'-32P-end-labeled duplex DNA fragment yielded equilibrium association constants of $2.8 \times 10^{5} \mathrm{M}^{-1}$ for 1 binding to site $\mathrm{A}$ alone $\left(K_{1}\right), 1.5 \times 10^{6} \mathrm{M}^{-1}$ for 2 binding to site $\mathrm{B}$ alone $\left(K_{2}\right)$, and $2.2 \times 10^{7} \mathrm{M}^{-1}$ for 1 binding to site $\mathrm{A}$ in the presence of $5 \mu \mathrm{M} 2\left(K_{1+2}\right)$ (Figure 5.2 , Table 5.1). The binding enhancement $K_{1+2} / K_{1}$ was observed to be $81( \pm 12)$. This corresponds to an interaction energy $\mathrm{E}_{\mathrm{coop}}$ of $2.7( \pm 0.1) \mathrm{kcal} \bullet \mathrm{mol}^{-1}$.

Effect of a One Base Pair Gap Between Adjacent Sites. Quantitative DNase footprinting titrations were used to obtain equilibrium association constants for $\mathbf{1}$ binding in the absence and presence of 2 when the binding sites $A$ and $B$ are separated by one base pair (Figures 5.3 and 5.4, Table 5.2). The association constants for the binding of 1 to DNA in the absence and presence of oligonucleotide 2 are $K_{1}=2.8 \times 10^{5} \mathrm{M}^{-1}$ and $K_{1+2}=3.9 \times 10^{5} \mathrm{M}^{-1}$, respectively. Hence, when the binding sites are separated by one base pair, there is no enhancement of the binding of 1 in the presence of 2 within experimental error. 


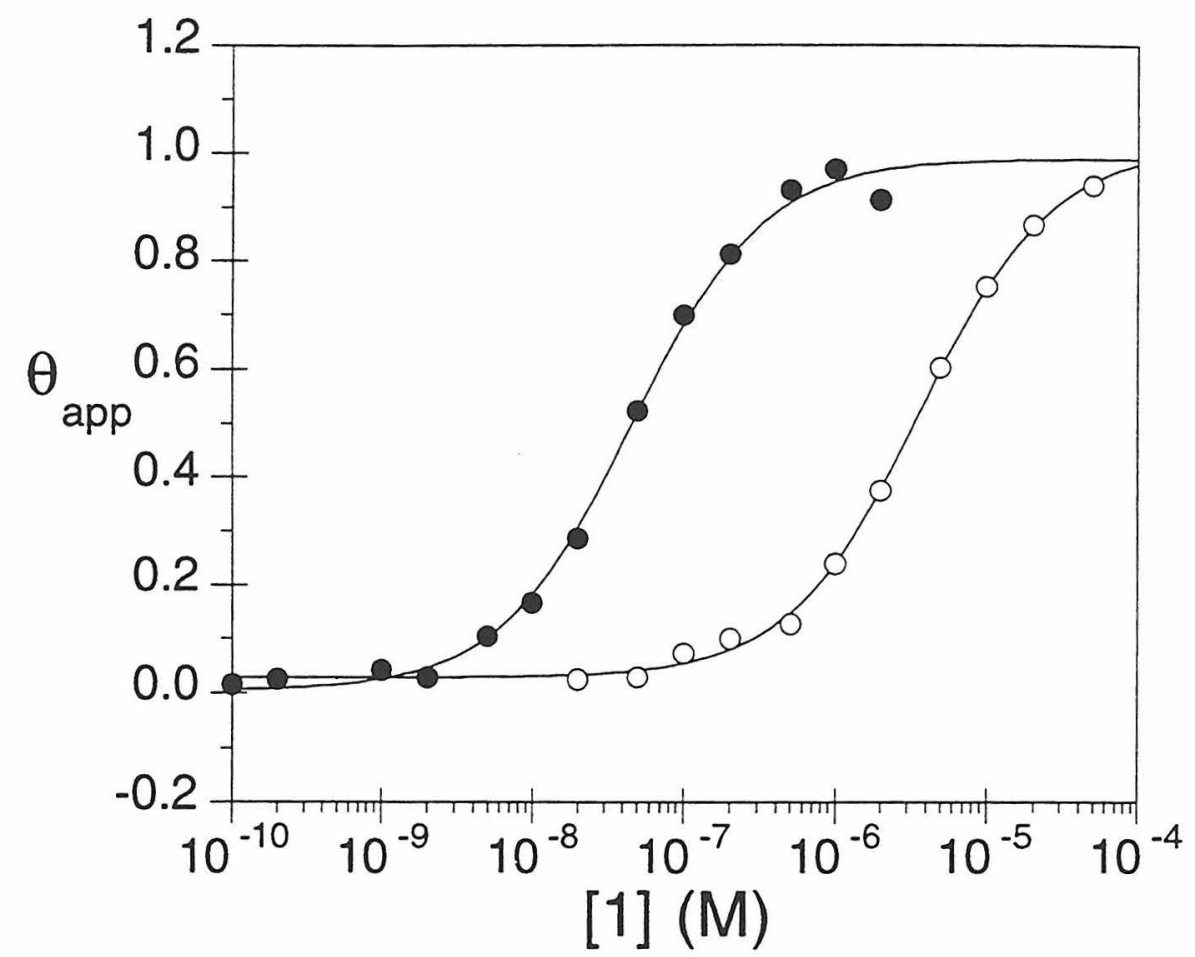

Figure 5.2. Binding isotherms obtained for oligonucleotide 1 alone (o), and in the presence of $5.0 \mu \mathrm{M}$ oligonucleotide $2(\bullet)$, using quantitative DNase footprinting titrations. Four complete data sets were used to determine each association constant. 


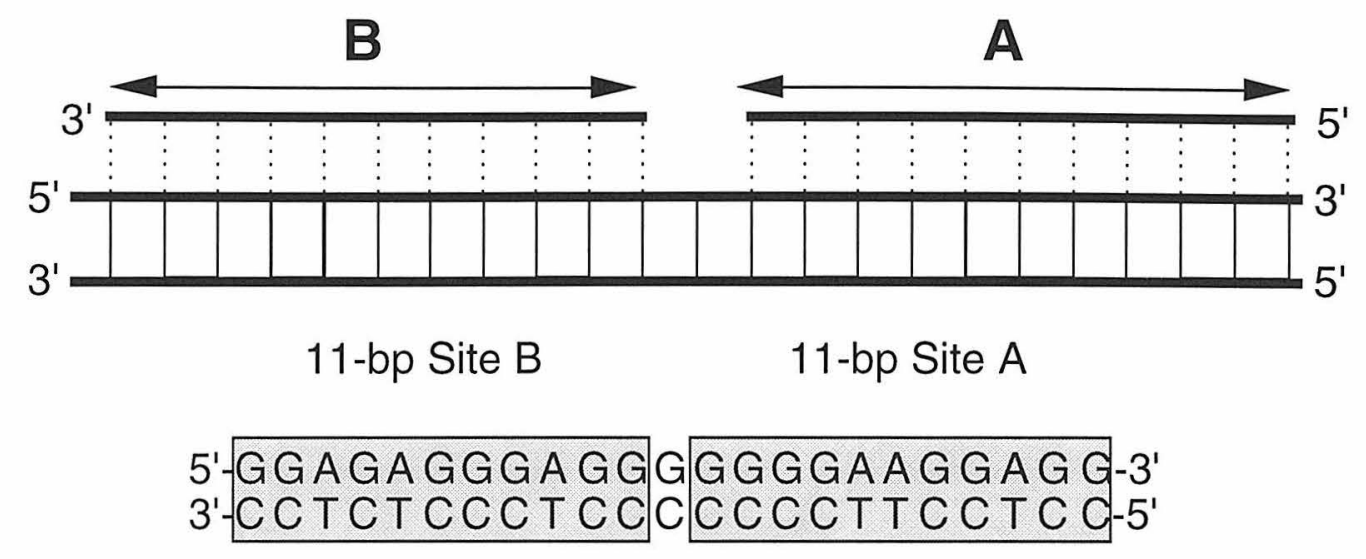

1 5'- GGTGGTTGGGG

2 5'- GGTGGGTGTGG

Figure 5.3. Schematic representation of a complex composed of two purine-rich triple helix forming oligonucleotides binding on doublehelical DNA where the two target sites are separated by one base pair. Thick solid lines represent the DNA backbone of the target site and associated oligonucleotides. Thin solid lines represent Watson-Crick hydrogen bonds while dashed lines indicate Hoogsteen hydrogen bonds. Binding of the oligonucleotides is assessed by quantitative DNase footprinting titrations. 


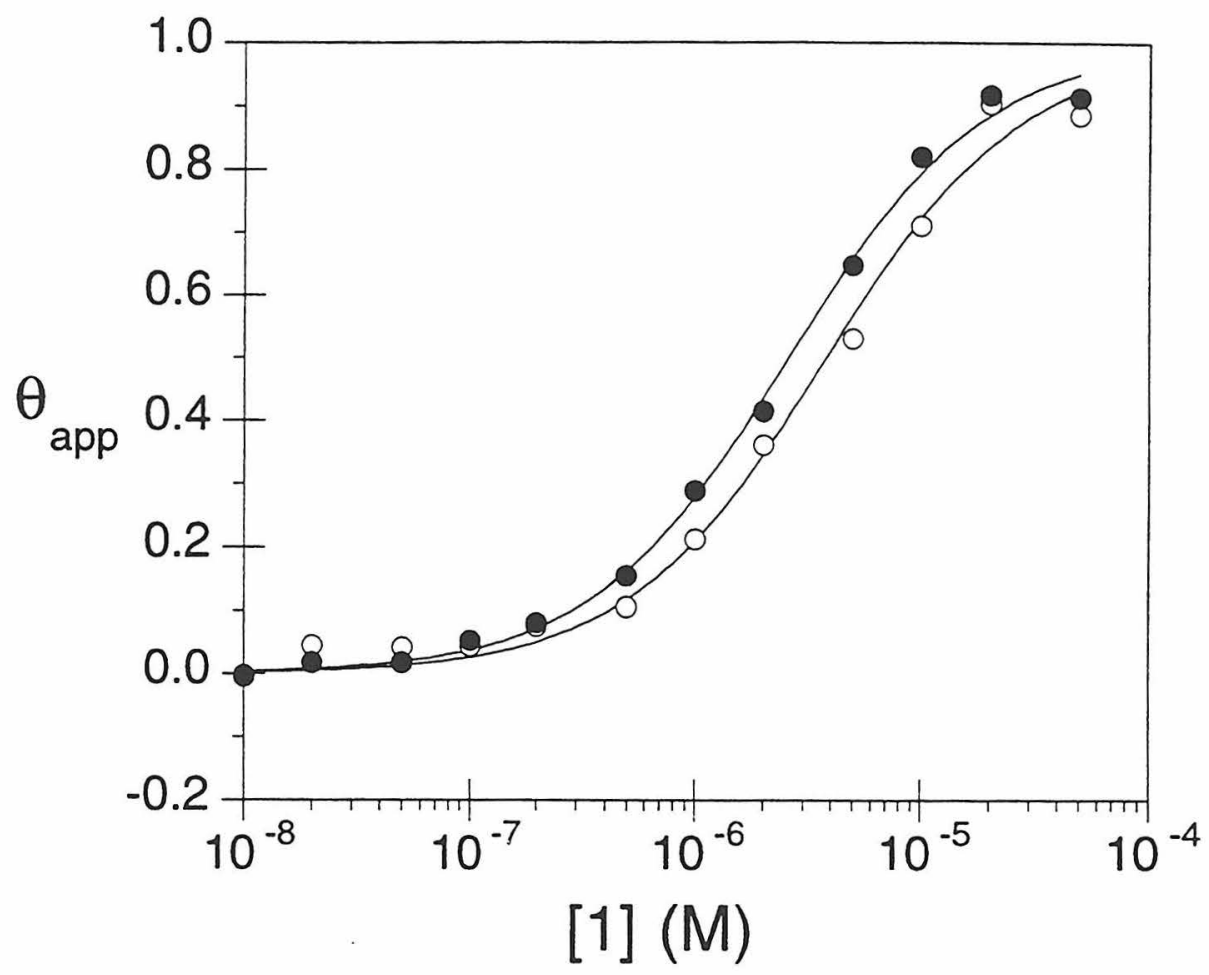

Figure 5.4. Binding isotherms obtained for oligonucleotide 1 alone (o), and in the presence of $5.0 \mu \mathrm{M}$ oligonucleotide $2(\bullet)$ bound to DNA where the two target sites are separated by one base pair. Three to four complete data sets were used to determine each association constant. 
Table 5.1: Equilibrium Association Constants for Two Purine-rich Triple Helix Forming Oligonucleotides Binding at Adjacent Sites on $\mathrm{DNA}^{a}$

\begin{tabular}{lcc}
\hline \multicolumn{1}{c}{ Oligonucleotide } & $K\left(\mathrm{M}^{-1}\right)$ & $\Delta \mathrm{G}\left(\mathrm{kcal} \bullet \mathrm{mol}^{-1}\right)$ \\
\hline 1 & $2.8( \pm 0.2) \times 10^{5}$ & $-7.4( \pm 0.1)$ \\
2 & $1.5( \pm 0.1) \times 10^{6}$ & $-8.4( \pm 0.1)$ \\
$1+2(5 \mu \mathrm{M})$ & $2.2( \pm 0.3) \times 10^{7}$ & $-10.0( \pm 0.1)$ \\
\hline$a$ Values reported in the table are mean values measured from DNase \\
footprinting titration experiments performed in Association buffer $(10 \mathrm{mM}$ \\
$\mathrm{NaCl}, 10 \mathrm{mM} \mathrm{MgCl}_{2}, 50 \mathrm{mM}$ Tris-acetate, $\left.\mathrm{pH} 7.0,24^{\circ} \mathrm{C}\right)$.
\end{tabular}

Table 5.2: Equilibrium Association Constants for Two Purine-rich Triple Helix Forming Oligonucleotides Binding on DNA where the Target Sites are Separated by One Base Pair ${ }^{a}$

\begin{tabular}{lcc}
\hline \multicolumn{1}{c}{ Oligonucleotide } & $K\left(\mathrm{M}^{-1}\right)$ & $\Delta \mathrm{G}\left(\mathrm{kcal} \bullet \mathrm{mol}^{-1}\right)$ \\
\hline $\mathbf{1}$ & $2.8( \pm 0.6) \times 10^{5}$ & $-7.4( \pm 0.1)$ \\
$1+2(5 \mu \mathrm{M})$ & $3.9( \pm 0.5) \times 10^{5}$ & $-7.6( \pm 0.1)$ \\
\hline$a$ Values reported in the table are mean values measured from DNase \\
footprinting titration experiments performed in Association buffer $(10 \mathrm{mM}$ \\
$\mathrm{NaCl}, 10 \mathrm{mM} \mathrm{MgCl} 2,50 \mathrm{mM}$ Tris-acetate, $\left.\mathrm{pH} 7.0,24^{\circ} \mathrm{C}\right)$.
\end{tabular}

\section{Discussion}

Two purine-rich oligonucleotides bind cooperatively to adjacent DNA sites with an interaction energy of $2.7 \mathrm{kcal} \bullet \mathrm{mol}^{-1}$. Cooperative interactions between oligonucleotides may arise from a structural transition between adjacent sites on DNA and increased base stacking between the terminal bases at the triplex junction. Recent data shows that cooperativity between pyrimidine oligonucleotides greatly varies from $1.5( \pm 0.1) \mathrm{kcal} \cdot \mathrm{mol}^{-1}$ to $2.9( \pm 0.1) \mathrm{kcal} \bullet \mathrm{mol}^{-1}$ depending on the sequence composition of the stack between the bases at the junction. ${ }^{3 \mathrm{c}}$ Previous experiments show that when two pyrimidine oligonucleotides bind on duplex DNA by triple helix formation to sites that are separated by one base pair, 
no cooperativity is observed. ${ }^{3 a, b}$ The results reported here show that a one base pair gap between adjacent triple helix sites abolishes cooperativity between purine-rich oligonucleotides, suggesting that there are no significant propagated structural changes beyond the immediately neighboring base pair in the purine motif as well. These combined results suggest that base stacking is the major contributor to cooperative interactions between pyrimidine and purine-rich triple helix forming oligonucleotides.

Base stacking interactions in aqueous solution arise from electrostatic, polarization, and dispersion forces. ${ }^{8}$ Optimized potential calculations show that dispersion and polarization interactions determine the magnitude of the total interaction energy, whereas electrostatic forces determine orientational preferences. ${ }^{8 d}$ The free energy of base stacking for monomer nucleosides associating in aqueous solution has been reported to vary between $-0.5 \mathrm{kcal} \bullet \mathrm{mol}^{-1}$ and -3.0 $\mathrm{kcal} \bullet \mathrm{mol}^{-1}$, depending on solution, salt conditions, nucleoside identity, concentration and temperature. ${ }^{8-i}$ While it is not clear to what extent hydrophobic forces, dispersion forces or interactions between partial charges dominate the free energy of base stacking, it is generally agreed that base stacking depends primarily on the size of the $\pi$-electron systems. ${ }^{8 f, g}$ The strong cooperativity observed between purine-rich oligonucleotides is consistent with the notion that a larger mobile $\pi$-electron system does contribute to a high free energy of stacking, which likely arises from favorable induced dipole and hydrophobic interactions between the terminal guanines at the triplex junction (Figure 5.5). The importance of maximal GG stacking interactions has been invoked in many biological systems, including genomic replication. ${ }^{9}$ 


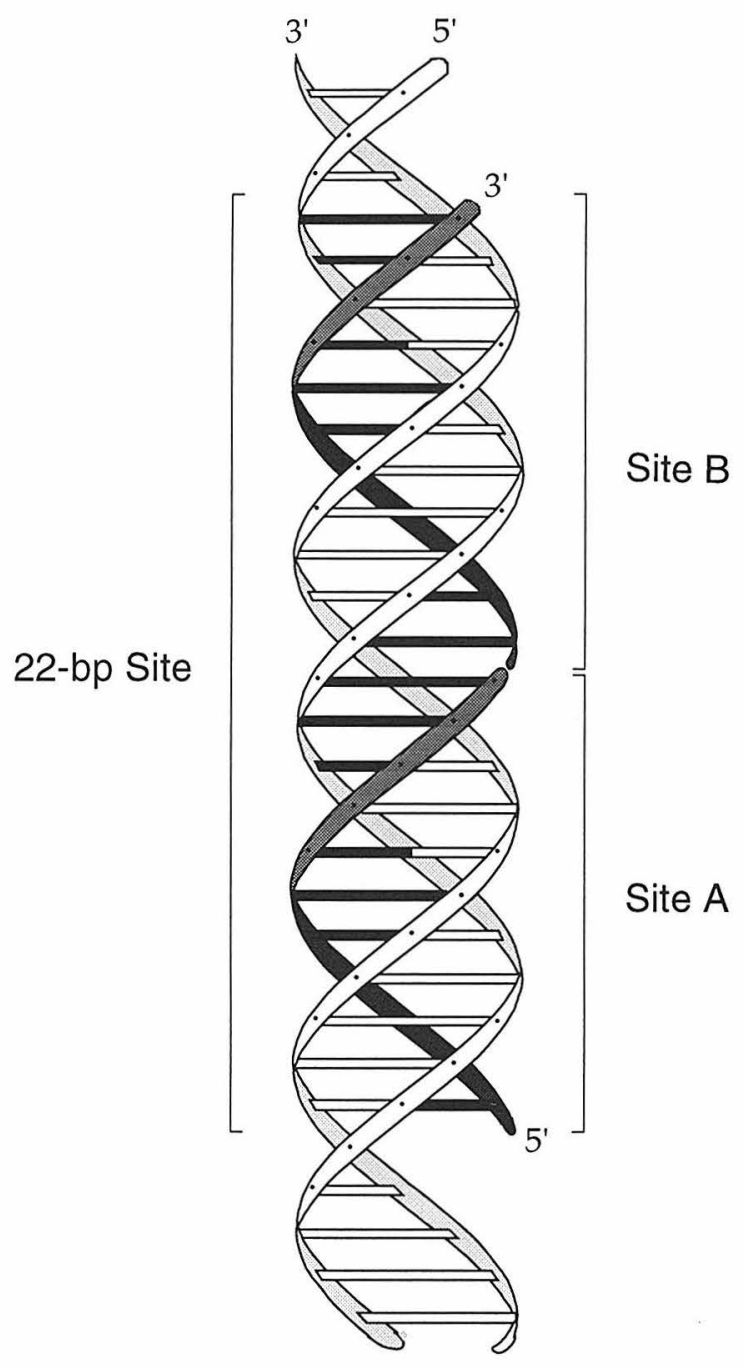

Figure 5.5. Ribbon model of oligonucleotides 1 and 2 bound at adjacent sites on duplex DNA by triple helix formation. The Watson-Crick duplex strands are shown as white ribbons, and the triple helix forming oligonucleotides are shown as dark ribbons. 


\section{Experimental Section}

General. E. coli JM110 was obtained from Stratagene. Qiagen plasmid kits were purchased from Qiagen Inc. Sonicated, deproteinized calf thymus DNA was purchased from Pharmacia. Nucleotide triphosphates were obtained from Pharmacia. Nucleotide triphosphates labeled with ${ }^{32} \mathrm{P}(\geq 3000 \mathrm{Ci} / \mathrm{mmol}$ ) were purchased from Amersham. Restriction endonucleases were purchased from New England Biolabs, and used according to the suggested protocol in the provided buffer. Thymidine and 2'-deoxyguanosine phosphoramidites were obtained from Glen Research. Sephadex resins were obtained from Pharmacia. Sequenase Version 2.0 was obtained from United States Biochemical. DNase was purchased from Pharmacia.

Construction of $\mathrm{pNC107A}$ and $\mathrm{pNC} 200$. This plasmid was prepared by standard methods. ${ }^{10}$ Briefly, pNC107A was prepared by hybridization of two synthetic oligonucleotides, 5'-d(AATTCTCTCTAAAAGGAGAGGGAGGGGGGAAGGAGGAAAACTCTCT)-3' and 5'-d(CTAGAGAGAGTTTTCCTCCTTCCCCCCTCCCTCTCCTTTTAGAGAG)-3', followed by ligation of the resulting duplex with pUC19 DNA previously digested with EcoRI and XbaI; this ligation mixture was used to transform E. coli JM110 (Stratagene). Plasmid DNA from ampicillin resistant white colonies was isolated and the presence of the desired insert confirmed by restriction analysis and Sanger sequencing. Preparative isolation of plasmid DNA was performed using a Qiagen plasmid kit. Plasmid pNC200 was prepared using a similar procedure with the oligonucleotides 5'd(AATTCTCTCTAAAAGGAGAGGGAGGGGGGGAAGGAGGAAAACTCTCT)-3' and 5'-d(CTAGAGAGAGTTTTCCTCCTTCCCCCCCTCCCTCTCCTTTTAGAGAG)-3'.

Oligonucleotide Preparation. Oligonucleotides were synthesized by standard automated solid-support chemistry on an Applied Biosystems Model 
380B DNA synthesizer using $O$-cyanoethyl- $N, N$-diisopropyl phosphoramidites. ${ }^{11}$ Oligonucleotides were deprotected with concentrated ammonium hydroxide at $55^{\circ} \mathrm{C}$ for $24 \mathrm{~h}$, and dried in vacuo. The crude 5 -terminal-dimethoxytrityl-protected oligonucleotides were heated at $90{ }^{\circ} \mathrm{C}$ for 5 minutes to prevent structure formation, purified by reverse phase FPLC on a ProRPC 10/10 $\left(C_{2}-C_{8}\right)$ column (Pharmacia LKB) and a gradient of $0-40 \% \mathrm{CH}_{3} \mathrm{CN}$ in $0.1 \mathrm{M}$ triethylammonium acetate, $\mathrm{pH} 7.0$, detritylated in $80 \% \mathrm{AcOH}$, and chromatographed a second time. The purified products were desalted on a NAP 25 column (Pharmacia) and dried in vacuo. Oligonucleotide concentrations were determined by UV absorbance at $260 \mathrm{~nm}$ using extinction coefficients $\left(\mathrm{M}^{-1} \mathrm{~cm}^{-1}\right)$ of $8800(\mathrm{~T})$ and $11700(\mathrm{G})$.

Preparation of Labeled Restriction Fragment. The 3'-32P-labeled duplex was prepared by digestion of the plasmid pNC107A with HindIII, followed by treatment with $\alpha-32 \mathrm{P}-\mathrm{dATP}, \alpha-32 \mathrm{P}-\mathrm{dCTP}, \alpha-32 \mathrm{P}-\mathrm{dGTP}$, and $\alpha-32 \mathrm{P}-\mathrm{TTP}$ in the presence of Sequenase. To remove nonincorporated radioactivity, the fragment was passed through a Pharmacia NICK column. The DNA was then digested with SspI, followed by separation of the resulting products on a $5 \%$ nondenaturing polyacrylamide gel (19:1, monomer/bis). The gel band corresponding to the desired 648-bp fragment was visualized by autoradiography, excised, crushed, and soaked in $10 \mathrm{mM}$ Tris, $\mathrm{pH} 8.0$, and $20 \mathrm{mM}$ EDTA, at $37^{\circ} \mathrm{C}$ for $15-18$ $h$. The resulting suspension was filtered through a $0.45-\mu \mathrm{m}$ filter, and the eluted DNA present in the supernatant was precipitated with $\mathrm{NaOAc} / \mathrm{EtOH}$. The DNA pellet was washed with $70 \% \mathrm{EtOH}$, dried in vacuo, resuspended in TE buffer (10 $\mathrm{mM}$ Tris, $\mathrm{pH}$ 8.0, $1 \mathrm{mM}$ EDTA), extracted five times with phenol, twice with 24:1 $\mathrm{CHCl}_{3}$ /isoamyl alcohol, and reprecipitated with $\mathrm{NaOAc} / \mathrm{EtOH}$. The DNA pellet was washed with $70 \% \mathrm{EtOH}$, dried in vacuo, and desalted on a Pharmacia NICK column. The precipitated pellet was resuspended in $25 \mathrm{mM}$ Tris-acetate, 100 $\mathrm{mM} \mathrm{NaCl}, \mathrm{pH} 7.0$ at a final activity of $100,000 \mathrm{cpm} / \mu \mathrm{L}$, and was stored at $-20^{\circ} \mathrm{C}$. 
Quantitative DNase Footprinting Titrations. In a typical experiment, a 5$\mathrm{nmol}$ aliquot of the desired oligonucleotide was dissolved in $50 \mu \mathrm{L}$ of water to produce a solution that was $100 \mu \mathrm{M}$ in oligonucleotide. This solution was then diluted serially to yield $100 \mu \mathrm{M}, 10 \mu \mathrm{M}, 1 \mu \mathrm{M}, 100 \mathrm{nM}, 10 \mathrm{nM}$, and $1 \mathrm{nM}$ solutions. The appropriate volume of these solutions was then distributed among 10$141.5 \mathrm{~mL}$ microcentrifuge tubes at the appropriate concentrations. A stock solution containing labeled target DNA, Tris-Acetate buffer, $\mathrm{NaCl}, \mathrm{MgCl}_{2}$, and calf thymus DNA, the second oligonucleotide where needed, and water, was distributed to each reaction tube in $12-\mu \mathrm{L}$ aliquots, and the appropriate volume of water were added to each tube to bring the total volume to $36 \mu \mathrm{L}$. After the oligonucleotide and the DNA were allowed to equilibrate for $24-48 \mathrm{~h}$ at $24^{\circ} \mathrm{C}$, the DNase footprinting reactions were initiated. A stock solution containing DNase $(0.2 \mathrm{mU} / \mu \mathrm{L})$ in Activity buffer ( $40 \mathrm{mM}$ Tris $\bullet \mathrm{HCl}, 6 \mathrm{mM} \mathrm{MgCl}_{2}, 2 \mathrm{mM} \mathrm{CaCl}_{2}, \mathrm{pH}$ 7.0), $300 \mathrm{mM} \mathrm{CaCl}_{2}, 15 \mathrm{mM} \mathrm{MgCl}_{2}$, and $15 \mu \mathrm{M}$ nonspecific oligonucleotide was prepared and distributed ( $4 \mu \mathrm{L} /$ tube). Final reaction conditions in $40 \mu \mathrm{L}$ of Association buffer were $50 \mathrm{mM}$ TrisOAc at pH 7.0, $10 \mathrm{mM} \mathrm{NaCl}, 10 \mathrm{mM} \mathrm{MgCl}$, $100 \mu \mathrm{M}$ bp calf thymus DNA, and approximately $10,000 \mathrm{cpm}$ labeled DNA. Control experiments have been carried out showing that the concentration of calf thymus DNA does not affect the equilibrium association constants of $11 \mathrm{mer}$ oligonucleotides binding to double-helical DNA due to their high specificity. The cleavage reactions were allowed to proceed for 8 minutes, and terminated by the addition of $8 \mu \mathrm{L}$ of $250 \mathrm{mM}$ EDTA followed by $\mathrm{NaOAc} / \mathrm{EtOH}$ precipitation. The DNA cleavage products were washed with $70 \%$ aqueous $\mathrm{EtOH}$, dissolved in $35 \mu \mathrm{L}$ of water, and dried in vacuo. The DNA was then resuspended in $10 \mu \mathrm{L}$ of formamide-TBE loading buffer and heated at $55^{\circ} \mathrm{C}$ for 10 minutes to effect dissolution. The Cerenkov radioactivity of the solutions was measured with a scin- 
tillation counter. The DNA was denatured at $95^{\circ} \mathrm{C}$ for 3 minutes, and $5 \mu \mathrm{L}$ from each sample were loaded onto a $8 \%$ denaturing polyacrylamide gel.

Construction of Titration Binding Isotherms. Gels were exposed to photostimulable storage phosphor imaging plates (Kodak Storage Phosphor Screen S0230 obtained from Molecular Dynamics) in the dark at $24{ }^{\circ} \mathrm{C}$ for 9-18 h. ${ }^{12} \mathrm{~A}$ Molecular Dynamics 400S PhosphorImager was used to obtain data from the phosphorimaging screens. Rectangles of the same dimensions were drawn around the target site and at the reference site. The ImageQuant v. 3.3 program running on a $66 \mathrm{MHz}$ AST Premium 486/33 computer was used to integrate the volume of each rectangle.

The apparent occupancy of the sites in a given lane was determined from the cleavage data using the following equation of Ackers and coworkers: ${ }^{7}$

$Y_{\text {app }}=1-\frac{I_{\text {site }} / I_{\text {ref }}}{I_{\text {site }} / I^{\circ} \text { ref }}$

where $I_{\text {site }}$ and $I_{\text {ref }}$ are the intensities of the cleavage bands at the target site and at the reference site, respectively, and $I^{\circ}$ site and $I^{\circ}$ ref are the corresponding intensities from a control lane to which no oligonucleotide has been added. The data was fit using an unweighted nonlinear least square procedure with three adjustable parameters. The following equation was used in the fitting procedure:

$Y_{\mathrm{app}}=\theta_{\min }+\left(\theta_{\max }-\theta_{\min }\right) \frac{K T[\mathrm{O}]_{\mathrm{tot}}}{1+K T[\mathrm{O}]_{\mathrm{tot}}}$

where $\theta_{\min }$ and $\theta_{\max }$ represent the experimentally observed values of $Y_{\text {app }}$ at $\theta$ $=0$ and $\theta=1$, respectively, $K_{T}$ is the equilibrium association constant for triple helix formation, and [O]tot is the oligonucleotide concentration. All data from a 
gel were used unless visual inspection revealed a flaw in the gel at either the target or reference site. The goodness of fit of the binding curve was judged by the reduced chi-squared criterion. Fits with $\chi^{2} n>1.5$ were discarded. Fits which met this criterion had correlation coefficients greater than 0.95. All $K_{T}$ values reported in the text or tables are the means of four experimental observations plus or minus the standard error of the mean. 


\section{References and Notes}

1. (a) Ptashne, M. A Genetic Switch; Blackwell Scientific Publications and Cell Press: Palo Alto, CA, 1986. (b) Cantor, C. R.; Schimmel, P. R. Biophysical Chemistry Part III: The Behavior of Biological Macromolecules; W. H. Freeman and Co.: New York, N. Y., 1980. (c) Hill, T. L. Cooperativity Theory in Biochemistry: Steady State and Equilibrium Systems; Springer-Verlag: New York, N. Y., 1985. (d) Adhya, S. Annual Reviews in Genetics 1989, 23, 227.

2. (a) Strobel, S. A.; Dervan, P. B. J. Am. Chem. Soc. 1989, 111, 6956. (b) Distefano, M. D.; Shin, J. A.; Dervan, P. B. J. Am. Chem. Soc. 1991, 113, 5901. (c) Distefano, M. D.; Dervan, P. B. J. Am. Chem. Soc. 1992, 114, 11006. (d) Distefano, M. D.; Dervan, P. B. Proc. Natl. Acad. Sci. USA 1993, 90, 1179.

3. (a) Colocci, N.; Distefano, M. D.; Dervan, P. B. J. Am. Chem. Soc. 1993, 115, 4468. (b) Colocci, N.; Dervan, P. B. J. Am. Chem. Soc. 1994, 116, 785. (c) Colocci, N.; Dervan, P. B. J. Am. Chem. Soc. 1995, 117, 4781. (d) Colocci, N.; Dervan, P. B. Manuscript in preparation.

4. Mergny, J. L.; Duval-Valentin, G.; Nguyen, C. H.; Perrouault, L.; Faucon, B.; Rougée, M.; Montenay-Garestier, T.; Bisagni, E.; Helène, C. Science $1992,256,1681$.

5. (a) Cooney, M.; Czernuszewics, G.; Postel, E. H.; Flint, S. J.; Hogan, M. E. Science 1988, 241, 456. (b) Beal, P. A.; Dervan, P. B. Science 1991, 251, 1360. (c) Durland, R. H.; Kessler, D. J.; Gunnell, S.; Duvic, M.; Pettitt, B. M.; Hogan, M. E. Biochemistry 1991, 30, 9246. (d) Pilch, D. S.; Levenson, C.; Shafer, R. H. Biochemistry 1991, 30, 6081. (e) Radhakrishnan, P.; de los Santos, C.; Patel, D. J. J. Mol. Biol. 1991, 221, 1403. (f) Beal, P. A.; Dervan, P. B. Nucleic Acids Res. 1992, 20, 2773. 
6. Singleton, S. F.; Dervan, P. B. J. Am. Chem. Soc. 1992, 114, 6956.

7. (a) Brenowitz, M.; Senear, D. F.; Shea, M. A.; Ackers, G. K. Meth. Enzymol. 1986, 130, 132. (b) Senear, D. F.; Brenowitz, M.; Shea, M. A.; Ackers, G. K. Biochemistry 1986, 125, 7344. (c) Brenowitz, M.; Senear, D. F.; Shea, M. A.; Ackers, G. K. Proc. Natl. Acad. Sci. USA 1986, 83, 8462.

8. (a) Sowers, L. C.; Shaw, B. R.; Sedwick, W. D. Biochem. Biophys. Res. Commun. 1987, 148, 790. (b) DeVoe, H.; Tinoco, I. J. Mol. Biol. 1962, 4, 500. (c) Sanyal, N. K.; Roychoudhury, M.; Ruhela, K. R.; Tiwari, S. N. J. Comput. Chem. 1986, 8, 604. (d) Ornstein, R. L.; Rein, R.; Breen, D. L.; MacElroy, R. D. Biopolymers 1978, 17, 2341. (e) Broom, A. D.; Schweizer, M. P.; Ts'o, P. O. P. J. Am. Chem. Soc. 1967, 89, 3612. (f) Ts'o, P. O. P. Molecular Associations in Biology; Academic Press: New York, N. Y., 1968, pp 39-75. (g) Nakano, N. I.; Igarishi, S. J. Biochemistry 1970, 9, 577. (h) Breslauer, K. J.; Frank, R.; Blocker, H.; Marky, L. A. Proc. Natl. Acad. Sci. USA 1986, 83, 3746. (i) Delcourt, S. G.; Blake, R. D. J. Biol. Chem. 1991, 266, 15160. (j) Herskovitz, T. T. Arch. Biochem. Biophys. 1962, 97, 474. (k) Herskovitz, T. T. Biochemistry 1963, 2, 335.

9. Maizels, N.; Weiner, A. M. The RNA World; Cold Spring Harbor Laboratory Press, 1983.

10. Sambrook, J.; Fritsch, E. F.; Maniatis, T. Molecular Cloning; 2nd ed., Cold Spring Harbor Laboratory Press: New York, N. Y., 1989.

11. Gait, M. J. (Ed.) Oligonucleotide Synthesis: A Practical Approach; IRL Press: Oxford, 1984.

12. Johnston, R. F.; Pickett, S. C.; Barker, D. L. Electrophoresis 1990, 11, 355. 


\section{CHAPTER SIX:}

\section{Synthesis of Oligonucleotide Analogs Containing 5-(1-Propynyl) and 2'-O-Allyl Substituents.}

\section{Introduction}

The reduction in size of oligonucleotides targeted to DNA sequences is biologically relevant as it may facilitate oligonucleotide penetration through cell membranes in vivo, and improve the specificity of oligonucleotides by increasing their sensitivity to single-base pair mismatches. Experiments have shown that short ( $<11$ nucleotides) pyrimidine oligonucleotides comprising unmodified bases are not able to bind DNA at micromolar concentrations at $\mathrm{pH} 7.0,24^{\circ} \mathrm{C}$ (see Chapter Four). Consequently, there has been a great interest in this laboratory and others in designing and synthesizing short oligonucleotide analogs containing nonnatural bases that bind double-helical DNA with high affinities.

In order to improve the strength of hybridization to RNA and DNA targets, oligonucleotides modified in the phosphate backbone, sugar moiety or heterocyclic base have been synthesized, and their properties regarding hybridization, nuclease resistance, and cellular uptake have been studied., ${ }^{1,2}$ Modifications of the phosphate backbone include replacement of the phosphodiester group by alkyl phosphonates, phosphorothioates, phosphoramidates, sulfones, sulfonates, sulfonamides, and methylhydroxylamines. ${ }^{1,2}$ Modifications of the sugar include opening of the ring, ${ }^{3 a}$ replacement of the furanose by a hexose ring ${ }^{3 \mathrm{~b}, \mathrm{c}}$ or a carbocyclic ring, ${ }^{3 \mathrm{~d}}$ and alkylation of the $2^{\prime}$-hydroxyl group. Modifications of the base aimed at improving pairing or stacking include extensive substitutions in both the aromatic nuclei and exocyclic functionalities. ${ }^{2}$ 
Among modifications in the sugar moiety, 2'-O-alkylation of oligonucleotides has shown to improve hybridization properties. More specifically, oligonucleotides containing 2'-O-alkyl substituents have shown to lead to enhanced double helix formation from single strand RNA and DNA. Methylation at the 2'position has resulted in increased thermal stability of double-stranded polyadenylic acid complexes, ${ }^{4 a}$ 2'-O-methylribonucleoside-RNA complexes, ${ }^{4 b, 4 c, 4 e, 4 h}$ and triple-stranded 2'-O-methylribonucleoside $\bullet$ DNA-DNA complexes. ${ }^{4 g}$ Methyl substitution at the 2'-OH has also rendered oligonucleotides less susceptible towards nuclease degradation than unmodified oligonucleotides. ${ }^{4 b, 4 d, 4 e}$ Finally, 2'-O-methylribonucleoside-RNA duplexes have shown to be RNase $\mathrm{H}$ substrates, suggesting that 2'-O-methyl analogs may be suited as antisense probes. ${ }^{4 c, 4 f}$ In an effort to understand why methylation of the 2'hydroxyl confers greater stability to the modified double- and triple-helical hybrids, several observations regarding how a 2'-O-methyl substituent affects the sugar puckering and the orientation of the base relative to the sugar have been put forth. ${ }^{4 a, 4 g, 5}$ However, while it is agreed that methylation may cause slight changes in the stacking interactions and rigidity of the backbone in a helical complex, the structure of complexes containing 2'-O-methylated analogs has not been unambiguously established. ${ }^{4 a, 4 b, 4 g, 5}$

Oligonucleotides containing a 2'-O-allyl substituent have even higher affinity and specificity for single strand RNA than the corresponding 2'-O-methyl analogs. ${ }^{4 e, 6}$ Unlike 2'-O-methyl analogs, 2'-O-allyl analogs were found to be completely resistant to certain RNA and DNA nucleases. ${ }^{4 e, 6}$ Moreover, 2'-O-allylsubstituted oligonucleotides were found to bind to complementary RNA sequences in crude HeLa cell nuclear extracts much more rapidly and selectively than the corresponding 2'-O-methyl-substituted or unmodified oligonucleotides. ${ }^{4 e}$ The high specificity of 2'-O-allyl relative to 2'-O-methyl derivatives in 
crude nuclear extracts is presumably due to a greater steric hindrance imposed on protein binding by the bulkier allyl group. In other experiments, oligonucleotides with an even bulkier substituent, such as a 2'-O-(3,3-dimethylallyl) group, were found to be more resistant to nuclease degradation, but could not form stable hybrids with complementary RNA sequences, possibly because of steric hindrance. ${ }^{4 e}$ The improved hybridization and nuclease resistance properties of 2'-O-allyl substituted oligonucleotides indicated that these may be useful for antisense inhibition.

Among modifications in the heterocyclic base, alkyl and alkenyl substitutions at the 5-position of 2'-deoxypyrimidines have resulted in increased binding affinity of oligodeoxyribonucleotides to single- and double-stranded DNA. ${ }^{78}$ Pyrimidine 2'-deoxynucleosides with unsaturated substituents at the 5-position have shown antiviral and anticancer properties. ${ }^{9}$ Thermal denaturation studies revealed that 5-(1-propynyl)-2'-deoxyuridine significantly enhances double and triple helix formation on DNA (see also Chapter Four). ${ }^{10}$ It was proposed that the propynyl group, which is planar with the heterocycle, may both increase the enthalpy of binding by enhancing base stacking, and favor the entropy of binding due to the greater hydrophobicity and bulkiness of the propynyl relative to the methyl group. Interestingly, it was also shown that a 1-propynyl substituent at the 5-position of deoxycytidine destabilizes triple-helical complexes, while stabilizing double-helical ones, presumably due to a decrease in $\mathrm{pKa}$ of the nucleotide. ${ }^{10}$ In addition, it was observed that the increased hydrophobicity of the 5-(1-propynyl)-substituted heterocycle may facilitate oligonucleotide penetration through cell membranes. The greater stability of double-helical 5-(1-propynyl)ribonucleoside $\bullet$ DNA and triple-helical 5-(1propynyl)ribonucleoside $\bullet$ DNA-DNA structures indicated that 5-(1-propynyl)- 
substituted oligonucleotides may in fact be useful for the sequence-specific recognition of short DNA tracts.

\section{Research Design}

In light of previous studies showing that a 2'-O-allyl- or 5-(1-propynyl)substitution increases the stability of triple helices, we decided to synthesize modified nucleosides containing both 2'-O-allyl and 5-(1-propynyl) substitutions (Figure 6.1). At the time the decision was made, no complete thermodynamic characterization of triplexes containing 2'-O-allyl- and/or 5-(1-propynyl)substituted oligonucleotides had been reported. In order to elucidate the factors contributing to the higher stability of triplexes containing 2'-O-allyl and 5-(1propynyl) derivatives, we proposed to determine the energetics of oligonucleotide-directed triple helix formation for pyrimidine oligonucleotide analogs containing the 5-(1-propynyl)- and the 2'-O-allyl-modified nucleosides shown in Figure 6.1 using quantitative affinity cleavage titrations. ${ }^{7 a}$

Figure 6.2 shows the pyrimidine oligonucleotide analogs proposed to be synthesized and their DNA target site. The equilibrium association constant of the oligodeoxyribonucleotide-EDTA $\bullet$ Fe conjugate $5^{\prime}-\mathrm{d}\left({ }^{*}{ }^{T T T T T}{ }^{m}{ } T^{m}{ }^{m} T^{m} C{ }^{m} C-\right.$ $\left.\mathrm{T}^{\mathrm{m} C T}\right)-3^{\prime}\left(1\right.$, Figure 6.2) binding to duplex DNA at $22^{\circ} \mathrm{C}, \mathrm{pH} 7.0(100 \mathrm{mM} \mathrm{NaCl}$, $1 \mathrm{mM}$ spermine) had been previously determined using quantitative affinity cleavage titrations. ${ }^{7 a}$ The equilibrium association constant of oligonucleotideEDTA $\bullet$ Fe conjugate analog 2 containing 5-(1-propynyl)-2'-deoxyuridine (I) instead of $\mathrm{T}$ would provide information regarding the influence of the propynyl substitution of $U$ on triple helix formation. Similarly, the equilibrium association constant of oligonucleotide analog 3 containing 5-methyl-2'-O-allyluridine (II) and 5-methyl-2'-O-allylcytidine (III) instead of $\mathrm{T}$ and $\mathrm{m}_{\mathrm{C}}$, respectively, would provide information regarding the influence of the allyl substitution of $U$ and 

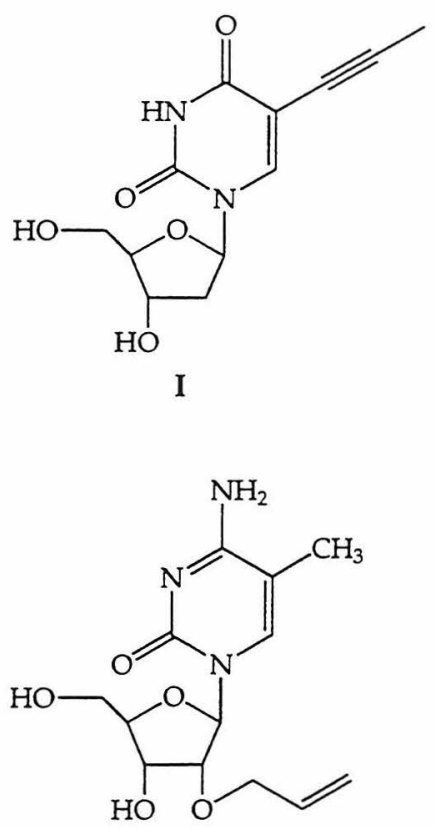

III
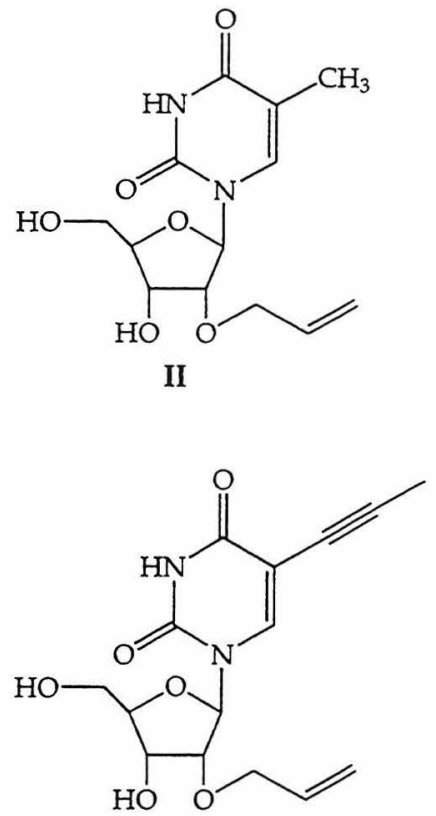

IV

Figure 6.1. Nucleoside analogs bearing 5-(1-propynyl)- and/or 2'-O-allylsubstituents. I: 5-(1-propynyl)-2'-deoxyuridine; II: 5-methyl-2'-O-allyluridine; III 5-methyl-2'-O-allylcytidine; IV: 5-(1-propynyl)-2'-O-allyluridine.

$\mathrm{m}_{\mathrm{C}}$ on triple helix formation. Finally, the equilibrium association constant of oligonucleotide 4 containing 5-(1-propynyl)-2'-O-allyluridine (IV) and 5-methyl2'-O-allylcytidine (III) instead of $\mathrm{T}$ and $\mathrm{m}_{\mathrm{C}}$, respectively, would provide information regarding the influence of the simultaneous presence of the allyl and propynyl groups on triple helix formation. In addition, work towards the synthesis of the 2'-O-methyl and 5-(1- propynyl) derivatives of 1 was being undertaken in our laboratory as well. The combined results of these experiments would give information on the relative energetic contributions of the 2'-Omethyl, 2'-O-allyl, and 5-(1-propynyl) groups to the stability of triplexes. 


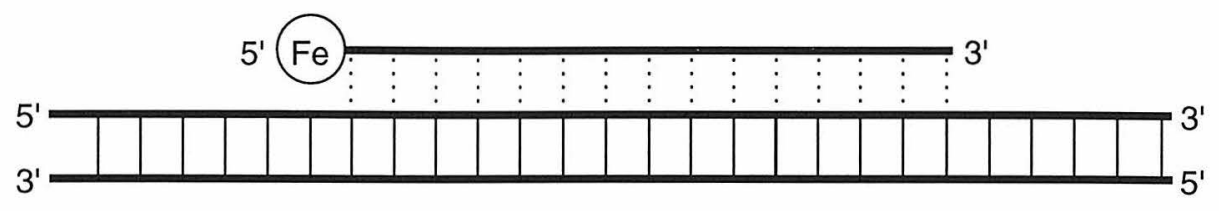

15-bp Site

5'-A A GG A A A A A A A A A A A AGAGA T C T G-3' 3'-T T C C T T TT T T T T T T T CTCTCTAG A C $-5^{\prime}$

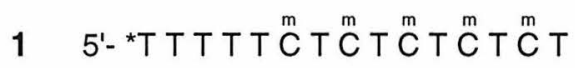

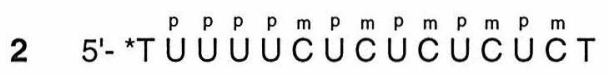

3 5- *

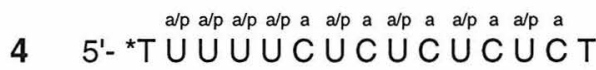

Figure 6.2. Schematic representation of a 15-nt oligonucleotide binding to double-helical DNA by triple helix formation. ${ }^{\mathrm{m}} \mathrm{C}=5$-methyl-2'-deoxycytidine; $\mathrm{PU}=5$-(1-propynyl)-2'-deoxyuridine; ${ }^{\mathrm{U}} \mathrm{U}=2$ - $-\mathrm{O}$-allyluridine; ${ }^{\mathrm{a}} \mathrm{C}=$ 5-methyl-2'-O-allylcytidine; ${ }^{\text {a/pU }}=$ 5-(1-propynyl)-2'-O-allyluridine. 
The syntheses of 5-(1-propynyl)-2'-deoxyuridine (I) and of its 5'-O-DMTprotected phosphoramidite derivative, now commercially available, are described in Chapter Four. The syntheses of the 5'-O-DMT-protected phosphoramidites of 5-methyl-2'-O-allyluridine, 5-methyl-2'-O-allylcytidine, and 5-(1-propynyl)-2'-O-allyluridine, and of oligonucleotides $1,2,3$, and 4, are described below. The thermodynamic analysis of the binding of oligonucleotides 1, 2, 3, and 4 to double-helical DNA by triple helix formation has not been carried out yet.

\section{Synthesis of Nucleosides}

The synthesis of 5-(1-propynyl)-2'-O-allyluridine is shown in Figure 6.3. $\mathrm{N}^{3}$ Benzoyl protection of 5-iodouridine ${ }^{11}$ followed by treatment of VI with 1,3dichloro-1,1,3,3-tetraisopropyldisiloxane $\mathrm{h}^{4 \mathrm{~h}}$ afforded the sugar-protected compound VII, which was then coupled to propyne in the presence of palladium to afford the 5-(1-propynyl)-substituted derivative VIII in 92\% yield. Treatment of VIII with allyl bromide in the presence of $\mathrm{Ag}_{2} \mathrm{O}^{4 \mathrm{~b}}$ afforded the 2 '-O-allyl derivative IX in $45 \%$ yield. Removal of the benzoyl group with dilute $\mathrm{NH}_{4} \mathrm{OH}_{1}^{4 \mathrm{~b}}$ followed by deprotection of the sugar hydroxyls with $0.5 \mathrm{~N} \mathrm{HCl}^{4 \mathrm{~b}}$ afforded 5-(1propynyl)-2'-O-allyluridine IV, which was converted into the 5'-O-DMTprotected phosphoramidite derivative XII according to standard protocols.

The 5'-O-DMT-protected phosphoramidite derivatives of 5-methyl-2'-Oallyluridine (XXII) (Figure 6.4) and 5-methyl-2'-O-allylcytidine (XXVII) (Figure 6.5) were synthesized in an analogous manner to that used by Froehler et al. for the syntheses of 2'-O-allyluridine and 2'-O-allylcytidine. ${ }^{12}$ Reaction of $\beta-\mathrm{D}$ ribofuranose-1-acetate-2,3,5-tribenzoate (XIII) with thymine in the presence of $\mathrm{N}, \mathrm{O}$-bis(trimethylsilyl)acetamide and stannic chloride, followed by deprotection of the sugar hydroxyls with $\mathrm{NaOH}$ afforded 5-methyluridine (XVI) in 85\% 

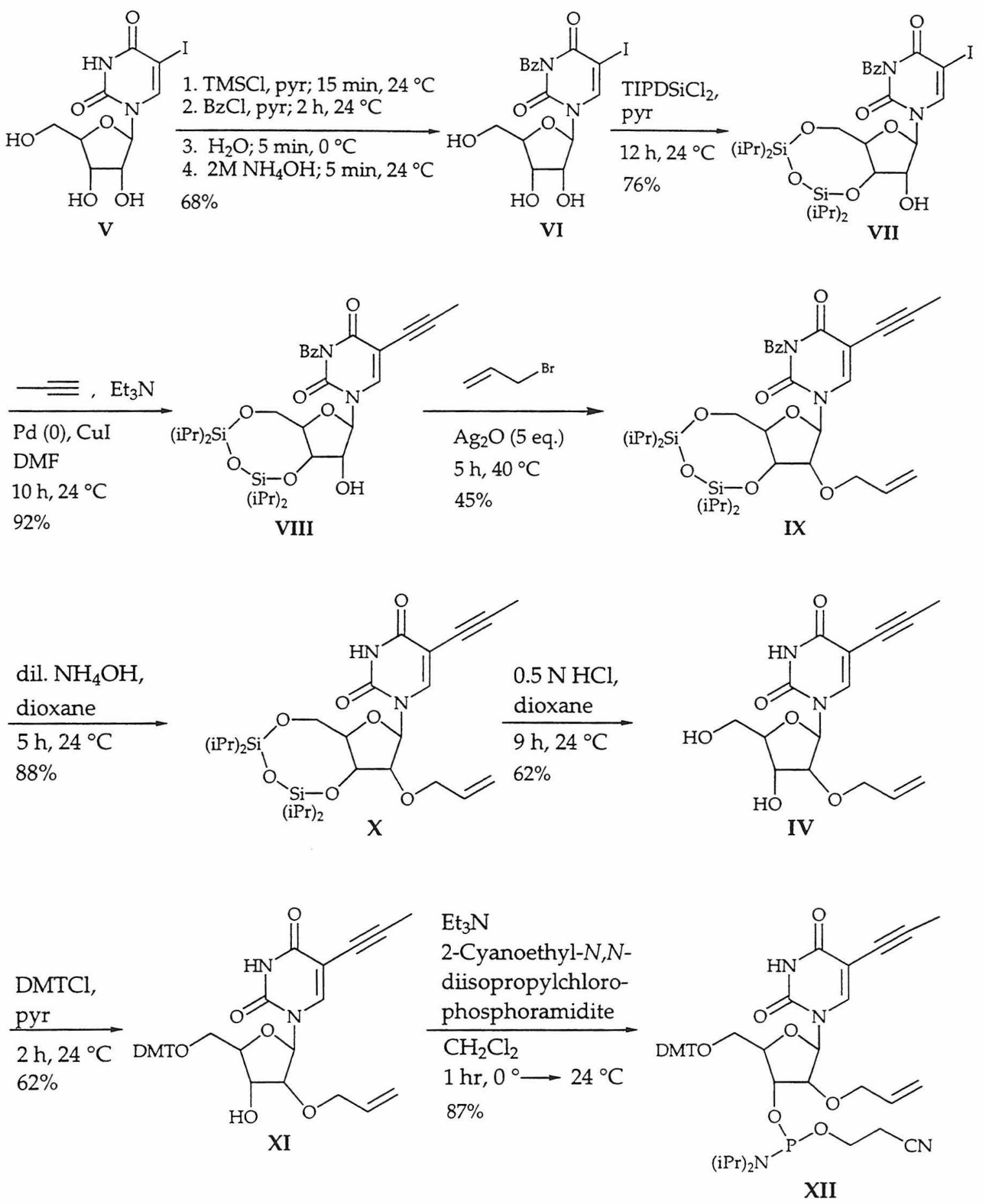

Figure 6.3. Synthesis of the 5'-O-DMT-protected phosphoramidite of 5-(1propynyl)-2'-O-allyluridine. 

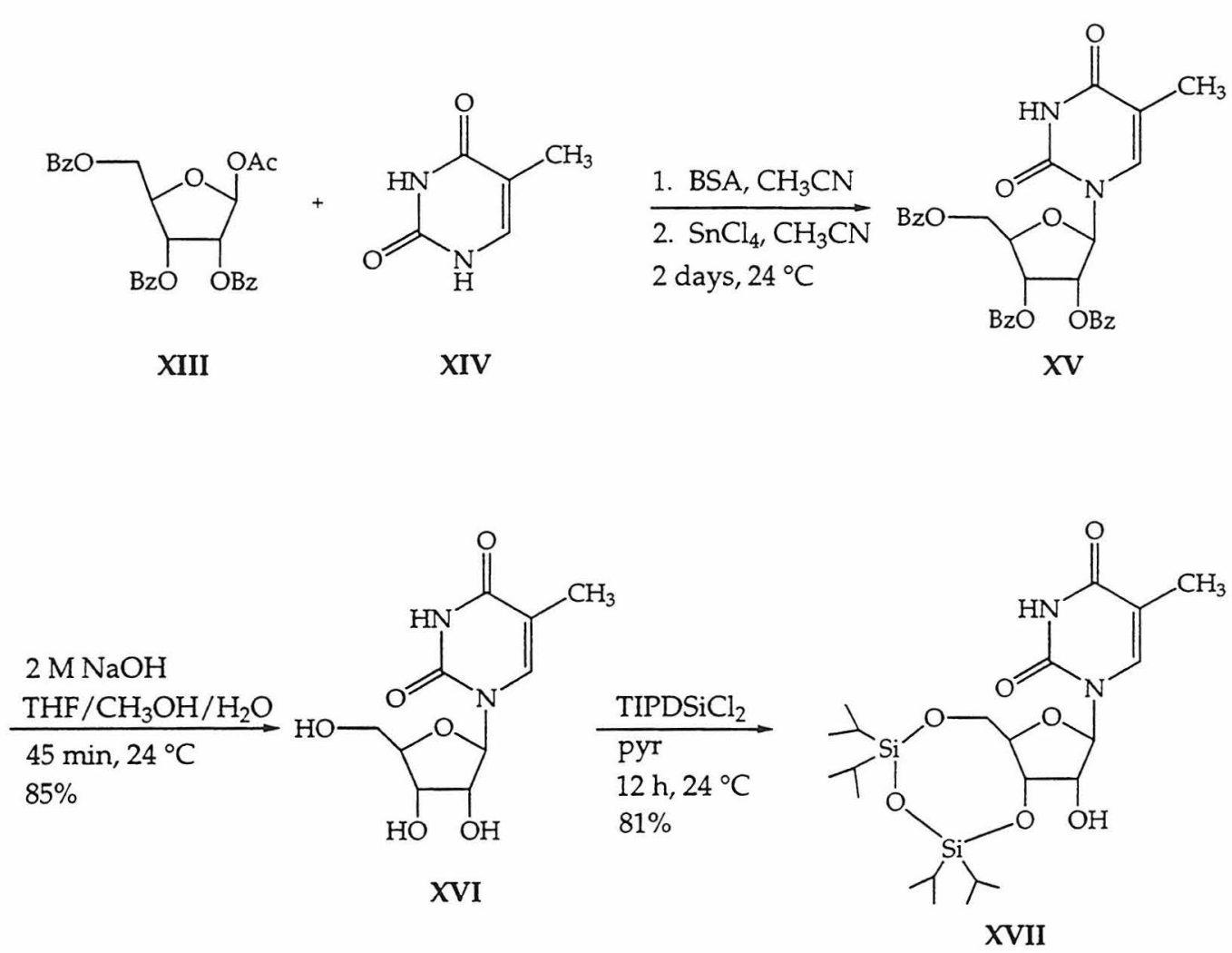

1. $\mathrm{Et}_{3} \mathrm{~N}, 2$-mesitylenesulfonylchloride,

DMAP

$\mathrm{CH}_{2} \mathrm{Cl}_{2}$

2. 2,6-Dichlorophenol,

1,4-diazabicyclo[2,2,2]octane,

$\mathrm{CH}_{2} \mathrm{Cl}_{2}$

4 days, $24^{\circ} \mathrm{C}$

$82 \%$

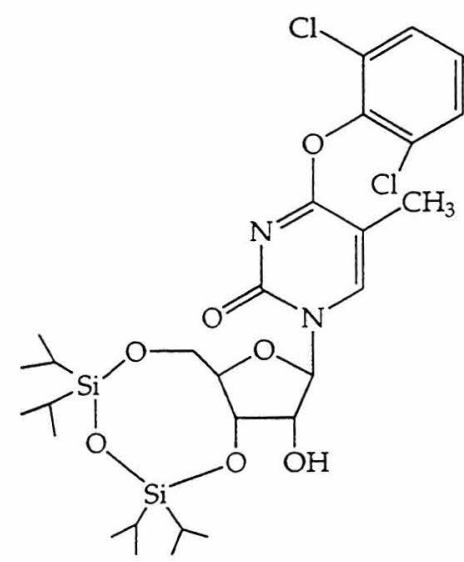

XVIII 

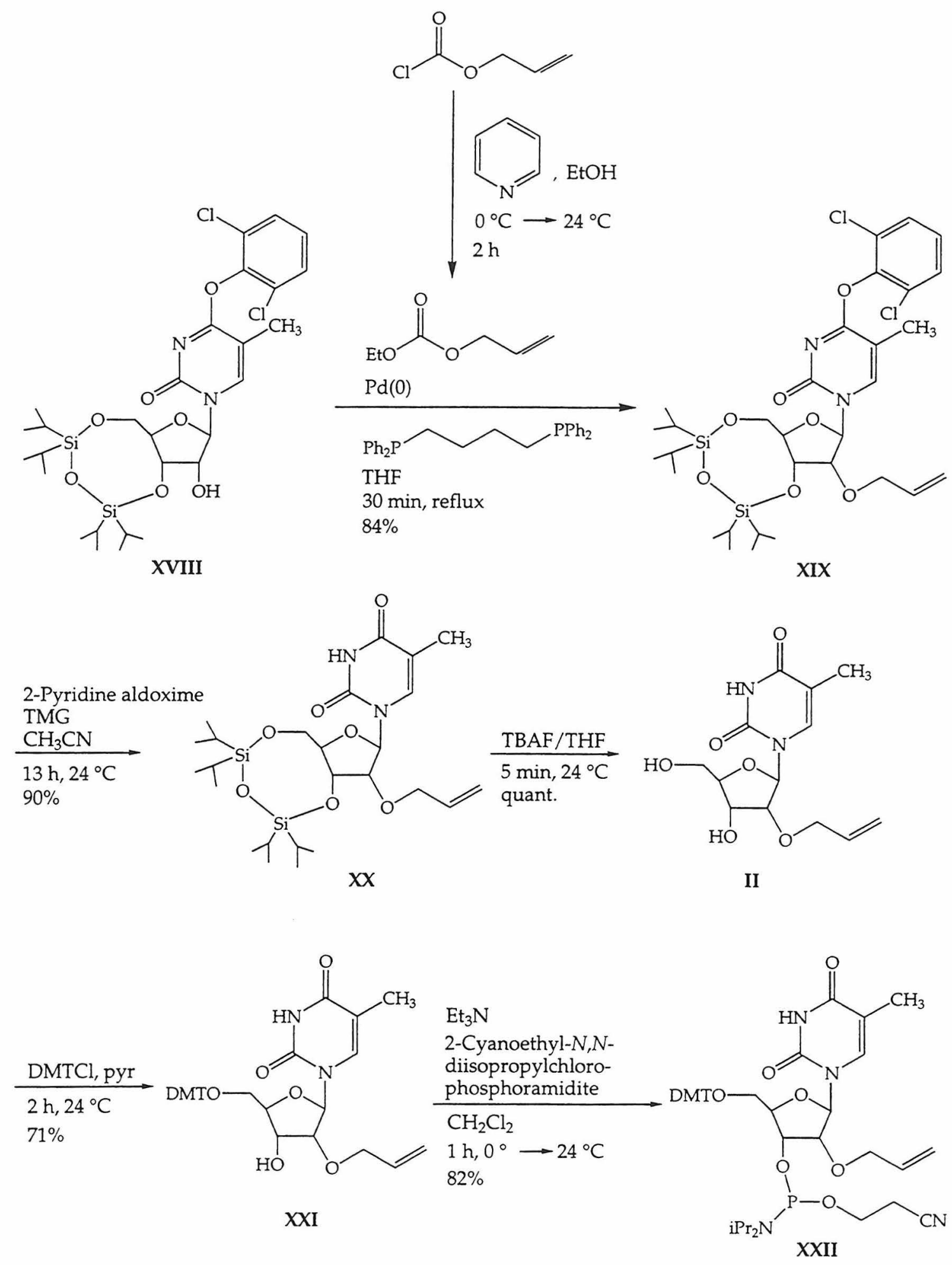

Figure 6.4. Synthesis of the 5'-O-DMT-protected phosphoramidite of 5-methyl2'-O-allyluridine. 

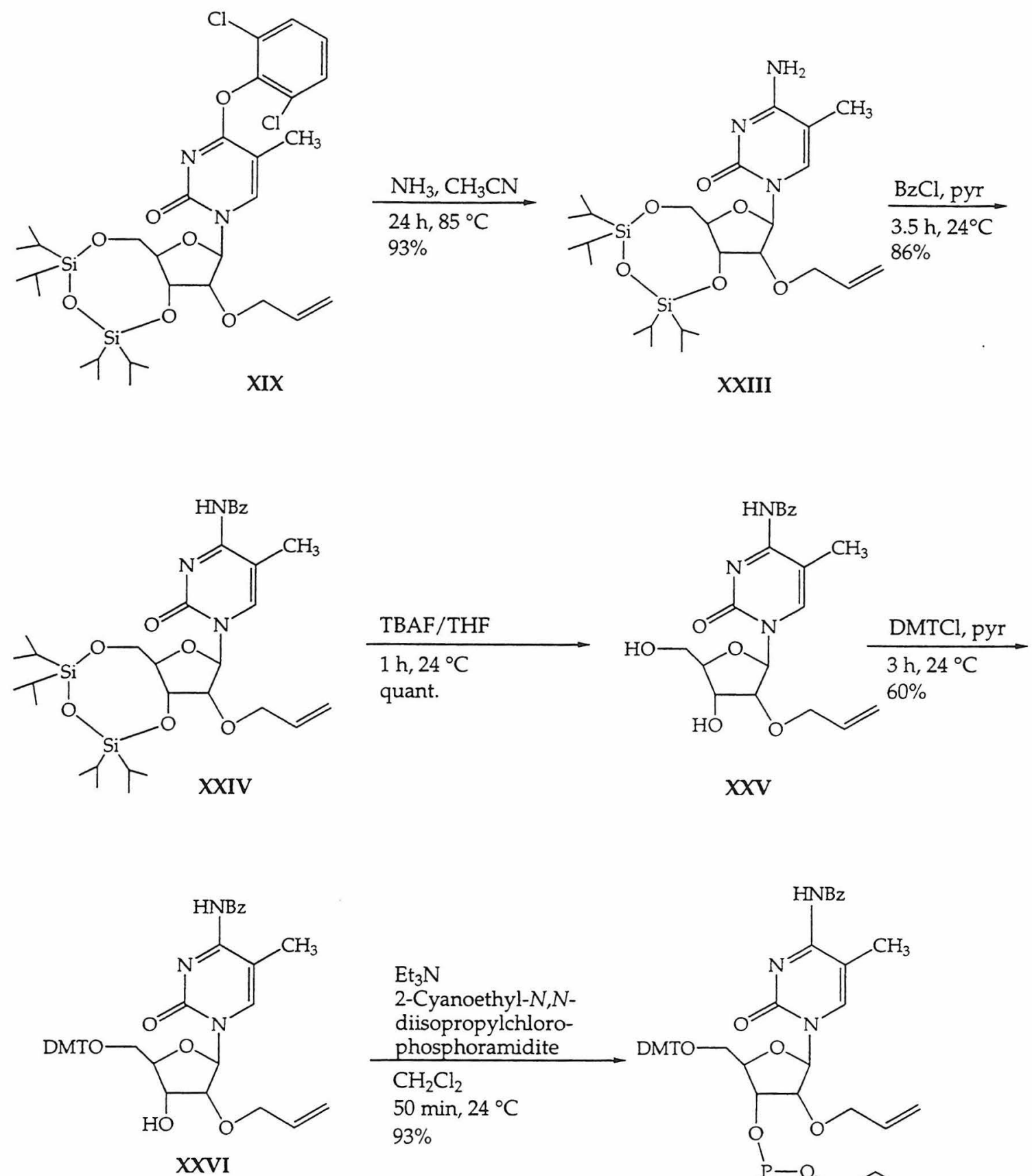

$\mathrm{Et}_{3} \mathrm{~N}$

2-Cyanoethyl- $N, N$ diisopropylchlorophosphoramidite $\mathrm{CH}_{2} \mathrm{Cl}_{2}$

$50 \mathrm{~min}, 24^{\circ} \mathrm{C}$

$93 \%$

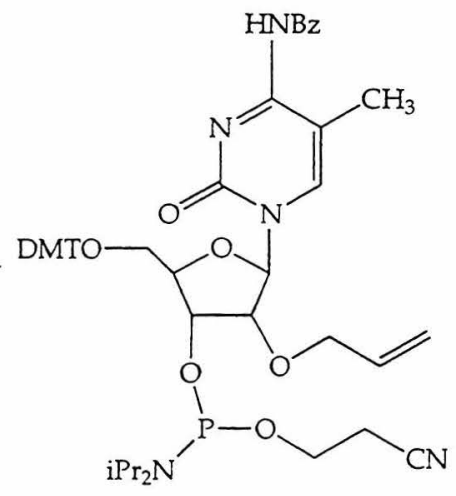

XXVII

Figure 6.5 Synthesis of the 5'-O-DMT-protected phosphoramidite of 5-methyl-2'O-allylcytidine. 
overall yield. Treatment of XVI with 1,3-dichloro-1,1,3,3-tetraisopropyldisiloxane followed by protection of the C4 carbonyl group with 2,6-dichlorophenol ${ }^{13}$ afforded compound XVIII in $82 \%$ yield. Reaction of adduct XVIII with allyl ethyl carbonate ${ }^{14}$ in the presence of palladium ${ }^{15}$ afforded the 2'-O-allyl derivative XIX in $84 \%$. Removal of the 2,6-dichlorophenyl group with 2-pyridinealdoxime ${ }^{12}$ followed by deprotection of the 3'- and 5'-sugar hydroxyls with TBAF afforded 5methyl-2'-O-allyuridine (II) in excellent overall yield. 5-Methyl-2'-O-allyluridine was converted into the corresponding 5'-O-DMT-protected phosphoramidite derivative XXII according to standard procedures.

The synthesis of the 5'-O-DMT-protected phosphoramidite of 5-methyl-2'-Oallylcytidine (XXVII) is shown in Figure 6.5. Reaction of the 2'-O-allyl derivative XIX with gaseous ammonia ${ }^{12}$ followed by protection of the exocyclic amino group with benzoyl chloride ${ }^{11}$ and removal of the disiloxane group afforded $\mathrm{N}^{4}$ benzoyl-5-methyl-2'-O-allylcytidine (XXV) in very good yield. The corresponding 5'-O-DMT-protected phosphoramidite derivative XXVII was synthesized according to standard procedures.

\section{Experimental Section}

General. ${ }^{1} \mathrm{H}$ and ${ }^{13} \mathrm{C}$ NMR spectra were recorded on a General Electric QE 300 NMR spectrometer and chemical shifts are reported in ppm using the solvent peak (DMSO, $2.49 \mathrm{ppm} ; \mathrm{CDCl}_{3}, 7.26 \mathrm{ppm}$ ) as internal standard. Mass spectra were obtained from the mass spectroscopy facility at the University of California, Riverside. Flash chromatography was carried out under positive air pressure using EM Science Kieselgel 60 (230-400 mesh size).

Materials. Dry DMF and dry $\mathrm{nBuOH}$ were obtained from Aldrich. Pyridine and triethylamine were distilled from $\mathrm{CaH}_{2}$. Commercially available propyne was purchased from Lancaster. Dimethoxytrityl chloride, 1,3-dichloro-1,1,3,3- 
tetraisopropyldisiloxane, and Dowex $1 \times 2$ resin $\left(\mathrm{Cl}^{-}\right.$form, 100-200 mesh) were obtained from Fluka. 5-Iodo-2'-deoxyuridine, 5-iodouridine, CuI, tetrakis(triphenylphosphine)palladium (0), 1,2-dibromopropane, trimethylsilyl chloride, benzoyl chloride, and allyl bromide were obtained from Aldrich.

$N^{3}$-Benzoyl-5-iodouridine (VI). After coevaporation with pyridine (3x), 5iodouridine $(10.0 \mathrm{~g}, 27.0 \mathrm{mmol})$ was dissolved in dry pyridine $(100 \mathrm{~mL})$ under argon. Trimethylsilyl chloride $(24 \mathrm{~mL}, 0.19 \mathrm{~mol})$ was slowly added, and the resulting suspension was allowed to stir at room temperature for 30 minutes. After addition of benzoyl chloride $(15.6 \mathrm{~mL}, 0.13 \mathrm{~mol})$, the reaction mixture was allowed to stir at room temperature for $2.5 \mathrm{~h}$. The reaction mixture was cooled in an ice bath, water $(20 \mathrm{~mL})$ was added, and the suspension was stirred at $4{ }^{\circ} \mathrm{C}$ for 5 minutes. Concentrated $\mathrm{NH}_{4} \mathrm{OH}(20 \mathrm{~mL}, 2 \mathrm{~N}$ final concentration) was added, and the mixture was allowed to stir at room temperature for 15 minutes. The mixture was concentrated in vacuo, suspended in EtOAc $(600 \mathrm{~mL})$, and washed with a saturated solution of $\mathrm{NaHCO}_{3}(600 \mathrm{~mL})$. The organic layers were dried $\left(\mathrm{Na}_{2} \mathrm{SO}_{4}\right)$, and concentrated. Flash chromatography $\left(6 \% \mathrm{MeOH} / \mathrm{CH}_{2} \mathrm{Cl}_{2}\right)$ afforded $8.73 \mathrm{~g}\left(68 \%\right.$ yield) of product in the form of a white solid. ${ }^{1} \mathrm{H}$ NMR (DMSO) $\delta 3.43-3.63(\mathrm{~m}, 1 \mathrm{H}), 3.70-3.80(\mathrm{~m}, 1 \mathrm{H}), 3.85-3.92(\mathrm{~m}, 1 \mathrm{H}), 4.02-4.08(\mathrm{~m}, 2$ $\mathrm{H})$, 5.13-5.18 $(\mathrm{m}, 1 \mathrm{H}), 5.38-5.39(\mathrm{~m}, 1 \mathrm{H}), 5.52-5.54(\mathrm{~m}, 1 \mathrm{H}), 5.67-5.68(\mathrm{~m}, 1 \mathrm{H})$, 7.57-7.59 (m, $2 \mathrm{H})$, 7.62-7.79 (m, $1 \mathrm{H}), 8.02-8.04(\mathrm{~m}, 1 \mathrm{H}), 8.76$ (s, $1 \mathrm{H}) .{ }^{13} \mathrm{C}$ NMR (DMSO) $\delta 59.88,69.01,74.35,84.88,89.61,115.45,115.96,129.73,130.81,130.92$, 135.02, 146.08; FABMS m/e (relative intensity) $475.0030(\mathrm{M}+\mathrm{H}, 475.0002$ calcd. for $\mathrm{C}_{16} \mathrm{H}_{16} \mathrm{IN}_{2} \mathrm{O}_{7}$ ).

$N^{3}$-Benzoyl-5-iodo-3', $5^{\prime}$-O-(tetraisopropyldisiloxane) uridine (VII). $N^{3}$-Benzoyl-5-iodouridine $(0.40 \mathrm{~g}, 0.80 \mathrm{mmol})$ was dissolved in dry pyridine $(4.0 \mathrm{~mL})$ under argon. To the solution was slowly added 1,3-dichloro-1,1,3,3tetraisopropyldisiloxane $(291 \mu \mathrm{L}, 0.90 \mathrm{mmol})$, and the resulting suspension was 
allowed to stir at room temperature for $12 \mathrm{~h}$. The reaction mixture was concentrated in vacuo, dissolved in EtOAc $(200 \mathrm{~mL})$, washed with water $(3 \times 200$ $\mathrm{mL})$, dried $\left(\mathrm{Na}_{2} \mathrm{SO}_{4}\right)$, and reconcentrated. Flash chromatography (5-10\% EtOAc/petroleum ether) afforded $0.43 \mathrm{~g}$ ( $76 \%$ yield) of product in the form of a white foam. ${ }^{1} \mathrm{H}$ NMR $\left(\mathrm{CDCl}_{3}\right) \delta 1.01-1.08(\mathrm{~m}, 28 \mathrm{H}), 2.79(\mathrm{~m}, 1 \mathrm{H}), 3.98-4.04(\mathrm{~m}$, $1 \mathrm{H}), 4.08-4.13(\mathrm{~m}, 2 \mathrm{H}), 4.19-4.21(\mathrm{~m}, 1 \mathrm{H}), 4.37-4.40(\mathrm{~m}, 1 \mathrm{H}), 5.73(\mathrm{~s}, 1 \mathrm{H}), 7.48-7.53$ $(\mathrm{m}, 2 \mathrm{H}), 7.64-7.66(\mathrm{~m}, 1 \mathrm{H}), 7.89-7.92(\mathrm{~m}, 2 \mathrm{H}), 8.07(\mathrm{~s}, 1 \mathrm{H}) .{ }^{13} \mathrm{C}$ NMR $\left(\mathrm{CDCl}_{3}\right) \delta$ $12.49,12.64,12.92,13.40,16.82-17.62,59.96,67.90,68.83,75.04,82.27,91.16,129.16$, $130.52,130.88,135.28,143.89,148.59,158.82,167.58$; FABMS m/e (relative intensity) $717.1517\left(\mathrm{M}+\mathrm{H}, 717.1525\right.$ calcd. for $\left.\mathrm{C}_{28} \mathrm{H}_{38} \mathrm{IN}_{2} \mathrm{O}_{8} \mathrm{Si}_{2}\right)$.

$N^{3}$-Benzoyl-5-(1-propynyl)-3', $5^{\prime}$-O-(tetraisopropyldisiloxane)uridine (VIII). A mixture of $N^{3}$-benzoyl-5-iodo-3',5'-O-(tetraisopropyldisiloxane)uridine (VII) (1.50 g, $2.10 \mathrm{mmol}), \mathrm{CuI}(0.08 \mathrm{~g}, 0.42 \mathrm{mmol})$, tetrakis(triphenylphosphine)palladium (0) $(0.24 \mathrm{~g}, 0.21 \mathrm{mmol})$, and triethylamine $(0.62 \mathrm{~mL}, 4.41 \mathrm{mmol})$ in dry DMF (30 mL) was stirred under argon. Commercial propyne was bubbled through the mixture for $10 \mathrm{~h}$. The mixture was allowed to stir at room temperature for $8 \mathrm{~h}$. To the reaction mixture were added methanol $(17 \mathrm{~mL})$, methylene chloride $(17 \mathrm{~mL})$, and $\mathrm{NaHCO}_{3}(2.5 \mathrm{~g})$. After 30 minutes, the mixture was filtered through Celite, and concentrated in vacuo. The resulting residue was dissolved in EtOAc $(200 \mathrm{~mL})$, and washed with water $(3 \times 200 \mathrm{~mL})$. The organic layers were combined, dried $\left(\mathrm{Na}_{2} \mathrm{SO}_{4}\right)$, and concentrated under reduced pressure. Flash chromatography (10-20\% EtOAc/petroleum ether) afforded $1.20 \mathrm{~g}(92 \%$ yield) of product as a yellow foam. ${ }^{1} \mathrm{H}$ NMR $\left(\mathrm{CDCl}_{3}\right) \delta 1.00-1.04(\mathrm{~m}, 28 \mathrm{H}), 2.01(\mathrm{~s}$, $3 \mathrm{H}), 2.76(\mathrm{~s}, 1 \mathrm{H}), 3.98-4.10(\mathrm{~m}, 1 \mathrm{H}), 4.11-4.13(\mathrm{~m}, 2 \mathrm{H}), 4.15-4.21(\mathrm{~m}, 1 \mathrm{H}), 4.35-4.40$ $(\mathrm{m}, 1 \mathrm{H}), 5.76(\mathrm{~s}, 1 \mathrm{H}), 7.46-7.52(\mathrm{~m}, 2 \mathrm{H}), 7.62-7.67(\mathrm{~m}, 1 \mathrm{H}), 7.89-7.90(\mathrm{~m}, 2 \mathrm{H}), 7.92$ (s, 1H); FABMS m/e (relative intensity) $629.2697(\mathrm{M}+\mathrm{H}, 629.2714$ calcd. for $\mathrm{C}_{31} \mathrm{H}_{45} \mathrm{~N}_{2} \mathrm{O}_{8} \mathrm{Si}_{2}$ ). 
$N^{3}$-Benzoyl-5-(1-propynyl)-2'-O-allyl-3',5'-O-(tetraisopropyldisiloxane) uridine (IX). $N^{3}$-Benzoyl-5-(1-propynyl)-3',5'-O-(tetraisopropyldisiloxane)uridine (VIII) $(7.43 \mathrm{~g}, 11.9 \mathrm{mmol})$ was dissolved in excess allyl bromide $(178 \mathrm{~mL})$. Silver (I) oxide (13.8 g, $59.4 \mathrm{mmol})$ was added, and the resulting mixture was refluxed at $80^{\circ} \mathrm{C}$ under argon for $6 \mathrm{~h}$. The reaction mixture was filtered through Celite, washed with EtOAc, and concentrated in vacuo. Flash chromatography (20\% EtOAc/petroleum ether) afforded $3.60 \mathrm{~g}$ (45\% yield) of product in the form of a white foam, and $1.10 \mathrm{~g}$ of a mixture of two products containing the desired one which was used for subsequent steps without further purification. ${ }^{1} \mathrm{H}$ NMR $\left(\mathrm{CDCl}_{3}\right) \delta 1.01-1.07(\mathrm{~m}, 28 \mathrm{H}), 2.00(\mathrm{~s}, 3 \mathrm{H}), 3.91-3.92(\mathrm{~d}, 1 \mathrm{H}, \mathrm{J}=3.4 \mathrm{~Hz}), 3.97-4.01$ $(\mathrm{m}, 1 \mathrm{H}), 4.21-4.32(\mathrm{~m}, 5 \mathrm{H}), 5.12-5.16(\mathrm{~m}, 1 \mathrm{H})$ 5.23-5.33 (m, 1H), $5.72(\mathrm{~s}, 1 \mathrm{H}), 5.80-$ $5.90(\mathrm{~m}, 1 \mathrm{H})$, 7.47-7.52 (m, 2H), 7.63-7.66 (m, 1H), 7.90-7.94 (m, 2H), $8.07(\mathrm{~s}, 1 \mathrm{H})$. ${ }^{13} \mathrm{C} \mathrm{NMR}\left(\mathrm{CDCl}_{3}\right) \delta 12.45,12.78,12.89,13.50,16.87-17.50,59.10,67.78,70.06,71.29$, $81.00,82.10,89.67,91.60,100.48,104.89,117.48,129.17,130.60,131.02,134.07$, $135.29,140.43,148.03,161.13,168.09 ;$ FABMS m/e (relative intensity) 669.3066 (M $+\mathrm{H}, 669.3027$ calcd. for $\mathrm{C}_{34} \mathrm{H}_{49} \mathrm{~N}_{2} \mathrm{O}_{8} \mathrm{Si}_{2}$ ).

5-(1-Propynyl)-2'-O-allyl-3',5'-O-(tetraisopropyldisiloxane) uridine (X). $\mathrm{N}^{3}$ Benzoyl-5-(1-propynyl)-2'-O-allyl-3',5'-O-(tetraisopropyldisiloxane)uridine (IX) (164 mg, $0.247 \mathrm{mmol}$ ) was dissolved in dioxane $\left(2.3 \mathrm{~mL}\right.$ ). Concentrated $\mathrm{NH}_{4} \mathrm{OH}$ $(280 \mu \mathrm{L})$ was added, and the solution was stirred at room temperature for $5 \mathrm{~h}$. Flash chromatography (30\% EtOAc/petroleum ether) afforded $122 \mathrm{mg}(88 \%$ yield) of product in the form of a white solid. ${ }^{1} \mathrm{H}$ NMR $\left(\mathrm{CDCl}_{3}\right) \delta 0.98-1.11(\mathrm{~m}$, $28 \mathrm{H}), 2.00(\mathrm{~s}, 3 \mathrm{H}), 3.88(\mathrm{~s}, 1 \mathrm{H}), 3.93-3.98(\mathrm{~d}, 1 \mathrm{H}, \mathrm{J}=15.3 \mathrm{~Hz}), 4.18-4.29(\mathrm{~m}, 3 \mathrm{H})$, 4.36-4.39 (m, 2H), 5.18-5.21 (m, 1H), 5.34-5.41 (m, 1H), $5.71(\mathrm{~s}, 1 \mathrm{H})$, 5.92-6.00 (m, $1 \mathrm{H}), 7.96(\mathrm{~s}, 1 \mathrm{H}), 9.17(\mathrm{~s}, 1 \mathrm{H}) .{ }^{13} \mathrm{C} \mathrm{NMR}\left(\mathrm{CDCl}_{3}\right) \delta 12.47,12.76,12.88,13.46,16.83-$ $17.48,59.11,67.89,70.41,71.26,80.90,81.90,89.46,90.93,100.33,117.42,134.26$, 
140.98, 148.90, 162.17; FABMS m/e (relative intensity) $565.2763(\mathrm{M}+\mathrm{H}, 565.2765$ calcd. for $\mathrm{C}_{27} \mathrm{H}_{45} \mathrm{~N}_{2} \mathrm{O}_{7} \mathrm{Si}_{2}$ ).

5-(1-Propynyl)-2'-O-allyluridine (IV). 5-(1-Propynyl)-2'-O-allyl-3',5'-O(tetraisopropyldisiloxane)uridine (X) $(3.12 \mathrm{~g}, 5.52 \mathrm{mmol})$ was dissolved in dioxane $(30 \mathrm{~mL}) .1 \mathrm{~N} \mathrm{HCl}(30 \mathrm{~mL})$ was added, and the resulting suspension was allowed to stir at room temperature for $9 \mathrm{~h}$. The reaction mixture was neutralized with Dowex 1 (bicarbonate form) resin and filtered. The resin was washed with $\mathrm{H}_{2} \mathrm{O}-\mathrm{MeOH}(9: 1 \mathrm{v} / \mathrm{v})$, and the combined filtrates were concentrated in vacuo. Flash chromatography (50-80\% EtOAc/petroleum ether) afforded 1.11 $\mathrm{g}\left(62 \%\right.$ yield) of product in the form of a white solid. ${ }^{1} \mathrm{H}$ NMR (DMSO) $\delta 1.97$ (s, $3 \mathrm{H})$, 3.57-3.66 (m, $2 \mathrm{H}), 3.85-3.93(\mathrm{~m}, 2 \mathrm{H}), 4.08-4.14(\mathrm{~m}, 3 \mathrm{H}), 5.09-5.28(\mathrm{~m}, 4 \mathrm{H})$, 5.81-5.91 (m, 2H), 8.22 (s, 1H), 11.62 (bs, $1 \mathrm{H}) .{ }^{13} \mathrm{C}$ NMR (DMSO) $\delta 60.19,68.30$, 70.35, 72.18, 81.01, 85.20, 86.81, 89.39, 99.37, 104.68, 116.76, 135.16, 142.67, 149.79, 162.09; FABMS m/e (relative intensity) $323.1258(\mathrm{M}+\mathrm{H}, 323.1243$ calcd. for $\mathrm{C}_{15} \mathrm{H}_{419} \mathrm{~N}_{2} \mathrm{O}_{6}$ ).

5-(1-Propynyl)-2'-O-allyl-5'-O-(4,4'-dimethoxytrityl)uridine (XI). A solution of 5-(1-propynyl)-2'-O-allyluridine (IV) (1.08 g, $3.35 \mathrm{mmol})$ and dimethoxytrityl chloride $(1.53 \mathrm{~g}, 4.52 \mathrm{mmol})$ in dry pyridine $(15 \mathrm{~mL})$ was allowed to stir under argon at room temperature for $2 \mathrm{~h}$. Methanol $(5 \mathrm{~mL})$ was added, and the solution was stirred at room temperature for 30 minutes. The solution was concentrated in vacuo. The resulting residue was dissolved in methylene chloride $(200 \mathrm{~mL})$, washed with water $(3 \times 200 \mathrm{~mL})$, dried $\left(\mathrm{Na}_{2} \mathrm{SO}_{4}\right)$, and concentrated in vacuo. Flash chromatography (55\% EtOAc/petroleum ether) afforded $1.25 \mathrm{~g}$ (62\% yield) of product in the form of a slightly yellow solid requiring further purification. ${ }^{1} \mathrm{H}$ NMR $\left(\mathrm{CDCl}_{3}\right) \delta 1.60(\mathrm{~s}, 3 \mathrm{H}), 3.40-3.42(\mathrm{~m}, 2 \mathrm{H}), 3.80(\mathrm{~s}, 6 \mathrm{H}), 4.10-$ $4.18(\mathrm{~m}, 3 \mathrm{H}), 4.20-4.50(\mathrm{~m}, 3 \mathrm{H}), 5.22-5.38(\mathrm{~m}, 2 \mathrm{H}), 5.8-5.98(\mathrm{~m}, 1 \mathrm{H}), 6.8-6.85(\mathrm{~d}$, 
$4 \mathrm{H})$, 7.20-7.44 (m, 9H), $8.02(\mathrm{~s}, 1 \mathrm{H}), 8.30(\mathrm{~s}, 1 \mathrm{H}) ; \mathrm{FABMS} \mathrm{m} / \mathrm{e}$ (relative intensity) $624.2495\left(\mathrm{M}+\mathrm{H}, 624.2472\right.$ calcd. for $\left.\mathrm{C}_{36} \mathrm{H}_{37} \mathrm{~N}_{2} \mathrm{O}_{8}\right)$.

5-(1-Propynyl)-2'-O-allyl-3'-(2-cyanoethyl- $N, N$-diisopropylphosphoramidite)-5'-O-(4,4'-dimethoxytrityl)uridine (XII). A solution of 5-(1-propynyl)-2'-Oallyl-5'-O-(4,4'-dimethoxytrityl)uridine (XI) $(0.79 \mathrm{~g}, 0.96 \mathrm{mmol})$ in dry methylene chloride $(7 \mathrm{~mL})$ was cooled to $0{ }^{\circ} \mathrm{C}$, and to it were added dry triethylamine $(0.40$ $\mathrm{mL}, 2.88 \mathrm{mmol})$ and 2-cyanoethyl- $N, N$-diisopropylchlorophosphoramidite $(0.32$ $\mathrm{mL}, 1.44 \mathrm{mmol})$. The solution was allowed to stir under argon at $0{ }^{\circ} \mathrm{C}$ for 10 minutes, after which it was allowed to warm to room temperature. After $1 \mathrm{~h}$, it was diluted with $50 \mathrm{~mL}$ of methylene chloride, washed with a saturated solution of $\mathrm{NaHCO}_{3}(2 \times 50 \mathrm{~mL})$, dried $\left(\mathrm{Na}_{2} \mathrm{SO}_{4}\right)$, and concentrated in vacuo. Flash chromatography (1:3 EtOAc/petroleum ether) afforded $0.435 \mathrm{~g}$ (87\% yield) of product in the form of a white solid.

2',3',5'-Tribenzoate-5-methyluridine (XV). To a mixture of $\beta$-D-ribofuranose1-acetate-2,3,5-tribenzoate (XIII) (11.59 g, $23 \mathrm{mmol})$ and thymine (XIV) (4.35 g, 34 mmol) in dry acetonitrile $(200 \mathrm{~mL})$ was added $\mathrm{N}, \mathrm{O}$-bis(trimethylsilyl)acetamide (BSA) $(17.1 \mathrm{~mL}, 69 \mathrm{mmol})$. The suspension was allowed to stir under argon. After $4 \mathrm{~h}$, a clear solution was obtained, to which stannic chloride $(9.6 \mathrm{~mL}, 82$ $\mathrm{mmol}$ ) was slowly added in three portions over a period of $36 \mathrm{~h}$. The mixture was allowed to stir at room temperature for 2 days overall, after which it was diluted with chloroform $(500 \mathrm{~mL})$. Subsequently the organic mixture was washed with water $(200 \mathrm{~mL})$, and a saturated solution of $\mathrm{NaHCO}_{3}(2 \times 200 \mathrm{~mL})$, and the aqueous layers were extracted with chloroform. The organic layers were combined, dried $\left(\mathrm{MgSO}_{4}\right)$, and concentrated in vacuo. The yellowish residue was used without further purification.

5-Methyluridine (XVI). A suspension of crude XV $(<23 \mathrm{mmol})$ in 5:4:1 THF $/ \mathrm{MeOH} / \mathrm{H}_{2} \mathrm{O}(920 \mathrm{~mL})$ was cooled to $0{ }^{\circ} \mathrm{C}$, and to it was added $2 \mathrm{M} \mathrm{NaOH}$ 
(92 mL, $184 \mathrm{mmol}$ ). The mixture was stirred for 20 minutes at $0{ }^{\circ} \mathrm{C}$, after which ammonium chloride $(11.8 \mathrm{~g}, 284 \mathrm{mmol})$ was added. Stirring was continued for 25 minutes, after which a clear solution was obtained. The solution was extracted with ether, and the organic layer was concentrated in vacuo. Flash chromatography $\left(5-25 \% \mathrm{MeOH} / \mathrm{CH}_{2} \mathrm{Cl}_{2}\right.$ ) afforded $5.05 \mathrm{~g}$ (85\% yield from XV) of product in the form of a white solid. ${ }^{1} \mathrm{H}$ NMR (DMSO) $\delta 1.75(\mathrm{~s}, 3 \mathrm{H}), 3.37-3.59$ (m, 2H), 3.79-3.82 (m, 1H), 3.94-4.03 (m, 2H), 4.10-4.20 (bs, 1H), 5.15-5.17 (bs, 2H), 5.3 (bs, $1 \mathrm{H}), 5.74-5.76(\mathrm{~d}, 1 \mathrm{H}), 7.73(\mathrm{~s}, 1 \mathrm{H}), 8.00-8.80(\mathrm{bs}, 1 \mathrm{H}) .{ }^{13} \mathrm{C}$ NMR (DMSO) $\delta$ $60.19,68.30,70.35,72.18,81.01,85.20,86.81,89.39$, 99.37, 104.68, 116.76, 135.16, $142.67,149.79,162.09$.

5-Methyl-3',5'-O-(tetraisopropyldisiloxane)uridine (XVII). A solution of 5methyluridine (XVI) $(2.00 \mathrm{~g}, 7.75 \mathrm{mmol})$ in dry pyridine $(20 \mathrm{~mL})$ was cooled to 0 ${ }^{\circ} \mathrm{C}$ under argon. To it was slowly added 1,3-dichloro-1,1,3,3-tetraisopropyldisiloxane $(2.73 \mathrm{~mL}, 8.52 \mathrm{mmol})$, and the resulting suspension was allowed to stir first at $0{ }^{\circ} \mathrm{C}$ for 20 minutes, and then at room temperature overnight. The reaction was quenched by addition of methanol $(5 \mathrm{~mL})$, and was subsequently concentrated in vacuo. The residue was dissolved in methylene chloride (300 $\mathrm{mL})$, washed with water $(250 \mathrm{~mL})$, dried $\left(\mathrm{Na}_{2} \mathrm{SO}_{4}\right)$, and concentrated in vacuo. Flash chromatography (1:1 EtOAc/petroleum ether) afforded $3.11 \mathrm{~g}$ (81\% yield) of product in the form of a white foam. ${ }^{1} \mathrm{H}$ NMR $\left(\mathrm{CDCl}_{3}\right) \delta 0.94-1.23(\mathrm{~m}, 28 \mathrm{H})$, $1.90(\mathrm{~s}, 3 \mathrm{H}), 3.40-3.50(\mathrm{bs}, 1 \mathrm{H}), 3.97-4.12(\mathrm{~m}, 1 \mathrm{H}), 4.17-4.22(\mathrm{~m}, 4 \mathrm{H}), 4.35-4.40(\mathrm{~m}$, $1 \mathrm{H}), 5.70(\mathrm{~s}, 1 \mathrm{H}), 7.43(\mathrm{~s}, 1 \mathrm{H}), 9.00-9.20$ (bs, 1H); FABMS m/e (relative intensity) $501.2436\left(\mathrm{M}+\mathrm{H}, 501.2452\right.$ calcd. for $\left.\mathrm{C}_{22} \mathrm{H}_{40} \mathrm{~N}_{2} \mathrm{O}_{7} \mathrm{Si}_{2}\right)$.

4-(2,6-Dichlorophenyl)-5-methyl-3',5'-O-(tetraisopropyldisiloxane) uridine (XVIII). To a suspension of 5-methyl-3',5'-O-(tetraisopropyldisiloxane)uridine (XVII) (5.00 g, $7.74 \mathrm{mmol}$ ) and $\mathrm{N}, \mathrm{N}$-dimethyl-4-aminopyridine (DMAP) (0.94 g, $7.74 \mathrm{mmol})$ in dry methylene chloride $(50 \mathrm{~mL})$ were added dry triethylamine (1.1 
$\mathrm{mL}, 7.74 \mathrm{mmol}$ ) and 2-mesitylenesulfonylchloride (2.34 g, $7.74 \mathrm{mmol})$ under argon. After $3 \mathrm{~h}$, one more equivalent of triethylamine and 2-mesitylenesulfonylchloride were added, and the suspension was allowed to stir at room temperature. After $10 \mathrm{~h}$, a third equivalent of triethylamine and 2-mesitylenesulfonylchloride were added, and the reaction mixture was allowed to stir overnight. Then, 2,6-dichlorophenol (1.26 g, $7.74 \mathrm{mmol})$, triethylamine (1.1 mL, $7.74 \mathrm{mmol})$, and diazabicyclo[2,2,2]octane $(0.23 \mathrm{~mL}, 1.55 \mathrm{mmol})$ were added, and the reaction mixture was allowed to stir for 4 days. When the reaction seemed near completion by TLC, it was diluted with methylene chloride, washed with a saturated solution of $\mathrm{NaHCO}_{3}(3 \mathrm{x})$, dried $\left(\mathrm{MgSO}_{4}\right)$, and concentrated in vacuo. Flash chromatography (35\% EtOAc/petroleum ether) afforded $4.1 \mathrm{~g}$ (82\% yield) of product in the form of a yellow solid. ${ }^{1} \mathrm{H} \mathrm{NMR}\left(\mathrm{CDCl}_{3}\right) \delta 1.01-1.28(\mathrm{~m}, 28 \mathrm{H})$, $2.18(\mathrm{~s}, 3 \mathrm{H}), 4.05-4.17(\mathrm{~m}, 2 \mathrm{H}), 4.22-4.28(\mathrm{~m}, 2 \mathrm{H}), 4.37-4.40(\mathrm{~m}, 1 \mathrm{H}), 5.72(\mathrm{~s}, 1 \mathrm{H})$, 7.13-7.16 (t, $1 \mathrm{H}), 7.33-7.35(\mathrm{~d}, 2 \mathrm{H}), 7.86(\mathrm{~s}, 1 \mathrm{H}) .{ }^{13} \mathrm{C} \mathrm{NMR}\left(\mathrm{CDCl}_{3}\right) \delta$ 12.40, 12.49, $12.65,12.96,13.41,16.87-17.43,60.40,69.02,74.92,82.05,92.26,103.57,127.05$, $128.68,141.95,145.10,154.82,168.92 ;$ FABMS m/e (relative intensity) 645.1960 (M $+\mathrm{H}, 645.1986$ calcd. for $\mathrm{C}_{28} \mathrm{H}_{43} \mathrm{Cl}_{2} \mathrm{~N}_{2} \mathrm{O}_{7} \mathrm{Si}_{2}$ ).

\section{4-(2,6-Dichlorophenyl)-5-methyl-2'-O-allyl-3',5'-O-(tetraisopropyldisiloxa-}

ne)uridine (XIX). To a solution of XVIII ( $3.00 \mathrm{~g}, 4.64 \mathrm{mmol})$ in dry THF (20 mL) was added allyl ethyl carbonate $(1.21 \mathrm{~mL}, 9.28 \mathrm{mmol})$ under argon. This solution was added to a suspension of tris(dibenzyledene)dipalladium $(0.42 \mathrm{~g}, 0.46 \mathrm{mmol})$ and 1,4-bis(diphenylphosphino)butane $(0.79 \mathrm{~g}, 1.86 \mathrm{mmol})$ in THF $(40 \mathrm{~mL})$, and the greenish mixture was allowed to reflux under argon for 30 minutes. Then the suspension was filtered over Celite, the Celite was washed with ethyl acetate, and the combined organic layers were concentrated in vacuo. Flash chromatography (15\% EtOAc/petroleum ether) afforded $2.67 \mathrm{~g}$ ( $84 \%$ yield) of product in the form of a yellow foam. ${ }^{1} \mathrm{H}$ NMR $\left(\mathrm{CDCl}_{3}\right) \delta 0.94-1.12(\mathrm{~m}, 28 \mathrm{H}), 2.17$ 
(s, 3H), 3.97-4.02 (m, 2H), 4.18-4.31 (m, $4 \mathrm{H}), 4.41-4.45(\mathrm{~m}, 1 \mathrm{H}), 5.13-5.18(\mathrm{dd}, 1 \mathrm{H})$, 5.36-5.43 (dd, $1 \mathrm{H}), 5.73-5.92(\mathrm{~m}, 1 \mathrm{H}), 7.10-7.16(\mathrm{t}, 1 \mathrm{H}), 7.33-7.36(\mathrm{~d}, 2 \mathrm{H}), 8.04(\mathrm{~s}$, 1H). ${ }^{13} \mathrm{C} \mathrm{NMR}\left(\mathrm{CDCl}_{3}\right) \delta 12.44,12.51,12.73,12.93,13.51,16.90,17.06,17.27,17.36$, $17.48,60.00,67.73,71.15,80.64,81.93,90.24,103.27,117.10,127.00,128.78,129.10$, 134.68, 141.54, 145.21, 154.87, 168.89; FABMS m/e (relative intensity) 685.2314 (M $+\mathrm{H}, 685.2299$ calcd. for $\mathrm{C}_{31} \mathrm{H}_{47} \mathrm{Cl}_{2} \mathrm{~N}_{2} \mathrm{O}_{7} \mathrm{Si}_{2}$ ).

Allyl ethyl carbonate. Dry pyridine $(27 \mathrm{~mL}, 0.33 \mathrm{~mol})$ and absolute ethanol (29.2 $\mathrm{mL}, 0.49 \mathrm{~mol}$ ) were mixed at $0{ }^{\circ} \mathrm{C}$ under argon. Then allyl chloroformate ( $35.3 \mathrm{~mL}, 0.33 \mathrm{~mol}$ ) was added very slowly. Gas evolution was observed. A white precipitate was seen all of a sudden. The suspension was allowed to stir at room temperature for $2 \mathrm{~h}$. Then ether $(333 \mathrm{~mL})$ was added with stirring, the mixture was filtrated, and the filtrate was washed with a saturated solution of $\mathrm{NaCl}$, dried $\left(\mathrm{Na}_{2} \mathrm{SO}_{4}\right)$, and concentrated in vacuo to afford a clear liquid which was stored under argon at $0{ }^{\circ} \mathrm{C} .{ }^{1} \mathrm{H}$ NMR $\left(\mathrm{CDCl}_{3}\right) \delta 1.22-1.30(\mathrm{t}, 3 \mathrm{H}), 4.13-4.21(9$, $2 \mathrm{H}), 4.59-4.61(\mathrm{~m}, 2 \mathrm{H}), 5.20-5.40(\mathrm{~m}, 2 \mathrm{H}), 5.82-6.00(\mathrm{~m}, 1 \mathrm{H})$.

5-Methyl-2'-O-allyl-3',5'-O-(tetraisopropyldisiloxane)uridine (XX). To a solution of XIX ( $0.10 \mathrm{~g}, 0.146 \mathrm{mmol})$ and 2-pyridinealdoxime (0.089 g, $0.73 \mathrm{mmol})$ in dry acetonitrile $(5 \mathrm{~mL})$ was added 1,1,3,3-tetramethylguanidine ( $82 \mu \mathrm{L}, 0.66$ $\mathrm{mmol}$ ) under argon. The reaction mixture was allowed to stir at room temperature for $13 \mathrm{~h}$. It was then diluted with EtOAc, washed with water (3x), dried $\left(\mathrm{Na}_{2} \mathrm{SO}_{4}\right)$, and concentrated in vacuo. Flash chromatography (35:65 EtOAc/petroleum ether) afforded $0.71 \mathrm{~g}$ (90\% yield) of product in the form of a whitish solid. ${ }^{1} \mathrm{H}$ NMR $\left(\mathrm{CDCl}_{3}\right) \delta$ 0.94-1.28 (m, 28H), $1.91(\mathrm{~s}, 3 \mathrm{H}), 3.88-3.89(\mathrm{~d}$, $1 \mathrm{H})$, 3.96-4.00 (m, $1 \mathrm{H}), 4.13-4.27(\mathrm{~m}, 3 \mathrm{H}), 4.38-4.40(\mathrm{~m}, 2 \mathrm{H}), 5.18-5.22(\mathrm{dd}, 1 \mathrm{H})$, 5.34-5.41 (dd, 1H), $5.72(\mathrm{~s}, 1 \mathrm{H})$, 5.89-5.96 (m, 1H), $7.60(\mathrm{~s}, 1 \mathrm{H}), 8.34(\mathrm{~s}, 1 \mathrm{H})$; FABMS $\mathrm{m} / \mathrm{e}$ (relative intensity) $541.2776\left(\mathrm{M}+\mathrm{H}, 541.2765\right.$ calcd. for $\left.\mathrm{C}_{25} \mathrm{H}_{45} \mathrm{~N}_{2} \mathrm{O}_{7} \mathrm{Si}_{2}\right)$. 
5-Methyl-2'-O-allyluridine (II). To a solution of XX (1.92 g, $3.55 \mathrm{mmol})$ in dry THF $(10 \mathrm{~mL})$ was added $1 \mathrm{M}$ tetrabutylammoniumfluoride/THF $(7.1 \mathrm{~mL}, 7.10$ $\mathrm{mmol}$ ). The mixture was allowed to stir at room temperature for 45 minutes. Then ammonium chloride $(0.47 \mathrm{~g}, 8.87 \mathrm{mmol})$ was added, and the mixture was concentrated in vacuo. Flash chromatography (3-5\% $\left.\mathrm{MeOH} / \mathrm{CH}_{2} \mathrm{Cl}_{2}\right)$ afforded quantitative yield of product in the form of a white solid. ${ }^{1} \mathrm{H}$ NMR (DMSO) $\delta$ 1.28-1.31 (s, 3H), 3.56-3.64 (m, 2H), 3.84-3.92 (m, 2H), 4.03-4.13 (m, 3H), 5.08-5.25 $(\mathrm{m}, 4 \mathrm{H}), 5.81-5.89(\mathrm{~m}, 2 \mathrm{H}), 7.78(\mathrm{~s}, 1 \mathrm{H}), 11.31(\mathrm{~s}, 1 \mathrm{H})$; FABMS m/e (relative intensity) $299.1232\left(\mathrm{M}+\mathrm{H}, 299.1243\right.$ calcd. for $\left.\mathrm{C}_{13} \mathrm{H}_{19} \mathrm{~N}_{2} \mathrm{O}_{6}\right)$.

5-Methyl-2'-O-allyl-5'-O-(4,4'-dimethoxytrityl)uridine (XXI). A solution of 5-methyl-2'-O-allyluridine (II) $(0.18 \mathrm{~g}, 0.60 \mathrm{mmol})$ and dimethoxytrityl chloride $(0.264 \mathrm{~g}, 0.78 \mathrm{mmol})$ in dry pyridine $(9 \mathrm{~mL})$ was allowed to stir under argon at room temperature for $2 \mathrm{~h}$. Methanol $(5 \mathrm{~mL})$ was added, and the solution was concentrated in vacuo. The resulting residue was dissolved in methylene chloride $(50 \mathrm{~mL})$, washed with water $(3 \times 70 \mathrm{~mL})$, dried $\left(\mathrm{Na}_{2} \mathrm{SO}_{4}\right)$, and concentrated in vacuo. Flash chromatography ( $40 \% \mathrm{EtOAc} /$ petroleum ether) afforded $0.23 \mathrm{~g}$ (71\% yield) of product in the form of a slightly yellow foam. ${ }^{1} \mathrm{H} \mathrm{NMR}\left(\mathrm{CDCl}_{3}\right) \delta$ $1.35(\mathrm{~s}, 3 \mathrm{H}), 3.40-3.57(\mathrm{~m}, 2 \mathrm{H}), 3.79(\mathrm{~s}, 6 \mathrm{H}), 4.08-4.15(\mathrm{~m}, 3 \mathrm{H}), 4.25-4.27(\mathrm{~m}, 2 \mathrm{H})$, 4.36-4.47 (m. 3H), 5.24-5.36 (m, 2H), 5.82-6.00 (m, 1H), $6.02(\mathrm{~s}, 1 \mathrm{H}), 6.82-6.86(\mathrm{~d}$, $4 \mathrm{H}), 7.23-7.32(\mathrm{~m}, 9 \mathrm{H}), 7.67(\mathrm{~s}, 1 \mathrm{H}), 8.20-8.40(\mathrm{bs}, 1 \mathrm{H})$; FABMS m/e (relative intensity) $600.2456\left(\mathrm{M}+\mathrm{H}, 600.2472\right.$ calcd. for $\left.\mathrm{C}_{34} \mathrm{H}_{37} \mathrm{~N}_{2} \mathrm{O}_{8}\right)$.

5-Methyl-2'-O-allyl-3'-(2-cyanoethyl- $N, N$-diisopropylphosphoramidite)-5'$O-\left(4,4^{\prime}\right.$-dimethoxytrityl)uridine (XXII). A solution of 5-methyl-2'-O-allyl-5'-O$\left(4,4^{\prime}\right.$-dimethoxytrityl)uridine (XXI) $(0.218 \mathrm{~g}, 0.36 \mathrm{mmol})$ in dry methylene chloride $(5 \mathrm{~mL})$ was cooled to $0{ }^{\circ} \mathrm{C}$, and to it were added dry triethylamine $(0.15$ $\mathrm{mL}, 1.08 \mathrm{mmol})$ and 2-cyanoethyl- $N, N$-diisopropylchlorophosphoramidite $(0.12$ $\mathrm{mL}, 0.54 \mathrm{mmol})$. The solution was allowed to stir under argon at $0{ }^{\circ} \mathrm{C}$ for 10 
minutes, after which it was allowed to warm to room temperature. After $1 \mathrm{~h}$, it was diluted with $50 \mathrm{~mL}$ of methylene chloride, washed with a saturated solution of $\mathrm{NaHCO}_{3}(2 \times 50 \mathrm{~mL})$, dried $\left(\mathrm{Na}_{2} \mathrm{SO}_{4}\right)$, and concentrated in vacuo. Flash chromatography (1:1 EtOAc/petroleum ether) afforded $0.236 \mathrm{~g}$ (82\% yield) of product in the form of a white solid. ${ }^{1} \mathrm{H}$ NMR $\left(\mathrm{CDCl}_{3}\right) \delta 1.00-1.34(\mathrm{~m}, 14 \mathrm{H}), 1.52-$ $1.55(\mathrm{~s}, 3 \mathrm{H}), 2.35-2.39(\mathrm{t}, 2 \mathrm{H}), 2.61-2.65(\mathrm{t}, 2 \mathrm{H}), 3.28-3.33(\mathrm{~m}, 1 \mathrm{H}), 3.51-3.64(\mathrm{~m}, 3 \mathrm{H})$, 3.76-3.84 (m, 6H), 4.11-4.23 (m, 3H), $4.50(\mathrm{~m}, 1 \mathrm{H}), 5.20-5.34(\mathrm{~m}, 2 \mathrm{H}), 5.80-5.99(\mathrm{~m}$, $1 \mathrm{H}), 6.03-6.11(\mathrm{~m}, 1 \mathrm{H}), 6.81-6.85(\mathrm{~m}, 4 \mathrm{H}), 7.23-7.37(\mathrm{~m}, 9 \mathrm{H}), 7.68-7.69(\mathrm{~m}, 1 \mathrm{H})$, 7.95-8.00 (s, 1H); FABMS m/e (relative intensity) 801.3595 (M + H, 801.3628 calcd. for $\left.\mathrm{C}_{43} \mathrm{H}_{54} \mathrm{~N}_{4} \mathrm{O} 9 \mathrm{P}\right)$.

5-Methyl-2'-O-allyl-3',5'-O-(tetraisopropyldisiloxane)cytidine (XXIII). A solution of XIX $(0.50 \mathrm{~g}, 0.73 \mathrm{mmol})$ in dry acetonitrile $(10 \mathrm{~mL})$ in a sealed tube was placed in an ice-salt bath, and allowed to cool to $-3{ }^{\circ} \mathrm{C}$. Gaseous ammonia was bubbled through the solution for 20 minutes. Then the sealed tube was placed in a warm oil bath $\left(\sim 85^{\circ} \mathrm{C}\right)$, and the reaction solution was allowed to stir for $24 \mathrm{~h}$. The solution was allowed to cool to room temperature and concentrated in vacuo. Flash chromatography $\left(7 \% \mathrm{MeOH} / \mathrm{CH}_{2} \mathrm{Cl}_{2}\right)$ afforded 0.365 $\mathrm{g}\left(93 \%\right.$ yield) of product in the form of a white solid. ${ }^{1} \mathrm{H}$ NMR (DMSO) $\delta 0.87-1.06$ $(\mathrm{m}, 28 \mathrm{H}), 1.79-1.81(\mathrm{~s}, 3 \mathrm{H}), 3.84-4.34(\mathrm{~m}, 8 \mathrm{H}), 5.10-5.14(\mathrm{~m}, 1 \mathrm{H}), 5.28-5.35(\mathrm{~m}, 1 \mathrm{H})$, $5.58(\mathrm{~s}, 1 \mathrm{H}), 5.84-5.93(\mathrm{~m}, 1 \mathrm{H}), 6.82-6.83(\mathrm{bs}, 1 \mathrm{H}), 7.34-7.35$ (bs, 1H), $7.41(\mathrm{~s}, 1 \mathrm{H})$. ${ }^{13}$ C NMR (DMSO) $\delta 12.21,12.34,12.53,12.96,13.73,16.95,17.01,17.04,17.10$, $17.27,17.36,17.51,59.79,68.46,70.32,80.84,80.88,89.11,100.90,116.23,135.30$, 137.08, 154.84, 165.65; FABMS m/e (relative intensity) 540.2913 ( $\mathrm{M}+\mathrm{H}, 540.2925$ calcd. for $\mathrm{C}_{25} \mathrm{H}_{46} \mathrm{~N}_{3} \mathrm{O}_{6} \mathrm{Si}_{2}$ ).

\section{$N^{4}$-Benzoyl-5-methyl-2'-O-allyl-3', $5^{\prime}$-O-(tetraisopropyldisiloxane)cytidine}

(XXIV). To a solution of XXIII $(0.20 \mathrm{~g}, 0.37 \mathrm{mmol})$ in dry pyridine $(5 \mathrm{~mL})$ was added benzoyl chloride $(0.21 \mathrm{~mL}, 1.85 \mathrm{mmol})$ under argon. The solution was 
allowed to stir at room temperature for $3.5 \mathrm{~h}$. Then ammonium hydroxide $(0.72$ mL) was added, and the reaction was allowed to stir for an additional 15 minutes. It was subsequently concentrated in vacuo, dissolved in EtOAc, washed with water $(2 \mathrm{x})$, dried $\left(\mathrm{Na}_{2} \mathrm{SO}_{4}\right)$ and concentrated in vacuo. Flash chromatography $\left(5 \% \mathrm{MeOH} / \mathrm{CH}_{2} \mathrm{Cl}_{2}\right)$ afforded $0.204 \mathrm{~g}$ ( $86 \%$ yield) of product in the form of a white solid. ${ }^{1} \mathrm{H}$ NMR (DMSO) $\delta$ 0.91-1.98 (m, 28H), $1.98(\mathrm{~s}, 3 \mathrm{H}), 3.31$ (s, 6H), 3.91-4.31 (m, 8H), 5.13-5.16 (dd, 1H), 5.30-5.36 (dd, 1H), $5.64(\mathrm{~s}, 1 \mathrm{H}), 5.86-$ $5.91(\mathrm{~m}, 1 \mathrm{H}), 7.46-7.51(\mathrm{t}, 2 \mathrm{H}), 7.56-7.59(\mathrm{t}, 1 \mathrm{H}), 7.72-7.73(\mathrm{~s}, 1 \mathrm{H}), 8.13-8.19(\mathrm{bm}$, $2 \mathrm{H})$; FABMS m/e (relative intensity) $644.3156(\mathrm{M}+\mathrm{H}, 644.3187$ calcd. for $\mathrm{C}_{32} \mathrm{H}_{50} \mathrm{~N}_{3} \mathrm{O}_{7} \mathrm{Si}_{2}$ ).

$N^{4}$-Benzoyl-5-methyl-2'-O-allylcytidine (XXV). To a solution of XXIV (0.26 $\mathrm{g}, 0.41 \mathrm{mmol})$ in dry THF $(4 \mathrm{~mL})$ was added $1 \mathrm{M}$ tetrabutylammoniumfluoride/ THF (0.82 mL, $0.82 \mathrm{mmol})$. The mixture was allowed to stir at room temperature for 15 minutes. Then ammonium chloride $(0.027 \mathrm{~g}, 0.51 \mathrm{mmol})$ was added, and the mixture was concentrated in vacuo. Flash chromatography $(5 \% \mathrm{MeOH} /$ $\mathrm{CH}_{2} \mathrm{Cl}_{2}$ ) afforded quantitative yield of product in the form of a white solid. ${ }^{1} \mathrm{H}$ NMR (DMSO) $\delta 2.00(\mathrm{~s}, 3 \mathrm{H}), 3.60-3.80(\mathrm{~m}, 2 \mathrm{H}), 3.90-4.00(\mathrm{~m}, 2 \mathrm{H}), 4.10-4.20(\mathrm{~m}$, $3 \mathrm{H}), 5.11-5.20(\mathrm{~m}, 2 \mathrm{H}), 5.21-5.33(\mathrm{~m}, 2 \mathrm{H}), 5.78(\mathrm{~s}, 1 \mathrm{H}), 5.80-5.96(\mathrm{~m}, 2 \mathrm{H}), 7.45-7.55$ $(\mathrm{t}, 2 \mathrm{H}), 7.56-7.60(\mathrm{t}, 1 \mathrm{H}), 7.78-7.80(\mathrm{~d}, 1 \mathrm{H}), 8.10-8.30(\mathrm{~m}, 2 \mathrm{H})$.

$N^{4}$-Benzoyl-5-methyl-2'-O-allyl-5'-O-(4,4'-dimethoxytrityl)cytidine (XXVI). A solution of XXV $(0.183 \mathrm{~g}, 0.45 \mathrm{mmol})$ and dimethoxytrityl chloride $(0.198 \mathrm{~g}$, $0.585 \mathrm{mmol})$ was allowed to stir in dry pyridine $(8 \mathrm{~mL})$ under argon at room temperature for $2 \mathrm{~h}$. More dimethoxy trityl chloride $(0.068 \mathrm{~g}, 0.20 \mathrm{mmol})$ was added, and the solution was allowed to stir for an additional $3.5 \mathrm{~h}$. Methanol (8 $\mathrm{mL}$ ) was added, and the solution was concentrated in vacuo. The resulting residue was dissolved in methylene chloride $(75 \mathrm{~mL})$, washed with water $(3 \times 60$ $\mathrm{mL})$, dried $\left(\mathrm{Na}_{2} \mathrm{SO}_{4}\right)$, and concentrated in vacuo. Flash chromatography $(10-40 \%$ 
EtOAc/petroleum ether) afforded $0.19 \mathrm{~g}$ (60\% yield) of product in the form of a slightly orange solid. ${ }^{1} \mathrm{H}$ NMR $\left(\mathrm{CDCl}_{3}\right) \delta 1.56(\mathrm{~s}, 3 \mathrm{H}), 3.43-3.61(\mathrm{~m}, 2 \mathrm{H}), 3.80(\mathrm{~s}$, $6 \mathrm{H}), 4.10-4.13(\mathrm{~m}, 2 \mathrm{H}), 4.29-4.31(\mathrm{~m}, 1 \mathrm{H}), 4.42-4.50(\mathrm{~m}, 2 \mathrm{H}), 5.25-5.37(\mathrm{~m}, 2 \mathrm{H})$, 5.80-6.00 (m, 1H), $6.03(\mathrm{~d}, 1 \mathrm{H}), 6.84-6.87(\mathrm{~d}, 4 \mathrm{H}), 7.25-7.52(\mathrm{~m}, 9 \mathrm{H}), 7.87(\mathrm{~s}, 1 \mathrm{H})$, 8.27-8.30 (d, 2H); FABMS m/e (relative intensity) 704.2976 $(\mathrm{M}+\mathrm{H}, 704.2972$ calcd. for $\mathrm{C}_{41} \mathrm{H}_{42} \mathrm{~N}_{3} \mathrm{O}_{8}$ ).

\section{$N^{4}$-Benzoyl-5-methyl-2'-O-allyl-3'-(2-cyanoethyl- $N, N$-diisopropylphospho-} ramidite)-5'-O-(4,4'-dimethoxytrityl)cytidine (XXVII). A solution of XXVI $(0.387 \mathrm{~g}, 0.55 \mathrm{mmol})$ in dry methylene chloride $(7 \mathrm{~mL})$ was cooled to $0{ }^{\circ} \mathrm{C}$, and to it were added dry triethylamine $(0.23 \mathrm{~mL}, 1.65 \mathrm{mmol})$ and 2-cyanoethyl- $\mathrm{N}, \mathrm{N}$ diisopropylchlorophosphoramidite $(0.18 \mathrm{~mL}, 0.825 \mathrm{mmol})$. The solution was allowed to stir under argon at $0{ }^{\circ} \mathrm{C}$ for 10 minutes, after which it was allowed to warm to room temperature. After 50 minutes, it was diluted with $50 \mathrm{~mL}$ of methylene chloride, washed with a saturated solution of $\mathrm{NaHCO}_{3}(2 \times 50 \mathrm{~mL})$, dried $\left(\mathrm{Na}_{2} \mathrm{SO}_{4}\right)$, and concentrated in vacuo. Flash chromatography (25\% EtOAc/ petroleum ether) afforded $0.435 \mathrm{~g}$ ( $87 \%$ yield) of product in the form of a white foam. ${ }^{1} \mathrm{H}$ NMR $\left(\mathrm{CDCl}_{3}\right) \delta$ 0.98-1.28 (m, 14H), 1.50-1.53 (s, 3H), 2.35-2.39 (t, $\left.2 \mathrm{H}\right)$, 2.61-2.65 (t, $2 \mathrm{H}), 3.32-3.35(\mathrm{~m}, 1 \mathrm{H}), 3.53-3.62(\mathrm{~m}, 3 \mathrm{H}), 3.64-3.82(\mathrm{~s}, 6 \mathrm{H}), 4.11-4.31$ $(\mathrm{m}, 3 \mathrm{H}), 4.49-4.52(\mathrm{~m}, 1 \mathrm{H}), 5.20-5.36(\mathrm{~m}, 2 \mathrm{H}), 5.80-6.00(\mathrm{~m}, 1 \mathrm{H}), 6.14(\mathrm{~d}, 1 \mathrm{H}), 6.82-$ $6.87(\mathrm{~m}, 4 \mathrm{H})$, 7.24-7.51 (m, 9H), 7.84-7.91 (s, 1H), 8.27-8.30 (d, 2H); FABMS m/e (relative intensity) $904.4084\left(\mathrm{M}+\mathrm{H}, 904.4050\right.$ calcd. for $\left.\mathrm{C}_{50} \mathrm{H}_{59} \mathrm{~N}_{5} \mathrm{O}_{9} \mathrm{P}\right)$.

Oligonucleotide preparation. Oligonucleotides were synthesized by standard automated solid-support chemistry on an Applied Biosystems Model 380B DNA synthesizer using $O$-(cyanoethyl)- $N, N$-diisopropylphosphoramidites. ${ }^{13 b}$ The phosphoramidite of the Amino-Modifier-dT [5'-(dimethoxytrityl)-5[[[N-(trifluoroacetyl)amino]ethyl]3-acrylimido]-2'-deoxuridine,3'-O-(2-cyanoethyl)- $N, N$-diisopropylphosphoramidite] purchased from Glen Research was 
incorporated at the 5'-terminus of oligonucleotides 1, 2, 3, and 4 during oligonucleotide synthesis. Oligonucleotide concentrations were determined by UV absorbance at $280 \mathrm{~nm}$ using extinction coefficients $\left(\mathrm{M}^{-1} \mathrm{~cm}^{-1}\right)$ of $6400\left(\mathrm{~T}\right.$ and $\mathrm{T}^{*}$ derivative from Glen Research, aU), 8300 ( $\left.\mathrm{mC},{ }^{a} \mathrm{C}\right), 9700(\mathrm{PU})$, and $9500(\mathrm{a} / \mathrm{pU})$. Oligonucleotide deprotection and purification were carried out by Scott F. Singleton in our laboratory. 


\section{References and Notes}

1. Goodchild, J. Bioconjugate Chem. 1990, 1, 165, and references therein.

2. English, U.; Gauss, D. H. Angew. Chem. Int. Ed. Engl. 1991, 30, 613, and references therein.

3. (a) Schneider, K.; Benner, S. A. J. Am. Chem. Soc. 1990, 112, 453. (b) Eschenmoser, A.; Dobler, M. Helv. Chim. Acta 1992, 75, 218. (c) Böhringer, M.; Roth, H. J.; Hunziker, J.; Göbel, M.; Krishnan, R.; Giger, A.; Schweizer, B.; Schreiber, J.; Leumann, C.; Eschenmoser, A. Helv. Chim. Acta 1992, 75, 1416. (d) Froehler, B. C.; Ricca, D. J. J. Am. Chem. Soc. 1992, 114, 8320.

4. (a) Bobst, A. M.; Rottman, F.; Cerutti, P. A. J. Mol. Biol. 1969, 46, 221. (b) Inoue, H.; Hayase, Y.; Imura, A.; Shigenori, I.; Miura, K.; Ohtsuka, E. Nucleic Acids Res. 1987, 15, 6131. (c) Shibahara, S.; Mukai, S.; Nishihara, T.; Inoue, H.; Ohtsuka, E.; Morisawa, H. Nucleic Acids Res. 1987, 15, 4403. (d) Sproat, B. S.; Lamond, A. I.; Beijer, B.; Neuner, P.; Ryder, U. Nucleic Acids Res. 1989, 17, 3373. (e) Iribarren, A. M.; Sproat, B. S.; Neuner, P.; Sulston, I.; Ryder, U.; Lamond, A. I. Proc. Natl. Acad. Sci. USA 1990, 87, 7747. (f) Hayase, Y.; Inoue, H.; Ohtsuka, E. Biochemistry 1990, 29, 8793. (g) Schimizu, M; Konishi, A.; Shimada, Y.; Inoue, H.; Ohtsuka, E. FEBS, 1992, 302, 155. (h) Häner, R.; Dervan, P. B. Unpublished data.

5. (a) Bobst, A. M.; Cerutti, P. A.; Rottman, F. J. Am. Chem. Soc. 1969, 91, 1246.

(b) Leslie, A. G. W.; Arnott, S. J. Mol. Biol. 1978, 119, 399.

6. Sproat, B. S.; Iribarren, A. M.; Garcia, R. G.; Beijer, B. Nucleic Acids Res. 1991, 19, 733.

7. (a) Singleton, S. F.; Dervan, P. B. J. Am. Chem. Soc. 1992, 114, 6956. (b) Singleton, S. F.; Dervan, P. B. Biochemistry 1992, 31, 10995. 
8. (a) Arnott, S.; Selsing, E. J. Mol. Biol. 1974, 88, 509. (b) Collier, D. A.; Mergny, J. L., Thuong, N. T.; Helene, C. Nucleic Acids Res. 1991, 19, 4219. (c) Povsic, T. J. Ph. D. Dissertation, California Institute of Technology, Pasadena, CA, 1992.

9. (a) De Clercq, E. D.; Descamps, J.; Balzarini, J.; Giziewicz, J.; Barr, P. J.; Robins, M. J. J. Med. Chem. 1983, 26, 661. (b) Goodchild, J.; Porter, R. A.; Raper, R. H.; Sim, I. S.; Upton, R. M.; Viney, J.; Wadsworth, H. J. J. Med. Chem. 1983, 26, 1252.

10. Froehler, B. C.; Wadwani, S.; Terhorst, T. J.; Gerrard, S. R. Tetrahedron Lett. $1992,33,5307$.

11. Ti, G. S.; Gaffney, B. L.; Jones, R. A. J. Am. Chem. Soc. 1982, 104, 1316.

12. Froehler, B. C.; Jones, R. J.; Cao, X.; Terhost, T. J. Tetrahedron Lett. 1993, 34, 1003.

13. (a) Nylas, A.; Chattopadhyaya, J. Acta Chem. Scand. 1986, B40, 826. (b) Gait, M. J. Oligonucleotide Synthesis: A Practical Approach; IRL Press: Oxford, 1985. (c) Sproat, B. S.; Beijer, B.; Iribarren, A. Nucleic Acids Res. 1990, 18, 41 .

14. Sproat, B. S.; Iribarren, A. M.; Garcia, R. C.; Beijer, B. Nucleic Acids Res. 1991, 19, 733.

15. Sproat, B. S.; Iribarren, A.; Beijer, R.; Pieles, U.; Lamond, A. I. Nucleosides \& Nucleotides 1991, 10, 25. 


\section{CHAPTER SEVEN:}

\section{Progress Towards the Synthesis of $\mathbf{N}^{7}-2^{\prime}$-Deoxyisoinosine}

\section{Introduction}

One of the goals in the area of triple helix formation is understanding the chemical principles underlying the sequence-specific recognition of doublehelical DNA. This understanding is crucial to our ability to uniquely recognize any single site in megabase size DNA. Until recently, two general motifs for the sequence-specific recognition of double-helical DNA by triple helix formation had been developed. These motifs differ in sequence composition of the third strand, the relative orientation and position of the third strand, and the hydrogen-bonding patterns. In one motif, pyrimidine oligodeoxyribonucleotides bind in the major groove of DNA parallel to the homopurine strand by formation of specific Hoogsteen hydrogen bonds between thymine and adenine $(\mathrm{T} \bullet \mathrm{AT}$ triplet) and protonated cytosine and guanine (C+GC triplet). ${ }^{1}$ In the other motif, purine-rich oligonucleotides bind antiparallel to the homopurine strand by formation of specific A $\bullet \mathrm{AT}$ or $\mathrm{T} \bullet \mathrm{AT}$ and $\mathrm{G} \bullet \mathrm{GC}$ triplets (see Chapter One). ${ }^{2}$

The inability to recognize mixed pyrimidine-purine sequences, as well as the observed sensitivity of triple helix formation to $\mathrm{pH}^{1 \mathrm{1c}, 3}$ and metal cation concentration and nature, ${ }^{4}$ have spurred efforts to design nonnatural bases capable of sequence-specific DNA recognition within wider sequence contexts and experimental conditions. To circumvent the $\mathrm{pH}$ dependence of the formation of triple helices containing C+GC triplets, ${ }^{1 c, 3}$ a nonnatural base, 1(2-deoxy- $\beta$-D-ribofuranosyl)-3-methyl-5-amino- $1 H$-pyrazolo[4,3-d]pyrimidin- 
7-one (P1), was synthesized in our laboratory and shown to bind GC base pairs within a pyrimidine triple helix motif as selectively and strongly as $C$ but over an extended $\mathrm{pH}$ range (see Chapter One). ${ }^{5}$ Additional nonnatural bases mimicking the hydrogen bonding functionality of protonated cytosine have been synthesized in other laboratories (see Chapter One). ${ }^{6}$ Other nonnatural nucleotides have been designed to recognize TA or CG base pairs within the pyrimidine or purine motif. Among these, 1-(2-deoxy- $\beta$-D-ribofuranosyl)-4(3-benzamido)phenylimidazole $\left(D_{3}\right)$ was shown to form specific hydrogen bonds with TA base pairs when incorporated into pyrimidine-rich oligonucleotides, ${ }^{7}$ and 2'-deoxynebularine was found to recognize CG and AT base pairs when incorporated into purine-rich oligonucleotides, although subsequent experiments showed that the specificity of 2 -deoxynebularine is dependent on solution conditions and sequence composition. ${ }^{8}$ Nonetheless, despite these encouraging findings, the formidable challenge of finding a general solution to the sequence-specific recognition of mixed pyrimidinepurine sequences still confronts us.

The recent development of a third nonnatural motif for the recognition of double-helical DNA may represent a significant step towards finding a solution to this problem. In this motif, the geometry of a base triplet found in the purine-purine-pyrimidine triple helix is maintained, while the third strand orientation is reversed by moving the third strand deoxyribose from the N9 to the N7 position. The development of this new motif originated from the discovery that an $N^{7}$-glycosylated purine, 7-(2'-deoxy- $\beta$-D-erythropentofuranosyl)guanine $\left({ }^{7} \mathrm{G}\right)$ binds a GC base pair with high specificity when incorporated in a pyrimidine oligonucleotide (Figure 7.1). ${ }^{9}$ This finding is important as it suggested that a new parallel-stranded motif containing wholly N7-purines may lead to the generation of a new class of N7-purine 


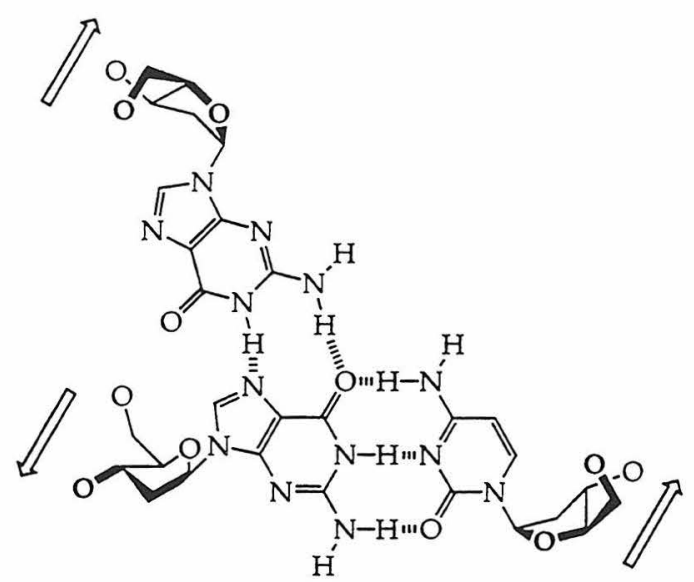

$G \cdot G C$

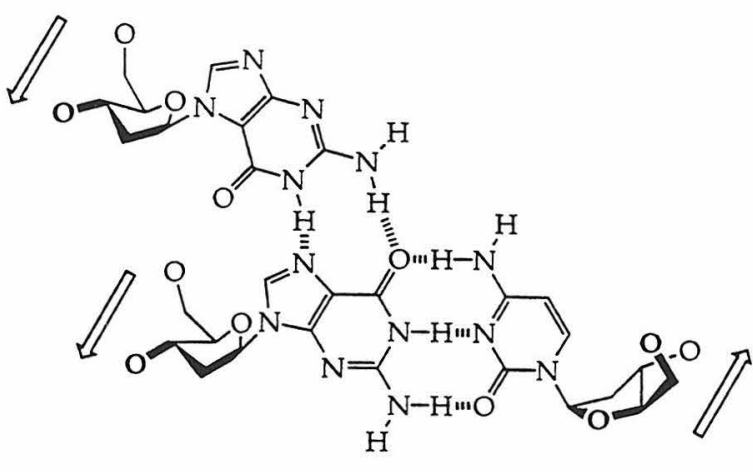

${ }^{7} \mathrm{G} \cdot \mathrm{GC}$

Figure 7.1. Schematic representation of $G \bullet G C$ and ${ }^{7} G \bullet G C$ triplets. The third strand orientation is reversed by moving the third strand deoxyribose from the N9 to the N7 position.

oligodeoxyribonucleotides capable of sequence-specific recognition of DNA by triple helix formation. Subsequent experiments were carried out to elucidate the sequence composition limitations of this new motif. In these experiments, the equilibrium association constants for triple helix formation for two sets of sequences containing either alternating or largely contiguous ${ }^{7} \mathrm{G} \bullet \mathrm{GC}$ triplets were determined, and indicated that in those cases in which the ${ }^{7} \mathrm{G} \bullet \mathrm{GC}$ triplets are alternating with $\mathrm{T} \bullet \mathrm{AT}$ triplets, there is a slight energetic penalty presumably due to the fact that ${ }^{7} \mathrm{G} \bullet \mathrm{GC}$ and $\mathrm{T} \bullet \mathrm{AT}$ triplets are not isomorphous (Figure 7.2) ${ }^{10 a}$ In addition, $\mathrm{pH}$ dependence studies indicated that triple helix formation is not sensitive to changes in $\mathrm{pH}$, as the third strand ${ }^{7} G$ does not require protonation for specific hydrogen bond formation. ${ }^{10 a}$

Following the design of $\mathrm{N}^{7}-2$-deoxyguanosine, studies were directed towards the design of N7-purine bases capable of AT recognition. As N ${ }^{9}-2$ - 
Alternating Triplets ( $\mathrm{pH} 7.0$ and 7.5):

Third Strand Oligonucleotide: $\quad 5^{1}-\mathrm{TTTTT}^{7} \mathrm{GT}^{7} \mathrm{GT}^{7} \mathrm{GT}^{7} \mathrm{GT}^{7} \mathrm{GT}-3^{\prime}$

Duplex: 5 '-ATATAAAAAGAGAGAGAGATGGA-3'

3 ' -TATATTTTTCTCTCTCTCTACCT-5'

\section{Contiguous Triplets ( $\mathrm{pH} 7.0$ and 7.5):}

Third Strand Oligonucleotide: $\quad 5^{1}-\mathrm{TTTT}^{7} \mathrm{GTTTT}^{7} \mathrm{G}^{7} \mathrm{G}^{7} \mathrm{G}^{7} \mathrm{G}^{7} \mathrm{G}^{7} \mathrm{GT}-3^{\prime}$

Duplex: $\quad 5^{\prime}$-TTTTAAAAGAAAGGGGGGACTGG-3 '

3'-AAAATTTTCTTTTCCCCCCTGACC-5'

Figure 7.2. Schematic representation of ${ }^{7} \mathrm{G}$-containing oligonucleotides and their target sites on double-helical DNA. The binding free energy for triple helix formation for two sets of sequences containing either alternating or largely contiguous ${ }^{7} \mathrm{G} \cdot \mathrm{GC}$ triplets were determined by quantitative DNase footprint titrations.

deoxyadenosine is known to bind $\mathrm{AT}$ base pairs when incorporated into purine-rich oligonucleotides, ${ }^{2}$ the binding properties of $\mathrm{N}^{7}-2^{\prime}$-deoxyadenosine $\left({ }^{7} \mathrm{~A}\right)$ (Figure 7.3$)$ were analyzed in the context of a pyrimidine-rich oligonucleotides. ${ }^{10 \mathrm{~b}}$ Experiments show that the stability of base triplets decreases in the order ${ }^{7} \mathrm{~A} \bullet \mathrm{AT}>>^{7} \mathrm{~A} \bullet \mathrm{CG}>>^{7} \mathrm{~A} \bullet \mathrm{GC}>>^{7} \mathrm{~A} \bullet \mathrm{TA}$ when one ${ }^{7} \mathrm{~A}$ is incorporated at a single site in a pyrimidine-rich oligonucleotide $(100 \mathrm{mM} \mathrm{NaCl}, 10 \mathrm{mM}$ BisTris $\bullet \mathrm{HCl}, 0.25 \mathrm{mM}$ spermine, $\mathrm{pH} 7.0,22{ }^{\circ} \mathrm{C}$ ), indicating that ${ }^{7} \mathrm{~A}$ is specific for AT base pair recognition. Experiments on the binding properties of ${ }^{7} \mathrm{~A}$ in the context of N7-purine oligonucleotides were to be carried out at the time this thesis was written (Figure 7.4). However, it was noted that the fact that ${ }^{7} \mathrm{G} \bullet \mathrm{GC}$ 


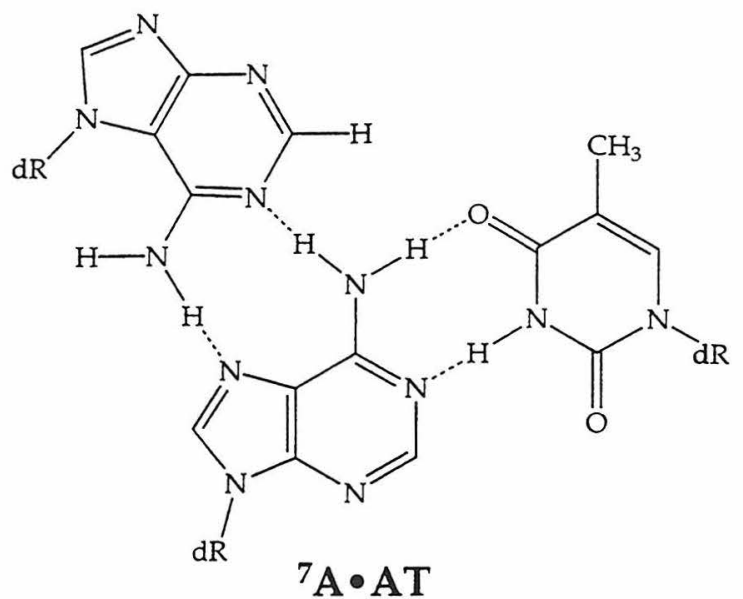

Figure 7.3. Schematic representation of the $\mathrm{N}^{7}-2^{\prime}$-deoxyadenosine $\bullet A T$ triplet.

and ${ }^{7} \mathrm{~A} \bullet \mathrm{AT}$ triplets are not isomorphous may cause some energetic penalty to the binding of double-helical DNA by oligonucleotides containing alternating ${ }^{7} \mathrm{G} \bullet \mathrm{GC}$ and ${ }^{7} \mathrm{~A} \bullet \mathrm{AT}$ triplets (Figure 7.5). ${ }^{10 \mathrm{~b}}$ Finally, additional studies have been carried out on the binding properties of $\mathrm{N}^{7}-2^{2}$-deoxynebularine as a potential AT and GC binder, and $\mathrm{N}^{7}-2^{\prime}$-deoxyinosine as a potential CG and TA binder, and indicated that these bases are not specific for their desired targets.

\section{Research Design}

To overcome the limitations associated with the fact that ${ }^{7} \mathrm{~A} \bullet \mathrm{AT}$ and ${ }^{7} \mathrm{G} \bullet \mathrm{GC}$ triplets are not isomorphous, we were interested in designing an isomorphous parallel N7 purine motif. $\mathrm{N}^{7}-2^{\prime}$-deoxyisoinosine ( $\left.{ }^{7} \mathrm{iI}\right)$ was proposed as a base potentially capable of forming specific ${ }^{7} \mathrm{i} \bullet \mathrm{AT}$ triplets isomorphous with ${ }^{7} \mathrm{G} \bullet \mathrm{GC}$ triplets when incorporated into oligonucleotides containing wholly N7-purines (Figures 7.6 and 7.7). Although the synthesis of $\mathrm{N}^{9}-2^{1}$-deoxyisoinosine had been reported, the synthesis of $\mathrm{N}^{7}-2^{\prime}$-deoxyisoinosine had yet to be reported. ${ }^{11}$ We proposed to analyze the specificity of 

Alternating Triplets:
Third Strand Oligonucleotide:
$5^{\prime}-{ }^{7} A^{7} A^{7} A^{7} A^{7} A^{7} G^{7} A^{7} G^{7} A^{7} G^{7} A^{7} G^{7} A^{7} G^{7} A-3^{\prime}$
Duplex:
5 ' - ATATAAAAAGAGAGAGAGATGGA-3'
3 ' -TATATTTTTCTCTCTCTCTACCT-5'

\section{Contiguous Triplets:}

Third Strand Oligonucleotide: $\quad 5^{\prime}-{ }^{7} A^{7} A^{7} A^{7} A^{7} G^{7} A^{7} A^{7} A^{7} A^{7} G^{7} G^{7} G^{7} G^{7} G^{7} G^{7} A-3^{\prime}$

Duplex:

$$
\begin{aligned}
& 5 \text { ' -TTTTAAAAGAAAAGGGGGACTGG-3 ' } \\
& 3^{\prime} \text {-AAAATTTTCTTTTCCCCCCTGACC-5 ' }
\end{aligned}
$$

Figure 7.4. Schematic representation of wholly N7-purine oligonucleotides containing ${ }^{7} \mathrm{G}$ and ${ }^{7} \mathrm{~A}$, and their target sites on double-helical DNA. The binding free energy for triple helix formation for two sets of sequences containing either alternating or largely contiguous ${ }^{7} \mathrm{~A} \bullet \mathrm{AT}$ triplets were proposed to be determined.

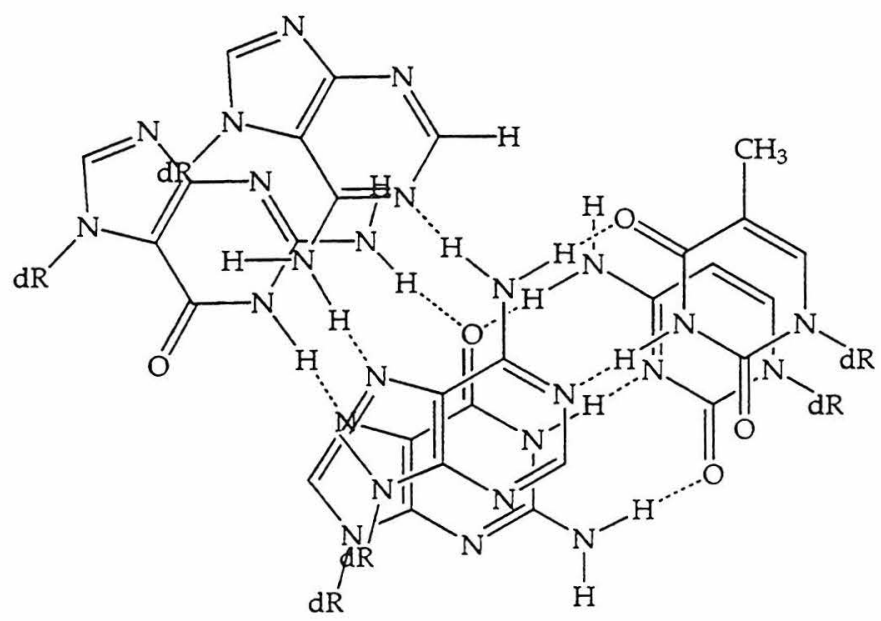

\section{${ }^{7} \mathrm{~A} \cdot \mathrm{ATT} / \mathrm{G} \cdot \mathrm{GC}$}

Figure 7.5. Diagram showing that $a^{7} \mathrm{~A} \bullet \mathrm{AT}$ and $a{ }^{7} \mathrm{G} \bullet \mathrm{GC}$ triplet are not isomorphous. 
A

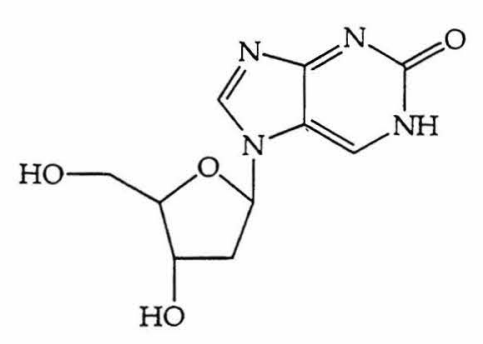

$\mathrm{N}^{7}$-2'-Deoxyisoinosine

B

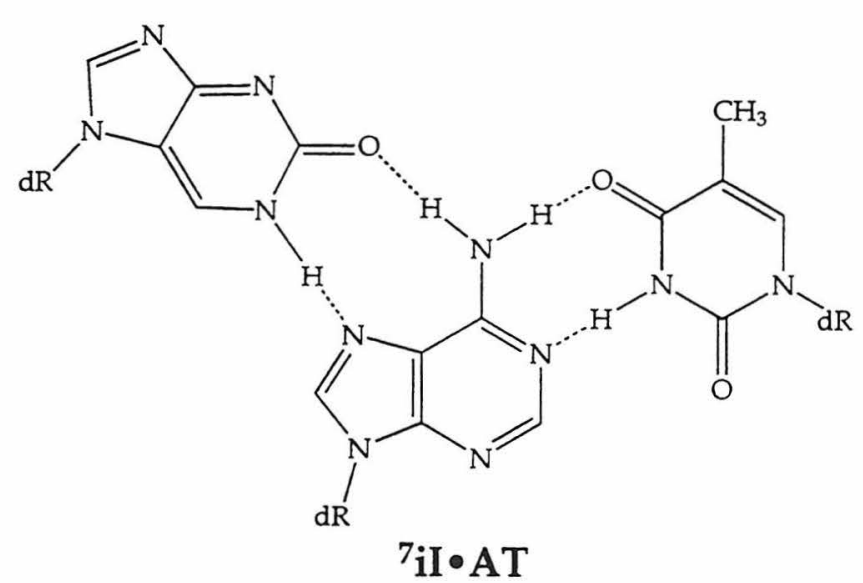

C

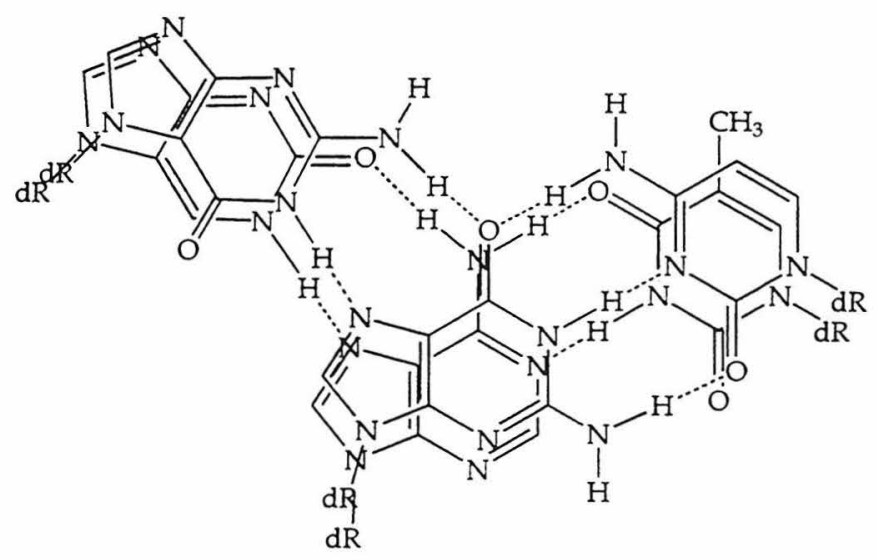

${ }^{7} \mathrm{iI} \cdot \mathrm{AT} /{ }^{7} \mathrm{G} \cdot \mathrm{GC}$

Figure 7.6. Structure of $\mathrm{N}^{7}-2$-deoxyisoinosine ( $\left.{ }^{7} \mathrm{iI}\right)(\mathrm{A})$, the ${ }^{7} \mathrm{i} I \bullet A T$ triplet (B), and representation of isomorphous ${ }^{7} \mathrm{iI} \bullet \mathrm{AT} / /^{7} \mathrm{G} \bullet \mathrm{GC}$ triplets $(\mathrm{C})$. 

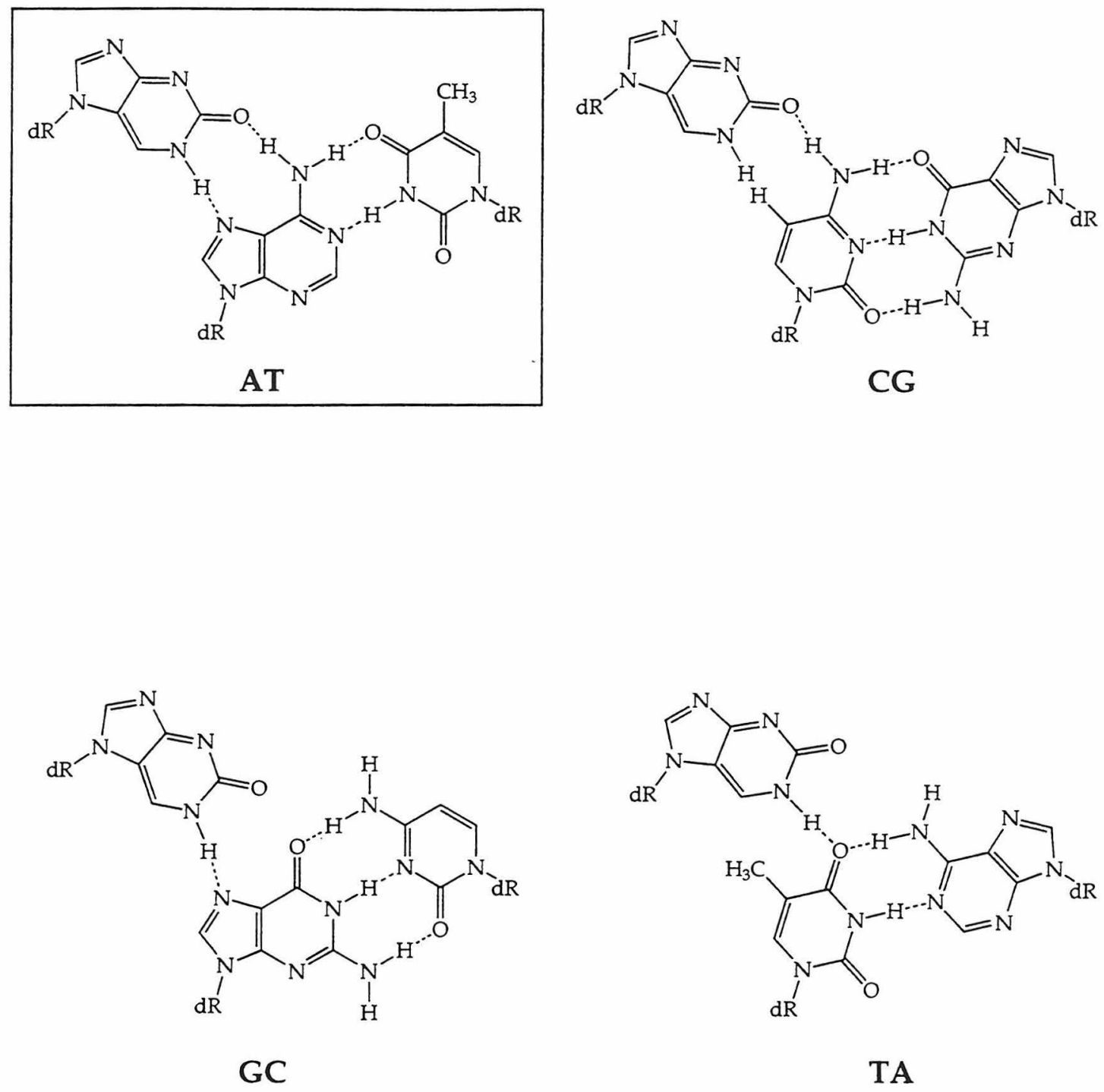

TA

Figure 7.7. Putative interaction of the four base pairs with $\mathrm{N}^{7}-2^{2}$-deoxyisoinosine. 
triple helix formation by pyrimidine oligodeoxyribonucleotides containing ${ }^{7} \mathrm{iI}$ by quantitative DNase I footprint titrations. ${ }^{5 c, 12,13}$ More specifically, we proposed to determine the equilibrium association constant of a pyrimidinerich oligonucleotide containing $\mathrm{N}^{7}-2$-deoxyisoinosine binding to targets on duplex DNA containing all four natural base pairs juxtaposed to the novel base $\left({ }^{7} \mathrm{I} \bullet \mathrm{AT},{ }^{7} \mathrm{I} \bullet \mathrm{GC},{ }^{7} \mathrm{I} \bullet \mathrm{TA},{ }^{7} \mathrm{I} \bullet \mathrm{CG}\right)$ (Figure 7.8). ${ }^{12,13}$ Our ultimate goal is the study of the binding properties of ${ }^{7}$ iI within oligonucleotides containing wholly N7-purines to double-helical DNA by triple helix formation (Figure 7.8), with the hope of observing very stable triple helices with little $\mathrm{pH}$ dependence and few sequence composition limitations.

Below is a description of the progress made towards the synthesis of the 5'O-DMT-protected phosphoramidite of 7iI. Efforts towards the completion of the synthesis beyond compound VII (Figure 7.9), and of the synthesis of oligonucleotides containing ${ }^{7}$ iI were being undertaken by postdoctoral fellow Helmut Brunar at the time this thesis was written.

\section{Synthesis of $\mathbf{N}^{7}-2^{\prime}$-deoxyisoinosine}

The synthesis of $\mathrm{N}^{7}-2$-deoxyisoinosine is shown in Figure 7.9. Silylation of 2-amino-6-chloropurine with $\mathrm{N}, \mathrm{O}$-bis(trimethylsilyl)acetamide followed by coupling to $\beta$-D-ribofuranose $1,2,3,5$-tetraacetate in the presence of stannic chloride afforded the $\beta$-anomer of the $\mathrm{N}^{7}$-glycosylated nucleotide III in $64 \%$ yield. ${ }^{14}$ The stereochemistry of the glycosidic bond as well as the regiochemistry of glycosidic bond formation was determined by comparison of the spectral data of the isolated product with that of previously characterized $\mathrm{N}^{7}$ 2'-deoxyguanosine. ${ }^{9}$ Initial attempts to convert the chloro-substituted adduct III into the corresponding 6-thio derivative, and catalytically hydrogenate this adduct in the presence of Raney Nickel to afford the desired compound IV 
A

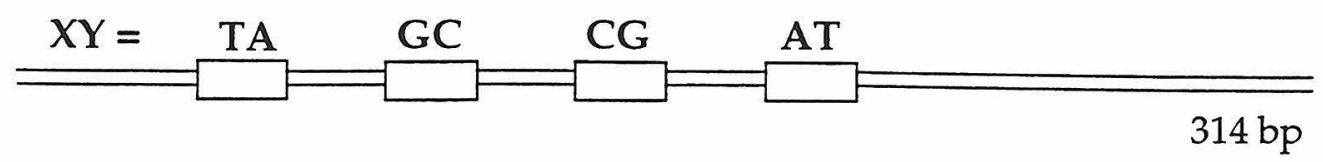

Third Strand Oligonucleotide: $\quad 5^{1}-\mathrm{TT}^{\mathrm{m}} \mathrm{CT}^{\mathrm{m}} \mathrm{CT}^{7} i I \mathrm{~T}^{\mathrm{m}} \mathrm{CT}^{\mathrm{m}} \mathrm{C}^{\mathrm{m}} \mathrm{CTTT}-3^{\prime}$

5 '-AAgAgAXAGAgGAAA-3
Duplex DNA:
3'-TTCTCTYTCTCCTTT-5

B

Alternating Triplets:

Third Strand Oligonucleotide: $\quad 5^{1}-{ }^{7} I^{7} I^{7} I^{7} I^{7} I^{7} G^{7} I^{7} G^{7} I^{7} G^{7} I^{7} G^{7} I^{7} G^{7} I-3$,

Duplex: 5 '-ATATAAAAAGAGAGAGAGATGGA-3'

3 '-TATATTTTTCTCTCTCTCTACCT-5'

Contiguous Triplets:

Third Strand Oligonucleotide: $5^{\prime}-{ }^{7} I^{7} I^{7} I^{7} I^{7} G^{7} I^{7} I^{7} I^{7} I^{7} G^{7} G^{7} G^{7} G^{7} G^{7} G^{7} I-3^{\prime}$

Duplex: 5 ' -TTTTAAAAGAAAGGGGGACTGG-3 '

$3^{\prime}$-AAAATTTTCTTTTCCCCCCTGACC-5'

Figure 7.8. Schematic representation of a pyrimidine oligodeoxyribonucleotide containing ${ }^{7} \mathrm{iI}$ binding to double-helical DNA targets containing all four natural base pairs (A), and of wholly N7-7iI-containing-purine oligonucleotides and their target sites on double-helical DNA (B). The binding free energy for triple helix formation for two sets of sequences containing either alternating or largely contiguous ${ }^{7} \mathrm{I} \bullet \mathrm{AT}$ triplets is proposed to be determined. ${ }^{\mathrm{m} C}$ denotes 5-methyl-2'-deoxycytidine. 
<smiles>CC(=O)OCC1OC(OC(C)=O)C(OC(C)=O)C1OC(C)=O</smiles>

I<smiles>Nc1nc(Cl)c2[nH]cnc2n1</smiles>

II
1. BSA, $\mathrm{CH}_{3} \mathrm{CN}$
$\frac{1 \mathrm{~h}, 24^{\circ} \mathrm{C}}{\text { 2. } \mathrm{SnCl}_{4}, \mathrm{CH}_{3} \mathrm{CN}}$
$12 \mathrm{~h}, 24^{\circ} \mathrm{C}$
$64 \%$<smiles>CC(=O)OCC1OC(n2cnc3nc(N)nc(Cl)c32)C(OC(C)=O)C1OC(C)=O</smiles>

1. $\mathrm{H}_{2} / \mathrm{Pd}, \mathrm{Et}_{3} \mathrm{~N}, \mathrm{DMF}$ $24 \mathrm{~h}, 24^{\circ} \mathrm{C}, 88 \%$

2. $\mathrm{NH}_{3} / \mathrm{MeOH}$ 24 h, $96 \%$

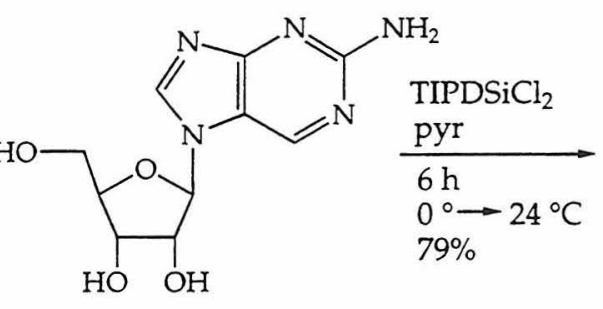

IV<smiles>Nc1ncc2c(ncn2C2OC3CO[SiH2]O[SiH2]OC3C2O)n1</smiles>

1. p-tolylchloroformate, DMAP, in $\mathrm{CH}_{3} \mathrm{CN}$ $14 \mathrm{~h}, 24^{\circ} \mathrm{C}, 66 \%$

2. $\mathrm{nBu}_{3} \mathrm{SnH}, \mathrm{AIBN}$, toluene $3 \mathrm{~h}, 75^{\circ} \mathrm{C}, 60 \%$

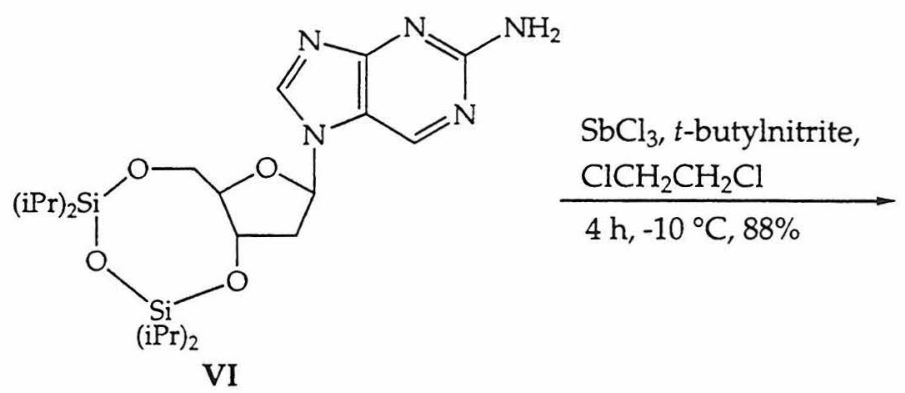

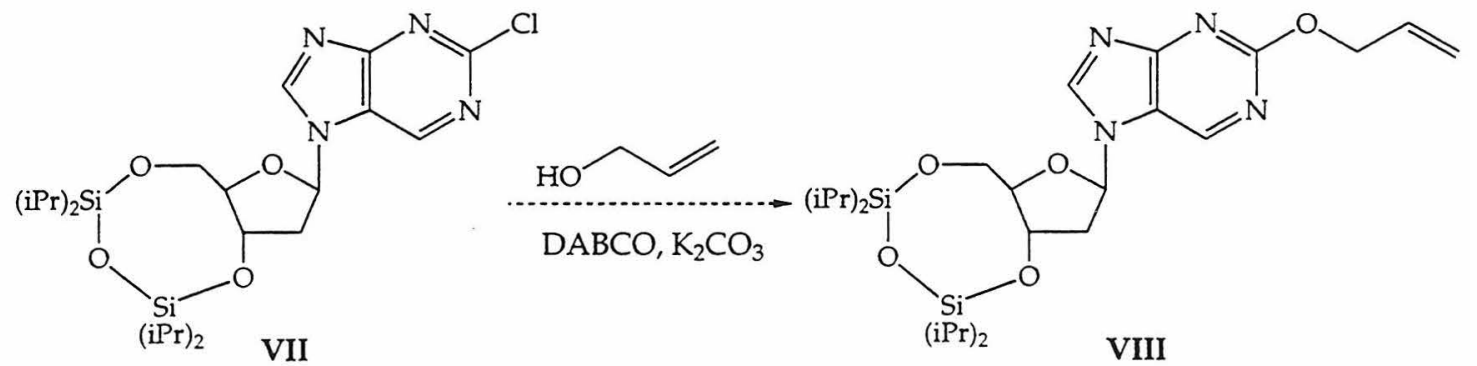

1. $1 \mathrm{M} \mathrm{TBAF} / \mathrm{THF}$

2. DMTCl, pyr

3. $\mathrm{Et}_{3} \mathrm{~N}, 2$-cyanoethyl- $N, N$ diisopropylchlorophosphoramidite $\mathrm{CH}_{2} \mathrm{Cl}_{2}$<smiles>[R6]OCC1OC(n2cnc3nc(OCC=C)ncc32)CC1OP(C(C)C)C(C)C</smiles>

IX

Figure 7.9. Synthesis of the 5'-O-DMT-protected phosphoramidite of ${ }^{7} \mathrm{iI}$. 
failed. However, catalytic hydrogenation over 10\% activated Palladium on carbon of the chloro derivative III in the presence of a stoichiometric amount of triethylamine afforded excellent yields of the crude $6 \mathrm{H}$-substituted derivative which, upon treatment with gaseous $\mathrm{NH}_{3}$, was converted into the deprotected compound IV in nearly quantitative yield according to a procedure used by Seela et al. for the synthesis of $\mathrm{N}^{9}-2$-deoxyisoinosine. ${ }^{11}$ Protection of the 3'- and 5'-hydroxyl groups with 1,3-dichloro-1,1,3,3-tetraisopropyldisiloxane, ${ }^{15}$ followed by removal of the 2'-hydroxyl group of the sugar under Barton deoxygenation conditions afforded 2-amino-7-(2'-deoxy-3',5'-O(tetraisopropyldisiloxane-1,3-diyl)- $\beta$-D-erythro-pentofuranosyl)purine (VI) in good overall yield. At this point, experiments were successfully carried out to convert the amino derivative VI into the corresponding oxo derivative by diazotization of VI with tert-butyl nitrite. ${ }^{16}$ Next, deprotection of the sugar hydroxyls followed by protection of the 5 '-OH with dimethoxytrityl chloride was attempted, ${ }^{17}$ but the instability of $\mathrm{N}^{7}-2^{2}$-deoxyisoinosine to the reaction conditions and silica gel chromatography indicated that an alternative route to the synthesis of the $5^{\prime}$-O-DMT-protected phosphoramidite of ${ }^{7} \mathrm{iI}$ should be followed. In one route, the order of the tritylation and diazotization reactions was reversed. In this route, the 5'-O-DMT-protected amino derivative of VI was obtained in good yield from treatment of the sugar-deprotected derivative of VI with DMTCl, but attempts to convert this adduct into ${ }^{7} \mathrm{iI}$ by diazotization with tert-butyl nitrite failed, due to the instability of the 5'-ODMT-protected 7iI adduct and its tendency to depurinate. Further attempts to protect the $\mathrm{O}^{6}$-carbonyl of $\mathrm{N}^{7}$-2'-deoxyisoinosine under Mitsunobu conditions also failed, due to the instability of the nucleoside. These results suggested a route in which the formation of ${ }^{7} \mathrm{iI}$ is avoided altogether, and the $\mathrm{O}^{6}$-protected adduct of ${ }^{7} \mathrm{i}$ is synthesized directly from the conversion of the amine adduct 
VI into the corresponding chloro-substituted derivative VII, and displacement of the chloro substituent of VII with a suitable protecting group such as allyl alcohol. This route is advantageous as it avoids the difficult purification of the remarkably polar $\mathrm{N}^{7}-2^{1}$-deoxyisoinosine. Compound VI was thus treated with $\mathrm{SbCl}_{3}$ in the presence of tert-butyl nitrite to afford the chloro adduct VII in $88 \%$ yield. ${ }^{18}$ This adduct proved to be stable to chromatography. Reaction of this compound with allyl alcohol in the presence of $\mathrm{NaH}$ led to depurination of the nucleotide. However, subsequent preliminary experiments carried out by $\mathrm{H}$. Brunar showed that reaction of VII with allyl alcohol in the presence of 1,4-diazabicyclo[2.2.2]octane and $\mathrm{K}_{2} \mathrm{CO}_{3}$ did not lead to decomposition of the product, but afforded the desired adduct VIII, albeit in low yield. ${ }^{19}$ Removal of the disiloxane group, followed by protection of the 5'-hydroxyl with $\mathrm{DMTCl}^{17}$ and conversion to the corresponding 2-cyanoethyl- $N, N$-diisopropyl phosphoramidite IX, as well as the subsequent syntheses of oligonucleotides containing $\mathrm{N}^{7}-2^{\prime}$-deoxyisoinosine were yet to be carried out by Brunar at the time this thesis was written.

\section{Experimental Section}

General. ${ }^{1} \mathrm{H}$ spectra were recorded on a General Electric QE 300 NMR spectrometer and chemical shifts are reported in ppm using the solvent peak (DMSO, 2.49 ppm; $\mathrm{CDCl}_{3}, 7.26 \mathrm{ppm}$ ) as internal standard. Flash chromatography was carried out under positive air pressure using EM Science Kieselgel 60 (230-400 mesh size).

Materials. Dry $\mathrm{CH}_{3} \mathrm{CN}$ was obtained from Aldrich, and dry dichloroethane and THF were obtained from Fluka. Pyridine was distilled from $\mathrm{CaH}_{2}$ and allyl alcohol was distilled from $\mathrm{K}_{2} \mathrm{CO}_{3}$. Stannic chloride, 1,3-dichloro-1,1,3,3- 
tetraisopropyldisiloxane, $p$-tolylchloroformate, and tributyltin hydride were purchased from Fluka. Tert-butyl nitrite was purchased from TCI America.

2-Amino-6-chloro-7-(2',3',5'-tri-O-acetyl- $\beta$-D-ribofuranosyl)purine (III). To a suspension of 2-amino-6-chloropurine $(5.00 \mathrm{~g}, 30 \mathrm{mmol})$ and $\beta$-D-ribofuranose 1,2,3,5-tetraacetate $(6.36 \mathrm{~g}, 20 \mathrm{mmol})$ in dry $\mathrm{CH}_{3} \mathrm{CN}$ under argon was added $\mathrm{N}, \mathrm{O}$-bis(trimethylsilyl)acetamide $(14.68 \mathrm{~mL}, 60 \mathrm{mmol})$. The suspension was allowed to stir for $1 \mathrm{~h}$, after which it turned into a clear solution. Then, the solution was cooled to $0{ }^{\circ} \mathrm{C}$, and to it $\mathrm{SnCl}_{4}(11.76 \mathrm{~mL}, 200 \mathrm{~mL})$ was slowly added over 15 minutes. The resulting yellow solution was allowed to stir at room temperature under argon overnight. It was then diluted with $\mathrm{CHCl}_{3}$ $(400 \mathrm{~mL})$, washed with water $(2 \times 200 \mathrm{~mL})$ and a saturated solution of $\mathrm{NaHCO}_{3}$ (2×200 mL), dried $\left(\mathrm{Na}_{2} \mathrm{SO}_{4}\right)$, and concentrated in vacuo. The resulting solid was triturated with EtOAc (10 mL), and washed to afford $5.51 \mathrm{~g}$ ( $64 \%$ yield) of product in the form of a white solid. ${ }^{1} \mathrm{H}$ NMR $\left(\mathrm{CDCl}_{3}\right) \delta 2.12(\mathrm{~s}, 3 \mathrm{H}), 2.14(\mathrm{~s}$, $3 \mathrm{H}), 2.18(\mathrm{~s}, 3 \mathrm{H}), 4.40-4.42(\mathrm{~m}, 2 \mathrm{H}), 4.47-4.49(\mathrm{~m}, 1 \mathrm{H}), 5.40-5.42(\mathrm{t}, 1 \mathrm{H}), 5.57-5.61$ $(\mathrm{t}, 1 \mathrm{H}), 6.49-6.51(\mathrm{~d}, 1 \mathrm{H}), 8.43(\mathrm{~s}, 1 \mathrm{H})$.

2-Amino-7-( $\beta$-D-ribofuranosyl)purine (IV). To a solution of 2-amino-6chloro-7-(2',3',5'-tri-O-acetyl- $\beta$-D-ribofuranosyl)purine (III) $(3.00 \mathrm{~g}, 7.00 \mathrm{mmol})$ and $\mathrm{Et}_{3} \mathrm{~N}(1.2 \mathrm{~mL}, 7.2 \mathrm{mmol})$ in $\operatorname{DMF}(35 \mathrm{~mL})$ was added $10 \%$ activated Palladium on carbon $(620 \mathrm{mg})$. The mixture was allowed to stir at room temperature for $24 \mathrm{hr}$ under $\mathrm{H}_{2}$ at 50 psi. The resulting suspension was filtered over Celite, and concentrated in vacuo. Flash chromatography (2\% $\left.\mathrm{Et}_{3} \mathrm{~N}, 7 \% \mathrm{MeOH}, 91 \% \mathrm{CH}_{2} \mathrm{Cl}_{2}\right)$ afforded $2.42 \mathrm{~g}(88 \%)$ of the $6 \mathrm{H}$-substituted product in the form of a yellow oil. Then, a solution this product $(0.60 \mathrm{~g}, 2.19$ mmol) in dry methanol $(50 \mathrm{~mL})$ was cooled to $0{ }^{\circ} \mathrm{C}$ and saturated with gaseous $\mathrm{NH}_{3}$. The solution was allowed to return to room temperature and stir under argon for $24 \mathrm{~h}$. The resulting cloudy solution was concentrated in 
vacuo. Flash chromatography $\left(20-30 \% \mathrm{MeOH} / \mathrm{CH}_{2} \mathrm{Cl}_{2}\right)$ afforded $0.57 \mathrm{~g}(96 \%$ yield) of the final desired product in the form of a white solid. ${ }^{1} \mathrm{H}$ NMR (DMSO) $\delta 3.61-3.64(\mathrm{~m}, 2 \mathrm{H}), 3.94-3.95(\mathrm{~m}, 1 \mathrm{H}), 4.07-4.27(\mathrm{~m}, 1 \mathrm{H}), 4.25-4.27(\mathrm{~m}, 1$ H), 5.17-5.19 (t, $1 \mathrm{H}), 5.22-5.23(\mathrm{~d}, 1 \mathrm{H}), 5.46-5.48(\mathrm{~d}, 1 \mathrm{H}), 5.74-5.76(\mathrm{~d}, 1 \mathrm{H}), 6.25(\mathrm{~s}$, $2 \mathrm{H}), 8.47(\mathrm{~s}, 1 \mathrm{H}), 8.82(\mathrm{~s}, 1 \mathrm{H})$.

\section{2-Amino-7-(3',5'-O-(tetraisopropyldisiloxane-1,3-diyl)- $\beta$-D-ribofuranosyl)-} purine (V). A solution of 2-amino-7-( $\beta$-D-ribofuranosyl)purine (IV) (3.94 g, $14.7 \mathrm{mmol})$ in dry pyridine $(60 \mathrm{~mL})$ was cooled to $0{ }^{\circ} \mathrm{C}$, and to it 1,3 -dichloro1,1,3,3-tetraisopropyldisiloxane $(5.2 \mathrm{~mL}, 16.2 \mathrm{mmol})$ was added. The solution was allowed to stir at $0{ }^{\circ} \mathrm{C}$ for 20 minutes. It was then allowed to return to room temperature and stir for $6 \mathrm{~h}$. The reaction solution was then concentrated in vacuo, and the resulting orange solid oil was dissolved in $\mathrm{CH}_{2} \mathrm{Cl}_{2}(100 \mathrm{~mL})$, washed with water $(50 \mathrm{~mL})$, and a saturated solution of $\mathrm{NaHCO}_{3}(50 \mathrm{~mL})$, and the combined aqueous layers were extracted with $\mathrm{CH}_{2} \mathrm{Cl}_{2}$. The combined organic layers were dried $\left(\mathrm{Na}_{2} \mathrm{SO}_{4}\right)$, and concentrated in vacuo. Flash chromatography $\left(3.5 \% \mathrm{MeOH} / \mathrm{CH}_{2} \mathrm{Cl}_{2}\right)$ afforded $5.89 \mathrm{~g}(79 \%$ yield) of product in the form of a reddish solid. ${ }^{1} \mathrm{H}$ NMR $\left(\mathrm{CDCl}_{3}\right) \delta 0.98-1.10$ $(\mathrm{m}, 28 \mathrm{H}), 4.12-4.15(\mathrm{~m}, 2 \mathrm{H}), 4.20-4.23(\mathrm{~m}, 1 \mathrm{H}), 4.51-4.52(\mathrm{~m}, 1 \mathrm{H}), 5.01(\mathrm{~s}, 2 \mathrm{H})$, 5.84-5.85 (d, 1H), $8.23(\mathrm{~s}, 1 \mathrm{H}), 8.64(\mathrm{~s}, 1 \mathrm{H})$.

\section{2-Amino-7-(2'-deoxy-3',5'-O-(tetraisopropyldisiloxane-1,3-diyl)- $\beta$-D-} erythro-pentofuranosyl)purine (VI). To a solution of 2-amino-7-(3',5'-O(tetraisopropyldisiloxane-1,3-diyl)- $\beta$-D-ribofuranosyl)purine (V) (4.0 g, 7.85 mmol) and $\mathrm{N}, \mathrm{N}$-dimethyl-4-aminopyridine $(2.11 \mathrm{~g}, 17.3 \mathrm{mmol})$ in dry $\mathrm{CH}_{3} \mathrm{CN}$ was added $p$-tolylchloroformate $(1.45 \mathrm{~mL}, 9.42 \mathrm{mmol})$ under argon. The yellow suspension was allowed to stir at room temperature for $14 \mathrm{~h}$. The resulting solution was diluted in $\mathrm{CH}_{2} \mathrm{Cl}_{2}$, and washed with cold $1 \mathrm{~N} \mathrm{HCl}$, and then with a saturated solution of $\mathrm{NaHCO}_{3}$. The aqueous layers were extracted 
with $\mathrm{CH}_{2} \mathrm{Cl}_{2}$, and the combined organic layers were dried $\left(\mathrm{MgSO}_{4}\right)$, and concentrated in vacuo. Flash chromatography $\left(3.5 \% \mathrm{MeOH} / \mathrm{CH}_{2} \mathrm{Cl}_{2}\right)$ yielded $3.39 \mathrm{~g}(66 \%)$ of a yellow-orange foam which was not further purified. The obtained product was dissolved in dry toluene $(75 \mathrm{~mL})$, and to it $\alpha, \alpha^{\prime}$-azobisisobutyronitrile $(0.20 \mathrm{~g}, 1.22 \mathrm{mmol})$ and $\mathrm{nBu}_{3} \mathrm{SnH}(1.96 \mathrm{~mL}, 7.38 \mathrm{mmol})$ were quickly added. The resulting orange solution was allowed to stir under argon at $75^{\circ} \mathrm{C}$ for $3 \mathrm{~h}$, during which time it was degassed frequently. The resulting yellow solution was concentrated in vacuo. Flash chromatography (3-4\% $\left.\mathrm{MeOH} / \mathrm{CH}_{2} \mathrm{Cl}_{2}\right)$ afforded $1.45 \mathrm{~g}$ (60\% yield) of a slightly yellow solid which was not further purified. ${ }^{1} \mathrm{H}$ NMR $\left(\mathrm{CDCl}_{3}\right) \delta 0.94-1.10(\mathrm{~m}, 28 \mathrm{H}), 2.57-2.60(\mathrm{~m}, 2 \mathrm{H})$, 3.91-3.94 (m, 2H), 4.06-4.10 (m, 1H), 4.60-4.70 (m, 1H), $4.99(\mathrm{~s}, 2 \mathrm{H}), 6.11-6.14(\mathrm{~m}$, $1 \mathrm{H}), 8.17(\mathrm{~s}, 1 \mathrm{H}), 8.57(\mathrm{~s}, 1 \mathrm{H})$.

\section{2-Chloro-7-(2'-deoxy-3',5'-O-(tetraisopropyldisiloxane-1,3-diyl)- $\beta$-D-} erythro-pentofuranosyl)purine (VII). A suspension of 2-chloro-7-(2'-deoxy3',5'-O-(tetraisopropyldisiloxane-1,3-diyl)- $\beta$-D-erythro-pentofuranosyl)purine (VI) $(0.030 \mathrm{~g}, 0.06 \mathrm{mmol})$ in dry dichloroethane $(1 \mathrm{~mL})$ was cooled to $\sim-10{ }^{\circ} \mathrm{C}$ (ice-salt water bath), and to it tert-butyl nitrite $(0.035 \mathrm{~mL}, 0.30 \mathrm{mmol})$ and $\mathrm{SbCl}_{3}$ $(0.025 \mathrm{~g}, 0.11 \mathrm{mmol})$ were added. The reaction mixture was allowed to stir under argon at $\sim 10^{\circ} \mathrm{C}$ for $4 \mathrm{~h}$. Then the mixture was poured onto an icewater bath and stirred. The mixture was transferred to a separatory funnel, and extracted with $\mathrm{CHCl}_{3}$. The organic layer was washed with water, a $5 \%$ solution of $\mathrm{NaHCO}_{3}$, dried $\left(\mathrm{Na}_{2} \mathrm{SO}_{4}\right)$, and concentrated in vacuo. Flash chromatography $\left(3 \% \mathrm{MeOH} / \mathrm{CH}_{2} \mathrm{Cl}_{2}\right)$ afforded $0.027 \mathrm{~g}$ ( $88 \%$ yield) of product in the form of a white solid. ${ }^{1} \mathrm{H} \mathrm{NMR}\left(\mathrm{CDCl}_{3}\right) \delta 1.01-1.14(\mathrm{~m}, 28 \mathrm{H}), 2.59-2.63(\mathrm{~m}$, $2 \mathrm{H}), 3.99-4.16(\mathrm{~m}, 3 \mathrm{H}), 4.71-4.76(\mathrm{~m}, 1 \mathrm{H}), 6.29-6.32(\mathrm{~m}, 1 \mathrm{H}), 8.56(\mathrm{~s}, 1 \mathrm{H}), 8.98(\mathrm{~s}$, $1 \mathrm{H})$. 


\section{References and Notes}

1. (a) Felsenfeld, G.; Davies, D. R.; Rich, A. J. Am. Chem. Soc. 1957, 79, 2023. (b) Howard, F. B.; Frazier, J.; Lipsett, M. N.; Miles, H. T. Biochem. Biophys. Res. Commun. 1964, 17, 93. (c) Moser, H. E.; Dervan, P. B. Science 1987, 238, 645. (d) Rajagopal, P.; Feigon, J. Nature 1989, 339, 637. (e) Radhakrishnan, I.; Gao, X.; de los Santos, C.; Live, D.; Patel, D. J. Biochemistry 1991, 30, 9022.

2. (a) Cooney, M.; Czernuszewics, G.; Postel, E. H.; Flint, S. J.; Hogan, M. E. Science 1988, 241, 456. (b) Beal, P. A.; Dervan, P. B. Science 1991, 251, 1360. (c) Durland, R. H.; Kessler, D. J.; Gunnell, S.; Duvic, M.; Pettitt, B. M.; Hogan, M. E. Biochemistry 1991, 30, 9246. (d) Pilch, D. S.; Levenson, C.; Shafer, R. H. Biochemistry 1991, 30, 6081. (e) Radhakrishnan, P.; de los Santos, C.; Patel, D. J. J. Mol. Biol. 1991, 221, 1403. (f) Beal, P. A.; Dervan, P. B. Nucleic Acids Res. 1992, 20, 2773.

3. (a) Povsic, T. J.; Dervan, P. B. J. Am. Chem. Soc. 1989, 111, 3059. (b) Plum, G. E.; Park, Y.-W.; Singleton, S. F.; Dervan, P. B.; Breslauer, K. J. Proc. Natl. Acad. Sci. USA 1990, 87, 9436. (c) Maher, L. J., III; Dervan, P. B.; Wold, B. J. Biochemistry 1990, 29, 8820. (d) Xodo, L. E.; Manzini, G.; Quadrifoglio, F.; van der Marel, G. A.; van Boom, J. H. Nucleic Acids Res. 1991, 19, 5625. (e) Singleton, S. F.; Dervan, P. B. Biochemistry 1992, 31, 10995.

4. Singleton, S. F.; Dervan, P. B. Biochemistry 1992, 32, 13171.

5. (a) Koh, J. S.; Dervan, P. B. J. Am. Chem. Soc. 1992, 114, 1470. (b) Radhakrishnan, I.; Patel, D. J.; Priestley, E. S.; Nash, H. M.; Dervan, P. B. Biochemistry 1993, 32, 11228. (c) Priestley, E. S.; Dervan, P. B. J. Am. Chem. Soc. 1994, 117, 4761. 
6. (a) Ono, A.; Ts'o, P. O. P.; Kan, L.-S. J. Am. Chem. Soc. 1991, $1134032-$ 4033. (b) Ono, A.; Ts'o, P. O. P.; L., K. J. Org. Chem. 1992, 57, 3225-3230. (c) Young, S. L.; Krawczyk, S. H.; Matteucci, M. D.; Toole, J. J. Proc. Natl. Acad. Sci. USA 1991, 88, 10023-10026. (d) Krawczyk, S. H.; Milligan, J. F.; Wadwani, S.; Moulds, C.; Froehler, B. C.; Matteucci, M. D. Proc. Natl. Acad. Sci. USA 1992, 89, 3761-3764. (e) Miller, P. S.; Bhan, P.; Cushman, C. D.; Trapane, T. L. Biochemistry 1992, 31, 6788-6793. (f) Jetter, M. C.; Hobbs, F. W. Biochemistry 1993, 32, 3249-3254. (g) Davison, E. C.; Johnsson, K. Nucleosides \& Nucleotides 1993, 12, 237-243.

7. (a) Kiessling, L. L.; Griffin, L. C.; Dervan, P. B. Biochemistry 1992, 31, 2829. (b) Griffin, L. C.; Kiessling, L. L.; Beal. P. A.; Gillespie, P.; Dervan, P. B. J. Am. Chem. Soc. 1992, 114, 7976. (c) Koshlap, K. M.; Gillespie, P.; Dervan, P. B.; Feigon, J. J. Am. Chem. Soc. 1993, 115, 7908.

8. Stilz, H. U.; Dervan, P. B. Biochemistry 1993, 32, 2177.

9. Hunziker, J.; Priestley, E. S.; Brunar, H.; Dervan, P. B. J. Am. Chem. Soc. 1995, 117, 2661.

10. (a) Brunar, H.; Dervan, P. B. Manuscript in preparation. (b) Priestley, E. S.; Dervan, P. B. Unpublished data.

11. Seela, F.; Chen, Y.; Bindig, U.; Kazimierczuk, Z. Helv. Chim. Acta 1994, 77, 194.

12. (a) Brenowitz, M.; Senear, D. F.; Shea, M. A.; Ackers, G. K. Methods Enzymol. 1986, 130, 132-181. (b) Singleton, S. F.; Dervan, P. B. J. Am. Chem. Soc. 1992, 114, 6957-6965.

13. For examples of a similar assay see: (a) Jones, R. J.; Swaminathan, S.; Milligan, J. F.; Wadwani, S.; Froehler, B. C.; Matteucci, M. D. J. Am. Chem. Soc. 1993, 115, 9816. (b) Jones, R. J.; Lin, K.-Y.; Milligan, J. F.; Wadwani, S.; Matteucci, M. D. J. Org Chem. 1993, 58, 2983. 
14. Garner, P.; Ramakanth, S. J. Org. Chem. 1988, 53, 1294.

15. Gait, M. J. Oligonucleotide Synthesis: A Practical Approach; IRL Press: Oxford, 1984.

16. (a) Robins, M. J.; Uznanski, B. Can. J. Chem. 1981, 59, 2608. (b) Robins, M. J. Nucleic Acids Res. 1981, 9, 61.

17. Dreyer, G. B.; Dervan, P. B. Proc. Natl. Acad. Sci. USA 1985, 82, 968.

18. Steinbrecher, T.; Wameling, C.; Oesch, F.; Seidel, A. Angew. Chem. Int. Ed. Engl. 1993, 32, 404.

19. Linn, J. A.; McLean, E. W.; Kelley, J. L. J. Chem. Soc. Chem. Comm. $1994,913$. 